\title{
APLICATIVO WINDOWS PARA ANÁLISE E DIMENSIONAMENTO DE PÓRTICOS PLANOS EM CONCRETO ARMADO
}

\author{
MALTON LINDQUIST
}

Dissertação apresentada à Escola de Engenharia de São Carlos, da Universidade de São Paulo, como parte dos requisitos para obtenção do Título de Mestre em Engenharia de Estruturas.

ORIENTADOR: João Batista de Paiva

São Carlos

2002 
A Deus 
"Regards and best wishes in your studies."

Dennis Ritchie

Criador da linguagem $\mathrm{C}$, por e-mail. 


\section{AGRADECIMENTOS}

Ao eterno Deus pelas oportunidades e bênçãos.

Ao professor José Samuel Giongo por sua paciência e bondade em comentar, aconselhar e dirigir várias partes deste trabalho.

Ao professor João Batista de Paiva por suas orientações e pela chance concedida de ingressar nas atividades de pesquisa ainda na graduação com a atividade de iniciação científica.

Aos meus queridos pais pelo apoio, dedicação e pela atenciosa revisão do texto.

À professora Elisabete Ferreira Pinto pelos valiosos ensinamentos guardados desde tenra idade.

Ao estimado professor Osmindo Malikoski Zitkievicz, que com muito esmero se dedica à tarefa de ensinar conceitos que possibilitam a formação tanto intelectual quanto social de seus alunos.

À Graziela Benaglia por seu companheirismo, apoio, incentivo e carinho.

Ao amigo Wilson Wesley Wutzow por tão pronta e pacientemente dedicar seu tempo em responder às mais variadas perguntas relacionadas a esta pesquisa.

Ao amigo Clayton Moreira de Castro por sua companhia e bom humor demonstrado sempre no ambiente de trabalho.

A Fernando Menezes de Almeida Filho, pela ajuda ao utilizar o programa TQS.

A Ana Raquel de Almeida Rodrigues por suas valiosas e indispensáveis orientações, pelo tempo e dedicação em organizar as páginas de impressão, e pela paciência e carinho em todas as horas.

A AEOLUS Engenharia e Consultoria S/C Ltda por ceder o exemplo utilizado neste trabalho.

À FAPESP pelo apoio financeiro que possibilitou a elaboração deste trabalho. 


\section{SUMÁRIO}

1. INTRODUÇÃO__ 1

1.1 OBJETIVO _ _ 1

1.2 JUSTIFICATIVA__ 2

1.3 APRESENTAÇÃO ___ 2

1.4 REVISÃO BIBLIOGRÁFICA ___ 4

2. PROPRIEDADES DOS MATERIAIS___ 9

2.1 INTRODUÇÃO__ 9

$2.2 \mathrm{AÇO}$

2.2.1 Características___ 9

2.2.2 Massa Específica___ 10

2.2.3 Módulo de Elasticidade ___ 10

2.2.4 Categorias _ 10

2.2.5 Resistência àTração _ـ_ 10

2.2.6 Diagrama Tensão-Deformação___ 11

2.3 CONCRETO _ 12

2.3.1 Características___ 12

2.3.2 Classes __ 13

2.3.3 Massa Específica___ 13

2.3.4 Resistência àTração _ـ 13

2.3.5 Módulo de Elasticidade ___ 14

2.3.6 Efeito Rüsch __ 14

2.3.7 Diagrama Tensão-Deformação___ 15

2.3.7.1 Compressão __ 15

2.3.7.2 Tração__ 16

3. ANÁLISE ESTRUTURAL___ 17

3.1 INTRODUÇÃO___ 17

3.2 PROCESSO INICIAL___ 17

3.3 CONSIDERAÇÕES SIMPLIFICADORAS NO PROJETO DE EDIFÍCIOS 19 
3.4 MODELAGEM DO EDIFÍCIO _ 20

3.5 MODELAGEM DE LAJES __ 22

3.6 MODELAGEM DE VIGAS E PILARES __ 23

3.6.1 Aproximações - Vigas Contínuas __ 24

3.6.2 Pilares _ 26

3.6.3 Dispensa da Análise dos Efeitos Locais de Segunda Ordem___ 28

3.6.4 Momento Mínimo Decorrente de Imperfeições Construtivas ___ 29

3.6.5 Excentricidades para o Dimensionamento de Pilares___ 30

3.6.5.1 Excentricidade Acidental __ 31

3.6.5.2 Excentricidade de Segunda Ordem _ 31

3.6.5.3 Excentricidade Inicial __ 32

3.6.5.4 Excentricidade Suplementar___ 32

3.6.5 Métodos para Dimensionamento de Pilares Isolados____ 33

3.6.5.1 Método Geral ___ 33

3.6.5.2 Métodos Aproximados __ 33

3.6.5.3 Método do Pilar Padrão com Curvatura Aproximada___ 33

3.6.5.4 Método do Pilar Padrão com Rigidez K Aproximada___ 34

3.6.5.5 Método do Pilar Padrão Acoplado a Diagramas

de $M, N, 1 / r \_35$

4. DIMENSIONAMENTO ___ 36

4.1 INTRODUÇÃO___ 36

4.2 HIPÓTESES BÁSICAS __ 36

4.3 ESTÁDIOS__ 37

4.3.1 Estádio I__ 38

4.3.2 Estádio II _ 38

4.3.3 Estádio III___ 39

4.4 ESTADOS LIMITES___ 39

4.4.1 Estados Limites Últimos (ELU) ___ 40

4.4.2 Estados Limites de Serviço (ELS)___ 40

4.4.3 Dutilidade___ 41

4.4.4 Domínios de Deformação ___ 42

4.4.4.1 Domínio 1 _ 42 
4.4.4.2 Domínio 2 43

4.4.4.3 Domínio 3 44

4.4.4.4 Domínio 4 44

4.4.4.5 Domínio 5 46

4.4.6 Flexão Normal 46

4.4.6.1 Equações de Equilíbrio 47

4.4.6.2 Equações de Compatibilidade de Deformações 49

4.4.6.3 Equacionamento 50

4.4.6.4 Dimensionamento de $\mathrm{d}$ e $\mathrm{A}_{\mathrm{s}}$ 51

4.4.6.5 Dimensionamento de $A_{s}$ e Determinação do

Momento Limite de Cálculo 52

4.4.7 Flexão Composta Normal 54

4.4.7.1 Processo Aproximado 54

4.4.7.2 Processo Iterativo 55

a) Região I 56

b) Região II 58

c) Região III 60

d) Expressão Geral 61

e) Equações de Equilíbrio 62

f) Exemplo Numérico 65

4.4.8 Força Cortante 68

4.4.8.1 Princípios Básicos 68

4.4.8.2 Analogia de Treliça Clássica 69

a) Elementos da Treliça __ 69

b) Hipóteses Básicas _ 70

4.4.8.3 Mecanismos de Ruptura__ 70

4.4.8.4 Taxa Mínima de Armadura___ 71

4.4.8.5 Verificação do Estado Limite Último __ 72

4.4.8.6 Armadura de Suspensão __ 74

5. DETALHAMENTO __ 77

5.1 INTRODUÇÃO___ 77

5.2 VIGAS _ 77 
5.2.1 Armadura Longitudinal 78

5.2.1.1 Quantidade Mínima 78

5.2.1.2 Quantidade Máxima 78

5.2.1.3 Distribuição Transversal 79

5.2.1.4 Distribuição Longitudinal 80

5.2.2 Armadura Transversal para Força Cortante 80

5.2.3 Comprimento de Ancoragem 81

5.2.4 Decalagem do Diagrama de Força no Banzo Tracionado 82

5.3 PILARES 83

5.3.1 Armadura Longitudinal 83

5.3.1.1 Quantidade Mínima 83

5.3.1.2 Quantidade Máxima 83

5.3.1.3 Diâmetro das Barras 83

5.3.1.4 Distribuição Transversal 84

5.3.1.5 Armaduras Transversais 84

5.3.2 Comprimento de Ancoragem 84

6. EXEMPLO DE APLICAÇÃO 85

6.1 INTRODUÇÃO___ 85

6.2 EDIFÍCIO DOM PEDRO II___ 85

6.3 Vigas _ 88

6.3.1 Viga V6 _ 89

6.3.2 Viga $V 19 \_92$

6.3.3 Viga V20 _ 94

6.3.4 Discussão dos Resultados _ـ 96

6.4 Força Cortante__ 98

6.5 Pilares _ 99

6.5.1 Pórtico V6 _ 99

6.5.2 Pórtico V19 101

6.5.3 Pórtico V20 _ 102

6.5.4 Discussão dos Resultados _ـ 103

6.5.5 Verificação__ 105

6.6 Detalhamento___ 107

7. CONSIDERAÇÕES FINAIS___ 110 
ANEXO -- TUTORIAL DTOOL A-1

A.1 INTRODUÇÃO___ A-1

A.2 LINGUAGEM DE PROGRAMAÇÃO____ A-2

A.3 PROGRAMAS ANTERIORES____ A-4

A.4 DTOOL _ A-6

A.4.1 Janela Inicial ___ A-6

A.4.1.1 Botão Abrir ___ A-7

A.4.1.2 Botão Sair___ A-10

A.4.1.3 Botão Apoios __ A-10

A.4.1.4 Botão Ações___ A-11

A.4.1.5 Botão Nós___ A-13

A.4.1.6 Botão Barras __ A-14

A.4.1.7 Botão Retas ___ A-14

A.4.1.8 Botão Deformada____ A-16

A.4.1.9 Botão Selecionar ___ A-19

A.4.1.10 Botão Flechas __ A-20

A.4.1.11 Botões de Controle do Tamanho do Desenho_____ A-21

A.4.1.12 Botão para Mudança de Janela ___ A-21

A.4.2 Janela de Diagramas ___ A-21

A.4.2.1 Botão Traços ___ A-24

A.4.2.2 Botão Valores___ A-25

A.4.2.3 Botões de Controle do Tamanho do Desenho____ A-25

A.4.2.4 Diagrama de Força Cortante ___ A-26

A.4.2.5 Caixa de Diálogo de Valores ___ A-28

A.4.2.6 Botões para Mudança de Janela ___ A-29

A.4.3 Janela de Dimensionamento____ A-30

A.4.3.1 Dimensionamento de Vigas àFlexão Normal ___ A-31

A.4.3.1.1 GroupBox Dados___ A-32

A.4.3.1.2 GroupBox Dimensões Necessárias____ A-33

A.4.3.1.3 GroupBox Utilizados____ A-33

A.4.3.1.4 Botão Dimensionar____ A-34 
A.4.3.1.5 Botão de Mudança de Vigas A-36

A.4.3.1.6 Botão Pilares A-37

A.4.3.2 Dimensionamento de Pilares àFlexão Normal Composta A-37

A.4.3.2.1 GroupBox Seção A-38

A.4.3.2.2 GroupBox de Informações A-40

A.4.3.2.3 GroupBox Características A-41

A.4.3.2.4 GroupBox Utilizar A-42

A.4.3.2.5 Botões de Mudança de Pilares A-43

A.4.3.3 Dimensionamento à Força Cortante A-44

A.4.3.3.1 GroupBox Armadura Mínima A-46

A.4.3.3.2 GroupBox Dimensionamento A-46

A.4.3.3.3 GroupBox Espaçamento Máximo (Norma) A-47

A.4.3.3.4 GroupBox Espaçamento Máximo A-48

A.4.3.3.5 GroupBox Utilizar A-48

A.4.3.4 Botão Salvar A-49

A.4.3.5 Botão DXF A-50

A.4.4 Janela de Detalhamento A-50

A.4.4.1 Botões para Controle do Tamanho do Desenho na Tela A-52

A.4.4.2 Botões para Mudança de Vigas A-53 A.5 DESENHOS A-54 


\section{LISTA DE FIGURAS}

FIGURA 2.1 - Diagrama tensão-deformação para aços de armaduras passivas 11

FIGURA 2.2 - Diagrama tensão-deformação idealizado 15

FIGURA 2.3 - Diagrama tensão-deformação bi-linear na tração 16

FIGURA 3.1 - Eixos para o dimensionamento 18

FIGURA 3.2 - Estrutura de um edifício de concreto armado 20

FIGURA 3.3 - Elementos básicos que compõem uma estrutura de concreto armado 22

FIGURA 3.4 - Modelagem simplificada considerando o efeito de pilar de extremidade 25

FIGURA 3.5 - Determinação do comprimento de flambagem nos casos usuais de estruturas de edifícios 27

FIGURA 3.6 - Efeitos a) Falta de retilinidade do pilar; b) Desaprumo do pilar 30

FIGURA 4.1 - Fases de comportamento da flexão pura 38

FIGURA 4.2 - Domínios em uma seção de concreto armado 42

FIGURA 4.3 - Seção retangular de concreto 47

FIGURA 4.4 - Arranjo de armadura caracterizado pelo parâmetro $\alpha_{\mathrm{s}}$ 55

FIGURA 4.5 - Regiões de deformação 56

FIGURA 4.6 - Deformações da região I 57

FIGURA 4.7 - Deformações da região II 59

FIGURA 4.8 - Deformações da região III 60

FIGURA 4.9 -Tensões e deformações em uma seção retangular 62

FIGURA 4.10 - Diagrama simplificado 64

FIGURA 4.11 -Exemplo numérico 66

FIGURA 4.12 - Treliça clássica Mörsch 69

FIGURA 4.13 - Esquema estático de um apoio indireto 74

FIGURA 4.14 - Região de distribuição da armadura de suspensão 75

FIGURA 4.15 -Porcentagem de distribuição 76

FIGURA 6.1 - Forma estrutural do pavimento tipo 86 
FIGURA 6.2 - Forma estrutural da cobertura 87

FIGURA 6.3 - Forma estrutural do ático 88

FIGURA 6.4 - Pórtico viga V6 89

FIGURA 6.5 - Ações no pórtico V6 90

FIGURA 6.6 - Diagrama de momento fletor para a viga V6 (DTool) 90

FIGURA 6.7 - Diagrama de momento fletor para a viga V6 (TQS) 90

FIGURA 6.8 - Modelagem do pórtico para a viga V19 93

FIGURA 6.9 - Diagrama de momento fletor para a viga V20 (DTool) 94

FIGURA 6.10 - Diagrama de momento fletor para a viga V20 (TQS) 95

FIGURA 6.11 - Detalhamento da armadura para a viga V20 em TQS no pavimento tipo junto ao pilar $\mathrm{P} 12$ 107

FIGURA 6.12 - Detalhamento da armadura para a viga V20 em DTool no pavimento tipo junto ao pilar P12 108

FIGURA 6.13 - Detalhamento da armadura para o pilar P8, primeiro tramo, em TQS

FIGURA 6.14 - Detalhamento da armadura para o pilar P8, primeiro tramo, em DTool 109

FIGURA A.1 - Janela de entrada A-1

FIGURA A.2 - Programa DVCA A-5

FIGURA A.3 - Programa DTool A-6

FIGURA A.4 - Caixa de diálogo para abrir arquivos A-7

FIGURA A.5 - Pilar exemplo A-8

FIGURA A.6 - Opção de desenho dos apoios A-11

FIGURA A.7 - Desenho das ações atuantes na estrutura A-12

FIGURA A.8 - Desenho do número e coordenadas dos nós A-13

FIGURA A.9 - Desenho do número das barras A-14

FIGURA A.10 -Desenho dos deslocamentos nodais A-15

FIGURA A.11 - TrackBar para desenho da estrutura deslocada A-15

FIGURA A.12 - Desenho dos deslocamento nodais em escala maior A-16

FIGURA A.13 - Desenho da estrutura deslocada A-18

FIGURA A.14 - Barras selecionadas A-19

FIGURA A.15 - Desenho das flechas na estrutura deslocada A-20 
FIGURA A. 16 -Diagrama de momento fletor para a barras selecionadas A-22

FIGURA A.17 - Diagrama de momento fletor A-24

FIGURA A.18 -Diagrama de momento fletor com traços internos A-25

FIGURA A.19 - Diagrama de momento fletor com valores A-26

FIGURA A.20 - Menu para mudança de diagrama A-27

FIGURA A.21 - Diagrama de força cortante com valores A-27

FIGURA A.22 - Diagrama de esforço axial com valores A-28

FIGURA A.23 - Caixa de diálogo de valores A-29

FIGURA A.24 - Janela de dimensionamento - Vigas A-31

FIGURA A.25 - Dimensionamento do ponto central, barra esquerda A-35

FIGURA A.26 - Dimensionamento da viga 2 A-36

FIGURA A.27 - TabControl com a opção pilares ativa A-37

FIGURA A.28 - Janela de dimensionamento - Pilares A-38

FIGURA A.29 - GroupBox de características da seção A-39

FIGURA A.30 - Dimensionamento utilizando 10 barras A-43

FIGURA A.31 - Dimensionamento do tramo superior A-44

FIGURA A.32 - Dimensionamento àforça cortante A-45

FIGURA A.33 - Dimensionamento àforça cortante, espaçamento $25 \mathrm{~mm}$ A-48

FIGURA A.34 - Janela de detalhamento A-51

FIGURA A.35 - Janela de detalhamento com desenho maximizado A-53

FIGURA A.36 - Janela de detalhamento para a viga 3 A-54 


\section{LISTA DE TABELAS}

TABELA 3.1 - Critérios para a modelagem dos pilares isolados conforme o índice de esbeltez

TABELA 5.1 - Valores de $\rho_{\min }$ em \% para flexão em vigas 78

TABELA 6.1 - Comparação entre o dimensionamento de TQS e DTool para a viga $\mathrm{V} 6$ no pavimento térreo 91

TABELA 6.2 - Comparação entre o dimensionamento de TQS e DTool para a viga $V 6$ no pavimento tipo 91

TABELA 6.3 - Comparação entre o dimensionamento de TQS e DTool para a viga $V 6$ na cobertura 92

TABELA 6.4 - Comparação entre o dimensionamento de TQS e DTool para a viga $\mathrm{V} 6$ no ático 92

TABELA 6.5 - Comparação entre o dimensionamento de TQS e DTool para a viga $\mathrm{V} 19$ no pavimento térreo 93

TABELA 6.6 - Comparação entre o dimensionamento de TQS e DTool para a viga V19 no pavimento tipo 94

TABELA 6.7 - Comparação entre o dimensionamento de TQS e DTool para a viga $\mathrm{V} 19$ na cobertura 94

TABELA 6.8 - Comparação entre o dimensionamento de TQS e DTool para a viga V20 no pavimento térreo 95

TABELA 6.9 - Comparação entre o dimensionamento de TQS e DTool para a viga V20 no pavimento tipo 95

TABELA 6.10 - Comparação entre o dimensionamento de TQS e DTool para a viga V20 na cobertura 96

TABELA 6.11 - Comparação entre o dimensionamento de TQS e DTool para a viga V20 no pavimento tipo com esforços semelhantes 97

TABELA 6.12 - Comparação entre o dimensionamento de TQS e DTool para a viga V20 no pavimento tipo com esforços e altura útil semelhantes 98

TABELA 6.13 - Comparação das diferenças entre o dimensionamento de TQS e DTool para a armadura transversal da viga V6 no pavimento térreo 
TABELA 6.14 - Comparação entre o dimensionamento de TQS e DTool para o pilar P7 no pórtico V6 99

TABELA 6.15 - Comparação entre o dimensionamento de TQS e DTool para o pilar P8 no pórtico V6 100

TABELA 6.16 - Comparação entre o dimensionamento de TQS e DTool para o pilar P9 no pórtico V6 100

TABELA 6.17 - Comparação entre o dimensionamento de TQS e DTool para o pilar P10 no pórtico V6 100

TABELA 6.18 - Comparação entre o dimensionamento de TQS e DTool para o pilar P11 no pórtico V6

TABELA 6.19 - Comparação entre o dimensionamento de TQS e DTool para o pilar P12 no pórtico V6

TABELA 6.20 - Comparação entre o dimensionamento de TQS e DTool para o pilar P17 no pórtico V19 101

TABELA 6.21 - Comparação entre o dimensionamento de TQS e DTool para o pilar P11 no pórtico V19

TABELA 6.22 - Comparação entre o dimensionamento de TQS e DTool para o pilar P3 no pórtico V19 102

TABELA 6.23 - Comparação entre o dimensionamento de TQS e DTool para o pilar P18 no pórtico V20 102

TABELA 6.24 - Comparação entre o dimensionamento de TQS e DTool para o pilar P12 no pórtico V20 103

TABELA 6.25 - Comparação entre o dimensionamento de TQS e DTool para o pilar P4 no pórtico V20 103

TABELA 6.26 - Comparação entre o dimensionamento de TQS e DTool para o pilar P11 no pórtico V6 e V19

TABELA 6.27 - Comparação entre o dimensionamento de TQS e DTool para o pilar P12 no pórtico V6 e V19 


\section{LISTA DE SÍMBOLOS}

$A_{c}$

$\mathrm{a} \ell$

$\mathrm{A}_{\mathrm{s}}$

$A_{s 1}, A_{s 2}$

$A_{s, \text { apoio }}$

$A_{s, \text { vão }}$

$A_{s, \text { sus }}$

$A_{s, \max }$

$A_{s, \text { min }}$

$A_{s i}$

$A_{s w}$

$b_{w}$

d

d'

e

$e_{1}$

$\mathrm{e}_{2}$

$\mathrm{e}_{\mathrm{a}}$

$e_{a, \min }$

$e_{c}$

$e_{i, a}, e_{i, b}$

$\mathrm{e}_{\mathrm{i}, \text { base }}$

$e_{i, c}$

$\mathrm{e}_{\mathrm{i}, \mathrm{topo}}$

$E_{c}$

$E_{c i}$
Área da seção transversal bruta de concreto

Decalagem do diagrama de força no banzo tracionado

Área da seção transversal da armadura longitudinal tracionada

Armaduras nas faces superior e inferior da viga

Área da seção transversal da armadura longitudinal positiva que se prolonga até a região dos apoios

Área da seção transversal da armadura longitudinal tracionada no ponto de máximo momento positivo

Área de aço necessária para armadura de suspensão

Armadura máxima para uma seção transversal de concreto

Armadura mínima para uma seção transversal de concreto

Área da seção transversal de uma camada de aço numa seção transversal de concreto

Área da seção transversal dos estribos

Largura das vigas de seção retangular

Altura útil da seção transversal

Cobrimento da seção transversal

Excentricidade resultante da divisão do momento solicitante de cálculo pela força normal solicitante de cálculo

Excentricidade de primeira ordem

Excentricidade de segunda ordem

Excentricidade acidental

Excentricidade acidental mínima

Excentricidade suplementar considerando o efeito da fluência

Excentricidades iniciais nas extremidades de um tramo de pilar

Excentricidade inicial na base do pilar

Excentricidade inicial na seção intermediária de um tramo de pilar

Excentricidade inicial no topo do pilar

Módulo de elasticidade longitudinal secante do concreto

Módulo de elasticidade tangente inicial 


\begin{tabular}{|c|c|}
\hline$E_{c s}$ & Módulo de elasticidade secante do concreto \\
\hline $\mathrm{El}_{\mathrm{inf}}$ & Rigidez do pilar inferior \\
\hline $\mathrm{El}_{\text {vig }}$ & Rigidez da viga \\
\hline$E_{s}$ & Módulo de elasticidade longitudinal do aço \\
\hline$f_{b d}$ & $\begin{array}{l}\text { Resistência de aderência de cálculo entre armadura e concreto na } \\
\text { ancoragem de armaduras passivas }\end{array}$ \\
\hline$f_{c d}$ & Resistência àcompressão de cálculo do concreto \\
\hline $\mathrm{f}_{\mathrm{ck}}$ & Resistência característica do concreto àcompressão \\
\hline $\mathrm{f}_{\mathrm{ctd}}$ & Resistência de cálculo do concreto àtração \\
\hline $\mathrm{f}_{\mathrm{ctk}, \mathrm{inf}}$ & Resistência característica do concreto inferior àtração \\
\hline $\mathrm{f}_{\text {ctk,sup }}$ & Resistência característica do concreto superior àtração \\
\hline$f_{c t m}$ & Resistência característica do concreto média àtração direta \\
\hline$f_{y d}$ & Tensão de escoamento de aço \\
\hline $\mathrm{f}_{\mathrm{yk}}$ & Tensão de escoamento característica do aço \\
\hline$f_{y w k}$ & Resistência característica dos estribos àtração \\
\hline$f_{y w d}$ & Resistência de cálculo dos estribos àtração \\
\hline g & Carregamento permanente \\
\hline $\mathrm{h}$ & $\begin{array}{l}\text { Dimensão do pilar paralelo àexcentricidade acidental considerada } \\
\text { Altura total da seção transversal }\end{array}$ \\
\hline$i$ & $\begin{array}{l}\text { Raio de giração da seção geométrica da peça (seção de concreto não } \\
\text { se considerando a presença da armadura) }\end{array}$ \\
\hline $\mathrm{I}_{\mathrm{c}}$ & Momento de inércia da seção de concreto \\
\hline$\ell$ & $\begin{array}{l}\text { Altura total da estrutura ou de um lance de pilar, } \\
\text { Vão } \\
\text { Distância entre os eixos dos elementos estruturais aos quais o pilar está } \\
\text { vinculado }\end{array}$ \\
\hline$\ell_{0}$ & $\begin{array}{l}\text { Distância entre as faces internas dos elementos estruturais, supostos } \\
\text { horizontais, que vinculam o pilar }\end{array}$ \\
\hline$\ell_{\mathrm{b}}$ & Comprimento de ancoragem \\
\hline$\ell_{\mathrm{e}}$ & Comprimento equivalente de flambagem \\
\hline$\ell_{\mathrm{inf}}$ & Comprimento do tramo inferior de pilar \\
\hline$\ell_{\text {sup }}$ & Comprimento do tramo superior de pilar \\
\hline
\end{tabular}




\begin{tabular}{|c|c|}
\hline M & Momento fletor \\
\hline $\mathrm{M}_{0}$ & Momento na viga em apoio de extremidade \\
\hline$M_{1 d, A}$ & Momento fletor de primeira ordem de cálculo na extremidade A do pilar \\
\hline$M_{1 d, \min }$ & Momento mínimo de cálculo \\
\hline$M_{A}, M_{B}$ & $\begin{array}{l}\text { Momentos fletores de primeira ordem de cálculo nas extremidades } \mathrm{A} \text { e } \\
\mathrm{B} \text { do pilar }\end{array}$ \\
\hline$M_{\text {apoio }}$ & Momento fletor atuante no apoio \\
\hline$M_{\text {base }}$ & Momento fletor na base do pilar \\
\hline$M_{C}$ & $\begin{array}{l}\text { Momento fletor de cálculo de primeira ordem no meio do pilar } \\
\text { Contribuição da resultante de compressão na seção transversal para } \\
\text { resistir ao momento fletor }\end{array}$ \\
\hline$M_{d}$ & Momento fletor de cálculo \\
\hline$M_{d, \text { tot }}$ & Momento fletor de cálculo total no tramo de pilar \\
\hline$M_{k}$ & Momento fletor característico \\
\hline$M_{\text {topo }}$ & Momento fletor no topo do pilar \\
\hline$M_{\text {eng }}$ & Momento de engastamento perfeito \\
\hline$M_{\text {ext }}$ & Momento externo \\
\hline$M_{\text {int }}$ & Momento interno \\
\hline $\mathrm{M}_{\mathrm{Sd}, \mathrm{eq}}$ & Momento fletor solicitante de cálculo equivalente \\
\hline $\mathrm{M}_{\mathrm{Sg}}$ & Momento fletor devido àcombinação quase permanente \\
\hline$M_{\text {vão }}$ & Momento fletor positivo máximo entre apoios \\
\hline $\mathrm{n}$ & Número de ramos dos estribos \\
\hline $\mathrm{N}$ & Força normal \\
\hline & Número de camadas de aço numa seção transversal de concreto \\
\hline $\mathrm{N}_{\mathrm{C}}$ & $\begin{array}{l}\text { Força de compressão resultante na seção transversal de uma peça de } \\
\text { concreto }\end{array}$ \\
\hline $\mathrm{N}_{\mathrm{d}}$ & Força normal total de cálculo \\
\hline $\mathrm{N}_{\mathrm{R}}$ & Força normal resitente \\
\hline $\mathrm{N}_{\mathrm{Sd}}$ & Força normal solicitante de cálculo \\
\hline $\mathrm{N}_{\mathrm{Sd}, \mathrm{eq}}$ & Força normal solicitante de cálculo equivalente \\
\hline $\mathrm{N}_{\mathrm{Sg}}$ & Força normal devida àcombinação quase permanente \\
\hline$q$ & Carregamento acidental \\
\hline
\end{tabular}


Raio de curvatura

$\mathrm{R}_{\mathrm{cc}}, \mathrm{R}_{\mathrm{c}} \quad$ Resultante das tensões de compressão do concreto

$R_{\mathrm{ct}} \quad$ Resultante das tensões de tração do concreto

$R_{d} \quad$ Força que a viga apoiada exerce sobre a que serve de apoio

$\mathrm{R}_{\mathrm{Si}} \quad$ Força normal em cada camada de armadura

$\mathrm{R}_{\mathrm{st}} \quad$ Força de tração na armadura

$r_{\text {inf }}$

Rigidez de tramo inferior de pilar em uma ligação tramo inferior de pilar - viga - tramo superior de pilar

$\mathrm{R}_{\mathrm{st}}, \mathrm{R}_{\mathrm{s}} \quad$ Resultante das tensões de tração na armadura

$r_{\text {sup }}$

Rigidez de tramo superior de pilar em uma ligação tramo inferior de pilar

- viga - tramo superior de pilar

$r_{\text {vig }}$

Rigidez da viga em uma ligação tramo inferior de pilar - viga - tramo superior de pilar

S

Espaçamento dos estribos, medido segundo o eixo longitudinal do elemento estrutural

$\mathrm{S}_{\max } \quad$ Espaçamento máximo entre estribos

$\mathrm{X}$

Distância da linha neutra à borda mais comprimida em uma seção transversal de um elemento

$x_{1} \quad$ Profundidade da linha neutra limite no estádio I

$x_{\|} \quad$ Profundidade da linha neutra limite no estádio II

$\mathrm{X}_{\text {III }} \quad$ Profundidade da linha neutra limite no estádio III

$x_{2, \lim }$

Limite da profundidade da linha neutra para o domínio 2

$x_{3, \lim }$

Limite da profundidade da linha neutra para o domínio 3

y

Região de atuação de tensões de compressão na seção transversal considerando o diagrama retangular de tensões

yo Distância entre o centro geométrico da seção transversal e a linha neutra

$\mathrm{V}_{\mathrm{c}} \quad$ Parcela de força cortante resistida por mecanismos complementares ao modelo de treliça

$\mathrm{V}_{\mathrm{c} 0} \quad$ Valor de referência para $\mathrm{V}_{\mathrm{c}}$ quando $\theta=45^{\circ}$

$V_{d} \quad$ Força cortante de cálculo

$\mathrm{y}_{\mathrm{si}} \quad$ Distância de cada camada de armadura ao centro geométrico da seção 


\begin{tabular}{|c|c|}
\hline $\mathrm{V}_{\mathrm{Rd} 2}$ & $\begin{array}{l}\text { Força cortante resistente de cálculo, relativa à ruína das diagonais } \\
\text { comprimidas de concreto }\end{array}$ \\
\hline $\mathrm{V}_{\mathrm{Rd} 3}$ & Força cortante resistente de cálculo, relativa àruína por tração diagonal \\
\hline $\mathrm{V}_{\mathrm{Sd}}$ & Força cortante solicitante de cálculo \\
\hline $\mathrm{V}_{\mathrm{sw}}$ & Parcela de força cortante resistida pela armadura transversal \\
\hline $\mathrm{z}_{\mathrm{c}}$ & $\begin{array}{l}\text { Distância entre o ponto de aplicação da resultante de compressão no } \\
\text { concreto e a linha neutra em uma seção transversal }\end{array}$ \\
\hline$\alpha$ & $\begin{array}{l}\text { Coeficiente para consideração de efeitos na tensão no concreto } \\
\text { Inclinação dos estribos em relação ao eixo longitudinal do elemento } \\
\text { estrutural }\end{array}$ \\
\hline$\alpha_{b}$ & Fator que define as condições de vínculo nos apoios \\
\hline$\beta_{\times 2, \lim }$ & $\begin{array}{l}\text { Relação limite para a profundidade da linha neutra e altura útil da seção } \\
\text { transversal para o domínio } 2\end{array}$ \\
\hline$\beta_{\times 3, \lim }$ & $\begin{array}{l}\text { Relação limite para a profundidade da linha neutra e altura útil da seção } \\
\text { transversal para o domínio } 3\end{array}$ \\
\hline$\beta_{y}$ & $\begin{array}{l}\text { Valor de } \beta_{x} \text { multiplicado por } 0,8 \text { para consideração do diagrama } \\
\text { retangular de tensões do concreto }\end{array}$ \\
\hline$\delta$ & $\begin{array}{l}\text { Distância do centro da armadura à borda mais próxima da seção } \\
\text { transversal de concreto (adimensional) }\end{array}$ \\
\hline$\gamma_{c}$ & Coeficiente de minoração da resistência do concreto \\
\hline$\gamma_{\mathrm{f}}$ & Coeficiente de majoração das ações \\
\hline$\gamma_{s}$ & Coeficiente de ponderação do aço \\
\hline$\varepsilon_{\mathrm{c}}$ & Deformação específica do concreto \\
\hline$\varepsilon_{\mathrm{c} 2}$ & Limite do encurtamento da borda comprimida para a região I \\
\hline$\varepsilon_{\mathrm{ct}}$ & Deformação última do concreto àtração \\
\hline$\varepsilon_{\text {cu2 }}$ & $\begin{array}{l}\text { Deformação específica convencional da ruptura do concreto } \\
\text { comprimido na região II }\end{array}$ \\
\hline$\varepsilon_{\text {cu3 }}$ & $\begin{array}{l}\text { Deformação específica convencional da ruptura do concreto } \\
\text { comprimido na região III }\end{array}$ \\
\hline$\varepsilon_{\mathrm{s}}$ & Deformação específica do aço no centro geométrico da armadura \\
\hline$\varepsilon_{\text {su }}$ & Deformação específica convencional do aço tracionado \\
\hline$\varepsilon_{\mathrm{t}}$ & creto na borda tracionada \\
\hline
\end{tabular}




\begin{tabular}{|c|c|}
\hline$\varepsilon_{\mathrm{ycd}}$ & Deformação de cálculo no aço na compressão \\
\hline$\varepsilon_{\mathrm{yd}}$ & Deformação de cálculo no aço \\
\hline$\varepsilon_{\mathrm{ycu}}$ & Deformação específica convencional de ruptura do aço na compressão \\
\hline$\varepsilon_{\mathrm{yu}}$ & Deformação específica convencional de ruptura do aço na tração \\
\hline$\phi_{f}$ & Diâmetro dos estribos \\
\hline $\mathrm{K}$ & Rigidez secante adimensional ou relativa \\
\hline$v$ & Força normal adimensional \\
\hline$\varphi$ & Coeficiente de fluência \\
\hline$\lambda$ & Índice de esbeltez \\
\hline$\lambda_{1}$ & $\begin{array}{l}\text { Valor limite para } \lambda \text { para que não se considerem os efeitos localizados } \\
\text { de segunda ordem }\end{array}$ \\
\hline$\theta_{1}$ & Desaprumo de um lance de pilar de altura $\ell$ \\
\hline$\theta_{1}$ & Desaprumo mínimo de um lance de pilar de altura $\ell$ \\
\hline$\rho_{\mathrm{c}}$ & Massa específica do concreto \\
\hline$\rho_{\min }$ & Taxa geométrica de armadura mínima \\
\hline$\rho_{\mathrm{sw}}$ & Taxa geométrica de armadura transversal \\
\hline$\sigma_{\mathrm{c}}$ & Tensão normal de compressão no concreto \\
\hline$\sigma_{\mathrm{cd}}$ & Tensão de cálculo do concreto \\
\hline$\sigma_{\mathrm{ct}}$ & Tensão de tração no concreto \\
\hline$\sigma_{\mathrm{sd}}$ & Tensão de cálculo na armadura \\
\hline$\sigma_{\mathrm{si}}$ & Tensão de cálculo em uma camada de aço \\
\hline$\sigma_{\mathrm{t}}$ & Tensão normal de tração no concreto \\
\hline$\xi$ & $\begin{array}{l}\text { Relação entre a profundidade da linha neutra e a altura total da seção } \\
\text { transversal }\end{array}$ \\
\hline
\end{tabular}




\section{RESUMO}

LINDQUIST, M. Aplicativo windows para análise e dimensionamento de pórticos planos em concreto armado. 115p. Dissertação (Mestrado) - Escola de Engenharia de São Carlos, Universidade de São Paulo.

O objetivo deste trabalho foi desenvolver um programa para auxílio didático em disciplinas que envolvam a análise estrutural, o dimensionamento e o detalhamento de pórticos planos de concreto armado. O programa age como um pós-processador, obtendo dados, como esforços nos nós e deslocamentos nodais de um processador existente, interpreta esses dados e dimensiona a estrutura para resistir aos esforços de acordo com a NBR 6118:2001. Para verificação dos resultados foi feita uma comparação entre o dimensionamento efetuado pelo programa DTool e o realizado pelo programa TQS, justificando as diferenças que possa haver entre os dois processos.

Palavras Chave: Concreto Armado, Projeto, Pórticos Planos, Programação de computadores 


\section{ABSTRACT}

LINDQUIST, M. Analisys and design of reinforced concrete plane frames using a windows based program. 115p. Dissertação (Mestrado) - Escola de Engenharia de São Carlos, Universidade de São Paulo.

The purpose of this paper is the development of a program capable to aid didactically in disciplines related to structural analysis, and in designing and projecting reinforced concrete plane frames. This software works as a postprocessor, receiving data from a processor such as nodal efforts and displacements. It interprets those data and designs the structure in order they resist acceptably those stresses, using processes that are recommended by the Brazilian code NBR 6118:2001. For results verification a comparison between design by DTool and TQS is presented, and eventual differences between them are justified.

Keywords: Reinforced concrete, Design, Plane Frames, Computer programming. 
CAPÍTULO 1

\section{INTRODUÇÃO}

\subsection{Objetivo}

O objetivo deste trabalho é obter um programa para auxílio didático no ensino de disciplinas que envolvam a análise estrutural, o dimensionamento e o detalhamento de pórticos planos de concreto armado. O programa age como um pós-processador, obtendo dados como esforços nos nós e deslocamentos nodais de um processador existente, interpreta esses dados e dimensiona a estrutura para resistir a esses esforços de acordo com a NBR 6118:2001.

Pode ser utilizado como pré-processador e processador o programa FTOOL, sistema gráfico interativo de auxílio para ensino de alunos de engenharia estrutural, desenvolvido para analisar pórticos planos.

O programa que servirá como auxílio na fase de dimensionamento e detalhamento de pórticos planos de concreto armado, de forma a levar o aluno a visualizar todo o processo, e assim facilitar sua compreensão da forma como é feito o projeto de estruturas de concreto armado; envolvendo dimensionar ao cisalhamento, à flexão simples e à flexão normal composta, mostrando o arranjo das armaduras para cada caso. 


\subsection{Justificativa}

Muitos programas computacionais têm sido desenvolvidos para projetos de estruturas de concreto armado. Tais programas, embora tenham-se tornado cada vez mais complexos e completos no que tange à manipulação de dados e interface com o usuário, envolvem um paradoxo, pois sua complexidade leva a uma inacessibilidade aos usuários que não têm prática em sua utilização, sendo necessário um longo processo de adaptação até que se possa utilizá-lo de forma satisfatória. Além disso, os softwares pouco possibilitam ao usuário facilidade de compreensão e de assimilação dos processos por eles utilizados, sendo o resultado final algo a ser aceito, e não necessariamente algo a ser compreendido.

No processo de aprendizagem, torna-se necessário levar o aluno a raciocinar, a tomar decisões, mesmo que estas decisões sejam errôneas e que os levem a resultados ruins do ponto de vista de qualidade de estruturas. Tais resultados devem ser comentados pelo programa, forçando o aluno a tomar novas decisões que levem a estrutura a estar de acordo com a norma brasileira.

Com o advento da nova norma para projeto de estruturas de concreto, torna-se necessário um programa computacional para o ensino de alunos de graduação que a ela devem estar familiarizados.

\subsection{Apresentação}

O capítulo 2 apresenta as propriedades dos materiais que constituem o concreto armado, concreto e aço, citando as principais características de cada um, assim como suas propriedades e critérios de classificação de acordo com NBR 6118:2001.

No capítulo 3 são apresentadas as formas de analisar estruturalmente uma edificação, com a aplicação dos conceitos de estados limites últimos e de serviço. As hipóteses e análises necessárias para o projeto de estruturas de concreto armado são mostradas.

A forma de modelagem de estruturas é apresentada com a divisão em elementos conforme a forma e a solicitação preponderante; elementos bidimensionais sob o efeito predominante de flexão, lajes; elementos representados 
unidimensionalmente sem o efeito relevante da força normal, vigas; e elementos unidimensionais com ação relevante de esforço normal, pilares.

Após a definição de cada elemento básico, é feita uma análise da modelagem de cada um, mostrando as hipóteses utilizadas no processo, bem como suas características mais importantes.

Para pilares foram necessárias explicações adicionais para identificar a forma de modelagem e os métodos para consideração de efeitos de segunda ordem.

O capítulo 4 aborda o processo de dimensionamento dos elementos, indicando as hipóteses necessárias para sua realização. São colocadas as definições de estados limites últimos e de serviço. Alguns conceitos, como a forma de garantir a dutilidade e os domínios de deformação em uma seção de concreto armado, tornaram-se necessários para melhor compreensão do processo de dimensionamento.

Após a definição dos conceitos iniciais, explica-se o projeto de estruturas de acordo com os esforços existentes. Primeiramente são definidas as equações para flexão normal, sendo o projeto baseado nos conceitos dos domínios de deformação. Para flexão normal composta é apresentado o processo aproximado sugerido pela NBR 6118:2001, assim como o método iterativo necessário para o caso geral. Por último é apresentado o processo para dimensionamento de armadura para resistir aos esforços de força cortante.

No capítulo 5 encontram-se recomendações e exigências necessárias para o detalhamento de armaduras em elementos lineares de concreto armado.

O capítulo 6 mostra uma comparação entre o dimensionamento feito pelo programa DTool e o realizado pelo programa TQS, justificando as diferenças que possa haver entre os dois processos. 


\subsection{Revisão Bibliográfica}

A construção sempre se apresentou como um desafio ao homem. Seja na produção de habitações, seja na transposição de obstáculos, seja no armazenamento de alimentos, ou para delimitar territórios. Este desafio deverá ser vencido com a produção de estruturas que se adaptem às necessidades impostas pela natureza.

Os materiais empregados, inicialmente blocos de pedra superpostos, com o tempo, e com o avanço da tecnologia, deram espaço para um material resistente e com uma característica peculiar, a sua moldabilidade. Esse material, o concreto, teve o seu desenvolvimento nas últimas décadas do século XIX e nas primeiras do século passado. Sobre as primeiras pesquisas com relação às características desse material podem-se citar, segundo AMARAL (1969), as seguintes:

1877 - Hyatt publicou os resultados de suas experiências;

1880 - Hennebique construiu a primeira laje armada com barras de aço de seção circular;

1892 - Hennebique obteve patente do primeiro tipo de viga como as atuais, utilizando estribos;

1902 a 1908 - antes da publicação dos trabalhos experimentais realizados por Wayss e Freytag, associados como firma especializada, Wayss publica, em 1887, seus trabalhos experimentais;

1902 - Mörsch, engenheiro pertencente à firma supracitada e que se tornou um dos maiores contribuintes para o progresso do concreto armado, publicou a primeira edição de seu livro, no qual apareciam resultados de numerosas experiências;

1900 a 1910 - são publicados os resultados de diversas comissões na França, Alemanha e Suíça.

Paralelamente às pesquisas sobre as características do material, surgiram os primeiros pesquisadores sobre a forma de calcular as obras de concreto armado: 
1886 - Koenen desenvolveu um método de dimensionamento empírico para alguns tipos de construção, com base nos resultados dos ensaios realizados por Monier;

1897 - Rabut iniciou o primeiro curso sobre concreto armado;

1902 - Mörsch desenvolveu os conceitos da teoria do concreto armado, iniciada por Koenen cujos fundamentos e seus elementos essenciais são ainda válidos.

Com a crescente utilização desse novo material na construção civil, surgem as primeiras normas, baseadas nos conceitos de tensões admissíveis. A partir da década de 20, há uma maior evolução destas normas, que passam a se basear em novas técnicas e métodos de cálculo, podendo-se citar o método do coeficiente de segurança externo.

$\mathrm{Na}$ década de 70 , passa a ser utilizado o método semi-probabilístico de cálculo, possibilitando a inserção de um novo conceito de segurança, mas que necessitava de um cálculo mais rigoroso no dimensionamento dos elementos. Essa necessidade foi suprida pela elaboração de ábacos e tabelas, podendo-se citar: CABRÉ (1972), MONTOYA (1973), SANTOS (1983), RODRIGUES (1985) e VENTURINI (1987).

Essa maior necessidade de cálculos acurados e precisos é alcançada pelo avanço na tecnologia computacional. Com a maior acessibilidade aos computadores, o cálculo de estruturas passa a ser muito facilitado. A existência da automatização do processo de cálculo, dimensionamento e detalhamento de peças de concreto armado era apenas uma questão de tempo.

A utilização de computadores no auxílio ao cálculo estrutural de pórticos de concreto iniciou-se juntamente com 0 desenvolvimento dos primeiros computadores. Na década de 60, foram desenvolvidos métodos para uso computacional que automatizavam o processo de verificação da carga de colapso em pórticos LIVESLEY (1967), COHN \& GRIERSON (1969), aplicando a teoria de BOWLES \& MERCHANT (1956), MCMINN (1961), dentre outros. Essa mínima carga de colapso era verificada por meio de teoremas estáticos. (NEAL, 1963; GRIERSON \& GLADWELL 1971). GABBAY (1977) aplicou o conceito de RankineMerchant e elaborou um programa em Fortran IV para o cálculo automatizado de cargas aproximadas de colapso de pórticos planos. 
A aplicação de softwares de forma pedagógica, para auxílio no ensino de disciplinas relacionadas ao projeto de estruturas de concreto ainda não tinha sido considerada, e sua importância era desconhecida ou desprezada. Porém, BROHN \& COWAN (1977) pesquisaram informações sobre 0 entendimento do comportamento estrutural por estudantes de engenharia civil e perceberam a necessidade de prover aos alunos conhecimentos intuitivos dos esforços em um pórtico plano.

Muitos alunos que tinham seguido ou estavam seguindo as disciplinas normais de um curso de engenharia civil eram incapazes de desenhar o comportamento do diagrama de força cortante e de momento fletor para um pórtico plano sem resolver as equações correspondentes. BROHN (1983) destacou a importância de desenvolver um conhecimento intuitivo do comportamento das estruturas nos discentes, ressaltando a necessidade de visualização no processo de aprendizagem.

Um programa pioneiro nesta área foi lançado em 1979. Chamado de CAL por WILSON (1979), este programa não interativo poderia ser considerado mais como uma calculadora para auxílio no cálculo de algumas aplicações específicas. Outra versão do mesmo programa foi lançada no mesmo ano por MOSS et al. (1979), versão esta que permitia um projeto interativo de vigas de aço. programa, após cada decisão, checava sua correção e conveniência.

Uma nova extensão deste programa, chamada CAL-GRAF, lançada por LEIMBACK (1981), permitia que o estudante definisse uma estrutura e visualizasse seus deslocamentos e esforços.

Um novo avanço nesta área aconteceu quando SLATER et al. (1984) lançaram um sistema que gerava exemplos de vigas ou permitia que elas fossem colocadas pelo usuário, então instava o estudante a colocar as equações de equilíbrio, resolvia-as instantaneamente e, se necessário, avaliava os resultados obtidos com a ajuda do estudante, que poderia interativamente fazer novas tentativas.

De forma diferente, SMITH (1984) desenvolveu um programa educativo no ensino do comportamento de estruturas que mostrava um conjunto de dez problemas. Em cada um, o estudante era convidado a estimar o valor do momento fletor em um ponto crítico, ponto de maior momento fletor, em uma escala de $-10 \mathrm{a}$ +10; o programa então desenhava o diagrama correto e marcava o valor estimado 
pelo estudante para que ele pudesse comparar sua estimativa com o diagrama correto.

Em 1986 a TQS Informática LTDA, no Brasil, lançou a primeira versão do seu programa para projeto de estruturas de concreto, chamado de CAD/Vigas para dimensionamento e desenho de vigas em ambiente gráfico.

Para auxílio pedagógico, desenvolveu-se em Curitiba por SCHMID (1988) um programa em Turbo Pascal chamado SIDICANU, para apoio ao ensino de cálculo numérico.

Em 1989, a TQS lança o seu programa CAD/Lajes, para o detalhamento de armaduras pelo processo convencional.

Em meados de 1991 CORSEUIL et al. (1992) começam a idealizar e implementar um programa interativo para o ensino do comportamento estrutural de pórticos planos chamado Ftool, desenvolvido em bolsa de iniciação científica na PUC-RJ. Entre o final de 1997 e o início de 1998, o programa foi reescrito por MARTHA (1999) de forma a poder ser executado tanto em ambiente windows como em Linux. Em janeiro de 2001 foi lançada a última versão, o Ftool 2.09.

Para auxílio no projeto automatizado de estruturas de concreto, SANTOS (1994) lançou um livro com sub-rotinas em BASIC para dimensionamento de peças de concreto armado. No mesmo ano, PFEILER et al. (1994) lançaram na Áustria a primeira versão de um programa instrutivo e interativo para auxílio no ensino de comportamento de pórticos planos sob diferentes carregamentos. Elaborado em alemão, ao programa foi dado o nome de RuckZuck, ou "muito rápido". Em 1996, LORENZ (2000) lançou a primeira versão de um programa também em alemão para dimensionamento de seções transversais de concreto, bem como para verificação da punção em lajes.

No ano de 1998 é lançado o programa CAD/Pilar para cálculo, dimensionamento e desenho de pilares de seção genérica, assim como a edição gráfica orientada de armaduras para o CAD/Lajes.

No mesmo ano, um programa educativo chamado SATS foi desenvolvido por COROVIC et al. (1998). Este programa, compilado em Turbo Pascal, desenha um pórtico simples com vários tipos possíveis de vinculações e vários tipos de cargas e leva o aluno a desenhar o diagrama de força cortante e momento fletor para que, após isso, o programa compare o desenho com o diagrama real. No Brasil, é lançado um sistema multimídia para apoio ao ensino de estruturas de concreto por MAGGI \& PEDROSO (1998). 
Em 2000, KAEFER (2000) modifica e amplia a aplicação do programa Ftool para obter uma ferramenta gráfica e interativa para a modelagem e dimensionamento de pórticos planos de concreto armado. Neste mesmo ano a TQS lança a versão para Windows do seu programa CAD/TQS.

Observam-se atualmente alguns pólos de pesquisa no desenvolvimento de programas para auxílio educacional, os programas chamados E-tools. O principal destes pólos está na PUC-RJ, outros se localizam na UFAL, UFMG, UFPR e na própria USP. Nestes locais, outras ferramentas para utilização de computadores no processo de ensino estão sendo desenvolvidas, podendo-se citar: recursos multimídia, animações em flash e Applets, utilizados como páginas da WEB. 


\section{PROPRIEDADES DOS MATERIAIS}

\subsection{Introdução}

O Concreto é um aglomerado que se constitui de agregados e possui cimento como aglomerante; é portanto uma rocha artificial. Por concreto armado, entende-se o concreto com barras de aço nele imersas. O concreto armado é, portanto um material de construção composto, no qual a ligação entre o concreto e a armadura de aço é devida à aderência do cimento e a efeitos de natureza mecânica. (LEONHARDT, 1977)

Neste capítulo serão apresentadas as características dos materiais que constituem o concreto armado, baseando-se nas informações normativas apresentadas na NBR 6118:2001. Mostrar-se-ão as características físicas dos materiais (módulo de elasticidade, diagramas tensão-deformação e características de resistência e comportamento), do concreto e do aço, necessárias para o projeto de estruturas de concreto armado.

\subsection{Aço}

\subsubsection{Características}

O aço tem como suas características, as seguintes:

- resistência semelhante àtração e àcompressão; 
- comportamento inicialmente elástico, com módulo sensivelmente constante, com fase plástica posterior, esta com características dependentes do tipo de aço;

- ausência de fluência e retração;

- efeito BAUSCHINGER sob ação de ciclos de cargas.

\subsubsection{Massa Específica}

Pode-se adotar, para massa específica de aços para armadura passiva, o valor de $7850 \mathrm{~kg} / \mathrm{m}^{3}$.

\subsubsection{Módulo de Elasticidade}

O módulo de elasticidade de aços para armadura passiva, na falta de ensaios para determiná-lo ou na falta de dados fornecidos pelo fabricante, pode ser considerado igual a $210 \mathrm{GPa}$. Este é um valor um pouco mais alto que o proposto pelo CEB/90, que é de $200 \mathrm{GPa}$.

\subsubsection{Categorias}

Os aços são classificados de acordo com o valor característico da sua resistência de escoamento, sendo classificados, para armadura passiva, em três categorias, CA-25, CA-50 e CA-60.

Os diâmetros e seções transversais devem estar de acordo com a norma NBR 7480:1996.

\subsubsection{Resistência àTração}

A resistência de cálculo das barras de aço àtração é definida como a tensão no patamar de escoamento, $f_{\mathrm{yk}}$, dividida pelo coeficiente de minoração $\gamma_{\mathrm{s}}$, portanto: 


$$
\mathbf{f}_{\mathbf{y d}}=\frac{\mathbf{f}_{y k}}{\gamma_{s}}
$$

e

$\left|\varepsilon_{\mathrm{yd}}\right|=\left|\varepsilon_{\mathrm{ycd}}\right|=\frac{\mathbf{f}_{y d}}{E_{s}}$

O valor de $\gamma_{s}$ é 1,15

\subsubsection{Diagrama Tensão-Deformação}

$\mathrm{Na}$ ausência de ensaios para determinar os valores da resistência de escoamento $\left(\mathfrak{f}_{y k}\right)$ à tração e da deformação das barras, a norma NBR 6118:2001 propõe um diagrama simplificado para cálculo de estados-limites de serviço e último para aços com ou sem patamar de escoamento, mostrado na figura a seguir.

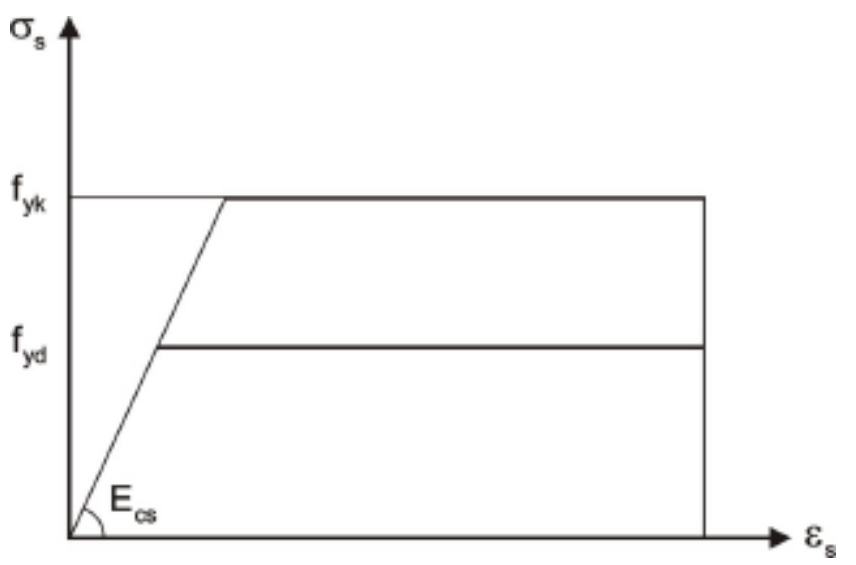

Figura 2.1 - Diagrama tensão-deformação para aços de armaduras passivas

O diagrama é válido tanto para tração como para compressão com temperaturas do material entre $-20^{\circ} \mathrm{C}$ e $150^{\circ} \mathrm{C}$.

O início do patamar de escoamento é dado pela seguinte razão:

$$
\left|\varepsilon_{y d}\right|=\left|\varepsilon_{y c d}\right|=\frac{\mathrm{f}_{\mathrm{yd}}}{\mathrm{E}_{\mathrm{s}}}
$$


As relações tensão deformação podem ser escritas da seguinte forma:

$$
\begin{aligned}
& \sigma_{s}=\mathrm{E}_{s} \cdot \varepsilon_{s} \quad \text { para } \quad\left\{\begin{array}{l}
\varepsilon_{y d} \leq \varepsilon_{s} \leq 0 \\
0 \leq \varepsilon_{s} \leq \varepsilon_{y c d}
\end{array}\right. \\
& \sigma_{s}=\mathrm{f}_{\mathrm{yd}} \quad \text { para }\left\{\begin{array}{l}
\left(\varepsilon_{y u}=10 \%\right) \leq \varepsilon_{s} \leq \varepsilon_{y c d} \\
\varepsilon_{y c d} \leq \varepsilon_{s} \leq\left(\varepsilon_{y c u}=3,5 \%\right. \text { oo }
\end{array}\right)
\end{aligned}
$$

\subsection{Concreto}

\subsubsection{Características}

O concreto possui as seguintes características:

- boa resistência à compressão e baixa resistência à tração, o que leva àsua fiss uração;

- $\quad$ existência de deformações diferidas produzidas ou não por tensões (fluência, retração);

- $\quad$ influência do tipo e da duração da solicitação na resistência do material (estado uniaxial ou multiaxial de tensões, efeito Rüsch, fadiga, etc.);

- baixa ductilidade do material, se comparado com o aço, com deformações últimas muito baixas;

- $\quad$ relação não-linear entre tensões de compressão e deformações, com a existência de um valor máximo e de um ramo descendente;

- comportamento sob cargas dinâmicas com ciclos de histerese, degradação da rigidez e da resistência do concreto. 


\subsubsection{Classes}

A norma brasileira NBR 8953:1992 estabelece classes para classificação do concreto quanto à sua resistência característica à compressão aos 28 dias ( $\left.f_{c k}\right)$. Os valores para classificação vão de 10 a $50 \mathrm{MPa}$, variando de 5 em 5 , ou sejam, concretos C10, C15, C20, C25, C30, C35, C40, C45 e C50. A norma se aplica a concretos de resistência normal, classificados como do grupo I.

Com o intuito de assegurar a durabilidade das estruturas, a NBR 6118:2001 estabelece que o valor mínimo da resistência característica para utilização em construções seja de $20 \mathrm{MPa}$ para concretos com armadura passiva, e de $25 \mathrm{MPa}$ para concretos com armadura ativa. Exceção feita para obras provisórias e fundações, que podem conter concreto com resistência característica de $15 \mathrm{MPa}$.

\subsubsection{Massa Específica}

Um valor mínimo e máximo de massa específica $\rho_{c}$ foi estabelecido, entre os quais a norma é válida.

$$
2000 \mathrm{~kg} / \mathrm{m}^{3} \leq \rho_{\mathrm{c}} \leq 2800 \mathrm{~kg} / \mathrm{m}^{3}
$$

Não se conhecendo a massa específica do concreto, pode-se considerá-la como sendo de $2400 \mathrm{~kg} / \mathrm{m}^{3}$ para concreto simples e de $2500 \mathrm{~kg} / \mathrm{m}^{3}$ para concreto armado.

Quando se conhecer a massa específica do concreto simples, pode-se obter o valor da massa específica do concreto armado adicionando-se de $100 \mathrm{~kg} / \mathrm{m}^{3}$ a $150 \mathrm{~kg} / \mathrm{m}^{3}$ ao valor conhecido.

\subsubsection{Resistência àTração}

A resistência à tração de um concreto pode ser estimada de ac ordo com expressões propostas pela norma NBR 6118:2001, utilizando todos os valores em MPa.

$$
\mathrm{f}_{\mathrm{ctm}}=0,3 \cdot \mathrm{f}_{\mathrm{ck}}{ }^{2 / 3}
$$




$$
\begin{aligned}
& \mathrm{f}_{\text {ctk,inf }}=0,7 \cdot \mathrm{f}_{\mathrm{ctm}} \\
& \mathrm{f}_{\text {ctk,sup }}=1,3 \cdot \mathrm{f}_{\mathrm{ctm}}
\end{aligned}
$$

\subsubsection{Módulo de Elasticidade}

A norma NBR 6118:2001 estabelece uma fórmula para estimar o valor do que chama de módulo de elasticidade tangente inicial $\left(E_{c i}\right)$.

$$
\mathrm{E}_{\mathrm{ci}}=5600 \cdot \mathrm{f}_{\mathrm{ck}}^{1 / 2}
$$

Onde:

$E_{c i}$ e $f_{c k}$ são dados em megapascals.

O módulo de elasticidade secante, utilizado para avaliação de um elemento estrutural ou seção transversal, ou para determinação de esforços solicitantes e verificação de estados limite de serviço, é calculado segundo (2.13). No entanto, para avaliação do comportamento global da estrutura e para cálculo de perdas na protensão, pode ser utilizado o módulo de deformação tangente inicial $\left(E_{c i}\right)$.

$$
\mathrm{E}_{\mathrm{cs}}=0,85 \cdot \mathrm{E}_{\mathrm{ci}}
$$

\subsubsection{Efeito Rüsch}

Uma das características do concreto é a perda de resistência para esforços de longa duração. Esta propriedade do concreto foi estudada por RÜSCH (1960). Suas conclusões mostram que para diferentes rupturas, ocorridas todas com a mesma duração de carregamento, é maior a resistência do concreto carregado progressivamente que o concreto carregado rapidamente e mantido sob carga constante. 
A relação entre a resistência obtida num ensaio lento e a resistência obtida num ensaio rápido, sendo ambos com a mesma idade, é consistentemente independente da qualidade do concreto e da idade de início de carregamento. Esta relação pode ser admitida com a tendência de ficar entre os limites 0,75 e 0,80, sendo considerado igual ao primeiro limite. Portanto, para consideração do efeito Rüsch, o concreto deve ser considerado com um fator de redução de 0,75 . Este valor é modificado e incluído no coeficiente $\alpha$ conforme item a seguir, para considerar outros efeitos característicos do concreto.

\subsubsection{Diagrama Tensão-Deformação}

\subsubsection{Compressão}

Para tensões menores que $0,5 \mathrm{f}_{\mathrm{c}}$, pode-se admitir uma relação linear entre a tensão e a deformação em uma peça de concreto com coeficiente angular igual ao módulo de elasticidade mostrado no item 2.3.5.

O diagrama tensão deformação do concreto, para análises no estado limite último, é admitido igual ao da figura 2.2.

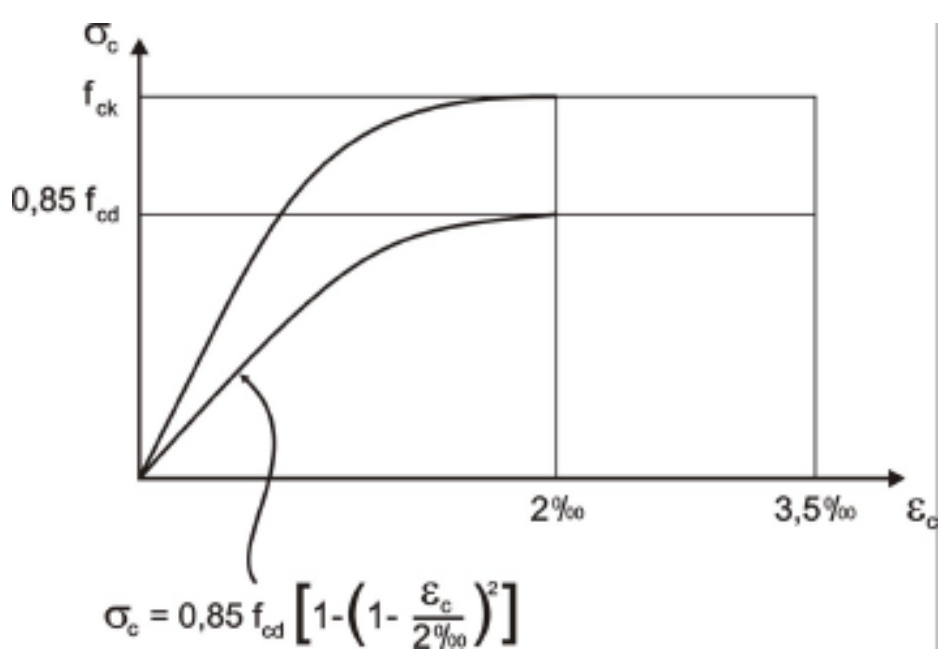

Figura 2.2 - Diagrama tensão-deformação idealizado

Para valores de $\varepsilon_{c}$ menores que $2 \%, \sigma_{c}$ varia segundo a equação do segundo grau descrita acima. 


$$
\sigma_{c d}=\alpha \cdot \mathrm{f}_{\mathrm{cd}}=\alpha \cdot \frac{\mathrm{f}_{\mathrm{ck}}}{\gamma_{\mathrm{c}}}
$$

Sendo:

$\gamma_{c}$ Coeficiente de minoração da resistência do concreto, sendo normalmente adotado como 1,4 para combinações normais, ou 1,2 para cargas especiais, excepcionais ou de construção.

$\alpha \quad$ Parâmetro que leva em consideração o aumento da resistência com a idade, considerado igual a 1,2, a deformação lenta do concreto ou efeito Rüsch no dimensionamento no estado limite último, que é igual a 0,75 , e a diferença de resistência à compressão em corpos -deprova e na estrutura, 0,95 (FUSCO-1989). A multiplicação destes três valores leva ao valor usual de 0,85 para o parâmetro $\alpha$ que também pode assumir o valor 1,10 para análise da não linearidade física.

\subsubsection{Tração}

Considera-se o concreto tracionado fissurado para estruturas dimensionadas no estado limite último, portanto não é considerada sua resistência à tração para o dimensionamento. Porém, para concreto não fissurado, pode se $r$ considerado o diagrama bi-linear.

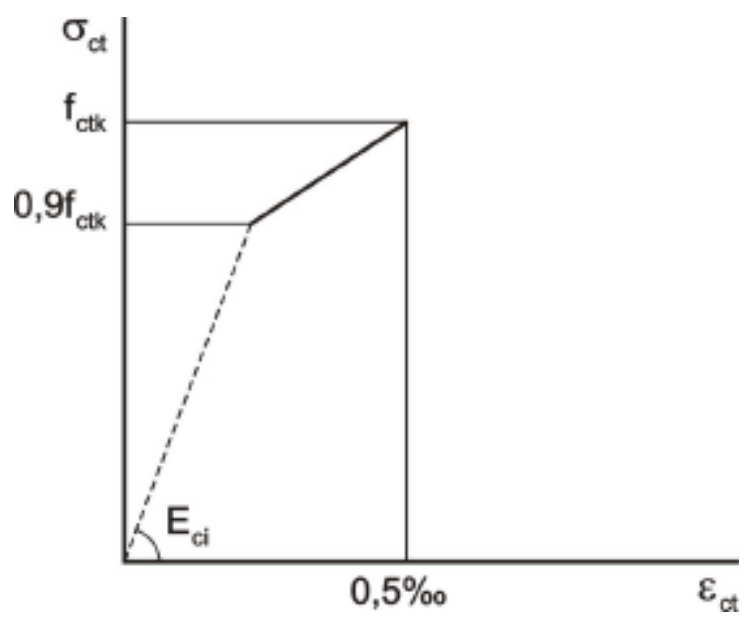


CAPÍTULO 3

\section{ANÁLISE ESTRUTURAL}

\subsection{Introdução}

Neste capítulo serão considerados os parâmetros para a análise estrutural de edifícios, identificando os seus elementos, e a forma como são abordados para o projeto baseado em conceitos de segurança.

\subsection{Processo Inicial}

Tendo como objetivo definir os esforços e seus efeitos numa edificação, a análise estrutural verifica a segurança de uma edificação considerando a aplicação dos conceitos de estados limites últimos e de serviço.

Depois de definida a forma estrutural da edificação, as dimensões previstas são estimadas, na maioria das vezes, por meio da experiência do projetista ou por um pré-dimensionamento inicial.

Os esforços solicitantes, por sua vez, são obtidos por meio de análise estrutural, observando-se os efeitos das ações na estrutura, com a finalidade de verificar os estados limites últimos e de serviço (NBR 6118:2001). A estrutura deve ser dimensionada para estes esforços solicitantes. Esse dimensionamento é baseado no cálculo necessário para determinação da seção transversal de concreto e das armaduras de aço.

Muitas vezes, o dimensionamento limita-se a calcular a área de aço necessária, quando as tensões de compressão no concreto e as respectivas deformações são examinadas. Deve-se considerar a correta disposição das barras, pois certas distâncias mínimas devem ser respeitadas para evitar problemas 
construtivos na concretagem. Também deve-se verificar se a distribuição e o diâmetro das barras garantem uma limitação satisfatória para a abertura de fissuras.

Nas estruturas, os esforços solicitantes (N, M e V) atuam simultaneamente. Porém, o dimensionamento das peças de concreto armado é feito para cada um em separado, fazendo-se uma verificação para os outros esforços. Além disso, em geral as estruturas das construções são excessivamente complexas para possibilitarem um tratamento numérico global. Desta forma, faz parte da análise estrutural a divisão das estruturas em elementos mais simples, identificando o comportamento estrutural principal destas partes simples para associá-las aos modelos da Teoria das Estruturas. A análise estrutural será tanto mais eficaz quanto mais os resultados do tratamento numérico simplificado se aproximarem dos valores reais esperados (ISHITANI, 1998 apud KAEFER, 2000).

Os momentos fletores e as forças cortantes podem atuar obliquamente, isto é, o momento fletor tendo componentes em duas direções, y e z. Porém isso não ocorre em pórticos planos, pois se consideram os esforços atuantes no plano no qual o pórtico está idealizado.

Para estruturas constituídas de materiais homogêneos, as tensões máximas podem ser facilmente encontradas com a utilização da Teoria da Elasticidade e da Resistência dos Materiais. Porém, para um material heterogêneo como o concreto armado, isso não é possível. Por isso, o dimensionamento de estruturas de concreto armado, em geral, é feito separadamente para:

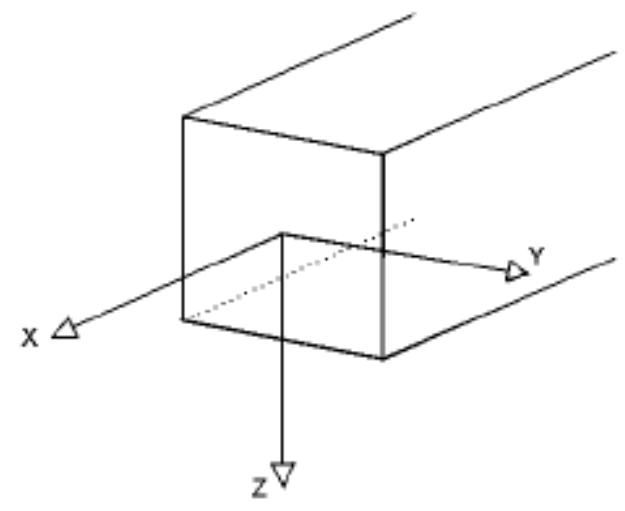

Figura 3.1 - Eixos para o dimensionamento 
- Momentos fletores em torno dos eixos y ou z, com ou sem força normal na direção $x$, os quais produzem apenas tensões normais ao plano da seção;

- Esforços cortantes nas direções z e y, as quais produzem tensões no plano da seção $(y, z)$, ou tensões principais inclinadas em relação ao eixo $\mathrm{x}$;

- Momentos de torção em torno do eixo $x$, os quais também produzem tensões no plano da seção, ou tensões principais inclinadas em relação ao eixo $x$.

Os efeitos são superpostos somente se se tornarem críticos.

\subsection{Considerações Simplificadoras no Projeto de Edifícios}

Dentre os aspectos a serem considerados no projeto de estruturas de concreto podem-se ressaltar os seguintes, de acordo com KAEFER (2000):

a) O emprego de materiais (concreto e aço) com diagramas tensãodeformação não lineares, com características físicas que variam conforme a idade do concreto (fluência e relaxação);

b) O processo de construção artesanal que acarreta problemas e imperfeições na construção: "bicheiras" como resultado da má vibração no concreto, de concretagem mal planejada ou espaçamento entre barras de aço insuficiente; falta de prumo nos pilares, cobrimentos insuficientes e concretos com características diversas em vários pontos da construção;

c) O processo de construção incremental, que faz com que existam concretos com idades diversas na construção e, portanto, com características físicas diferentes, o que ocasiona uma grande redistribuição de esforços pela estrutura [ISHITANI (1998)];

d) Interação solo-estrutura;

e) A ação do vento na edificação; 
f) A exigência de qualidade da estrutura, definida pela NBR 6118:2001 como a existência de capacidade resistente, de bom desempenho em serviço e durabilidade;

g) A grande quantidade de elementos básicos (vigas, pilares, lajes);

h) A presença de elementos complementares, como escadas, caixas d'água, e de fundações (blocos, estacas, sapatas).

Verifica-se, com as considerações supracitadas, a grandeza no número de conceitos a serem incluídos no projeto de uma estrutura de concreto, sendo esta grande variedade de informações mais facilmente interpretada com o auxílio de programas de computador.

\subsection{Modelagem do Edifício}

Usualmente, um edifício de concreto armado pode ser representado como um pórtico espacial, tendo elementos distintos com funções bem definidas e comportamentos coerentes com as ações a eles impostas.

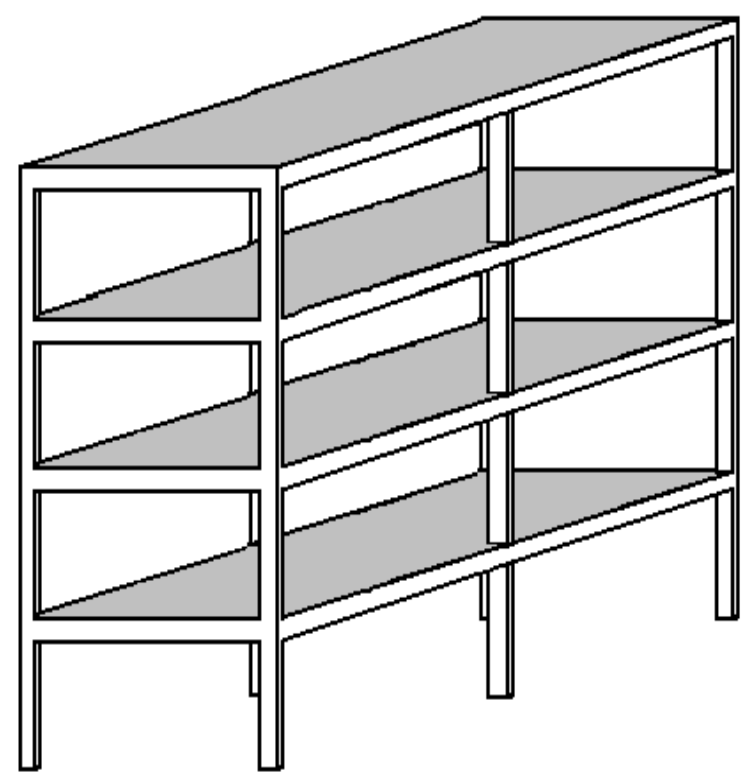

Figura 3.2 - Estrutura de um edifício de concreto armado 
Os elementos que podem ser observados em tal estrutura são:

Lajes: Elementos bidimensionais geralmente considerados como placa, estando predominantemente sob o efeito da flexão, sendo responsáveis por receber influência direta das ações às quais a estrutura está submetida, como a ação do peso próprio de piso e ações acidentais. São geralmente apoiadas em vigas que, por suas vezes, transmitem as ações aos pilares. Porém existem casos em que se apóiam diretamente nos pilares (lajes cogumelo).

Vigas: Elementos unidimensionais sem ação relevante de força normal, tendo como principais características a capacidade de resistir aos efeitos do momento fletor e da força cortante. Podem ser submetidos à ação de momento torçor no caso de suportarem platibandas, ou caso a estrutura tridimensional da qual faz parte lhe transmita tal esforço. Este elemento é representado por uma barra, geralmente horizontal.

Pilares: Elementos unidimensionais submetidos predominantemente à ação de esforços normais. Fornecem apoio às vigas, dando à estrutura o vão vertical dos compartimentos (pé-direito).

Além destes três elementos básicos, outros que compõem a superestrutura são escadas e reservatórios. Podem-se também citar elementos da infraestrutura, como blocos de fundação, radiers, sapatas e blocos sobre estacas. 


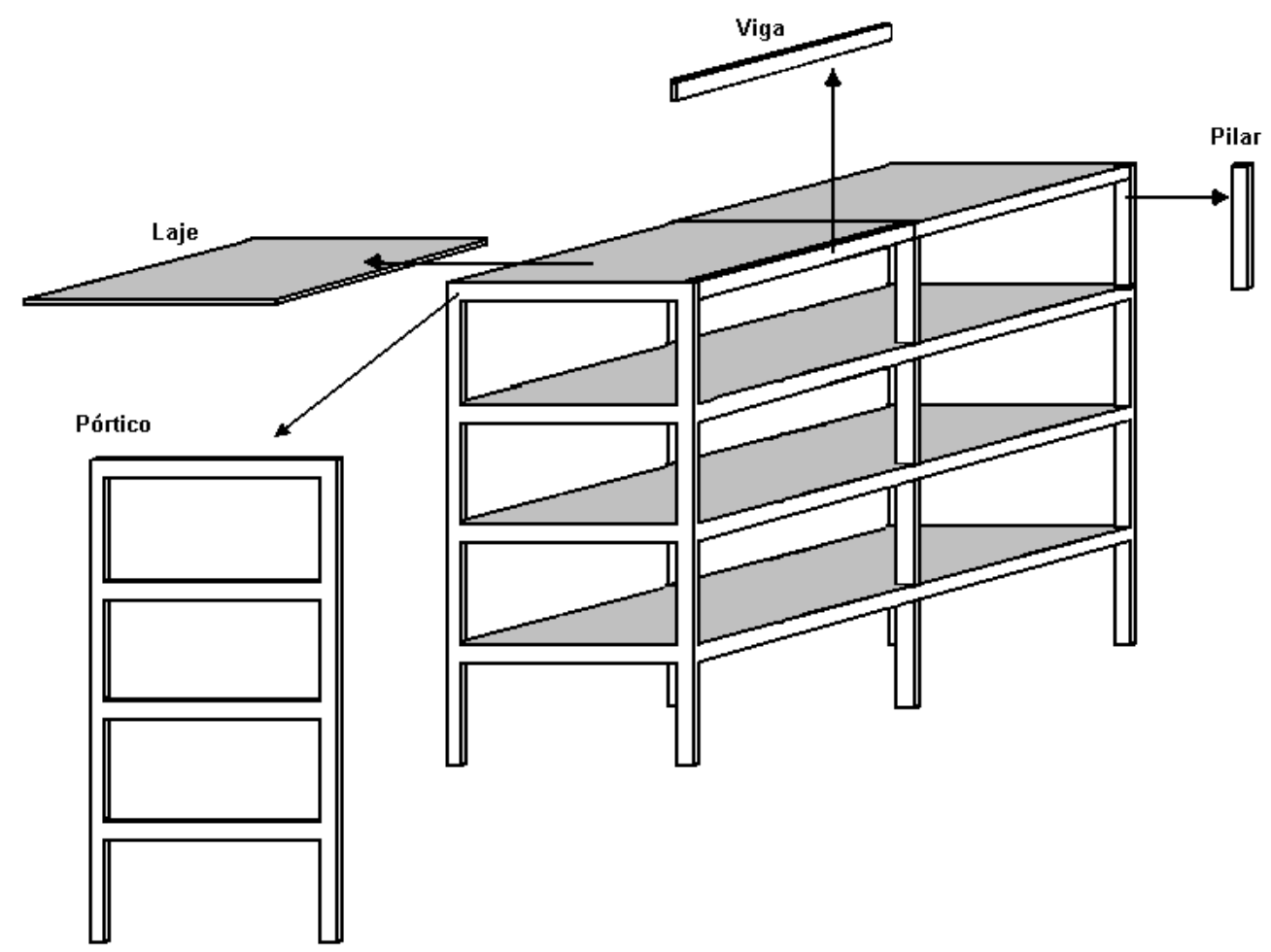

Figura 3.3 - Elementos básicos que compõem uma estrutura de concreto armado

A modelagem de uma estrutura tem como passo inicial a identificação dos elementos principais. Substituem-se os secundários por forças equivalentes, restando no modelo elementos representados tridimensionalmente por placas e barras. Um programa para dimensionamento de pórticos planos de concreto armado considerará a estrutura em duas dimensões, sendo uma delas a que representa a altura da edificação. Portanto, representará somente elementos principais lineares (barras): pilares e vigas. Os elementos de placa (lajes) são modelados àparte, restando no modelo uma estrutura que pode ser perfeitamente representada no plano.

\subsection{Modelagem de Lajes}

De acordo com a NBR 6118:2001, as estruturas de placas podem ser analisadas admitindo-se as seguintes hipóteses: 
a) manutenção da seção plana após a deformação, em faixas suficientemente estreitas;

b) representação dos elementos por seu plano médio.

As lajes são usualmente apoiadas nas vigas pertencentes ao seu piso, e podem ser consideradas isoladas das vigas, simplesmente transmitindo para estas esforços verticais, pois a resistência à torção da viga é desprezível em rela ção à resistência àflexão da laje, não transmitindo tais esforços para a viga. Considera se a torção em vigas se tal esforço for indispensável para o equilíbrio da estrutura, como no caso de lajes em balanço.

Pode-se considerar a análise de lajes como se estas estejam apoiadas livres àrotação e indeslocáveis àtranslação. Tal consideração é confirmada verificando se que os deslocamentos existentes em vigas são desprezíveis, se comparadas às existentes na sua laje adjacente.

As ações usualmente são constituídas pelo peso próprio, pelas cargas das alvenarias apoiadas diretamente na laje e as ações acidentais. Tais ações podem ser consideradas como as atuantes nos triângulos ou trapézios determinados pelas charneiras plásticas. As reações em cada apoio podem ser consideradas de maneira aproximada por retas inclinadas a partir dos vértices com os seguintes ângulos:

a) $45^{\circ}$ entre dois apoios do mesmo tipo;

b) $60^{\circ}$ a partir do apoio considerado engastado, se o outro for considerado simplesmente apoiado;

c) $90^{\circ}$ a partir do apoio, quando a borda vizinha for livre.

Com as aproximações efetuadas, o processo resultante pode não ser o mais exato, porém permite que as lajes sejam modeladas de uma forma simples, de modo a utilizar os resultados como ações atuantes nos elementos considerados em pórticos planos de concreto armado.

Outros tipos de lajes existentes são as lajes nervuradas e as cogumelo, apoiadas nos pilares com a existência ou não de capitéis. 


\subsection{Modelagem de Vigas e Pilares}

A partir das reações de apoio em lajes analisadas, podem-se considerar os elementos lineares nos quais tais ações atuam.

Segundo a NBR 6118:2001, estruturas ou parte de estruturas que possam ser assimiladas a elementos lineares (vigas, pilares, tirantes, arcos, pórticos, grelhas, treliças), podem ser analisadas admitindo-se as seguintes hipóteses:

a) manutenção da seção plana após a deformação;

b) representação dos elementos por seus eixos longitudinais;

c) comprimento limitado pelo centro de apoios ou pelo cruzamento com o eixo de outro elemento estrutural.

\subsubsection{Aproximações - Vigas Contínuas}

Para uma simplificação na modelagem de vigas contínuas, a NBR 6118:2001 cita que pode ser utilizado o modelo clássico de viga contínua, simplesmente apoiada nos pilares, para o estudo das ações verticais, considerando as seguintes correções adicionais:

a) não devem ser considerados momentos positivos menores que os que se obteriam se houvesse engastamento perfeito da viga nos apoios internos;

b) quando a viga for solidária com o pilar intermediário e a largura do apoio, medida na direção do eixo da viga, for maior que a quarta parte da altura do pilar, não pode ser considerado momento negativo de valor absoluto menor do que o de engastamento perfeito neste apoio;

c) quando não for realizado o cálculo exato da influência da solidariedade dos pilares com a viga, deve ser considerado, nos apoios externos, momento fletor igual ao momento de engastamento perfeito multiplicado pelos coeficientes estabelecidos nas seguintes equações:

Na viga, para considerar o efeito de pilar de extremidade: 


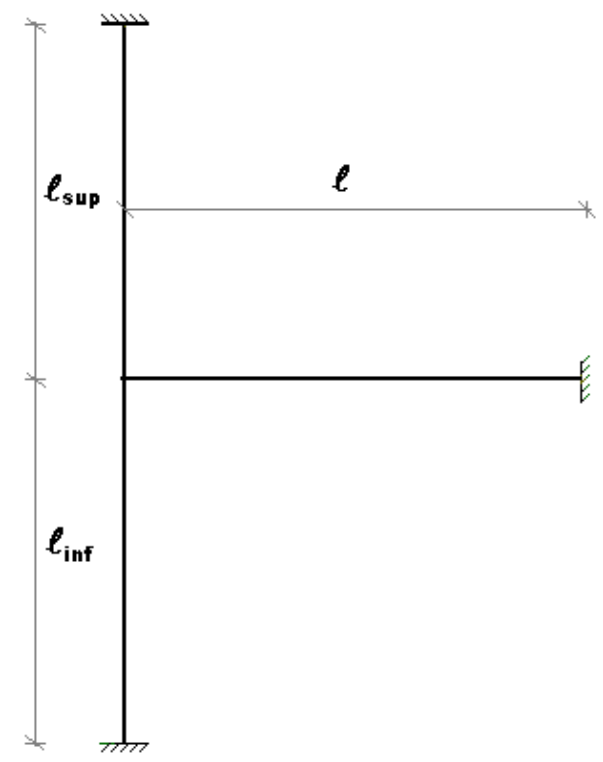

Figura 3.4 - Modelagem simplificada considerando o efeito de pilar de extremidade

$$
M_{0}=\frac{r_{\text {inf }}+r_{\text {sup }}}{r_{\text {vig }}+r_{\text {inf }}+r_{\text {sup }}} \cdot M_{\text {eng }} \quad \text { (Momento na viga, apoio de extremidade) }
$$

Sendo:

$$
\begin{aligned}
& \mathrm{M}_{\text {eng }}=\frac{(\mathrm{g}+\mathrm{q}) \cdot \ell^{2}}{12} \\
& r_{v i g}=\frac{4 E I_{\text {vig }}}{\ell} \\
& r_{\text {inf }}=\frac{4 E I_{\text {inf }}}{\ell_{\text {inf }}} \\
& r_{\text {sup }}=\frac{4 E I_{\text {sup }}}{\ell_{\text {sup }}}
\end{aligned}
$$

(Rigidez do pilar superior) 
$\mathrm{Na}$ modelagem de pórticos planos, o processo pode ser substituído considerando a perfeita solidariedade entre pilares e vigas, e, desta forma, leva a um modelo mais simples para vigas contínuas de concreto armado.

\subsubsection{Pilares}

Um fator crítico para a determinação do modo de modelagem de pilares de concreto armado é o índice de esbeltez:

$$
\lambda=\frac{\ell_{e}}{i}
$$

e

$$
i=\sqrt{\frac{I_{c}}{A_{c}}}
$$

Sendo:

$\ell_{e}=$ comprimento de flambagem

$i=$ raio de giração

$I_{c}=$ momento de inércia da seção transversal do pilar em relação ao eixo principal de inércia na direção considerada.

O comprimento de flambagem, $\ell_{e}$, pode ser considerado como a distância entre pontos de inflexão, considerando o pilar deformado. Porém, em estruturas consideradas indeslocáveis, pode ser medido da seguinte forma: 


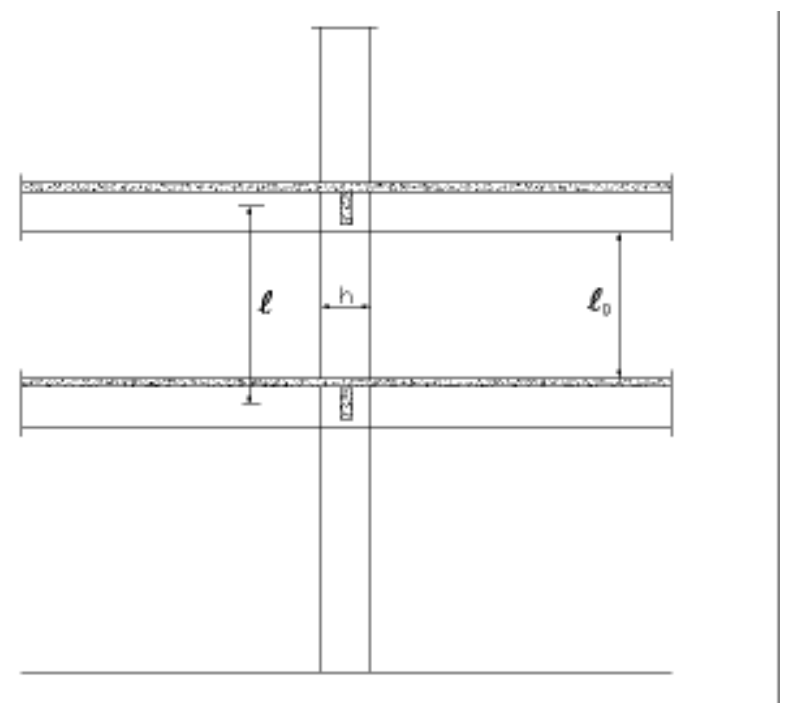

Figura 3.5 - Determinação do comprimento de flambagem nos casos usuais de estruturas de edifícios

O comprimento equivalente do elemento deve ser o menor dos seguintes fatores:

$$
\ell_{e}=\ell_{0}+h
$$

e

$$
\ell_{e}=\ell
$$

sendo:

$\ell_{0}: \quad$ distância entre as faces internas dos elementos estruturais, supostos horizontais, que vinculam o pilar;

$h$ : $\quad$ altura da seção transversal do pilar, medida no plano da estrutura em estudo;

$\ell$ : distância entre os eixos dos elementos estruturais aos quais o pilar está vinculado.

O modelo adotado deve ser compatível com o critério de modelagem, considerando o máximo índice de esbeltez para cada caso. 


\begin{tabular}{|l|l|}
\hline \multicolumn{1}{|c|}{$\lambda_{1}$} & 90 \\
\hline & Consideraçã̃o dos efeitos de $2^{\text {a }}$ ordem \\
\hline Método Geral & Consideraçẫo da fluência \\
\hline Método do Pilar Padrẵo com curvatura aproximada \\
\hline Método do Pilar Padrẫo com rigidez K aproximada \\
\hline Método do Pilar Padrẫo acoplado a diagramas $\mathrm{M}, \mathrm{N}, 1 / \mathrm{r}$ \\
\hline
\end{tabular}

Tabela 3.1 -- Critérios para a modelagem dos pilares isolados conforme o índice de esbeltez.

(KAEFER, 2000)

As duas primeiras linhas indicam quando se deve considerar os efeitos de segunda ordem e da fluência do concreto. As quatro linhas abaixo mostram os intervalos de $\lambda$ nos quais cada método pode ser empregado. A seguir será mostrada a forma de se encontrar o valor de $\lambda_{1}$ de acordo com os critérios da norma NBR 6118/2001.

\subsubsection{Dispensa da Análise dos Efeitos Locais de Segunda Ordem}

Para índices de esbeltez menores que 0 valor $\lambda_{1}$ pode ser desprezado 0 efeito da segunda ordem em elementos isolados, visto que este valor depende de vários fatores, dos quais os mais preponderantes são:
a) A excentricidade de $1^{\text {a }}$ ordem $e_{1} / h$;
b) A vinculação dos extremos da coluna isolada;
c) A forma do diagrama de momentos de $1^{\text {a }}$ ordem;

Considerando tais fatores, são estabelecidas expressões para determinação do valor do índice de esbeltez limite.

$$
\frac{35}{\mathrm{a}_{b}} \leq \lambda_{1}=\frac{25+12,5 e_{1}}{\dot{\mathrm{a}}_{b}} \leq 90
$$

O valor de $\alpha_{b}$ depende do tipo de vinculação existente no elemento, assim como da forma do diagrama de $1^{\text {a }}$ ordem. 
a) Para pilares biapoiados

$$
\begin{array}{ll}
\dot{a}_{b}=0,60+0,40 \frac{M_{\mathrm{B}}}{M_{\mathrm{A}}} \geq 0,40 & \text { (Se não houver cargas transversais) } \\
\dot{a}_{b}=1,0 & \text { (Se houver cargas transversais) }
\end{array}
$$

Os valores de $M_{A}$ e $M_{B}$ são os momentos de $1^{\text {a }}$ ordem nos extremos do pilar, sendo adotado o maior valor absoluto ao longo do pilar biapoiado e para $M_{B}$ o sinal positivo, se tracionar a mesma face que $M_{A}$ e negativo em caso contrário.

b) para pilares em balanço:

$$
\dot{a}_{b}=0,80+0,20 \frac{M_{C}}{M_{\mathrm{A}}} \geq 0,85
$$

Sendo o valor de $M_{A}$ igual ao momento de $1^{\text {a }}$ ordem no engaste e $M_{C}$ o valor do momento de $1^{\text {a }}$ ordem no meio do pilar em balanço.

c) para pilares biapoiados ou em balanço com momentos menores que 0 momento mínimo adota-se o valor de $\alpha_{b}$ igual a 1 se o maior momento ao longo da coluna for menor que o momento mínimo decorrente de imperfeições construtivas, definido em 3.6.4.

\subsubsection{Momento Mínimo Decorrente de Imperfeições Construtivas}

A NBR 6118:2001 estabelece um valor para o momento mínimo total, sendo o momento de primeira ordem acrescido dos efeitos das imperfeições locais.

As imperfeições locais são decorrentes do efeito do desaprumo ou da falta de retilinidade do eixo do pilar, conforme a figura a seguir. 


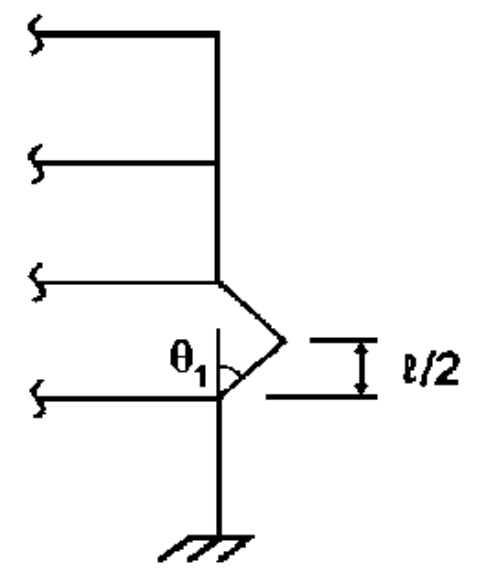

a)

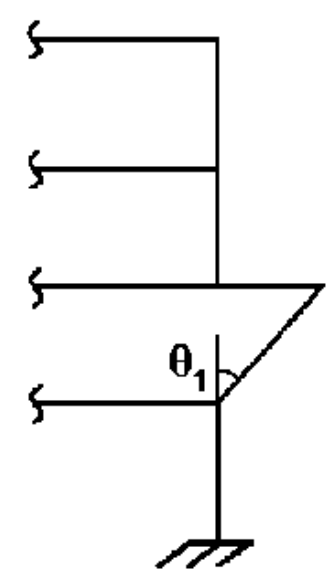

b)

Figura 3.6 - Efeitos: a) Falta de retilinidade do pilar; b) Desaprumo do pilar NBR 6118:2001

O momento mínimo deve ser o resultado da força normal multiplicada pelo valor da excentricidade provocada por tais imperfeições, sendo esta excentricidade igual a:

$$
\mathrm{e}_{\mathrm{a}, \min }=1,5+0,03 \cdot \mathrm{h}
$$

Sendo $\mathrm{h}$ a dimensão do pilar paralelo à excentricidade acidental considerada, em $\mathrm{cm}$.

O momento mínimo portanto pode ser considerado como sendo:

$$
\mathrm{M}_{1 \mathrm{~d}, \min }=\mathrm{N}_{\mathrm{d}} \cdot \mathrm{e}_{\mathrm{a}, \min }=(1,5+0,03 \cdot \mathrm{h}) \cdot \mathrm{N}_{\mathrm{d}}
$$

\subsubsection{Excentricidades para o Dimensionamento de Pilares}

No processo de dimensionamento de pilares existem quatro tipos de excentricidades a serem consideradas. Cada tipo será mostrado nos itens a seguir. 


\subsubsection{Excentricidade Acidental}

Considera erros de execução da estrutura e é calculada pela seguinte expressão:

$$
\mathrm{e}_{\mathrm{a}}=\frac{\mathrm{h}}{30} \geq 2,0 \mathrm{~cm}
$$

A norma NBR 6118:2001 considera a excentricidade acidental conforme indicado na figura 3.6, sendo:

$$
\theta_{1}=\frac{1}{100 \sqrt{\ell}}
$$

Este valor deve respeitar os valores mínimos:

$$
\begin{aligned}
& \theta_{1 \min }=\frac{1}{400}, \text { para estruturas de nós fixos; } \\
& \theta_{1 \min }=\frac{1}{300}, \text { para estruturas de nós móveis }
\end{aligned}
$$

\subsubsection{Excentricidade de Segunda Ordem}

Calculada obrigatoriamente para pilares com índice de esbeltez maior que 40, é calculada pela seguinte expressão:

$$
e_{2 y}=\frac{\ell_{e}^{2}}{10} \cdot \frac{0,0035+\frac{\mathrm{f}_{\mathrm{yd}}}{\mathrm{E}_{\mathrm{S}}}}{(v+0,5) \cdot h}
$$




\subsubsection{Excentricidade Inicial}

Obtendo-se os momentos fletores de topo e de base do pilar pela análise da estrutura, as excentricidades podem ser dadas da seguinte forma:

$$
\begin{aligned}
& \mathrm{e}_{\mathrm{i}, \text { topo }}=\frac{M_{\text {topo }}}{N} \\
& \mathrm{e}_{\mathrm{i} \text {,base }}=\frac{M_{\text {base }}}{N}
\end{aligned}
$$

Nas seções intermediárias, considera-se uma excentricidade inicial dada pela seguinte fórmula:

$$
\mathrm{e}_{\mathrm{iC}}=0,6 \cdot \mathrm{e}_{\mathrm{iA}}+0,4 \cdot \mathrm{e}_{\mathrm{iB}} \geq 0,4 \cdot \mathrm{e}_{\mathrm{iA}}
$$

\section{Sendo:}

$\mathrm{e}_{\mathrm{iC}}$ a excentricidade inicial na seção intermediária de um tramo de pilar;

$\mathrm{e}_{\mathrm{iA}} \mathrm{ee}_{\mathrm{iB}}$ as excentricidades iniciais nas extremidades de um tramo de pilar.

\subsubsection{Excentricidade Suplementar}

Para pilares esbeltos, $\lambda>90$, a consideração da fluência deve ser obrigatoriamente realizada, acrescentando-se à excentricidade de $1^{\text {a }}$ ordem a excentricidade mostrada a seguir.

$$
\mathrm{e}_{\mathrm{c}}=\left(\frac{\mathrm{M}_{\mathrm{Sg}}}{\mathrm{N}_{\mathrm{Sg}}}+\grave{\mathrm{e}}_{1} \frac{\ell_{\mathrm{e}}}{2}\right)\left(2,718^{\frac{\ddot{\mathrm{o} \mathrm{N}_{\mathrm{Sg}}}}{\mathrm{N}_{\mathrm{c}}-\mathrm{N}_{\mathrm{Sg}}}}-1\right)
$$

Sendo:

$$
\mathrm{N}_{\mathrm{e}}=\frac{10 \cdot \mathrm{E}_{\mathrm{c}} \mathrm{I}_{\mathrm{c}}}{\ell_{\mathrm{e}}^{2}}
$$


$\grave{e ̀}_{1}$, conforme 3.6.5.1.

$M_{S g}$ e $N_{S g}$ são os esforços solicitantes devidos à combinação quase permanente;

ö é o coeficiente de fluência.

\subsubsection{Métodos para Dimensionamento de Pilares Isolados}

A NBR 6118:2001 cita 4 métodos para determinação dos efeitos de $2^{a}$ ordem no dimensionamento de pilares isolados submetidos àação da flexão normal composta. A seguir serão apresentados tais métodos.

\subsubsection{Método Geral}

O método geral considera a análise não-linear de $2^{\mathrm{a}}$ ordem efetuada com discretização adequada da barra, considerando a relação momento-curvatura real em cada seção, e considerando a não-lineariedade geométrica de maneira não aproximada. O método é obrigatório para $\lambda>140$.

\subsubsection{Métodos Aproximados}

A norma também permite a utilização de métodos aproximados para a consideração dos efeitos de $2^{\mathrm{a}}$ ordem. Tais métodos valem-se de aproximações para simplificar a obtenção dos resultados, conforme os itens a seguir.

\subsubsection{Método do Pilar Padrão com Curvatura Aproximada}

Conforme a tabela 3.1 , pode ser utilizado para valores de $\lambda<90$, com seção constante e armadura simétrica e constante ao longo de seu eixo.

Há aproximações na consideração da não linearidade geométrica, supondo a deformada da barra como tendo a forma senoidal, e na não linearidade física, por meio de uma expressão aproximada da curvatura na seção crítica.

Considera-se o momento máximo no elemento da seguinte forma:

$$
\mathrm{M}_{\mathrm{d}, \mathrm{tot}}=\alpha_{b} \mathrm{M}_{1 \mathrm{~d}, \mathrm{~A}}+N_{d} \frac{\ell_{e}^{2}}{10} \cdot \frac{1}{r} \geq M_{1 d, A}
$$


A curvatura na seção crítica, 1/r, pode ser avaliada pela expressão aproximada:

$$
\frac{1}{\mathrm{r}}=\frac{0,005}{h(v+0,5)} \leq \frac{0,005}{h}
$$

Sendo:

h: $\quad$ Altura na direção considerada;

í : $\quad$ Força normal adimensional, expressa pela equação: í $=\frac{\mathrm{N}_{\mathrm{Sd}}}{\mathrm{A}_{\mathrm{c}} \cdot \mathrm{f}_{c d}}$;

$M_{d, A}$ deve respeitar o valor mínimo por causa das imperfeições construtivas, mostrado no item 3.6.4. $M_{1 d, A}$ e o coeficiente $\alpha_{b}$ são calculados de acordo com o item 3.6.3, sendo o primeiro igual ao valor de $M_{A}$.

\subsubsection{Método do Pilar Padrão com Rigidez K Aproximada}

Assim como o método anterior, também pode ser utilizado para esbeltez menor que 90 , em pilares de seção retangular constante, armadura simétrica e constante ao longo de seu eixo.

A não linearidade geométrica é considerada de forma aproximada, supondose que a deformação da barra seja senoidal. A não linearidade física é considerada com uma função aproximada da rigidez.

O momento total máximo no pilar é calculado pela expressão:

$$
M_{\mathrm{d}, \mathrm{tot}}=\frac{\mathrm{a}_{\mathrm{b}} \mathrm{M}_{1 \mathrm{~d}, \mathrm{~A}}}{1-\frac{\ddot{\mathrm{e}}^{2}}{120 \cdot \frac{\hat{\mathrm{e}}}{\hat{1}}}} \geq\left\{\begin{array}{l}
\mathrm{M}_{1 \mathrm{~d}, \mathrm{~A}} \\
\mathrm{M}_{1 \mathrm{~d}, \mathrm{~min}}
\end{array}\right.
$$


O valor aproximado da rigidez é dado pela expressão:

$$
\kappa=32 \cdot\left(1+5 \cdot \frac{M_{d, t o t}}{h \cdot N_{d}}\right) \cdot v
$$

As variáveis são definidas conforme indicado no item anterior. O método é iterativo, sendo necessárias de 2 a 3 iterações para determinar o valor do momento total máximo no elemento.

\subsubsection{Método do Pilar Padrão acoplado a diagramas $M, N, 1 / r$}

A determinação dos esforços locais de $2^{a}$ ordem em pilares com $\lambda \leq 140$ pode ser feita pelo método do pilar padrão ou pilar padrão melhorado, utilizando para a curvatura da seção crítica valores obtidos de diagramas $\mathrm{M}-\mathrm{N}-1 / \mathrm{r}$ específicos para o caso. 


\section{DIMENSIONAMENTO}

\subsection{Introdução}

Neste capítulo serão descritas as hipóteses de dimensionamento, assim como os conceitos que devem ser levados em consideração para o dimensionamento dos elementos feito pelo programa desenvolvido na pesquisa de mestrado.

Todas as prescrições para o dimensionamento estão de acordo com a NBR 6118:2001, salvo sob indicação em contrário.

São mostrados os processos de dimensionamento utilizados no programa, deduções e detalhes são citados quando se julgar relevante.

\subsection{Hipóteses Básicas}

O processo de dimensionamento de elementos estruturais em concreto armado é baseado em algumas hipóteses básicas. Podem-se citar:

a) As seções transversais se mantêm planas após a deformação (Hipótese de Navier-Bernoulli);

b) A deformação das barras aderentes, em tração ou compressão, é a mesma do concreto em seu entorno;

c) As tensões de tração no concreto, normais à seção transversal, podem ser desprezadas no Estado Limite Último; 
d) A distribuição de tensões no concreto se faz de acordo com o diagrama parábola-retângulo definido no item 2.3.7.1 com tensão de pico igual a 0,85 $\mathrm{f}_{\mathrm{cd}}$, ou pelo retângulo de altura $0,8 \times$ (onde x é a profundidade da linha neutra), com a seguinte tensão:

- $\quad 0,85 \mathrm{f}_{\mathrm{cd}}$ no caso em que a largura da seção, medida paralelamente àlinha neutra, não diminuir a partir desta para a borda comprimida.

- $0,80 \mathrm{f}_{\mathrm{cd}}$ no caso contrário;

e) A tensão nas barras das armaduras deve ser obtida a partir dos diagramas tensão-deformação do aço;

f) O estado limite último é caracterizado quando a distribuição das deformações na seção transversal pertencer a um dos domínios definidos na figura 4.2, item 4.4.4.

\subsection{Estádios}

Em uma peça de concreto armado submetida a uma ação que varia de zero até aquela considerada última, definem-se três estádios de comportamento da peça, sendo eles mostrados na figura 4.1. Têm-se:

(a) Seção transversal da viga;

(b) Estádio I - Concreto resiste àtração com diagrama triangular de tensões;

(c) Estádio II - Seção fissurada;

(d) Estádio III - Plastificação do concreto na compressão. 


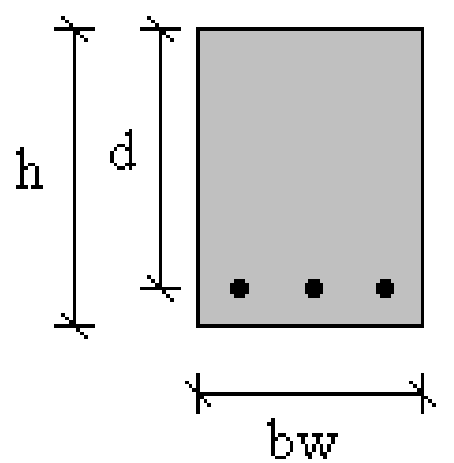

(a)
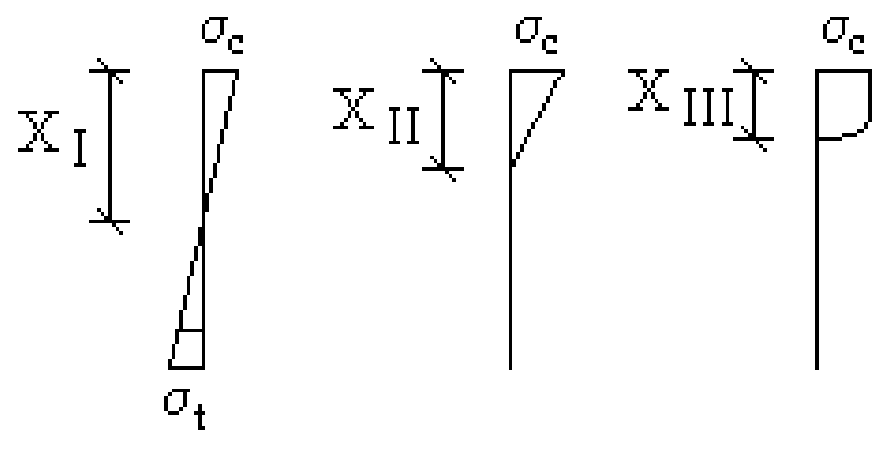

(c)

Figura 4.1 - Fases de comportamento na flexão pura

\subsubsection{Estádio I}

O estádio I ocorre quando a ação é pequena. O concreto ainda resiste à tração, portanto não apresenta fissuras no seu banzo tracionado. É admitida a linearidade de tensões ao longo de toda a seção transversal.

Para dimensionar nesse estádio as peças teriam dimensões exageradas, para que o concreto conseguisse resistir à tração, enquanto o aço estaria muito distante de seu limite de resistência. Seria antieconômico dimensionar peças de concreto armado no estádio I.

Porém, em elementos especiais em que se deseja evitar a fissuração, o estádio utilizado pode ser o Estádio I. Por exemplo: peças protendidas com protensão completa ou limitada.

\subsubsection{Estádio II}

Ocorre a fissuração do concreto no banzo tracionado, e o esforço de tração concentra-se totalmente na armadura. O diagrama de tensões ainda varia linearmente como indicado na figura 4.1, parte (c). 
Aumentando-se ainda mais as ações, as fissuras no concreto tracionado aumentam em direção ao banzo comprimido. A linha neutra sobe e a tensão na armadura cresce.

\subsubsection{Estádio III}

O concreto encontra-se na iminência da ruptura, chega-se ao estado limite último de ruptura do concreto, figura 4.1 (d).

No Estádio III admite-se que as tensões de compressão na seção transversal têm distribuição de acordo com o diagrama parábola-retângulo ou de acordo com um diagrama retangular simplificado.

As deformações nas barras da armadura ficam aquém do limite de escoamento.

O estádio III também pode ser caracterizado pelo alongamento excessivo da armadura, sem que haja ruína por esmagamento da peça.

\subsection{Estados Limites}

Solicitações normais provocam alongamento da armadura tracionada. Em casos em que a linha neutra corta a seção transversal de concreto, este alongamento leva à fissuração do concreto tracionado. É necessário que se definam os critérios de estados limites.

Visando a segurança, são definidos estados limites para as peças de concreto armado. Passando desses estados limites, a peça apresenta desempenho insatisfatório quanto àfinalidade para a qual ela foi projetada.

Pode-se dizer que uma estrutura ou parte dela atinge um estado limite quando, de modo efetivo ou convencional, se torna inutilizável ou quando deixa de satisfazer às condições previstas para sua utilização.

Os estados limites podem ser classificados em estados limites últimos ou estados limites de serviço; sendo aqueles, estados que se caracterizam pela ruína por ruptura, por deformação plástica excessiva ou por instabilidade de algum dos 
seus componentes; e estes, pelo limite da situação de serviço. As situações limites, indicadas em NBR 6118:2001, são convencionais.

\subsubsection{Estados Limites Últimos (ELU)}

São aqueles que se referem à capacidade última da estrutura, sendo exemplos:

a) Estado limite último da perda do equilíbrio da estrutura, admitida como corpo rígido;

b) Estado limite último de esgotamento da capacidade resistente da estrutura, no seu todo ou em parte, por conta das solicitações normais e tangenciais, admitindo-se a redistribuição de esforços internos, desde que seja respeitada a capacidade de adaptação plástica, e admitindo-se, em geral, as verificações separadas das solicitações normais e tangenciais;

c) Estado limite último de esgotamento da capacidade resistente da estrutura, no seu todo ou em parte, considerando os efeitos de segunda ordem.

d) Estado limite último provocado por solicitações dinâmicas;

e) Em construções especiais, pode ser necessário verificar a segurança em relação a outros estados limites últimos que eventualmente possam ocorrer, inclusive durante as fases construtivas.

\subsubsection{Estados Limites de Serviço (ELS)}

São aqueles relacionados com a durabilidade das estruturas, aparência, conforto do usuário e sua boa utilização funcional em relação àutilização.

De acordo com NBR 6118:1980 são exemplos:

a) Danos estruturais localizados que comprometam a estética ou a durabilidade da estrutura - fissuração; 
b) Deformações excessivas que afetem a utilização normal da construção ou o seu aspecto estético - Flechas (Deslocamento da peça pela ação das ações nela aplicadas);

c) Vibrações excessivas que causem desconforto a pessoas ou danos a equipamentos sensíveis.

Já a NBR 6118:2001 define que, para satisfazer às exigências da utilização da estrutura, dependendo de cada tipo de estrutura utilizada, deve-se fazer a verificação de:
a) estado limite de formação de fissuras;
b) estado limite de abertura das fissuras;
c) estado limite de deformações excessivas;
d) estado limite de descompressão parcial;
e) estado limite de compressão excessiva e
f) estado limite de vibrações excessivas.

\subsubsection{Dutilidade}

A capacidade de rotação dos elementos estruturais é função da posição da linha neutra no ELU. Quanto menor é $x / d$, maior é essa capacidade. A NBR 6118:2000, em seu anexo $A$, afirma que, em virtude do comportamento não linear do concreto estrutural, os esforços obtidos em análise linear não são os reais e, portanto, mesmo quando se utilizam esses esforços para o dimensionamento, deve-se garantir uma dutilidade mínima que pode ser caracterizada pela condição (x/d) max.

A NBR 6118:2001, determina limites para a posição da linha neutra a fim de garantir a dutilidade das estruturas nas regiões de apoio das vigas ou de ligações com outros elementos estruturais. A posição da linha neutra no estado limite último deve obedecer aos seguintes parâmetros:

a) $\mathrm{x} / \mathrm{d} \leq 0,50$ para concretos com $\mathrm{f}_{\mathrm{ck}} \leq 35 \mathrm{MPa}$; ou

b) $x / d \leq 0,40$ para concretos com $f_{c k}>35 \mathrm{MPa}$. 


\subsubsection{Domínios de Deformação}

Para dimensionar a seção transversal de uma peça de concreto armado, é necessário definir em qual domínio está situado o diagrama de deformações específicas de cálculo da seção analisada.

$\mathrm{Na}$ figura 4.2 estão mostrados os domínios possíveis em uma peça de concreto armado.

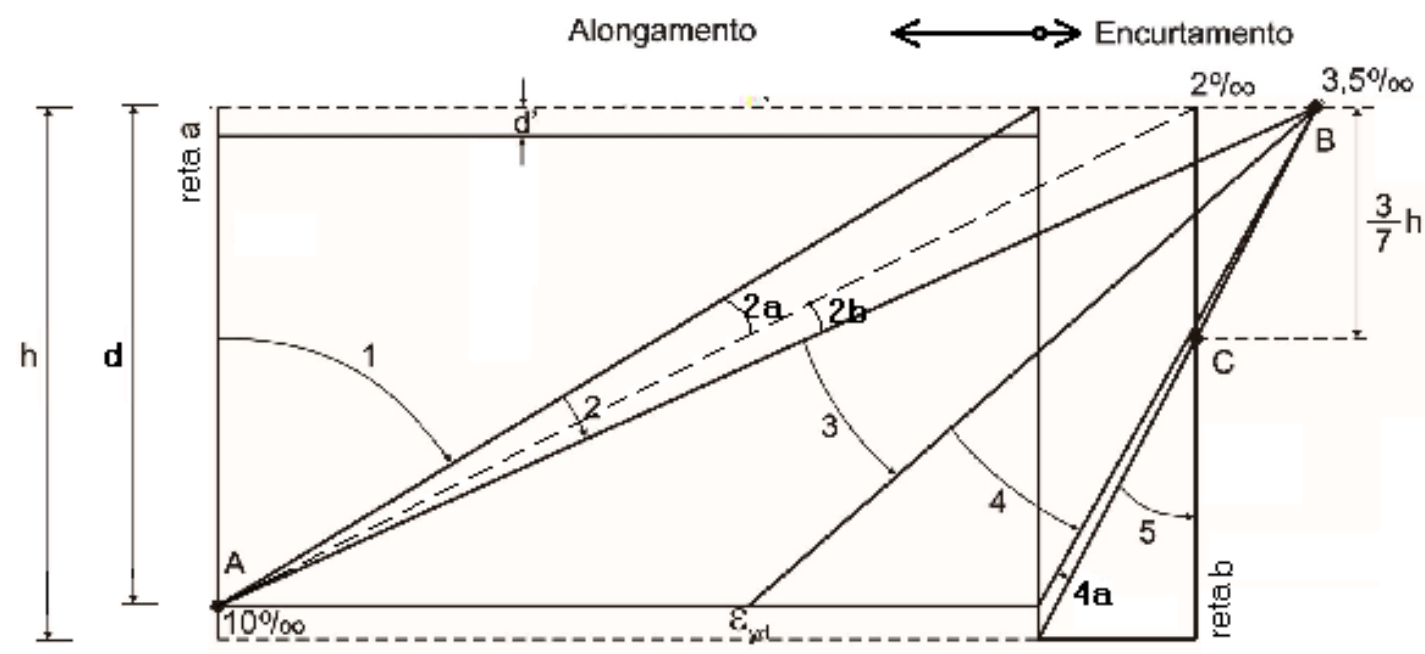

Figura 4.2 - Domínios em uma seção de concreto armado

\subsubsection{Domínio 1}

Inclui casos de tração axial e de tração excêntrica com pequena excentricidade. Em resumo, toda a peça está tracionada, podendo esta tração ser constante ao longo da seção transversal (Reta a) ou não. Só que necessariamente a linha neutra não corta a seção. 
É caracterizado pela deformação de $10 \%$ na armadura, ou o pólo de ruína A.

\subsubsection{Domínio 2}

Flexão simples ou composta sem ruptura no concreto comprimido. O estado limite último é caracterizado pela deformação de $10 \%$ na armadura, pólo de ruína A. A linha neutra corta a seção, havendo um banzo tracionado e outro comprimido.

No domínio 2 a armadura atinge a deformação de $10 \%$ antes que o concreto rompa ou atinja a deformação de 3,5\%.

Pode-se ver na figura 4.2 que no limite do domínio 2 com o domínio 3, sendo $x$ a distância da linha neutra àborda mais comprimida em uma seção transversal de um elemento, tem-se a seguinte relação:

$3,5 \% / x_{2, \lim }=10 \% /\left(d-x_{2, \lim }\right)$

Simplificando:

$0,35=x_{2, \lim } /\left(d-x_{2, \lim }\right)$

Modificando-se a equação:

$0,35^{\star} d-0,35^{\star} x_{2, \lim }=x_{2, \lim }$

Dividindo-se os dois membros por d, tem-se:

$0,35-0,35^{\star} x_{2, \lim } / d=x_{2, \text { lim }} / d$

$\mathrm{Ou}$

$0,35=1,35 x_{2, \lim } / d$ 
Pode-se definir o seguinte adimensional para caracterizar o limite entre os domínios 2 e 3 :

$$
\beta_{x 2, \lim }=x_{2, \lim } / d=0,35 / 1,35 \approx 0,259
$$

Pode-se observar que para o dimensionamento no domínio 2, o parâmetro $\beta_{x 2, \lim }$ atende aos limites para a relação $x / d$ impostos no item 4.4 .3 , pois o valor $x / d$ será, no máximo, igual a 0,259.

\subsubsection{Domínio 3}

Engloba os casos de flexão simples ou composta e caracteriza-se pela deformação de 3,5\% no concreto comprimido, pólo de ruína B. A linha neutra corta a seção, havendo um banzo tracionado e outro comprimido. A seção é chamada de seção subarmada, mas poderia ser chamada de normalmente armada.

Em sua situação última, a armadura tracionada está, pelo menos, no início do escoamento. Ocorre a ruptura do concreto no instante em que a armadura está em processo de escoamento $\left(\varepsilon_{\mathrm{s}} \geq \varepsilon_{\mathrm{yd}}\right)$. Esta situação é altamente desejável, pois a ruptura da peça de concreto é "avisada", por causa do aparecimento de fissuras, com o escoamento da armadura. Além disso, todos os componentes do concreto armado são utilizados em sua plenitude, pois ao mesmo tempo em que a armadura chega ao escoamento o concreto está no seu limite de ruptura.

O domínio é limitado pela condição:

$3,5 \% / x_{3, \lim }=\varepsilon_{y d} /\left(d-x_{3, \lim }\right)$

Sendo que na posição limite da linha neutra:

$$
\beta_{x 3, \lim }=x_{3, \lim } / d=0,0035 /\left(\varepsilon_{y d}+0,0035\right)
$$




\section{a) Aço CA-25}

O valor $\varepsilon_{\text {yd }}$ depende da classe do aço utilizado. Sendo, para aço CA-25:

$$
\varepsilon_{\mathrm{yd}}=1,04 \% \rightarrow \beta_{\mathrm{x} 3, \mathrm{lim}}=0,771
$$

Multiplicando-se por 0,8, tem-se o valor de $\beta_{y}$ para o aço CA-25, que é igual a aproximadamente 0,617 .

Observa-se que, para o dimensionamento no domínio 3 com aços CA-25, o valor limite entre os domínios 3 e 4 para o adimensional $x / d$ não obedece aos limites impostos no item 4.4.3, pois é bem maior que o valor máximo proposto para assegurar a dutilidade em estruturas nas regiões de apoio das vigas ou de ligações com outros elementos estruturais. Portanto, deve-se limitar o valor do adimensional $\beta_{x}$ naquelas regiões para os valores indicados no item referido.

\section{b) Aço CA-50}

Para o aço CA-50, utilizando a fórmula (4.8) o valor fica:

$$
\varepsilon_{\mathrm{yd}}=2,07 \% \rightarrow \beta_{\mathrm{x}, \mathrm{lim}}=0,628
$$

Multiplicando-se por 0,8, tem-se o valor de $\beta_{y}$ para o aço CA-50, que é igual a aproximadamente 0,503 .

Novamente, o valor do adimensional está acima do valor indicado no item 4.4.3 para garantir a dutilidade nas regiões de apoio das vigas ou de ligações com outros elementos estruturais. Portanto, nestas regiões, o valor da altura da linha neutra em relação àaltura útil da viga deve ser restrito a 0,50 ou 0,40 , conforme indicado no item.

\section{c) Aço CA-60}

Para aço CA-60: 


$$
\varepsilon_{\mathrm{yd}}=4,48 \% \rightarrow \beta_{\mathrm{x}, \mathrm{lim}}=0,438
$$

Multiplicando-se por 0,8, tem-se o valor de $\beta_{y}$ para o aço CA-60, que é igual a aproximadamente 0,351 .

O valor está de acordo com os limites impostos em 4.4.3 para $\mathrm{f}_{\mathrm{ck}} \leq 35 \mathrm{MPa}$, porém deve ser limitado a $0,40 \mathrm{x} / \mathrm{d}$ para $\mathrm{f}_{\mathrm{ck}}>35 \mathrm{MPa}$ nas regiões descritas no mesmo item.

\subsubsection{Domínio 4}

Inclui casos de flexão simples ou composta e caracteriza-se pela deformação de 3,5\% no concreto, ou pólo de ruína $B$.

Em sua situação última, a armadura tracionada não chega ao limite de escoamento e o concreto se rompe $\left(\varepsilon_{s} \leq \varepsilon_{y d}\right)$. A ruptura ocorre de forma frágil, sem aviso, sem a fissuração causada pelo escoamento da armadura de tração. É uma situação indesejável para projeto, pois não garante boas condições de dutilidade. Para melhorar esta característica, pode-se adicionar armadura de compressão para garantir que parte desses esforços seja resistida por esta armadura.

Neste domínio, as peças são chamadas superarmadas.

\section{a) Domínio 4a}

É caracterizado pela flexão composta com armaduras comprimidas e tem como pólo de ruína o ponto $B$, com encurtamento do concreto comprimido até seu limite último.

\subsubsection{Domínio 5}

Abrange os casos de flexo-compressão com pequena excentricidade e compressão centrada.

Se a linha neutra for tangente à seção, é admitido como deformação última do concreto o valor 3,5\%. Caso contrário, a deformação última é de $2 \%$ no ponto de distância $3 / 7 \mathrm{~h}$ da borda mais comprimida, pólo de ruína $\mathrm{C}$. 


\subsubsection{Flexão Normal}

Segundo LEONHARDT (1977), se um elemento estrutural tiver um plano de simetria e se os esforços externos atuarem nesse plano, diz-se que há uma solicitação normal. À flexão resultante dessa solicitação pode-se dar o nome de flexão normal.

\subsubsection{Equações de Equilíbrio}

O dimensionamento tem como equações duas situações de equilíbrio:

- Equilíbrio de forças normais, e

- Equilíbrio dos momentos.

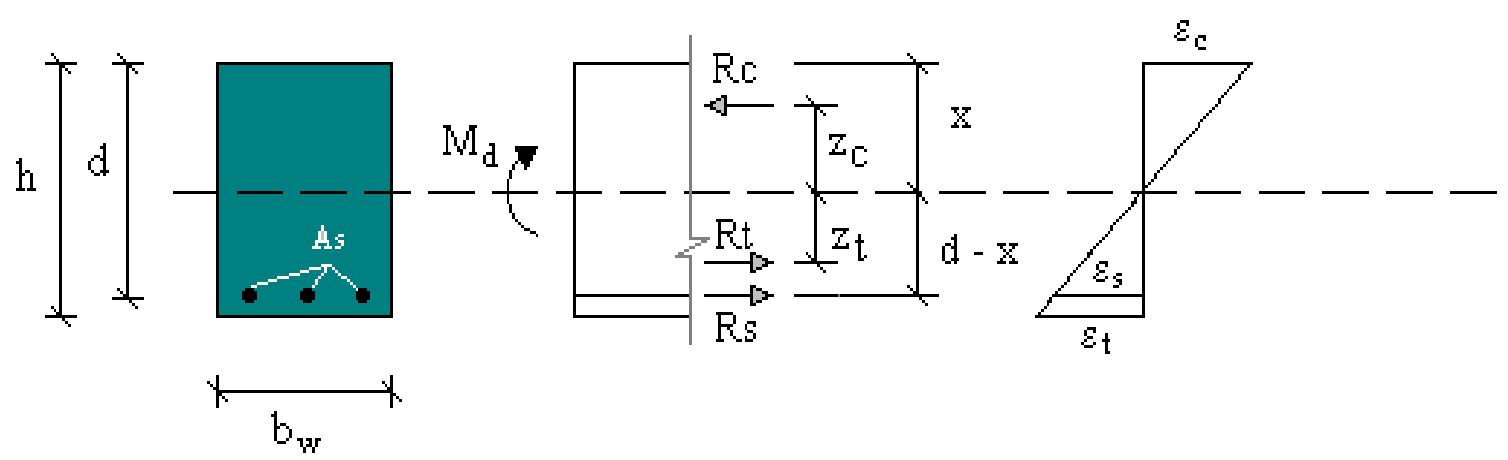

Figura 4.3 - Seção retangular de concreto

$$
\begin{aligned}
& \Sigma F=0 \rightarrow R_{c c}-R_{c t}-R_{s t}=0 \\
& M_{\text {ext }}=M_{\text {int }} \rightarrow M_{d}=R_{c c}{ }^{*} z_{c}+R_{c t}{ }^{*} z_{t}+R_{s t}{ }^{*}(d-x)
\end{aligned}
$$

Sendo:

- $\mathrm{R}_{\mathrm{cc}}$ a resultante de compressão no concreto; 
- $\mathrm{R}_{\mathrm{ct}}$ a resultante de tração no concreto;

- $\mathrm{R}_{\mathrm{st}}$ a resultante de tração na armadura.

No estádio I considera-se a resultante de tração no concreto $R_{c t}$, porém, nos estádios II e III este valor é nulo, pois o concreto está fissurado.

No Estado Limite Último, definindo-se $\beta_{\mathrm{y}}$ como sendo $\mathrm{y} / \mathrm{d}$, considerando o valor $\mathrm{R}_{\mathrm{ct}}$ nulo e calculando-se o momento em torno do ponto de aplicação da força $\mathrm{R}_{\text {st }}$, tem-se:

$$
\mathrm{M}_{\mathrm{d}}=\mathrm{R}_{\mathrm{cc}} \cdot\left(\mathrm{d}-\mathrm{X}+\mathrm{z}_{\mathrm{c}}\right)
$$

Sendo y igual a $0,8^{*} x$ e $z_{c}$, por sua vez, igual a $\left(\frac{y}{2}+0,2 \cdot x\right)$ de acordo com a figura 4.3, obtém-se:

$$
\mathrm{M}_{\mathrm{d}}=\mathrm{R}_{\mathrm{cc}} \cdot\left(\mathrm{d}-\frac{\mathrm{y}}{0,8}+\frac{\mathrm{y}}{2}+0,2 \cdot \frac{\mathrm{y}}{0,8}\right)
$$

Feito o cálculo, chega-se a:

$$
M_{d}=R_{c c} \cdot\left(d-\frac{y}{2}\right)
$$

Considerando que a força $R_{c c}$ pode ser calculada como a tensão atuante no concreto $0,85 \cdot \mathrm{f}_{\mathrm{cd}}$ multiplicada pela área $\left(\mathrm{b}_{\mathrm{w}} \mathrm{y}\right)$, tem-se:

$$
\mathrm{R}_{\mathrm{cc}}=0,85 \mathrm{f}_{\mathrm{cd}} \cdot \mathrm{b}_{\mathrm{w}} \cdot \mathrm{y}
$$

Substituindo na seção anterior vem:

$$
M_{d}=0,85 \cdot f_{c d} \cdot b_{w} \cdot y \cdot\left(d-\frac{y}{2}\right)
$$


Tendo-se como constante $\beta_{y}=y / d$ e dividindo-se ambos os membros da equação por $b_{w}{ }^{*} d^{2}$, tem-se finalmente a expressão:

$$
\frac{M_{d}}{b_{w} \cdot d^{2}}=0,85 \cdot f_{c d} \cdot\left(1-\frac{\beta_{y}}{2}\right) \cdot \beta_{y}
$$

De acordo com a figura 4.3, calculando o momento em torno do ponto de aplicação da força $R_{c c}$ tem-se a expressão:

$$
\mathrm{M}_{\mathrm{d}}=\mathrm{R}_{\mathrm{st}} \cdot\left(\mathrm{d}-\mathrm{X}+\mathrm{z}_{\mathrm{c}}\right)
$$

Como já exemplificado, $y=0,8 \cdot x \quad$ e $\quad z_{c}=\left(\frac{y}{2}+0,2 \cdot x\right)$. Então a equação fica:

$$
\mathrm{M}=\mathrm{R}_{\mathrm{st}} \cdot\left(\mathrm{d}-\frac{\mathrm{y}}{2}\right)
$$

$\mathrm{R}_{\mathrm{s}}$ é igual à tensão na armadura multiplicada pela área da armadura de tração, então:

$$
\mathrm{M}=\sigma_{s d} \cdot \mathrm{A}_{\mathrm{s}} \cdot\left(\mathrm{d}-\frac{\mathrm{y}}{2}\right)
$$

Novamente, substituindo os valores e calculando, a equação final é:

$$
\frac{A_{s} \cdot d}{M}=\frac{1}{\sigma_{s d} \cdot\left(1-\frac{\beta_{y}}{2}\right)}
$$




\subsubsection{Equações de Compatibilidade de Deformações}

As equações de compatibilidade baseiam-se na hipótese de NAVIERBERNOULLI, que garante que as deformações são compatíveis entre si quando se distribuem linearmente ao longo da altura da seção. Tomando-se como base o diagrama da figura 4.3, pode-se dizer que:

$$
\frac{\stackrel{\circ}{c}_{c}}{x}=\frac{\AA_{t}}{h-x}=\frac{\AA_{s}}{d-x}
$$

Sendo:

$\varepsilon_{\mathrm{c}} \rightarrow$ deformação específica do concreto na borda comprimida;

$\varepsilon_{\mathrm{t}} \rightarrow$ deformação específica do concreto na borda tracionada;

$\varepsilon_{\mathrm{s}} \rightarrow$ deformação específica das barras de aço no centro geométrico da armadura.

\subsubsection{Equacionamento}

Como já relatado no item 4.4.4, o adimensional $\beta_{y}$ é determinado de acordo com o domínio escolhido, e se este domínio for o 3, também depende da classe do aço utilizado.

$\mathrm{k}_{\mathrm{c}}$ é definido como:

$$
\mathrm{k}_{\mathrm{c}}=\frac{\mathrm{b}_{\mathrm{w}} \cdot \mathrm{d}^{2}}{\mathrm{M}_{\mathrm{d}}}
$$

Sendo:

$\mathrm{b}_{\mathrm{w}} \rightarrow$ a largura da viga em $\mathrm{cm}$;

$\mathrm{d} \rightarrow$ a altura útil da viga em $\mathrm{cm}$;

$\mathrm{M}_{\mathrm{d}} \rightarrow \mathrm{O}$ momento de cálculo em $\mathrm{kN}^{*} \mathrm{~cm}$.

$k_{s}$, por sua vez, é: 


$$
\mathrm{k}_{\mathrm{s}}=\frac{\mathrm{A}_{\mathrm{s}} \cdot \mathrm{d}}{\mathrm{M}_{\mathrm{d}}}
$$

Sendo:

$A_{s} \rightarrow$ a área de armadura necessária $\mathrm{em} \mathrm{cm}^{2}$.

$\mathrm{d}$ e $\mathrm{M}_{\mathrm{d}} \rightarrow$ como na expressão (4.25)

\subsubsection{Dimensionamento de $\mathrm{d}$ e $\mathrm{A}_{\mathrm{s}}$}

Sendo definidos:

- Momento fletor na viga $\left(M_{k}\right)$ em kN*m. $M_{d}=M_{k}{ }^{*} 1,40$;

- $b_{\mathrm{w}}$ em cm;

- Classe do aço a ser utilizado;

- Domínio a ser utilizado;

- $\mathrm{f}_{\mathrm{ck}}$ do concreto, em MPa.

Pode-se definir o valor de $\beta_{y}$ de acordo com o especificado nas explicações sobre os domínios de deformação 2 e 3.

Sendo $k_{c}$ definido pela equação (4.25) e valendo-se da expressão (4.19), verifica-se que o valor $k_{c}$ pode ser dado pela seguinte equação:

$$
\mathrm{k}_{\mathrm{c}}=\frac{1}{0,85 \cdot \mathrm{f}_{\mathrm{ck}} \cdot\left(1-\frac{\beta_{\mathrm{y}}}{2}\right) \cdot \beta_{\mathrm{y}}}
$$

Utilizando-se a equação (4.25), mostrada no item anterior, e isolando-se $d$, tem-se a seguinte equação:

$$
d= \pm \sqrt{\frac{k_{c} M_{d}}{b_{w}}}
$$


Como a altura útil da viga só pode ser positiva, determina-se o seu valor.

$$
\mathrm{d}=\sqrt{\frac{\mathrm{k}_{\mathrm{c}} \mathrm{M}_{\mathrm{d}}}{\mathrm{b}_{\mathrm{w}}}}
$$

Da mesma forma, valendo-se da equação (4.23) e a equação (4.26) obtémse:

$$
\mathrm{k}_{\mathrm{s}}=\frac{1}{\sigma_{\mathrm{sd}} \cdot\left(1-\frac{\mathrm{k}_{\mathrm{y}}}{2}\right)}
$$

Tendo o valor de $k_{s}$ e isolando o $A_{s}$ na equação (4.26), pode-se determinar a área de armadura como sendo:

$$
\mathrm{A}_{\mathrm{s}}=\mathrm{k}_{\mathrm{s}} \cdot \frac{\mathrm{M}_{\mathrm{d}}}{\mathrm{d}}
$$

Com esses dois valores, $d$ e $A_{s}$, fica dimensionada a viga, faltando somente dividir a área total de aço necessária $A_{s}$ pela área unitária de cada barra utilizada, determinando-se o número de barras necessárias para a seção.

\subsubsection{Dimensionamento de As e Determinação do Momento Limite de Cálculo}

Nesta opção, a altura útil deve ser determinada.

Determina-se o valor de $\mathrm{k}_{\mathrm{c}}$ de acordo com o item anterior. Porém, agora $\mathrm{o}$ que se quer determinar é o momento fletor máximo que a viga pode suportar no domínio 2 ou 3. Então, isola-se $M_{d}$, como na equação:

$$
M_{d \lim }=\frac{b_{w} d^{2}}{k_{c}}
$$


Encontra-se o valor de $A_{s}$ considerando o momento atuante na seção.

$O$ valor de $k_{c}$ é encontrado pela seguinte equação:

$$
\mathrm{k}_{\mathrm{c}}=\frac{\mathrm{b}_{\mathrm{w}} \mathrm{d}^{2}}{\mathrm{M}_{\mathrm{d}}}
$$

Sendo que todos os valores do segundo membro são conhecidos. Desejase determinar o valor de $\beta_{y}$ para que assim seja possível caracterizar o domínio utilizado. Então, considera-se a seguinte equação:

$$
\mathrm{k}_{\mathrm{c}}=\frac{1}{0,85 \mathrm{f}_{\mathrm{ck}}\left(1-\frac{\beta_{\mathrm{y}}}{2}\right) \beta_{\mathrm{y}}}
$$

Modificando a equação para se isolar o $\beta_{y}$, tem-se:

$$
\frac{1}{\mathrm{k}_{\mathrm{c}} \mathrm{k}_{\mathrm{y}}}=0,85 \cdot \mathrm{f}_{\mathrm{ck}}-0,85 \cdot \mathrm{f}_{\mathrm{ck}} \cdot \frac{\beta_{\mathrm{y}}}{2}
$$

Multiplicando-se os dois membros por $\frac{2 \beta_{\mathrm{y}}}{0,85 \mathrm{f}_{\mathrm{ck}}}$ :

$$
\frac{2}{\mathrm{k}_{\mathrm{c}} 0,85 \mathrm{f}_{\mathrm{ck}}}=2 \beta_{\mathrm{y}}-\beta_{\mathrm{y}}{ }^{2}
$$

Que é uma equação do segundo grau da qual pode ser encontrado o valor de $\beta_{y}$ e assim ser definido o domínio utilizado, sabendo-se a classe do aço e os valores limites de $\beta_{y}$ para cada um deles. A equação do segundo grau é:

$$
\beta_{\mathrm{y}}{ }^{2}-2 \cdot \beta_{\mathrm{y}}+\frac{2}{\mathrm{k}_{\mathrm{c}} \cdot 0,85 \cdot \mathrm{f}_{\mathrm{cd}}}=0
$$


Determinando-se as raízes desta equação, considera-se o valor de $\beta_{y}$ que estiver entre 0 e 1.

\subsubsection{Flexão Composta Normal}

\subsubsection{Processo Aproximado}

A NBR 6118:2001 prevê um cálculo simplificado para o dimensionamento de peças de concreto armado submetidas àflexo -compressão, para os casos em que a força normal reduzida ( $v$ ) seja menor ou igual a 0,7 , dimensionando como compressão centrada com força normal majorada, de acordo com a expressão (4.38).

$$
\begin{aligned}
& N_{\text {Sd,eq }}=N_{S d}\left(1+\beta \frac{e}{h}\right) \\
& M_{S d, e q}=0
\end{aligned}
$$

sendo:

$$
\begin{gathered}
v=\frac{N_{S d}}{A_{c} f_{c d}} \\
\frac{e}{h}=\frac{M_{S d}}{N_{S d}^{h}} \\
\beta=\frac{1}{(0,39+0,01 \alpha)-0,8 \frac{d^{\prime}}{h}}
\end{gathered}
$$

Sendo $\alpha$ s a relação: (soma das armaduras superior e inferior)/(armadura lateral), e o valor $\alpha$ dado por : 
- $\alpha=-1 / \alpha_{s}$

se $\alpha_{s}<1 \quad$ em seções retangulares;

- $\alpha=\alpha_{\mathrm{s}}$

se $\alpha_{s} \geq 1 \quad$ em seções retangulares;

- $\alpha=6$

se $\alpha_{s}>6 \quad$ em seções retangulares;

- $\alpha=-4$

em seções circulares.

O arranjo de armadura adotado para detalhamento deve ser fiel aos valores de $\alpha_{s}$ e d'/h pressupostos, de acordo com a figura 4.4 a seguir.

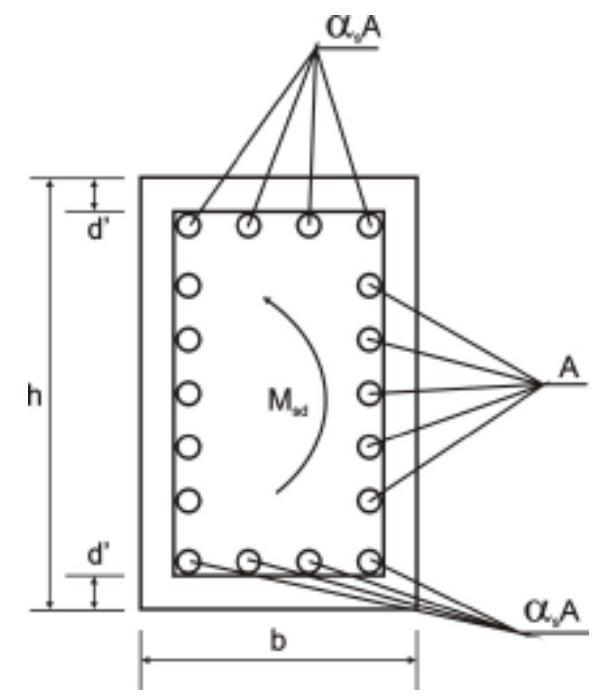

Figura 4.4 - Arranjo de armadura caracterizado pelo parâmetro $\alpha$ s.

Porém, para os demais casos, e para um cálculo mais completo para o dimensionamento de peças sob ação de flexão normal composta, ou flexão reta, é necessário considerar uma teoria mais completa e detalhada.

\subsubsection{Processo Iterativo}

De acordo com o processo mostrado por VENTURINI (1987), para dimensionamento de peças submetidas a flexão normal composta, é necessário dividir as possibilidades em três regiões de deformação. Conforme a figura a seguir. 


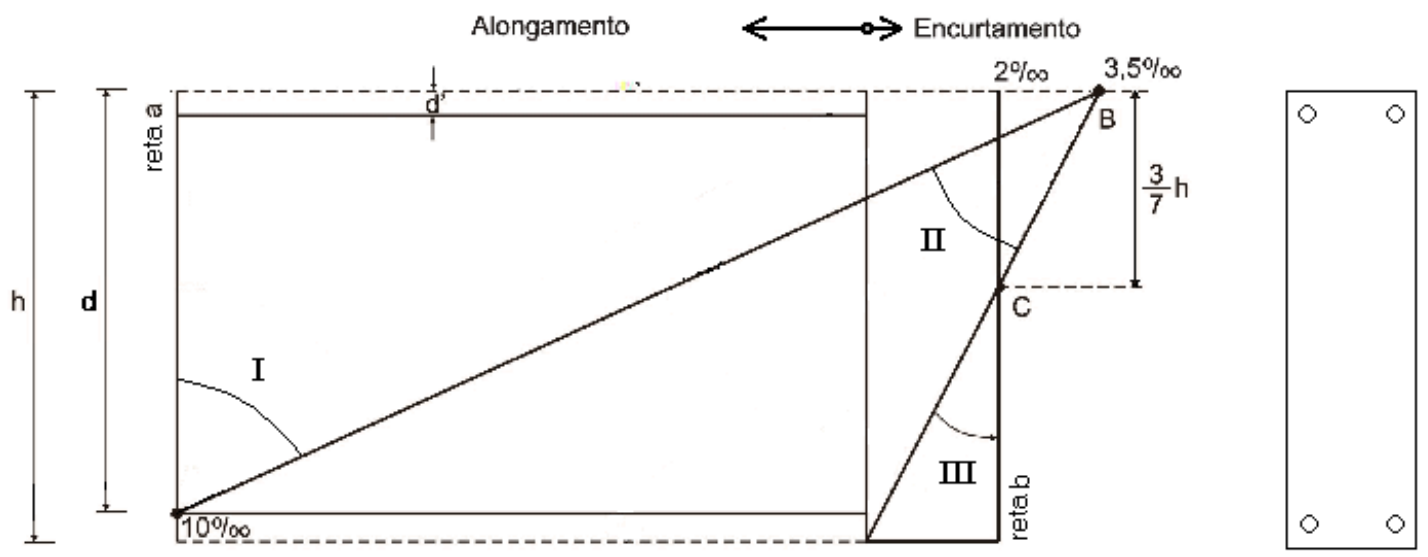

Figura 4.5 - Regiões de Deformação

Tendo como válida a hipótese da manutenção da seção plana nas deformações e considerando as deformações limites definidas na figura acima, podem-se formar expressões para compatibilidade de deformações em cada região.

\section{a) Região I}

Nesta região, que inclui os domínios 1 e 2, tem-se como valor último a deformação de $10 \%$ no banzo tracionado, pode-se escrever a seguinte relação para a deformação genérica $\varepsilon$ em um ponto genérico da peça distante y do centro geométrico. 


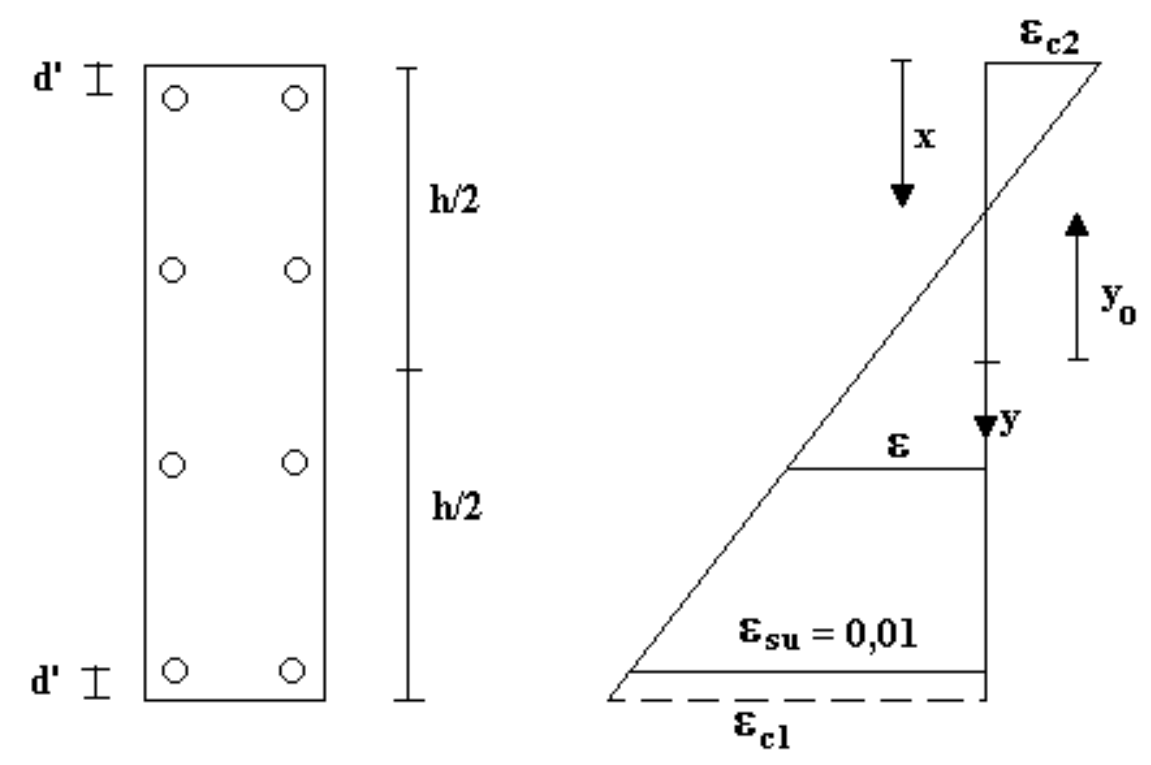

Figura 4.6 - Deformações da região I

$\frac{\stackrel{\circ}{\mathrm{a}-\mathrm{y}_{0}}}{\mathrm{~h}-\mathrm{d}^{\prime}-\mathrm{x}}$

Indicando a posição da linha neutra pelo parâmetro $\xi(\xi=x / h)$ e utilizando:

$\mathrm{x}=\frac{\mathrm{h}}{2}+\mathrm{y}_{0}$

Pode-se escrever a relação como:

$\stackrel{a}{a}=\stackrel{a}{s u}_{\text {su }} \frac{\hat{\imath}-\left(\hat{a}_{y}+0,5\right)}{\hat{\imath}-1-\ddot{a}}$

sendo:

$\ddot{a}=\frac{d^{\prime}}{h}$

$\hat{a}_{y}=\frac{y}{h}$ 
A equação 4.45 fornece a deformação do aço e do concreto para qualquer posição $\beta_{y}$, tendo conhecimento da posição da linha neutra $\xi$.

Pode-se observar que o limite do encurtamento na borda comprimida $\left(\varepsilon_{\mathrm{c} 2}\right)$ para a região I deve estar limitado a um valor de 3,5\%, conforme a figura 4.5. Então, têm-se:

$$
\varepsilon_{\mathrm{c} 2} \leq 10 \% \text { e } \varepsilon_{\mathrm{c} 2} \geq-3,5 \%
$$

A primeira inequação implica em $\xi$ pertencente aos números reais. Porém, introduzindo-se a segunda inequação em 4.45, obtém-se o seguinte:

$$
0,01 \frac{\hat{\imath}}{\hat{\imath}-1+\ddot{a}} \geq-0,0035
$$

Isolando-se o valor $\xi$ a inequação fica da seguinte forma:

$$
\hat{\imath} \leq 0,259(1-\ddot{a})
$$

Que é o limite para a região I. Portanto, para valores de $\xi$ maiores que o valor indicado em 4.48, a região em questão deve ser II ou III.

\section{b) Região II}

Inclui os domínios de deformação 3 e 4, e tem como limite para a deformação $\varepsilon_{\mathrm{c} 2} \circ$ valor $-3,5 \%$, figura 4.7 , que acontece na parte mais comprimida da peça. 

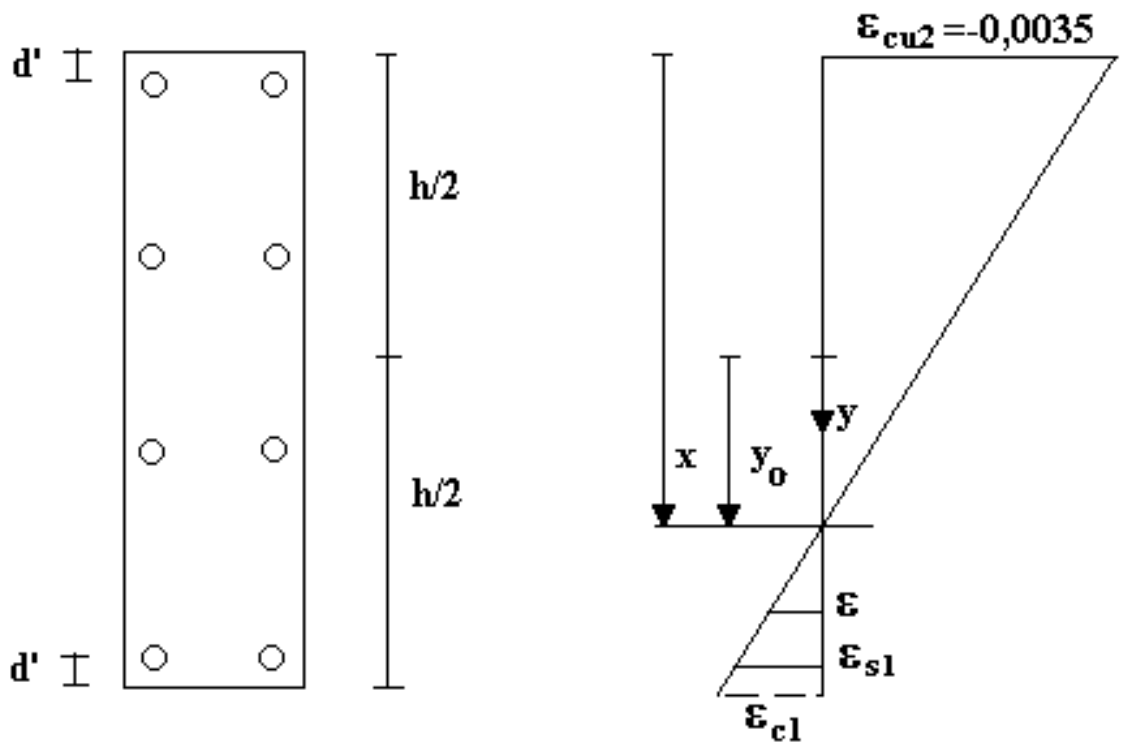

Figura 4.7 - Deformações da Região II

A equação de compatibilidade fica a seguinte:

$\frac{\stackrel{\AA}{y}-\mathrm{y}_{0}}{0,5 \cdot h+\mathrm{y}_{0}}$

Substituindo em 4.45 os valores de 4.44 e 4.46 , obtém-se:

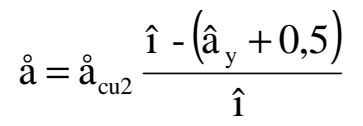

As restrições para a região II são as seguintes:

$$
\begin{aligned}
& \stackrel{\circ}{\mathrm{s}} \leq 0,01 \\
& \stackrel{\circ}{\mathrm{c} 1} \geq 0
\end{aligned}
$$

Para os casos em que a primeira condição não for atendida a análise pertence àregião I, se a segunda condição não for satisfeita, está -se na região III.

Substituindo-se 4.51 em 4.50, pode-se obter o seguinte intervalo para variação de $\xi$ dentro da região II: 


$$
0,259(1-\ddot{a}) \leq \hat{\imath} \leq 1
$$

\section{c) Região III}

Região correspondente ao domínio 5 , possui um valor $\varepsilon_{\text {cuз }}$ para o ponto localizado a 3/7 de $\mathrm{h}$ de distância da borda mais comprimida, sendo este valor igual a $2 \%$. A figura 4.8 mostra o diagrama de deformações para a região em questão.
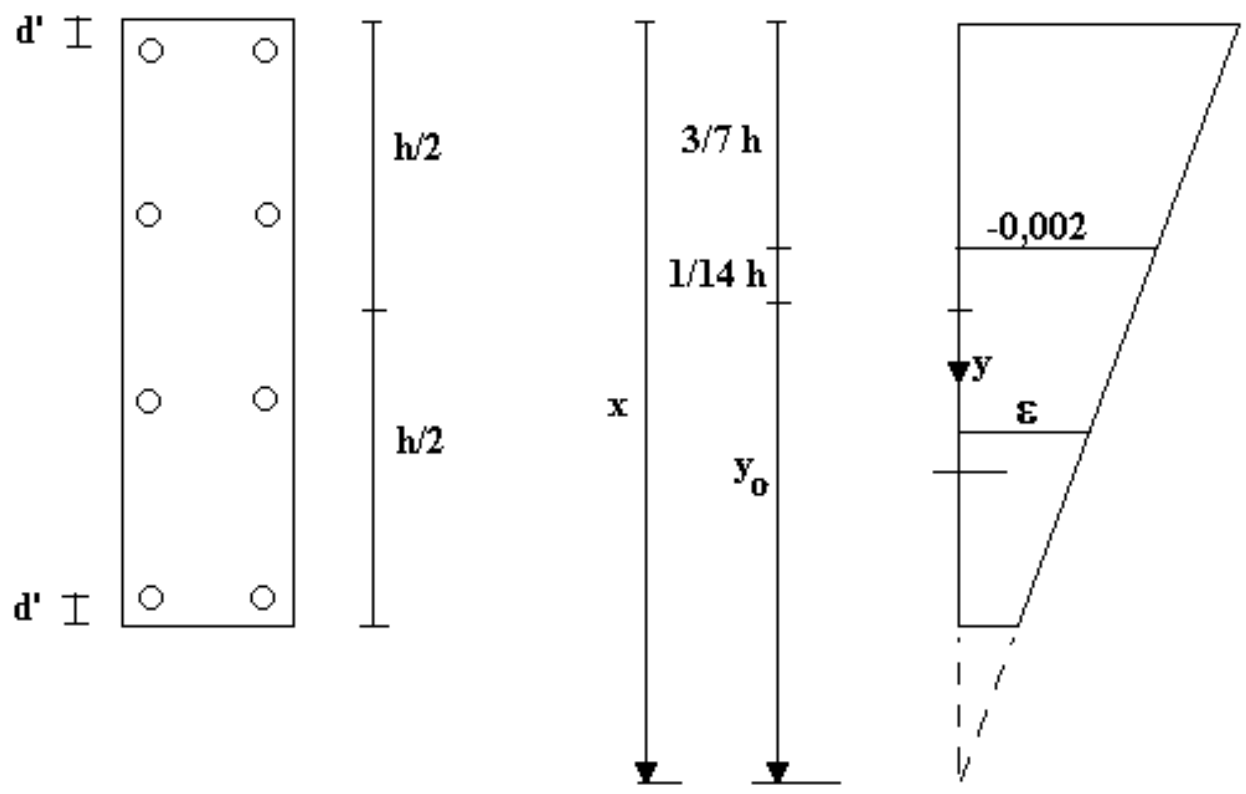

Figura 4.8 - Deformações da Região III

A expressão da deformação para qualquer ponto na região III é:

$$
\stackrel{a}{=}=0,002 \frac{\mathrm{y}-\mathrm{y}_{0}}{\mathrm{x}-\frac{3}{7} \cdot \mathrm{h}}
$$

Substituindo-se os valores, pode-se obter: 


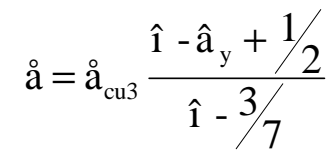

Sendo que a condição para que se esteja na região III é a seguinte:

$$
\stackrel{\circ}{\mathrm{c} 1}_{1} \leq 0
$$

Que implica, calculando-se 4.54, na fibra mais tracionada e com $\hat{a}_{y}=1 / 2 \mathrm{em}$ :

$$
\hat{\imath} \geq 1
$$

\section{d) Expressão Geral}

Fazendo-se uma fórmula geral para ă a partir de valores da deformação última $\AA_{\mathrm{u}}$ e uma constante adimensional $\hat{\mathrm{i}}_{0}$, pode-se escrever:

$$
\stackrel{\circ}{a}=\stackrel{\circ}{u}_{u} \frac{\hat{\imath}-\left(0,5+\hat{a}_{y}\right)}{\hat{\imath}-\hat{\imath}_{0}}
$$

Com os valores para cada região da seguinte forma:

$$
\text { Região I: } \begin{aligned}
& \stackrel{\circ}{\mathrm{u}}_{\mathrm{u}}=\stackrel{\circ}{\mathrm{su}}_{\mathrm{a}}=0,01 \\
& \hat{\mathrm{i}}_{0}=1-\ddot{\mathrm{a}}
\end{aligned}
$$

Região II: $\begin{aligned} & \stackrel{\circ}{u}_{\mathrm{u}}=\stackrel{̊}{\mathrm{cu}}_{\mathrm{c} 2}=-0,0035 \\ & \hat{\mathrm{i}}_{0}=0\end{aligned}$

$$
\text { Região III: } \hat{1}_{0}=3 / 7
$$

$$
\stackrel{\circ}{\mathrm{u}}_{\mathrm{u}}=\stackrel{\mathrm{a}}{\mathrm{cu} 3}=-0,002
$$




\section{e) Equações de Equilíbrio}

Uma seção de concreto possui, no caso indicado, as seguintes tensões e deformações:

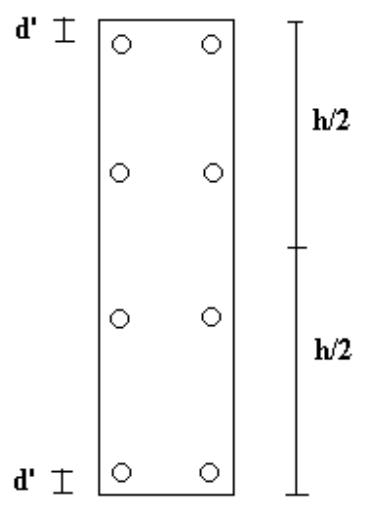

a) Geometria

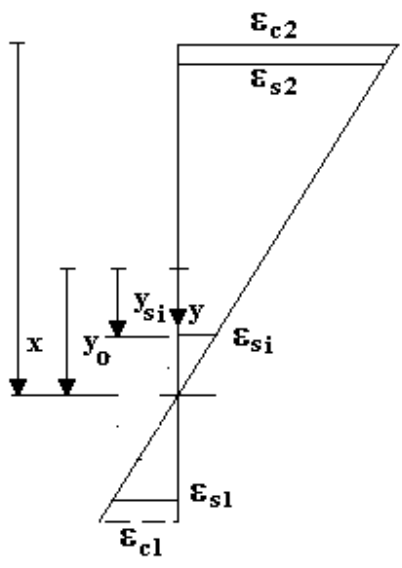

b) Deformaçổes

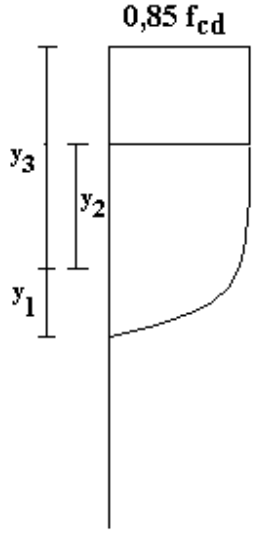

c) Tensỗes

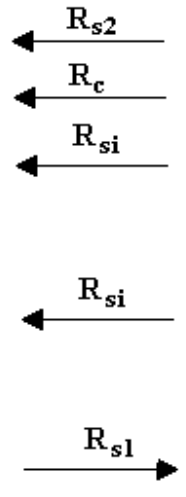

d) Resultantes

Figura 4.9 - Tensões e deformações em uma seção retangular

Por equilíbrio, pode-se prever que:

$$
\begin{aligned}
& \mathrm{N}_{\mathrm{R}}=\mathrm{R}_{\mathrm{C}}+\sum_{\mathrm{i}=1}^{\mathrm{N}} \mathrm{R}_{\mathrm{Si}} \\
& \mathrm{M}_{\mathrm{R}}=\mathrm{M}_{\mathrm{C}}+\sum_{\mathrm{i}=1}^{\mathrm{N}} \mathrm{R}_{\mathrm{Si}} \cdot \mathrm{y}_{\mathrm{si}}
\end{aligned}
$$

Sendo $\mathrm{N}$ o número de barras da armadura da seção, e $R_{c}$ e $M_{c}$ contribuições de resistência da seção comprimida do concreto para a peça, pode-se considerar essas resultantes como sendo:

$$
\begin{aligned}
& \mathrm{N}_{\mathrm{C}}=\int_{\mathrm{Ac}} \hat{o}_{\mathrm{C}} \mathrm{dA} \\
& \mathrm{M}_{\mathrm{C}}=\int_{\mathrm{Ac}} \mathrm{y} \cdot \hat{o}_{\mathrm{C}} \mathrm{dA}
\end{aligned}
$$

Somando-se as resultantes das barras de aço, obtidas pela multiplicação da tensão em cada barra pela sua respectiva área, pode-se obter: 


$$
\begin{aligned}
& \mathrm{N}_{\mathrm{R}}=\int_{\mathrm{Ac}} o_{\mathrm{C}} \mathrm{dA}+\sum_{\mathrm{i}=1}^{\mathrm{N}} o_{\mathrm{Si}} \mathrm{A}_{\mathrm{Si}} \\
& \mathrm{M}_{\mathrm{R}}=\int_{\mathrm{Ac}} \mathrm{y} \cdot o_{\mathrm{C}} \mathrm{dA}+\sum_{\mathrm{i}=1}^{\mathrm{N}} \mathrm{y}_{\mathrm{Si}} \cdot o_{\mathrm{Si}} \mathrm{A}_{\mathrm{Si}}
\end{aligned}
$$

Considerando-se que a seção é retangular, as integrais podem ser consideradas somente como função de $y$.

$$
\begin{aligned}
& \mathrm{N}_{\mathrm{R}}=\int_{-h / 2}^{\mathrm{y}_{0}} \mathrm{~b}_{\mathrm{w}} \cdot \hat{o}_{\mathrm{C}} \mathrm{dy}+\sum_{\mathrm{i}=1}^{\mathrm{N}} \mathrm{o}_{\mathrm{Si}} \mathrm{A}_{\mathrm{Si}} \\
& \mathrm{M}_{\mathrm{R}}=\int_{-h / 2}^{\mathrm{y}_{0}} \mathrm{~b}_{\mathrm{w}} \cdot y \cdot \sigma_{\mathrm{C}} \mathrm{dy}+\sum_{\mathrm{i}=1}^{\mathrm{N}} \mathrm{y}_{\mathrm{Si}} \cdot \mathrm{o}_{\mathrm{Si}} \mathrm{A}_{\mathrm{Si}}
\end{aligned}
$$

Nas equações acima, os esforços $N_{R}$ e $M_{R}$ são apenas função da posição da linha neutra. Para dimensionar a armadura, basta igualar os esforços:

$$
\begin{aligned}
& N_{d}=N_{R} \\
& M_{d}=M_{R}
\end{aligned}
$$

Portanto:

$$
\begin{aligned}
& \mathrm{N}_{\mathrm{d}}=\int_{-h / 2}^{\mathrm{y}_{0}} \mathrm{~b}_{\mathrm{w}} \cdot o_{\mathrm{C}} \mathrm{dy}+\sum_{\mathrm{i}=1}^{\mathrm{N}} \mathrm{o}_{\mathrm{Si}} \mathrm{A}_{\mathrm{Si}} \\
& \mathrm{M}_{\mathrm{d}}=\int_{-h / 2}^{\mathrm{y}_{0}} \mathrm{~b}_{\mathrm{w}} \cdot y \cdot o_{\mathrm{C}} \mathrm{dy}+\sum_{\mathrm{i}=1}^{\mathrm{N}} \mathrm{y}_{\mathrm{Si}} \cdot o_{\mathrm{Si}} \mathrm{A}_{\mathrm{Si}}
\end{aligned}
$$

Uma simplificação possível consiste em considerar o diagrama de tensões para o concreto simplificado, para o qual o diagrama tensão deformação parábolaretângulo pode ser substituído por um retângulo equivalente, com altura igual a 0,8 $x$. O diagrama é o seguinte: 


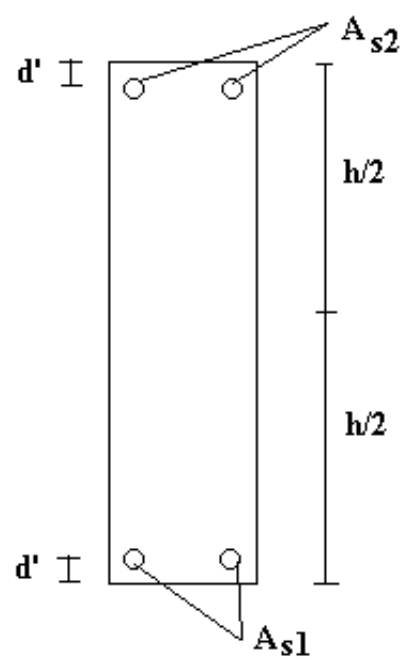

a) Geometria

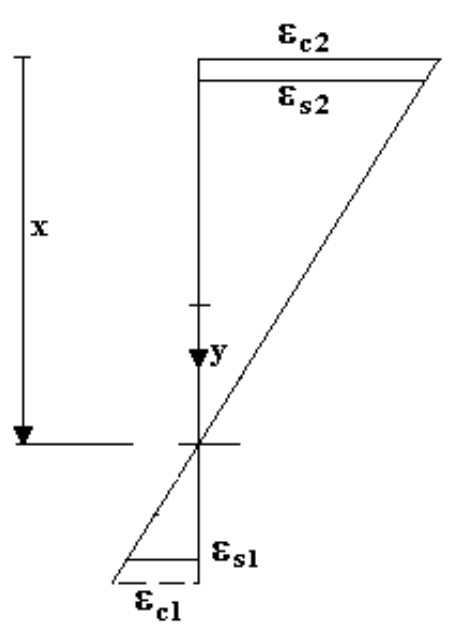

b) Deformaçốes

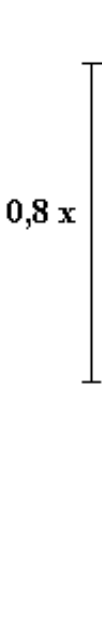

c) Tensốes

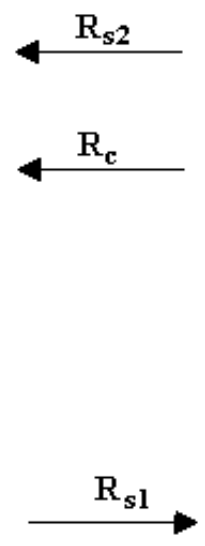

d) Resultantes

Figura 4.10 - Diagrama simplificado

Considerando o diagrama retangular de tensões, pode-se considerar 4.63 da seguinte forma:

$$
\begin{aligned}
& \mathrm{N}_{\mathrm{d}}=\int_{-h / 2}^{0,8 \mathrm{x}-\mathrm{h} / 2}-0,85 \cdot \mathrm{f}_{\mathrm{cd}} \cdot \mathrm{b}_{\mathrm{w}} \mathrm{dy}+\sum_{\mathrm{i}=1}^{\mathrm{N}} \mathrm{o}_{\mathrm{Si}} \mathrm{A}_{\mathrm{Si}} \\
& \mathrm{M}_{\mathrm{d}}=\int_{-h / 2}^{0,8 \mathrm{x}-\mathrm{h} / 2}-0,85 \cdot \mathrm{f}_{\mathrm{cd}} \cdot \mathrm{b}_{\mathrm{w}} \cdot \mathrm{ydy}+\sum_{\mathrm{i}=1}^{\mathrm{N}} \mathrm{y}_{\mathrm{Si}} \cdot \mathrm{o}_{\mathrm{Si}} \mathrm{A}_{\mathrm{Si}}
\end{aligned}
$$

Resolvendo-se as integrais, obtêm-se:

$$
\begin{aligned}
& \mathrm{N}_{\mathrm{d}}=-0,68 \cdot \mathrm{f}_{\mathrm{cd}} \cdot \mathrm{b}_{\mathrm{w}} \cdot \mathrm{x}+\sum_{\mathrm{i}=1}^{\mathrm{N}} \mathrm{o}_{\mathrm{Si}} \mathrm{A}_{\mathrm{Si}} \\
& \mathrm{M}_{\mathrm{d}}=-0,34 \cdot \mathrm{f}_{\mathrm{cd}} \cdot \mathrm{b}_{\mathrm{w}} \cdot \mathrm{x} \cdot(\mathrm{h}-0,8 \cdot \mathrm{x})+\sum_{\mathrm{i}=1}^{\mathrm{N}} \mathrm{y}_{\mathrm{Si}} \cdot \mathrm{o}_{\mathrm{Si}} \mathrm{A}_{\mathrm{Si}}
\end{aligned}
$$

No caso particular de duas armaduras, uma na face tracionada e outra na comprimida, conforme a figura 4.9 , pode-se escrever: 


$$
\begin{aligned}
& N_{D}=-0,68 \cdot f_{c d} \cdot b_{w} \cdot x+o_{S 1} A_{S 1}+o_{s 2} A_{S 2} \\
& M_{D}=-0,34 \cdot f_{c d} \cdot b_{w} \cdot x \cdot(h-0,8 \cdot x)+(0,5 \cdot h-d) \cdot\left(o_{s 1} A_{S 1}-o_{s 2} A_{S 2}\right)
\end{aligned}
$$

O dimensionamento de peças de concreto armado submetidas a ação de flexão normal composta é feito segundo a equação 4.63, considerando a equação de compatibilidade de deformações 4.57 para se encontrar a deformação e achando-se a tensão nas barras de aço de acordo com o diagrama tensãodeformação simplificado, exposto na figura 2.1.

Uma outra forma de resolver a equação 4.60 é utilizar o diagrama parábolaretângulo mostrado na figura 4.9 e considerar as variáveis adimensionais, conforme as equações a seguir.

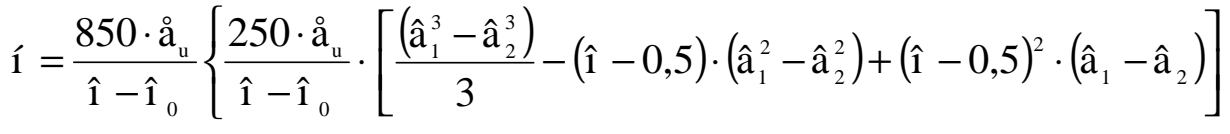

$$
\begin{aligned}
& \left.-\frac{\left(\hat{a}_{1}^{2}-\hat{a}_{2}^{2}\right)}{2}+(\hat{\imath}-0,5) \cdot\left(\hat{a}_{1}-\hat{a}_{2}\right)\right\}-0,85 \cdot\left(\hat{a}_{2}-\hat{a}_{3}\right)+\frac{\grave{u}}{f_{y d}} \sum_{i=1}^{N} ́_{s i} \cdot c_{s i} \\
& \mu=\frac{850 \cdot \stackrel{\circ}{u}_{u}}{\hat{\imath}-\hat{\imath}_{0}} \cdot\left\{-\frac{\left(\beta_{1}{ }^{3}-\beta_{2}{ }^{3}\right)}{3}+(\xi-0,5) \cdot \frac{\left(\beta_{1}{ }^{2}-\beta_{2}{ }^{2}\right)}{2}\right. \\
& \left.+\frac{250 \cdot \varepsilon_{u}}{\xi-\xi_{0}} \cdot\left[-2 \cdot(\hat{\mathrm{i}}-0,5) \cdot \frac{\left(\hat{\mathrm{a}}_{1}^{3}-\hat{\mathrm{a}}_{2}^{3}\right)}{3}+(\hat{\mathrm{i}}-0,5)^{2} \cdot \frac{\left(\hat{\mathrm{a}}_{1}^{2}-\hat{\mathrm{a}}_{2}^{2}\right)}{2}+\frac{\left(\hat{\mathrm{a}}_{1}^{4}-\hat{\mathrm{a}}_{2}^{4}\right)}{4}\right]\right\} \\
& -0,425 \cdot\left(\hat{a}_{2}^{2}-\hat{a}_{3}^{2}\right)+\frac{\grave{u}}{f_{y d}} \cdot \sum_{i=1}^{N} \sigma_{s i} \cdot \beta_{s i} \cdot c_{s i}
\end{aligned}
$$

\section{f) Exemplo Numérico}

Considerando o mesmo exemplo proposto por VENTURINI (1987), porém de acordo com o diagrama proposto pela NBR 6118:2001 para tensão-deformação do aço, e com concreto classe C20, analisar-se-á a seção: 


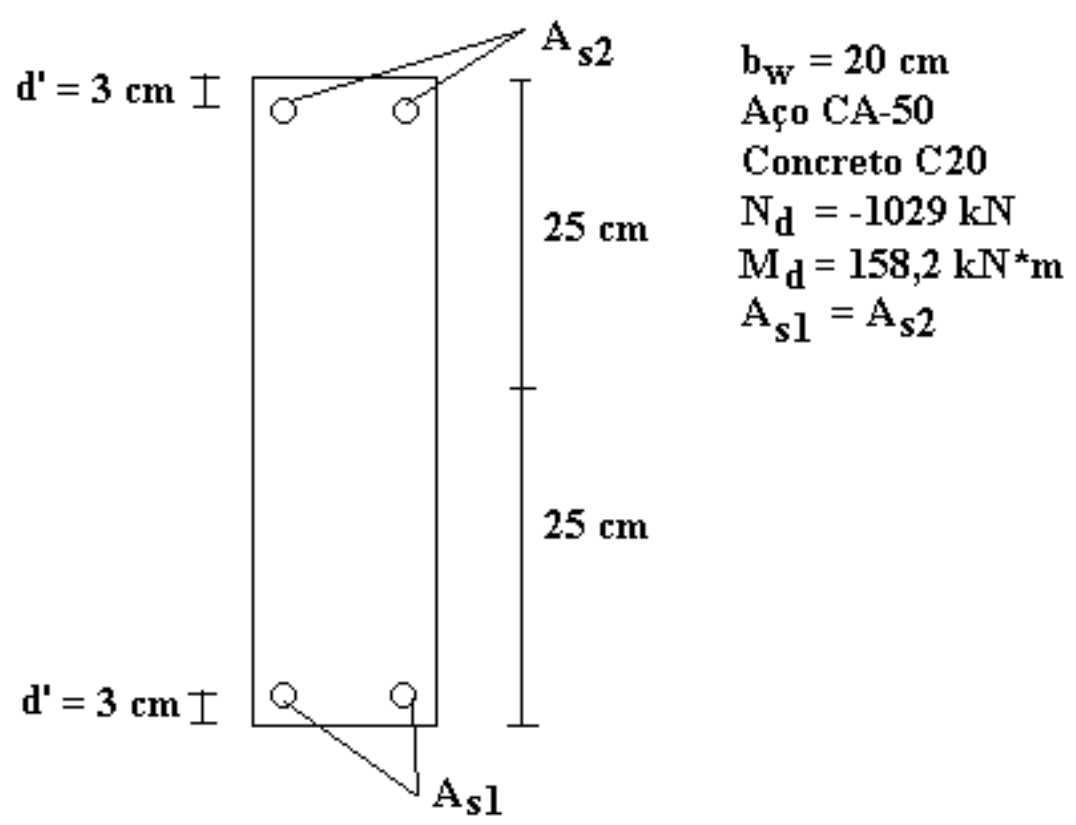

Figura 4.11 - Exemplo numérico

Fixando-se um valor estimado para $x$ de $50 \mathrm{~cm}$, primeiramente deve-se encontrar $\mathrm{o}$ valor de $\hat{\imath}$ e de ä para que se defina a região correspondente à solicitação. Sendo $\hat{\imath}=\frac{x}{h}$ e $\ddot{a}=\frac{d '}{h}$, calculando-se estes valores, encontram-se:

$$
\begin{aligned}
& \hat{\imath}=\frac{50}{50}=1,0 \\
& \text { e } \\
& \ddot{a}=\frac{3}{50}=0,06
\end{aligned}
$$

Pelas inequações mostradas em 4.48, 4.52 e 4.56, pode-se afirmar que se caracteriza pela região II, ou III, utilizando-se a II, neste caso.

$$
\begin{aligned}
& 0,259(1-\ddot{a}) \leq \hat{\imath} \leq 1 \\
& \text { ou } \\
& 0,24346 \leq \hat{\imath}=1,0 \leq 1
\end{aligned}
$$


O próximo passo será considerar a equação 4.57 com os limites da região II, de forma a obter:

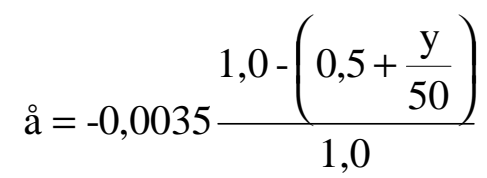

Portanto, para qualquer y (distância ao centro geométrico da seção em y), pode-se obter a deformação naquele ponto.

No caso da armadura superior, $\mathrm{y}=-\mathrm{h} / 2+\mathrm{d}^{\prime}=-25+3=-22 \mathrm{~cm}$.

Aplicando-se na fórmula 4.67, obtém-se:

$$
a ̊=-0,0035 \frac{1,0-\left(0,5+\frac{-22}{50}\right)}{1,0}=-0,00329 \text { ou }-3,29 \%
$$

Para esta deformação, o aço CA-50, já atingiu o ponto de escoamento, que acontece a uma deformação de aproximadamente - $2,07 \%$, portanto, a tensão no aço será igual a sua tensão resistente de cálculo, $\sigma_{\mathrm{s} 2} \approx-435 \mathrm{MPa}$.

O mesmo procedimento deve ser feito para se encontrar a tensão na armadura inferior, que, no entanto, não atingiu o seu ponto de escoamento. Achando-se uma tensão de -44,1 MPa (Valor negativo indicando compressão).

Aplicando os valores na equação 4.66 e sendo $A_{s 1}=A_{s 2}$, tem-se:

$$
\mathrm{N}_{\mathrm{R}}=-0,68 \cdot \frac{2,0}{1,4} \cdot 20 \cdot 50+(-43,5-4,41) \cdot \mathrm{A}_{\mathrm{S} 1}
$$

Igualando-se $N_{R}$ com $N_{d}$, pode-se isolar o valor $A_{S}$, obtendo-se a área de armadura necessária. O valor encontrado neste caso é:

$$
-1029=-0,68 \cdot \frac{2,0}{1,4} \cdot 20 \cdot 50+(-43,5-4,41) \cdot \mathrm{A}_{\mathrm{S} 1} \Rightarrow \mathrm{A}_{\mathrm{S} 1}=1,20 \mathrm{~cm}^{2}
$$


Sendo $A_{s 1}=A_{s 2}, A_{s}=2 A_{s 1}=2,40 \mathrm{~cm}^{2}$. Mas este valor da área da armadura deve satisfazer àequação de equilíbrio de momentos. Sendo esta:

$$
\begin{aligned}
& M_{R}=-0,34 \cdot \frac{2,0}{1,4} \cdot 20 \cdot 50 \cdot\left(50-\frac{27}{34} \cdot 50\right)+(0,5 \cdot 50-3) \cdot(-43,5+4,41) \cdot 1,20 \\
& M_{R}=6032 \mathrm{kN} \cdot \mathrm{cm} \neq M_{d}=15820 \mathrm{kN} \cdot \mathrm{cm}
\end{aligned}
$$

Portanto, deve-se adotar um novo valor de x. Baseado neste valor, deve-se achar uma nova área de aço necessária e verificar se o momento fletor resistente é igual ao momento fletor atuante na seção.

Como exemplificado, o processo torna-se iterativo, necessitando-se encontrar o valor de x para o qual a área de aço encontrada leve a um momento resistente igual ao momento atuante.

No exemplo acima, o valor exato de x é 40,77 cm, gerando uma armadura de $14,69 \mathrm{~cm}^{2}$. Os valores dos adimensionais para este caso são: $v=0,72, \mu=0,22$ que leva a um resultado com $\omega=0,45$. Sendo que, para este resultado, os valores de $M_{R}$ e $M_{d}$ são iguais.

\subsubsection{Força Cortante}

\subsubsection{Princípios Básicos}

Os esforços na alma correspondentes às tensões principais de tração exigem uma armadura denominada armadura de cisalhamento, visto que o concreto não deve resistir aos esforços de tração.

As tensões principais de tração dão origem às fissuras de cisalhamento, o que permite supor que a estrutura deve ser considerada no estádio II, como uma treliça.

A resistência das vigas de concreto armado depende da segurança com que, tanto os esforços de tração e de compressão que aparecem nas barras da treliça e da alma, quanto os esforços que surgem nos banzos, serão absorvidos.

A melhor orientação para a armadura de cisalhamento é análoga àda tensão principal de tração $\sigma_{x}$, ou seja, em um ângulo de $45^{\circ}$ com o eixo da peça. Porém, a 
dificuldade de execução torna mais práticos os estribos perpendiculares ao eixo da viga (estribos verticais).

Para verificação da resistência àforça cortante de vigas de concreto armado no Estádio II, os esforços de tração e de compressão na alma são calculados com o auxílio de um modelo de treliça no estado limite.

\subsubsection{Analogia de treliça clássica}

A teoria mais utilizada para cálculo da armadura transversal é a de treliça clássica de Ritter-Mörch. Nesta analogia entre viga e a treliça, a armadura longitudinal e o concreto comprimido formam o banzo tracionado e o banzo comprimido da treliça, respectivamente. As bielas comprimidas são limitadas pelas fissuras da alma. A armadura transversal (estribos) faz o papel dos montantes tracionados.

\section{a) Elementos da Treliça}

Banzo comprimido:

Banzo tracionado:

Montantes tracionados:

Diagonais comprimidas:
Formado pela zona comprimida de altura $\times$ (Figura 4.12);

Formado pelas barras da armadura longitudinal de tração;

Formados pela reunião dos estribos contidos na distância z, num único estribo equivalente; Formadas pela reunião das bielas de compressão contidas na distância z.

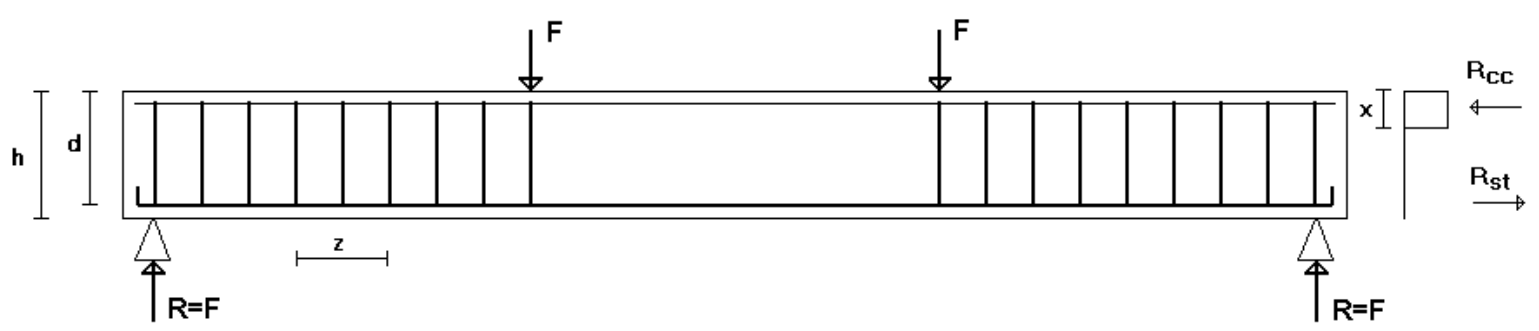

Figura 4.12 - Treliça clássica de Mörsch 


\section{b) Hipóteses Básicas}

- A treliça é isostática, portanto, as forças internas são calculadas a partir do esforço cortante, considerando-se apenas as equações de equilíbrio, sem a compatibilidade de deformações.

- As diagonais comprimidas têm inclinação de $45^{\circ}$ em relação ao eixo da viga;

- Os banzos, tracionados e comprimidos, são paralelos;

- Nas seções transversais, as resultantes de compressão no concreto $\left(R_{c c}\right)$ e de tração na armadura $\left(R_{\mathrm{st}}\right)$ são iguais.

\subsubsection{Mecanismo de Ruptura}

Quando as tensões principais de tração, inclinadas, na alma de uma viga, atingem a resistência à tração do concreto, aparecem fissuras de cisalhamento. Essas fissuras causam uma transposição dos esforços existentes na alma, no Estádio I, para a armadura de cisalhamento e para as diagonais comprimidas de concreto. Essa redistribuição dos esforços internos depende muito da quantidade e da direção da armadura de cisalhamento; assim sendo, são possíveis diversos tipos de ruptura por força cortante.

Admitindo-se que o banzo tracionado esteja satisfatoriamente ancorado, a treliça idealizada no item anterior deve ser verificada contra os seguintes estados limites últimos:

-- Estado limite último pós-escoamento da armadura transversal, (Força Cortante-Tração);

-- Estado limite último por esmagamento das bielas comprimidas, (Força Cortante-Compressão).

O primeiro estado limite é alcançado, quando as barras da armadura transversal atingem a resistência de escoamento. Este é um estado limite convencional, pois alcançá-lo não significa que simultaneamente ocorra o colapso 
da peça. De acordo com CILONI (1993), existem alguns mecanismos que podem acontecer após o escoamento da armadura transversal, podem-se citar:

1. Ruptura força cortante-compressão: o excessivo alongamento da armadura transversal gera nas bielas comprimidas, esforços adicionais de flexão que acarretam o seu esmagamento nas proximidades do banzo comprimido.

2. Ruptura força cortante-flexão: este tipo de ruptura ocorre em conseqüência da ação combinada do momento fletor com a força cortante. Com a fissuração na alma gerada pela força cortante, a altura do banzo comprimido diminui, acabando por ser esmagado pelas tensões normais oriundas do momento fletor.

3. Ruptura força cortante-tração: ocorre raramente, quando a armadura transversal rompe por tração.

4. Ruptura por flexão localizada da armadura longitudinal de tração: este tipo de ruptura ocorre quando a armadura longitudinal que serve de apoio para as bielas comprimidas de concreto perde a sua capacidade portante em conseqüência do escoamento da armadura transversal sobre a qual se apóia.

O estado limite força cortante-compressão é um estado limite efetivo que se configura, quando as diagonais comprimidas do concreto, entre as fissuras de cisalhamento, rompem de maneira brusca quando solicitadas até o limite da resistência à compressão do concreto, antes que a armadura da alma (estribos) entre em escoamento. A ruptura da diagonal comprimida determina o limite superior da capacidade resistente à força cortante das almas das vigas, a qual depende portanto da resistência àcompressão do concreto.

Evita-se este tipo de ruptura, limitando-se a tensão de compressão no concreto.

\subsubsection{Taxa Mínima de Armadura}

De acordo com NBR 6118:2001, todos os elementos lineares submetidos a força cortante devem conter armadura mínima constituída por estribos, com taxa geométrica igual a fórmula a seguir: 


$$
\rho_{s w}=\frac{A_{s w}}{b_{w} \cdot s \cdot \operatorname{sen}(\alpha)} \geq 0,2 \frac{\mathrm{f}_{c t m}}{\mathrm{f}_{y w k}}
$$

onde:

$A_{s w}$ é a área da seção transversal dos estribos;

s é o espaçamento dos estribos, medido segundo o eixo longitudinal do elemento estrutural;

$\alpha$ é a inclinação dos estribos em relação ao eixo longitudinal do elemento estrutural;

$b_{w}$ é a largura média da alma, medida ao longo da altura útil da seção.

Abordar-se-á o caso de armadura transversal com estribos dispostos perpendicularmente ao eixo dos elementos. Sendo:

$$
\rho_{s w}=\frac{A_{s w}}{b_{w} \cdot s} \geq 0,2 \frac{\mathrm{f}_{c t m}}{\mathrm{f}_{y w k}} \text { ou } \quad \frac{A_{s w}}{s} \geq 0,2 \frac{\mathrm{f}_{c t m} \cdot \mathrm{b}_{\mathrm{w}}}{\mathrm{f}_{y w k}}
$$

Sendo:

$$
\begin{aligned}
& \mathrm{f}_{\mathrm{ctm}}=0,3 \cdot \mathrm{f}_{\mathrm{ck}}^{2 / 3} \\
& \mathrm{f}_{\mathrm{ywk}} \leq 500 \mathrm{MPa}
\end{aligned}
$$

\subsubsection{Verificação do Estado Limite Último}

Utiliza-se o modelo de cálculo I de acordo com NBR 6118:2001.

$$
\begin{aligned}
& \mathrm{V}_{\mathrm{Sd}}<\mathrm{V}_{\mathrm{Rd} 2} \\
& \mathrm{~V}_{\mathrm{Sd}}<\mathrm{V}_{\mathrm{Rd} 3}=\mathrm{V}_{\mathrm{c}}+\mathrm{V}_{\mathrm{SW}}
\end{aligned}
$$

A equação 4.72 é para garantia de resistência nas diagonais comprimidas de concreto, e a 4.73 para verificação da tração diagonal. 
Verificação da compressão diagonal do concreto:

$$
\mathrm{V}_{\mathrm{Rd} 2}=0,27 \cdot\left(1-\frac{\mathrm{f}_{\mathrm{ck}}}{250}\right) \cdot \mathrm{f}_{\mathrm{cd}} \cdot \mathrm{b}_{\mathrm{w}} \cdot \mathrm{d}
$$

Cálculo da armadura transversal:

$$
\frac{\mathrm{A}_{\mathrm{sw}}}{s}=\frac{\mathrm{V}_{\mathrm{Sd}}-\mathrm{V}_{\mathrm{c}}}{0,9 \cdot \mathrm{d} \cdot \mathrm{f}_{\mathrm{ywd}}}
$$

Sendo $V_{c}$ igual a zero nos elementos estruturais tracionados quando a linha neutra se situa fora da seção, e igual a $V_{\text {co }}$ nos demais casos:

$$
\mathrm{V}_{\mathrm{c}}=\mathrm{V}_{\mathrm{co}}=0,6 \cdot \mathrm{f}_{\mathrm{ctd}} \cdot \mathrm{b}_{\mathrm{w}} \cdot \mathrm{d}
$$

Lembrando que:

$$
\mathrm{f}_{\mathrm{ctd}}=\frac{\mathrm{f}_{\mathrm{ctk}, \text { inf }}}{\gamma_{\mathrm{c}}}=0,7 \cdot \frac{\mathrm{f}_{\mathrm{ctm}}}{\gamma_{c}}
$$

Pode-se aumentar o valor de $\mathrm{V}_{\mathrm{c}}$ caso a solicitação seja a flexo-compressão, aproveitando o efeito favorável dos esforços de compressão na resistência ao cisalhamento na flexão. Neste caso, a norma brasileira propõe um fator de majoração da parcela de força cortante absorvida por mecanismos complementares ao de treliça, sendo esta majoração a seguinte:

$$
\mathrm{V}_{\mathrm{c}}=\mathrm{V}_{\mathrm{co}} \cdot\left(1+\frac{\mathrm{M}_{\mathrm{O}}}{\mathrm{M}_{\mathrm{Sd}, \text { máx }}}\right) \leq 2 \mathrm{~V}_{\text {co }}
$$

$M_{0}$ é o valor do momento fletor que anula a tensão normal de compressão na borda da seção (tracionada por $M_{d, \max }$ ), provocada pelas forças normais de diversas origens concomitantes com $V_{S d}$, sendo essa tensão calculada com valores de $\gamma_{f}$ e $\gamma_{p}$ iguais a 0,9 , os momentos correspondentes a essas forças normais não 
devem ser considerados no cálculo dessa tensão, pois são considerados em $M_{S d}$, apenas os momentos isostáticos de protensão;

$M_{S d, \text { max }}$ é o momento fletor de cálculo, máximo no trecho em análise, que pode ser tomado como o de maior valor no semitramo considerado.

\subsubsection{Armadura de Suspensão}

Nas proximidades de forças concentradas transmitidas à viga por outras vigas ou elementos discretos que nela se apóiem ao longo ou em parte de sua altura, ou fiquem nela penduradas, deve ser colocada armadura de suspensão. (NBR 6118:2001)

Tais apoios, vigas apoiadas em outras vigas, são chamados de apoios indiretos. A armadura chamada de suspensão tem como finalidade redistribuir a ação da viga apoiada na zona comprimida da viga que serve de apoio. (COSTA, 1990)

O dimensionamento da armadura de suspensão é feito no estado limite último de acordo com a reação na região da ligação, indicada na figura 4.12.

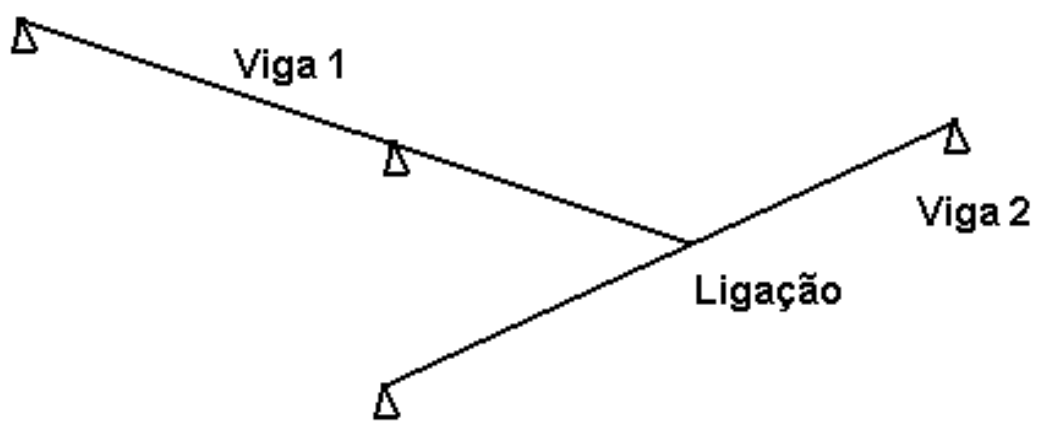

Figura 4.13 - Esquema estático de um apoio indireto

Como na consideração de pórticos planos a ligação só será tida como uma carga concentrada aplicada na viga no pórtico em questão, não se sabendo suas dimensões, considerar-se-á a viga apoiada como tendo a mesma altura da viga em que ela se apóia. Sendo $h_{1}=h_{2}$, a armadura de suspensão é dada por:

$$
a_{\mathrm{s}, \mathrm{sus}}=\frac{\mathrm{R}_{\mathrm{d}}}{\mathrm{f}_{\mathrm{yd}}}
$$


Sendo:

$R_{d}=$ Força que a viga apoiada exerce sobre a que serve de apoio;

$\mathrm{f}_{\mathrm{yd}}=$ Resistência de escoamento de cálculo das barras de aço.

A distribuição desta armadura pode ser de acordo com as figuras a seguir.

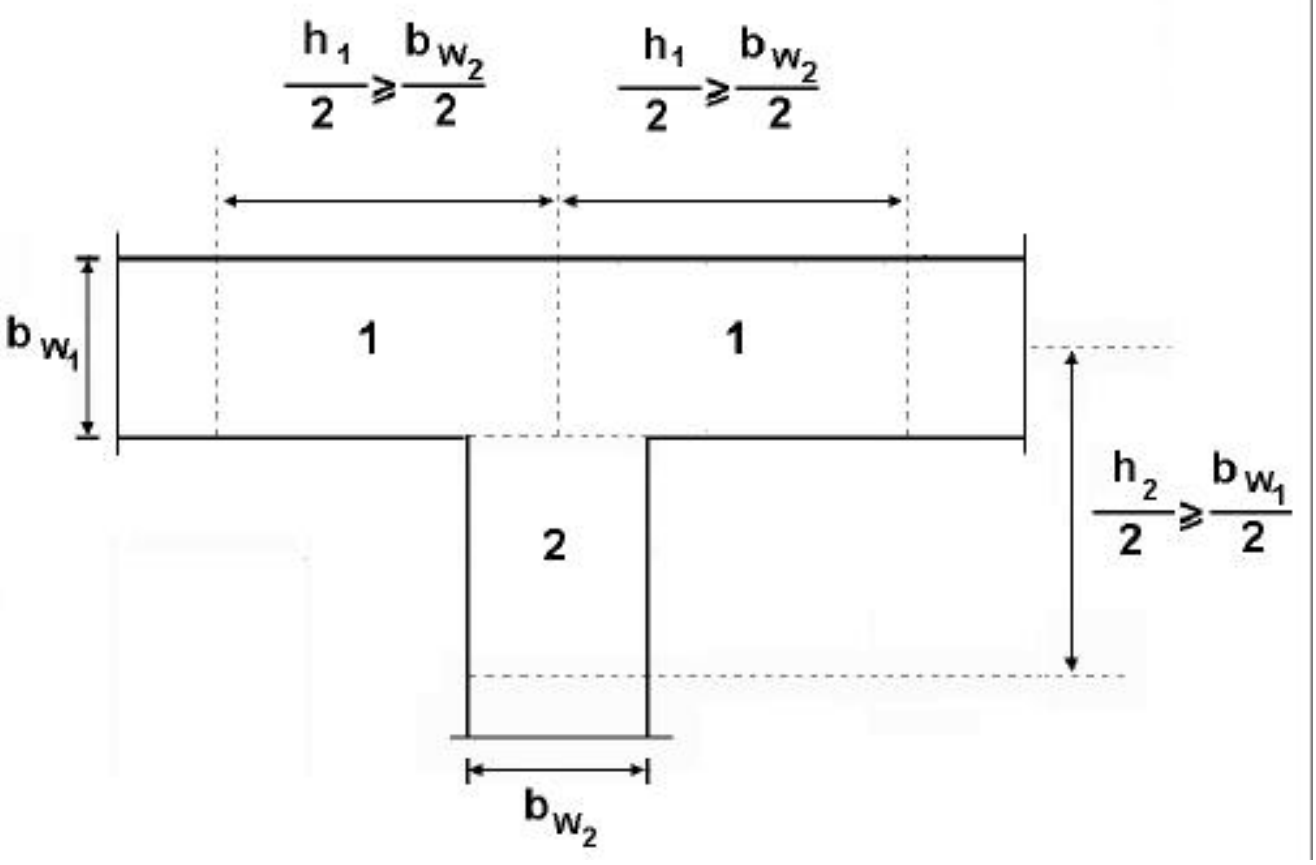

Figura 4.14 - Região de distribuição da armadura de suspensão 


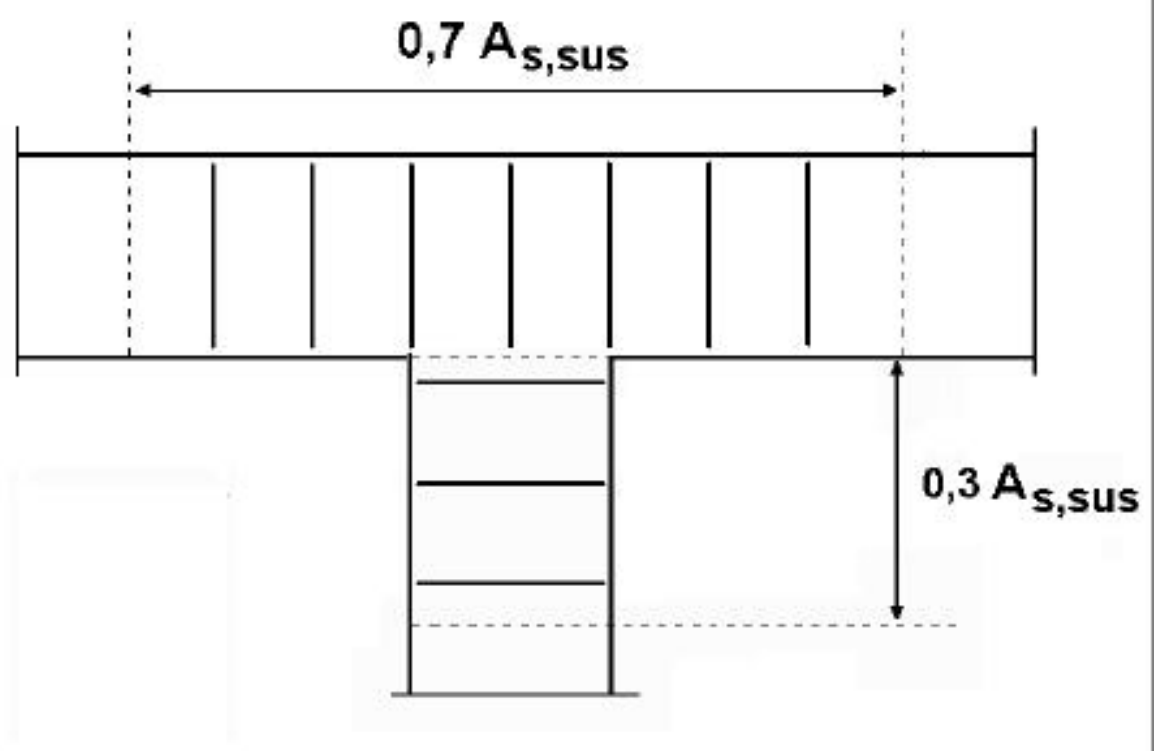

Figura 4.15 - Porcentagem de distribuição

Portanto, a área de aço necessária para redistribuir a ação da viga apoiada na zona comprimida da viga que serve de apoio é dada por 4.79, e distribuída conforme as figuras 4.14 e 4.15 . 


\section{CAPÍTULO 5}

\section{DETALHAMENTO}

\subsection{Introdução}

Segundo FIORIN (1998), a disposição das armaduras nos elementos estruturais não influencia somente o comportamento do elemento estrutural, mas também a facilidade e viabilidade da sua execução na obra.

O arranjo das armaduras deve atender não só àsua função estrutural como também às condições adequadas de execução, particularmente com relação ao lançamento e ao adensamento do concreto. (NBR 6118:2001)

O detalhamento tem como função principal dar com clareza informações que levarão a uma estrutura mais segura e fácil de ser executada. Tal clareza deve ser fruto da riqueza de informações referentes ao arranjo das armaduras, de modo que a correta execução impeça a segregação dos agregados e a ocorrência de vazios no interior do elemento estrutural.

Neste capítulo serão mostradas as exigências normativas para o detalhamento de elementos lineares de concreto armado.

\subsection{Vigas}

A NBR 6118:2001 estabelece parâmetros para o detalhamento de vigas isostáticas com relação $\ell / h \geq 3,0$, e para vigas contínuas com relação $\ell / h \geq 2,0$, sendo $\ell$ o vão teórico (dobro do comprimento para vigas em balanço), e $\mathrm{h}$ a altura total da viga. 


\subsubsection{Armadura Longitudinal}

\subsubsection{Quantidade Mínima}

A definição da quantidade mínima de armadura em vigas de concreto armado visa evitar a ruptura frágil da seção de concreto. Tal armadura mínima é dimensionada de acordo com um momento fletor mínimo dado por um valor correspondente que produziria a ruptura da seção de concreto simples, utilizando para resistência àtração o valor $f_{c t k, s u p}$, definida na equação 2.7.

Em tabela, a NBR 6118:2001 estabelece os valores mínimos para a taxa de armadura de flexão para vigas de acordo com a resistência característica do concreto utilizado no elemento. A tabela para seção retangular é a seguinte:

Tabela 5.1 - Valores de $\rho_{\min }$ em \% para flexão em vigas

\begin{tabular}{|c|c|c|c|c|c|c|}
\hline \multicolumn{7}{|c|}{$f_{c k}$} \\
\hline 20 & 25 & 30 & 35 & 40 & 45 & 50 \\
\hline 0,150 & 0,150 & 0,173 & 0,201 & 0,230 & 0,259 & 0,288 \\
\hline
\end{tabular}

Portanto, a quantidade mínima de armadura será dada pela equação:

$$
\mathrm{A}_{\mathrm{s}, \text { mín }}=\frac{\rho_{\text {min }} \cdot A_{c}}{100}
$$

\subsubsection{Quantidade Máxima}

Define-se uma quantidade máxima para a armadura necessária para resistir aos esforços cortantes em uma viga de concreto armado com o intuito de assegurar a dutilidade do elemento, e considerando os tipos de ensaios que foram necessários para estabelecer os critérios de dimensionamento destes elementos.

O valor máximo estabelecido é tal que a soma das armaduras na face superior e inferior da viga não exceda $4 \%$ da área de concreto $A_{c}$, em regiões sem emendas. 
Portanto:

$$
\mathrm{A}_{\mathrm{s}, \text { máx }}=\left(A_{s 1}+A_{s 2}\right) \leq 4 \% \cdot A_{c}
$$

Sendo $A_{s 1}$ e $A_{s 2}$ as armaduras nas faces superior e inferior da viga.

\subsubsection{Distribuição Transversal}

Existem parâmetros, de acordo com a NBR 6118:2001, para limitar a aproximação entre barras na seção transversal de vigas de concreto armado. Tais limites são impostos para assegurar uma boa concretagem possibilitando a passagem do agregado graúdo entre as barras de aço, assim como a utilização de vibradores para eliminar vazios (bolhas) no concreto do elemento.

Há limites para a distância horizontal e vertical entre barras, sendo:

a) No sentido horizontal, $a_{h}$ é o maior dos três valores:

- $20 \mathrm{~mm}$;

- diâmetro da barra, do feixe ou da luva;

- $\quad$ 1,2 vez o diâmetro máximo do agregado.

b) No sentido vertical, $a_{v}$ é o maior dos três valores:

- $20 \mathrm{~mm}$;

- diâmetro da barra, do feixe ou da luva;

- 0,5 vez o diâmetro máximo do agregado.

O limite maior para a distância horizontal se deve à necessidade do agregado passar por entre as barras para atingir a parte inferior da viga. Sem este limite, as barras de aço poderiam "peneirar" o agregado, deixando um acúmulo nas regiões acima da camada de aço, e um concreto ausente de agregados graúdos na face inferior da viga. 


\subsubsection{Distribuição Longitudinal}

De acordo com a norma NBR 6118:2001, as armaduras de tração que se estendem até os apoios são obtidas de acordo com a mais severa das seguintes condições:

a) No caso de ocorrência de momentos fletores positivos, as armaduras obtidas por meio do dimensionamento da seção;

b) Em apoios extremos, para garantir ancoragem da diagonal de compressão, armaduras capazes de resistir a uma força de tração $R_{\mathrm{st}}=$ $\left(a_{/} / d\right) \cdot V_{d}+N_{d}$, onde $V_{d}$ é a força cortante no apoio e $N_{d}$ é a força de tração eventualmente existente;

c) Em apoios extremos e intermediários, por prolongamento de uma parte da armadura de tração do vão $\left(\mathrm{A}_{\mathrm{s}, \text { vão }}\right)$, correspondente ao máximo momento positivo do tramo $\left(\mathrm{M}_{\text {vão }}\right)$ de modo que:

- $A_{s, \text { apoio }} \geq 1 / 3\left(A_{s, \text { vão }}\right)$ se $M_{\text {apoio }}$ for nulo ou negativo e de valor absoluto $\left|\mathrm{M}_{\text {apoio }}\right| \leq 0,5 \cdot M_{\text {vão }}$;

- $A_{s, \text { apoio }} \geq 1 / 4\left(A_{s, \text { vão }}\right)$ se $M_{\text {apoio }}$ for negativo e de valor absoluto $\left|\mathrm{M}_{\text {apoio }}\right|>0,5 \cdot M_{v \tilde{a} o}$.

\subsubsection{Armadura Transversal para Força Cortante}

O dimensionamento da armadura transversal deve ser feito de acordo com o item 4.4.8.5, mais especificamente de acordo com a equação 4.73. Porém, há limites mínimos e máximos para o espaçamento entre estribos, levando em consideração o eixo longitudinal do elemento.

O valor mínimo deve ser suficiente para a passagem do vibrador, garantindo um bom adensamento da massa de concreto. O valor máximo deve satisfazer às seguintes inequações:

se $V_{d} \leq 0,67 V_{R d 2}$, então $s_{\text {máx }}=0,6 d \leq 300 \mathrm{~mm}$;

se $V_{d}>0,67 V_{R d 2}$, então $s_{\text {máx }}=0,3 d \leq 200 \mathrm{~mm}$;

O valor de $V_{d}$ corresponde ao valor de $V_{S d}$ na equação 4.72 e 4.73 . 
Para áreas com uma força cortante pequena em relação às dimensões do elemento estrutural, a inequação (4.70) deve ser satisfeita, garantindo a existência de uma quantidade mínima de armadura. Tal quantidade mínima pode ser calculada utilizando as equações a seguir.

Sendo:

$$
\frac{A_{s w}}{s}=0,2 \frac{\mathrm{f}_{c t m} \cdot \mathrm{b}_{\mathrm{w}}}{\mathrm{f}_{y w k}}
$$

Logo, o espaçamento máximo é o resultado da seguinte expressão:

$$
s_{\max }=\frac{n \cdot \pi \cdot\left(\frac{\phi_{\mathrm{t}}}{2}\right)^{2}}{0,2 \cdot \frac{\mathrm{f}_{c t m} \cdot \mathrm{b}_{\mathrm{w}}}{\mathrm{f}_{y w k}}}
$$

Sendo:

$$
\begin{array}{ll}
-\mathrm{n}: & \text { Número de ramos nos estribos, } \\
& \text { (geralmente igual a } 2) ; \\
-\phi_{\mathrm{t}}: & \text { Diâmetro dos estribos. } \\
-\mathrm{f}_{\mathrm{ctm}}, \mathrm{b}_{\mathrm{w}} \text { e } \mathrm{f}_{\mathrm{ywk}}: & \text { Assim como em }(4.70)
\end{array}
$$

O espaçamento máximo será o valor mais crítico entre (5.3) e (5.5).

\subsubsection{Comprimento de Ancoragem}

Define-se um comprimento de ancoragem para transferência de tensão, numa peça de concreto armado, do aço para o concreto, fazendo-se com que os dois elementos permaneçam solidários. Esta transferência é resultado da aderência entre o aço e o concreto.

O comprimento de ancoragem básico pode ser calculado da seguinte forma: 


$$
\ell_{b}=\frac{\phi}{4} \cdot \frac{\mathrm{f}_{\mathrm{yd}}}{\mathrm{f}_{\mathrm{bd}}}
$$

O valor de $f_{b d}$, resistência de aderência de cálculo entre a armadura e o concreto na ancoragem de armaduras passivas, de acordo com NBR 6118:2001, pode ser obtido da seguinte forma:

$$
\mathrm{f}_{b d}=\eta_{1} \cdot \eta_{2} \cdot \eta_{3} \cdot \mathrm{f}_{\mathrm{ctd}}
$$

Os valores da expressão acima são os seguintes:

$\eta_{1}$ é igual a 1,0 para barras lisas, 1,4 para barras dentadas e 2,25 para barras nervuradas;

$\eta_{2}$ é considerado igual a 1,0 para situações de boa aderência, e 0,7, caso seja uma região de má aderência;

$\eta_{3}$ recebe o valor 1,0 para diâmetros da armadura menores ou iguais a $32 \mathrm{~mm}$, e o resultado da expressão $\eta_{3}=(132-\phi) / 100$, caso contrário;

$\mathrm{f}_{\mathrm{ctd}}=\mathrm{f}_{\mathrm{ctk}, \mathrm{inf}} / \gamma_{\mathrm{c}}$

$\mathrm{f}_{\mathrm{ctk}, \text { inf }}$ é calculado de acordo com a equação 2.6.

Para cálculo do fator $\eta_{2}$, considera-se como região de boa aderência aquela localizada no máximo a uma altura de $30 \mathrm{~cm}$ acima da face inferior do elemento, se o elementos tiver altura $\mathrm{h}<60 \mathrm{~cm}$. Caso o elemento tenha $60 \mathrm{~cm}$ ou mais de altura, $\mathrm{h} \geq 60 \mathrm{~cm}$, pode-se considerar como região de boa aderência aquela não compreendida nos primeiros $30 \mathrm{~cm}$ abaixo da face superior do elemento.

\subsubsection{Decalagem do Diagrama de Força no Banzo Tracionado}

Além do comprimento de ancoragem, os efeitos provocados pela fissuração oblíqua podem ser substituídos pela decalagem do diagrama de força no banzo tracionado, de acordo com a expressão: 


$$
\mathrm{a}_{\ell}=\mathrm{d} \cdot\left[\frac{\mathrm{V}_{\mathrm{Sd}, \text { máx }}}{2 \cdot\left(\mathrm{V}_{\mathrm{Sd}, \text { máx }}-\mathrm{V}_{\mathrm{c}}\right)} \cdot(1+\text { cotgá })-\text { cotgá }\right]
$$

Sendo que o valor de $\mathrm{a}_{\ell}$ deve ser necessariamente maior que $0,5 \mathrm{~d}$.

A norma estabelece que tal decalagem pode ser substituída pela correspondente decalagem do diagrama de momentos fletores.

\subsection{Pilares}

A NBR 6118:2001 estabelece exigências para a armadura em pilares cuja maior dimensão da seção transversal não exceda cinco vezes a menor dimensão, caso contrário, o pilar deve ser considerado como pilar parede.

\subsubsection{Armadura Longitudinal}

\subsubsection{Quantidade Mínima}

$$
\rho_{\text {min }}=\frac{A_{s}}{A_{c}}=0,15 \cdot \frac{f_{c d}}{f_{y d}} \cdot v \geq 0,40 \%
$$

Sendo $v$ a força normal adimensional, conforme (4.40).

\subsubsection{Quantidade Máxima}

$$
\mathrm{A}_{\mathrm{s}, \text { máx }}=8,0 \% \cdot A_{c}
$$

Mesmo em regiões de emendas.

\subsubsection{Diâmetro das Barras}

O diâmetro das barras longitudinais nos pilares não deve ser maior que 1/8 da menor dimensão transversal do pilar, nem ser inferior a $10 \mathrm{~mm}$. 


\subsubsection{Distribuição Transversal}

É estabelecido um valor para o mínimo espaçamento entre barras nos pilares, sendo o maior dentre os seguintes fatores:

- $40 \mathrm{~mm}$;

- 4 vezes o diâmetro da barra;

- $\quad$ 1,2 vez o diâmetro máximo do agregado, inclusive nas emendas.

\subsubsection{Armaduras Transversais}

A armadura transversal em pilares deve ter diâmetro maior que $5 \mathrm{~mm}$ e $1 / 4$ do diâmetro da barra isolada.

O espaçamento longitudinal deve ser menor do que o menor dos seguintes valores:

- $200 \mathrm{~mm}$;

- menor dimensão da seção;

- $24 \phi$ para CA-25, 12 ф para CA-50.

\subsubsection{Comprimento de Ancoragem}

Conforme item 5.2.3. 


\section{EXEMPLO DE APLICAÇÃO}

\subsection{Introdução}

Neste capítulo é mostrado um exemplo de aplicação para verificação da aplicabilidade do programa DTool, comparando seu dimensionamento e detalhamento com o mesmo processo realizado pelo programa TQS. A ênfase será dada nos resultados obtidos pelo programa DTool, estando detalhes da sua utilização no anexo $A$.

Para análise de resultados é utilizado o projeto realizado pelo programa TQS (TQS Informática Ltda.), por estar disponível no Departamento de Engenharia de Estruturas, por cessão de uso dos Sistemas CAD/TQS - TQS Informática Ltda para a Escola de Engenharia de São Carlos - USP, sob o processo USP $\mathrm{n}^{\circ}$ 97.1.1254.18.7.

\subsection{Edifício Dom Pedro II}

Para verificação dos resultados do programa DTool, utiliza-se o projeto realizado pelo escritório AEOLUS Engenharia e Consultoria S. C. Ltda. O edifício escolhido, chamado Dom Pedro II, localizado em São Carlos-SP na rua Dom Pedro II, esquina com Cezar Ricomi, é composto por três pavimentos tipo, cobertura e ático. Os desenhos das formas do pavimento tipo, da cobertura e do ático do edifício podem ser vistas nas figuras 6.1 a 6.3 . 


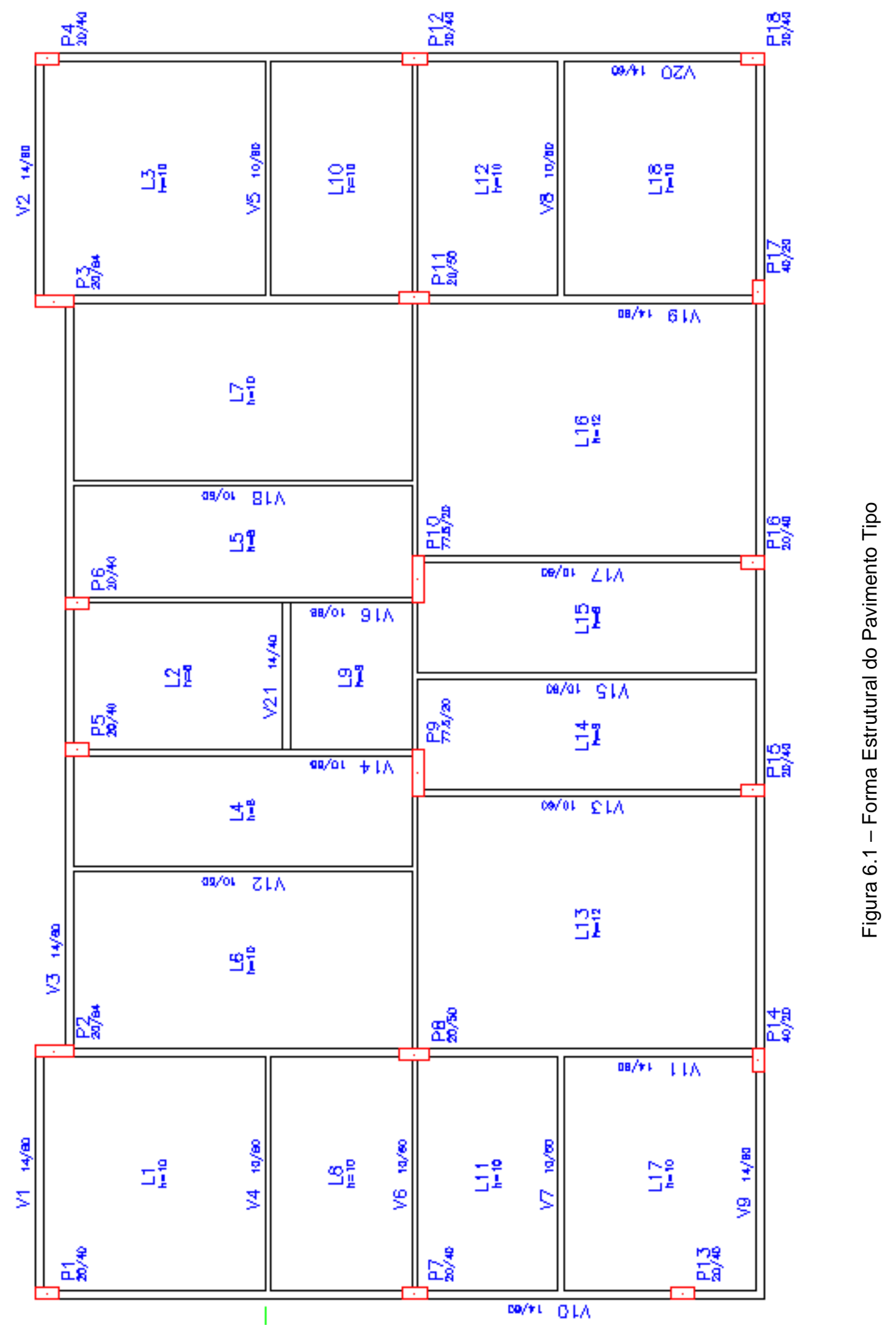




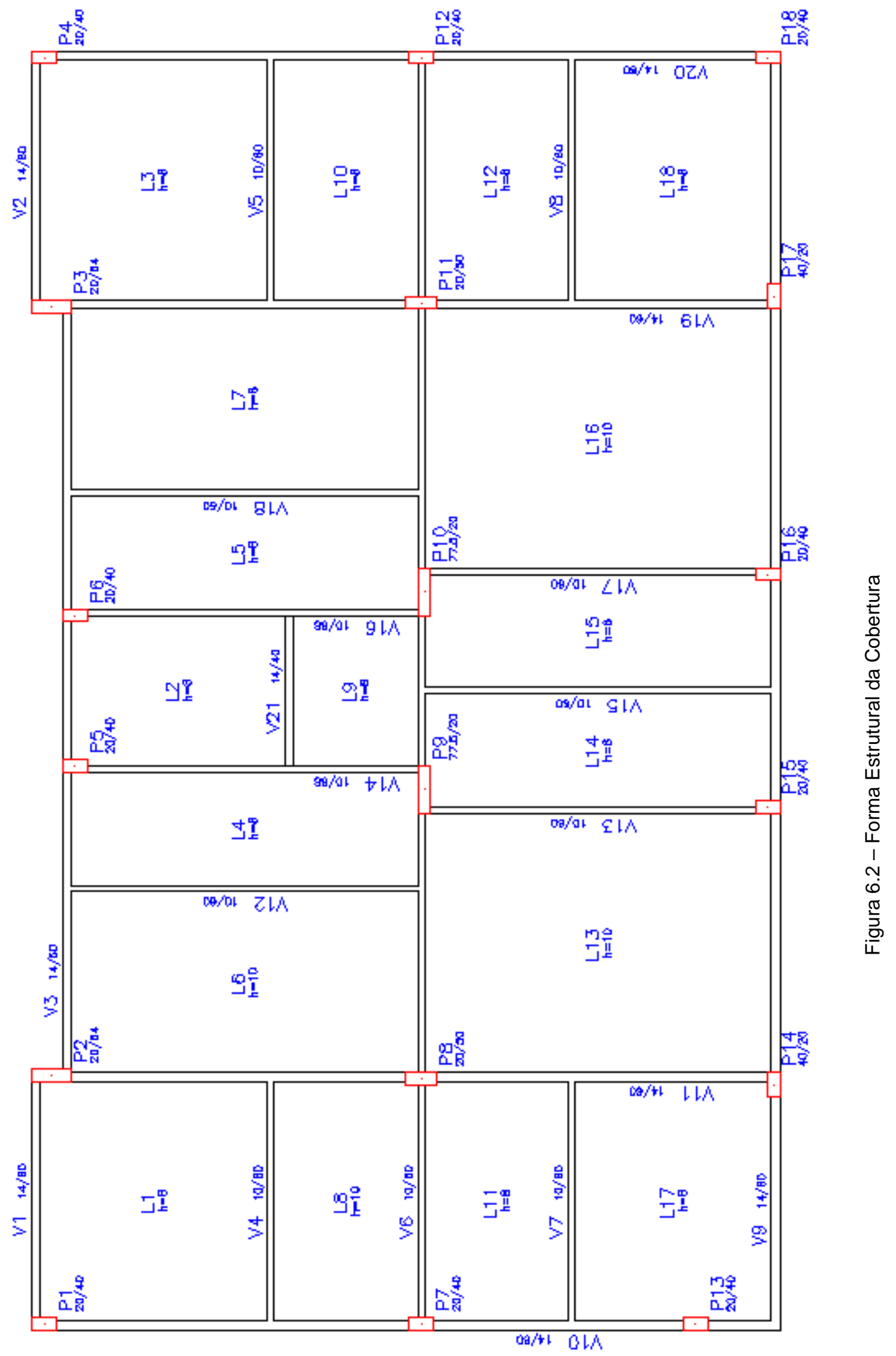




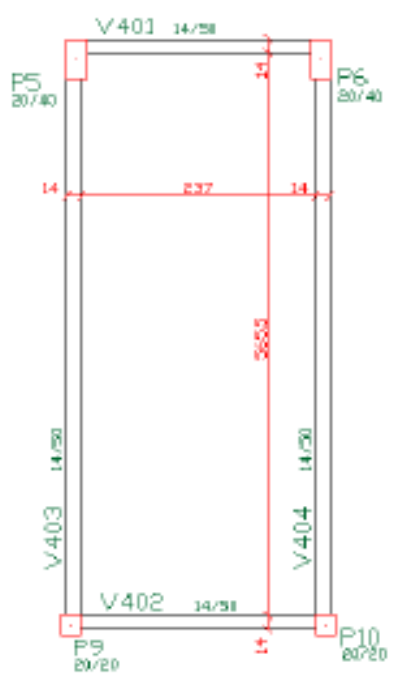

Figura 6.3 - Forma Estrutural do Ático

(S/ Escala)

Os pórticos escolhidos para verificação do dimensionamento são os que contêm as vigas V6, V19 e V20.

O modelo utilizado para dimensionamento usando o programa TQS foi o de pórticos tridimensionais, sem considerar os esforços de vento, utilizando os esforços solicitantes obtidos em tal modelo para o dimensionamento da estrutura.

Para o projeto de cada elemento do pórtico foram adicionadas cargas na estrutura plana para considerar os esforços atuantes nesta seção conforme as ações consideradas no programa TQS para o projeto da edificação.

\subsection{Vigas}

O processo de dimensionamento de vigas foi feito a partir da análise feita pelo programa TQS utilizando o modelo de pórtico tridimensional, utilizando os esforços solicitantes encontrados para o dimensionamento e detalhamento de vigas e pilares na comparação de resultados. Neste processo de cálculo são consideradas as rigidezes dos pilares no cálculo dos momentos fletores que ocorrem nas extremidades das vigas. Este modelo é o que mais se aproxima do 
comportamento real da estrutura, pois na prática os elementos estruturais estão interligados entre si, trabalhando em conjunto.

\subsubsection{Viga V6}

V6 é a viga central do edifício, sendo uma das maiores vigas nele existentes. Para a verificação do dimensionamento o pórtico plano é modelado conforme a figura a seguir.

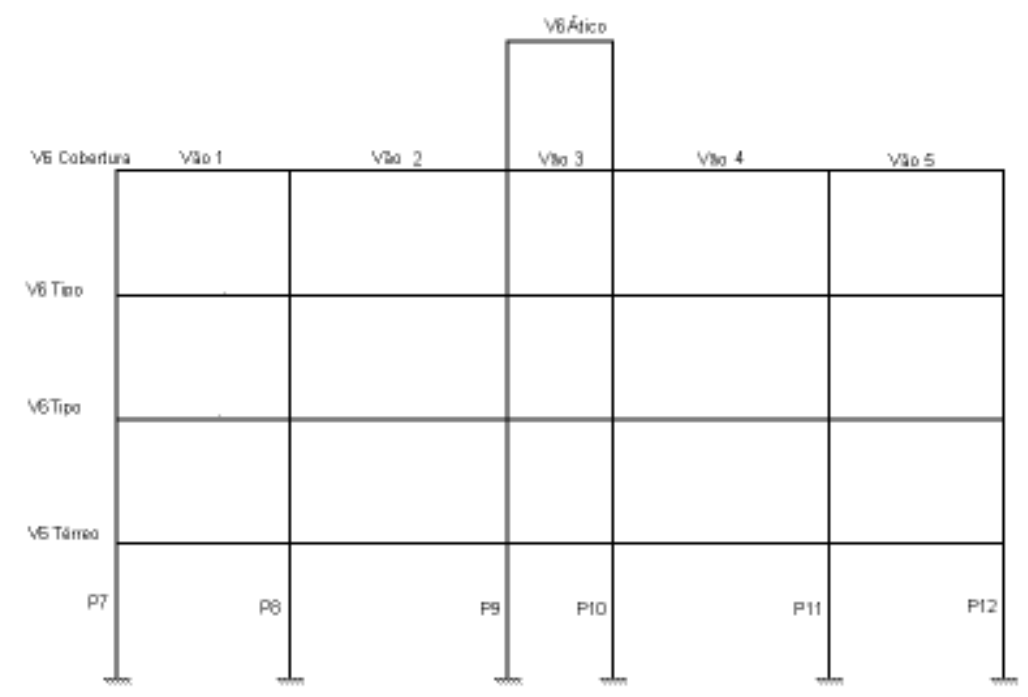

Figura 6.4 - Pórtico Viga V6

As cargas distribuídas aplicadas nas barras são referentes ao peso próprio dos elementos e às ações das lajes nas vigas. As forças concentradas referem -se æ̀ vigas perpendiculares ao plano da estrutura que se apóiam nos elementos mostrados no pórtico plano considerado. As ações consideradas no pórtico plano V6 podem ser vistas na figura 6.5 . 


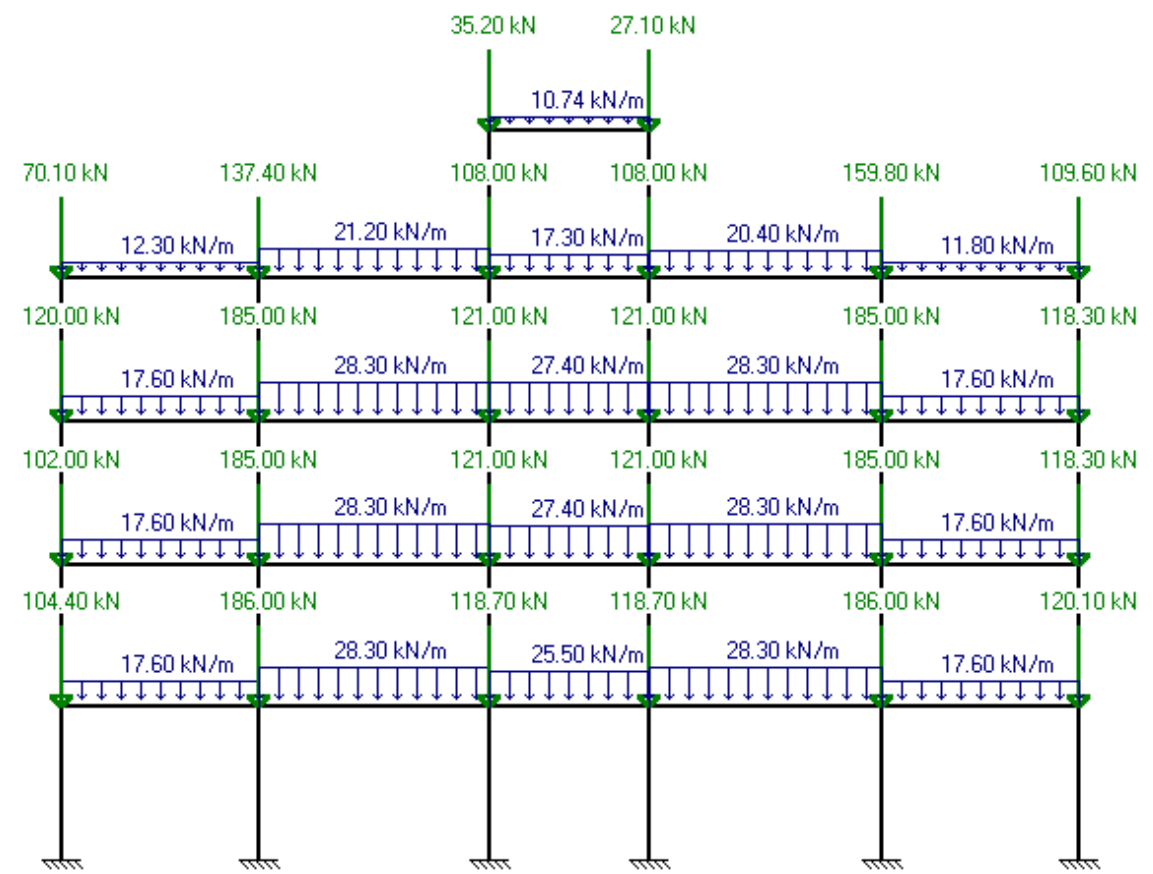

Figura 6.5 - Ações no Pórtico V6

O diagrama de momento fletor para a viga difere um pouco, pela própria diferença entre as análises de pórtico tridimensional considerada pelo TQS e bidimensional aplicada no programa DTool. As figuras a seguir mostram esta diferença entre os diagramas para a viga $\mathrm{V} 6$.

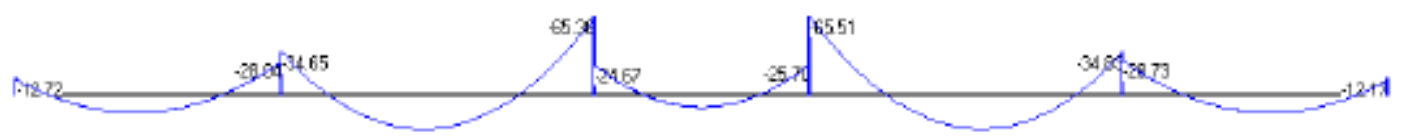

Figura 6.6 - Diagrama de momento fletor para a viga V6 em $\mathrm{kN}^{*} \mathrm{~m}$ no pavimento tipo utilizando DTool

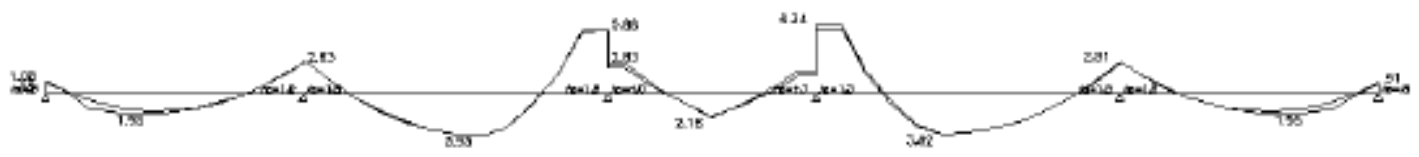

Figura 6.7 - Diagrama de momento fletor para a viga V6 em $\mathrm{ff}^{*} \mathrm{~m}$ no pavimento tipo pelo TQS 
Nas tabelas a seguir é feita uma comparação entre o dimensionamento realizado pelo programa TQS e o DTool.

Tabela 6.1 - Comparação entre o dimensionamento de TQS e DTool para a viga V6 no pavimento térreo

\begin{tabular}{|c|c|c|c|c|c|c|c|}
\hline V6 & P7 & Vão 1 & P8 & Vão 2 & P9 & Vão 3 & P10 \\
\hline Térreo & Armadura & Armadura & Armadura & Armadura & Armadura & Armadura & Armadura \\
\hline $10 / 60$ & $\begin{array}{c}\text { Negativa } \\
\text { Apoio }\end{array}$ & Positiva & $\begin{array}{c}\text { Negativa } \\
\text { Apoio }\end{array}$ & Positiva & $\begin{array}{l}\text { Negativa } \\
\text { Apoio }\end{array}$ & Positiva & $\begin{array}{c}\text { Negativa } \\
\text { Apoio }\end{array}$ \\
\hline$\overline{T Q S}$ & $2 \phi 8$ & $2 \phi 10$ & $3 \phi 10$ & $2 \phi 12,5$ & $2 \phi 16$ & $2 \phi 10$ & $2 \phi 16$ \\
\hline $\mathrm{M}_{\mathrm{k}}\left(\mathrm{kN}^{*} \mathrm{~m}\right)$ & 8,1 & 19,5 & 30,6 & 39,3 & 57,4 & 21,0 & 58,4 \\
\hline $\mathrm{A}_{\mathrm{s}}$ necessário $\left(\mathrm{cm}^{2}\right)$ & 0,80 & 1,20 & 2,00 & 2,40 & 3,80 & 1,20 & 3,90 \\
\hline $\mathrm{A}_{\mathrm{s}}$ Utilizado $\left(\mathrm{cm}^{2}\right)$ & 1,01 & 1,57 & 2,36 & 2,45 & 4,02 & 1,57 & 4,02 \\
\hline DTool & $2 \phi 12,5$ & $2 \phi 10$ & $2 \phi 12,5$ & $3 \phi 10$ & $4 \phi 12,5$ & $2 \phi 10$ & $4 \phi 12,5$ \\
\hline $\mathrm{M}_{\mathrm{k}}\left(\mathrm{kN}^{*} \mathrm{~m}\right)$ & 9,4 & 15,0 & 38,8 & 28,6 & 60,8 & 9,4 & 60,9 \\
\hline$A_{s}$ necessário $\left(\mathrm{cm}^{2}\right)$ & 0,50 & 0,90 & 2,40 & 1,80 & 4,10 & 0,50 & 4,10 \\
\hline $\mathrm{A}_{\mathrm{s}}$ Utilizado $\left(\mathrm{cm}^{2}\right)$ & 2,45 & 1,57 & 2,45 & 2,36 & 4,91 & 1,57 & 4,91 \\
\hline & $\begin{array}{c}\text { Vão } 4 \\
\text { Armadura } \\
\text { Positiva }\end{array}$ & $\begin{array}{c}\text { P11 } \\
\text { Armadura } \\
\text { Negativa } \\
\text { Apoio }\end{array}$ & $\begin{array}{c}\text { Vão } 5 \\
\text { Armadura } \\
\text { Positiva }\end{array}$ & $\begin{array}{c}\mathrm{P} 12 \\
\text { Armadura } \\
\text { Negativa } \\
\text { Apoio }\end{array}$ & & & \\
\hline TQS & $2 \phi 12,5$ & $3 \phi 10$ & $2 \phi 10$ & $2 \phi 8$ & & & \\
\hline $\mathrm{M}_{\mathrm{k}}\left(\mathrm{kN}^{*} \mathrm{~m}\right)$ & 39,1 & 30,9 & 19,5 & 7,8 & & & \\
\hline $\mathrm{A}_{\mathrm{s}}$ necessário $\left(\mathrm{cm}^{2}\right)$ & 2,40 & 2,00 & 1,20 & 0,80 & & & \\
\hline$A_{s}$ Utilizado $\left(\mathrm{cm}^{2}\right)$ & 2,45 & 2,36 & 1,57 & 1,01 & & & \\
\hline DTool & $3 \phi 10$ & $2 \phi 12,5$ & $2 \phi 10$ & $2 \phi 12,5$ & & & \\
\hline $\mathrm{M}_{\mathrm{k}}\left(\mathrm{kN}^{*} \mathrm{~m}\right)$ & 28,7 & 38,9 & 15,0 & 9,0 & & & \\
\hline$A_{s}$ necessário $\left(\mathrm{cm}^{2}\right)$ & 1,8 & 2,4 & 0,9 & 0,5 & & & \\
\hline $\mathrm{A}_{\mathrm{s}}$ Utilizado $\left(\mathrm{cm}^{2}\right)$ & 2,36 & 2,45 & 1,57 & 2,45 & & & \\
\hline
\end{tabular}

Tabela 6.2 - Comparação entre o dimensionamento de

TQS e DTool para a viga V6 no pavimento tipo

\begin{tabular}{|c|c|c|c|c|c|c|c|}
\hline & P7 & Vão 1 & P8 & Vão 2 & P9 & Vão 3 & P10 \\
\hline Tipo & Armadura & Armadura & Armadura & Armadura & Armadura & Armadura & Armadura \\
\hline $10 / 60$ & $\begin{array}{c}\text { Negativa } \\
\text { Apoio }\end{array}$ & Positiva & $\begin{array}{c}\text { Negativa } \\
\text { Apoio }\end{array}$ & Positiva & $\begin{array}{c}\text { Negativa } \\
\text { Apoio }\end{array}$ & Positiva & $\begin{array}{c}\text { Negativa } \\
\text { Apoio }\end{array}$ \\
\hline$\overline{T Q S}$ & $2 \phi 8$ & $2 \phi 10$ & $3 \phi 10$ & $2 \phi 12,5$ & $2 \phi 16$ & $2 \phi 10$ & $4 \phi 12,5$ \\
\hline $\mathrm{M}_{\mathrm{k}}\left(\mathrm{kN}^{*} \mathrm{~m}\right)$ & 10,8 & 19,5 & 28,3 & 39,3 & 58,8 & 21,8 & 63,4 \\
\hline $\mathrm{A}_{\mathrm{s}}$ necessário $\left(\mathrm{cm}^{2}\right)$ & 0,80 & 1,20 & 1,90 & 2,40 & 4,00 & 1,30 & 4,70 \\
\hline $\mathrm{A}_{\mathrm{s}}$ Utilizado $\left(\mathrm{cm}^{2}\right)$ & 1,01 & 1,57 & 2,36 & 2,45 & 4,02 & 1,57 & 4,91 \\
\hline DTool & $2 \phi 12,5$ & $2 \phi 10$ & $2 \phi 12,5$ & $3 \phi 10$ & $4 \phi 12,5$ & $2 \phi 10$ & $4 \phi 12,5$ \\
\hline $\mathrm{M}_{\mathrm{k}}\left(\mathrm{kN}^{*} \mathrm{~m}\right)$ & 12,7 & 15,0 & 34,7 & 28,5 & 65,4 & 10,5 & 65,5 \\
\hline $\mathrm{A}_{\mathrm{s}}$ necessário $\left(\mathrm{cm}^{2}\right)$ & 0,70 & 0,90 & 2,10 & 1,80 & 4,50 & 0,60 & 4,50 \\
\hline$A_{s}$ Utilizado $\left(\mathrm{cm}^{2}\right)$ & 2,45 & 1,57 & 2,45 & 2,36 & 4,91 & 1,57 & 4,91 \\
\hline & $\begin{array}{c}\text { Vão } 4 \\
\text { Armadura } \\
\text { Positiva }\end{array}$ & $\begin{array}{c}\text { P11 } \\
\text { Armadura } \\
\text { Negativa } \\
\text { Apoio }\end{array}$ & $\begin{array}{c}\text { Vão } 5 \\
\text { Armadura } \\
\text { Positiva }\end{array}$ & $\begin{array}{c}\text { P12 } \\
\text { Armadura } \\
\text { Negativa } \\
\text { Apoio }\end{array}$ & & & \\
\hline TQS & $3 \phi 10$ & $3 \phi 10$ & $2 \phi 10$ & $2 \phi 8$ & & & \\
\hline $\mathrm{M}_{\mathrm{k}}\left(\mathrm{kN}^{\star} \mathrm{m}\right)$ & 38,2 & 29,1 & 19,5 & 9,1 & & & \\
\hline$A_{s}$ necessário $\left(\mathrm{cm}^{2}\right)$ & 2,40 & 1,90 & 1,20 & 0,80 & & & \\
\hline$A_{s}$ Utilizado $\left(\mathrm{cm}^{2}\right)$ & 2,36 & 2,36 & 1,57 & 1,01 & & & \\
\hline DTool & $3 \phi 10$ & $2 \phi 12,5$ & $2 \phi 10$ & $2 \phi 12,5$ & & & \\
\hline $\mathrm{M}_{\mathrm{k}}\left(\mathrm{kN}^{*} \mathrm{~m}\right)$ & 28,4 & 34,8 & 15,0 & 12,2 & & & \\
\hline $\mathrm{A}_{\mathrm{s}}$ necessário $\left(\mathrm{cm}^{2}\right)$ & 1,80 & 2,10 & 0,90 & 0,70 & & & \\
\hline$A_{s}$ Utilizado $\left(\mathrm{cm}^{2}\right)$ & 2,36 & 2,45 & 1,57 & 2,45 & & & \\
\hline
\end{tabular}


Tabela 6.3 - Comparação entre o dimensionamento de TQS e DTool para a viga V6 na cobertura

\begin{tabular}{|c|c|c|c|c|c|c|c|}
\hline & P7 & Vão 1 & P8 & Vão 2 & P9 & Vão 3 & P10 \\
\hline Cobertura & Armadura & Armadura & Armadura & Armadura & Armadura & Armadura & Armadura \\
\hline & $\begin{array}{c}\text { Negativa } \\
\text { Apoio }\end{array}$ & Positiva & $\begin{array}{c}\text { Negativa } \\
\text { Apoio }\end{array}$ & Positiva & $\begin{array}{c}\text { Negativa } \\
\text { Apoio }\end{array}$ & Positiva & $\begin{array}{c}\text { Negativa } \\
\text { Apoio }\end{array}$ \\
\hline TQS & $2 \phi 8$ & $2 \phi 8$ & $2 \phi 10$ & $3 \phi 10$ & $4 \phi 10$ & $2 \phi 8$ & $4 \phi 10$ \\
\hline $\mathrm{M}_{\mathrm{k}}\left(\mathrm{kN} \mathrm{N}^{*} \mathrm{~m}\right)$ & 6,2 & 13,6 & 19,7 & 29,0 & 40,3 & 13,5 & 45,5 \\
\hline$A_{s}$ necessário $\left(\mathrm{cm}^{2}\right)$ & 0,80 & 0,80 & 1,20 & 1,80 & 2,70 & 0,80 & 3,10 \\
\hline$A_{s}$ Utilizado $\left(\mathrm{cm}^{2}\right)$ & 1,01 & 1,01 & 1,57 & 2,36 & 3,14 & 1,01 & 3,14 \\
\hline DTool & $2 \phi 10$ & $2 \phi 8$ & $2 \phi 10$ & $3 \phi 8$ & $5 \phi 10$ & $2 \phi 8$ & $5 \phi 10$ \\
\hline $\mathrm{M}_{\mathrm{k}}\left(\mathrm{kN}^{*} \mathrm{~m}\right)$ & 7,4 & 12,4 & 20,2 & 23,4 & 52,5 & 4,3 & 51,7 \\
\hline$A_{s}$ necessário $\left(\mathrm{cm}^{2}\right)$ & 0,40 & 0,80 & 1,20 & 1,50 & 3,60 & 0,20 & 3,50 \\
\hline $\mathrm{A}_{\mathrm{s}}$ Utilizado $\left(\mathrm{cm}^{2}\right)$ & 1,57 & 1,01 & 1,57 & 1,51 & 3,93 & 1,01 & 3,93 \\
\hline & $\begin{array}{c}\text { Vão } 4 \\
\text { Armadura } \\
\text { Positiva }\end{array}$ & $\begin{array}{c}\text { P11 } \\
\text { Armadura } \\
\text { Negativa } \\
\text { Apoio }\end{array}$ & $\begin{array}{c}\text { Vão } 5 \\
\text { Armadura } \\
\text { Positiva }\end{array}$ & $\begin{array}{c}\text { P12 } \\
\text { Armadura } \\
\text { Negativa } \\
\text { Apoio } \\
\end{array}$ & & & \\
\hline TQS & $2 \phi 10$ & $2 \phi 10$ & $2 \phi 8$ & $2 \phi 8$ & & & \\
\hline$M_{k}\left(k N^{*} m\right)$ & 25,5 & 19,8 & 13,1 & 4,6 & & & \\
\hline$A_{s}$ necessário $\left(\mathrm{cm}^{2}\right)$ & 1,50 & 1,20 & 0,80 & 0,80 & & & \\
\hline$A_{s}$ Utilizado $\left(\mathrm{cm}^{2}\right)$ & 1,57 & 1,57 & 1,01 & 1,01 & & & \\
\hline$\overline{\text { DTool }}$ & $3 \phi 8$ & $2 \phi 10$ & $2 \phi 8$ & $2 \phi 10$ & & & \\
\hline $\mathrm{M}_{\mathrm{k}}\left(\mathrm{kN}^{*} \mathrm{~m}\right)$ & 22,2 & 18,9 & 12,0 & 6,8 & & & \\
\hline$A_{s}$ necessário $\left(\mathrm{cm}^{2}\right)$ & 1,40 & 1,10 & 0,70 & 0,40 & & & \\
\hline$A_{s}$ Utilizado $\left(\mathrm{cm}^{2}\right)$ & 1,51 & 1,57 & 1,01 & 1,57 & & & \\
\hline
\end{tabular}

Tabela 6.4 - Comparação entre o dimensionamento de TQS e DTool para a viga V6 no ático

\begin{tabular}{lccc}
$\begin{array}{c}\text { V6 } \\
\text { Ático } \\
14 / 50\end{array}$ & $\begin{array}{c}\text { P7 } \\
\text { Armadura } \\
\text { Negativa } \\
\text { Apoio }\end{array}$ & $\begin{array}{c}\text { Vão 1 } \\
\text { Prmadura }\end{array}$ & $\begin{array}{c}\text { Po } \\
\text { Armadiva } \\
\text { Negativa } \\
\text { Apoio }\end{array}$ \\
\hline TQS & $2 \phi 8$ & $3 \phi 8$ & $2 \phi 8$ \\
$\mathrm{M}_{\mathrm{k}}\left(\mathrm{kN}^{*} \mathrm{~m}\right)$ & 11,2 & 16,2 & $-13,7$ \\
$\mathrm{~A}_{\mathrm{s}}$ necessário $\left(\mathrm{cm}^{2}\right)$ & 1,00 & 1,20 & 0,20 \\
$\mathrm{~A}_{\mathrm{s}}$ Utilizado $\left(\mathrm{cm}^{2}\right)$ & 1,01 & 1,51 & 1,01 \\
\hline DTool & $2 \phi 8$ & $2 \phi 8$ & $2 \phi 8$ \\
$\mathrm{M}_{\mathrm{k}}\left(\mathrm{kN}{ }^{*} \mathrm{~m}\right)$ & 1,0 & 13,0 & 1,1 \\
$\mathrm{~A}_{\mathrm{s}}$ necessário $\left(\mathrm{cm}^{2}\right)$ & 0,10 & 0,90 & 0,10 \\
$\mathrm{~A}_{\mathrm{s}}$ Utilizado $\left(\mathrm{cm}^{2}\right)$ & 1,01 & 1,01 & 1,01 \\
\hline
\end{tabular}

\subsubsection{Viga V19}

A viga V19 é perpendicular à $V 6$ no plano das lajes, tendo em comum com V6 o apoio central no pilar P11. Suas ações e características podem ser verificadas na figura 6.8 .

A figura a seguir mostra o pórtico plano que contém a viga $\mathrm{V} 19$ nos diversos pavimentos do edifício com as cargas atuantes em cada elemento. 


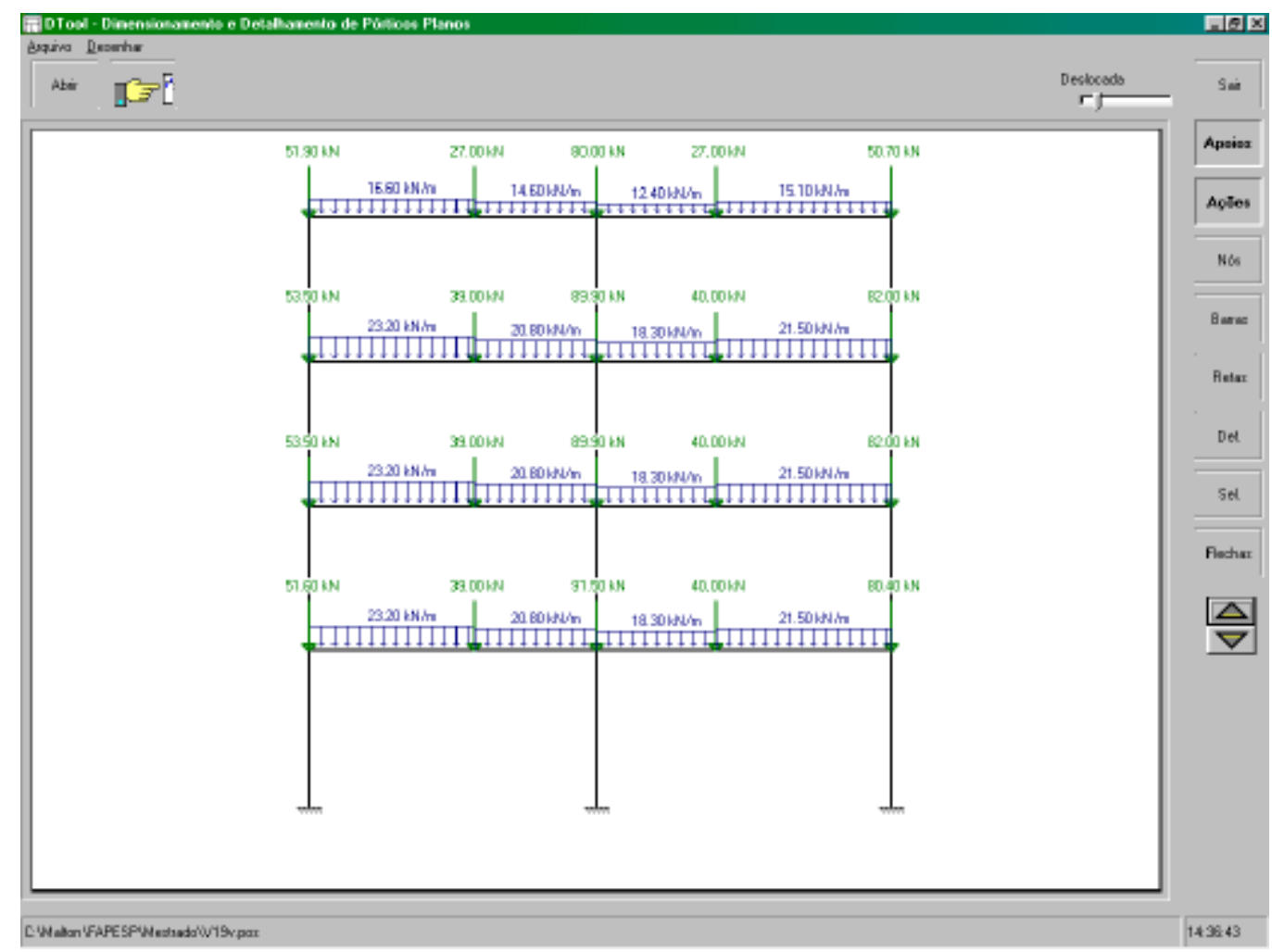

Figura 6.8 - Modelagem do pórtico para a viga V19.

As tabelas a seguir fazem a comparação do dimensionamento realizado pelo TQS e por DTool.

Tabela 6.5 - Comparação entre o dimensionamento de TQS e DTool para a viga $\mathrm{V} 19$ no pavimento térreo

\begin{tabular}{|c|c|c|c|c|c|}
\hline V19 & P17 & Vão 1 & P11 & Vão 2 & P3 \\
\hline Térrec & Armadura & Armadura & Armadura & Armadura & Armadura \\
\hline $14 / 60$ & $\begin{array}{c}\text { Negativa } \\
\text { Apoio }\end{array}$ & Positiva & $\begin{array}{c}\text { Negativa } \\
\text { Apoio }\end{array}$ & Positiva & $\begin{array}{c}\text { Negativa } \\
\text { Apoio }\end{array}$ \\
\hline TQS & $3 \phi 10$ & $4 \phi 12,5$ & $2 \phi 20$ & $4 \phi 12,5$ & $3 \phi 12,5$ \\
\hline $\mathrm{M}_{\mathrm{k}}\left(\mathrm{kN} \mathrm{N}^{*} \mathrm{~m}\right)$ & 27,9 & 76,5 & 93,3 & 69,8 & 55,2 \\
\hline $\mathrm{A}_{\mathrm{s}}$ necessário $\left(\mathrm{cm}^{2}\right)$ & 1,70 & 4,90 & 6,20 & 4,40 & 3,40 \\
\hline$A_{s}$ Utilizado $\left(\mathrm{cm}^{2}\right)$ & 2,36 & 4,91 & 6,28 & 4,91 & 3,68 \\
\hline DTool & $5 \phi 12,5$ & $3 \phi 12,5$ & $6 \phi 12,5$ & $3 \phi 12,5$ & $5 \phi 12,5$ \\
\hline $\mathrm{M}_{\mathrm{k}}\left(\mathrm{kN} \mathrm{N}^{*} \mathrm{~m}\right)$ & 78,3 & 56,7 & 94,8 & 53,1 & 82,2 \\
\hline $\mathrm{A}_{\mathrm{s}}$ necessário $\left(\mathrm{cm}^{2}\right)$ & 5,20 & 3,50 & 6,60 & 3,30 & 5,50 \\
\hline$A_{s}$ Utilizado $\left(\mathrm{cm}^{2}\right)$ & 6,14 & 4,91 & 7,36 & 3,68 & 6,14 \\
\hline
\end{tabular}


Tabela 6.6 - Comparação entre o dimensionamento de TQS e DTool para a viga $\mathrm{V} 19$ no pavimento tipo

\begin{tabular}{|c|c|c|c|c|c|}
\hline V19 & P17 & Vão 1 & P11 & Vão 2 & P3 \\
\hline Tipo & Armadura & Armadura & Armadura & Armadura & Armadura \\
\hline $14 / 60$ & $\begin{array}{c}\text { Negativa } \\
\text { Apoio }\end{array}$ & Positiva & $\begin{array}{c}\text { Negativa } \\
\text { Apoio }\end{array}$ & Positiva & $\begin{array}{c}\text { Negativa } \\
\text { Apoio }\end{array}$ \\
\hline TQS & $3 \phi 10$ & $3 \phi 16$ & $2 \phi 20$ & $4 \phi 12,5$ & $3 \phi 12,5$ \\
\hline$M_{k}\left(k N^{*} m\right)$ & 39,2 & 78,5 & 94,0 & 69,8 & 58,8 \\
\hline $\mathrm{A}_{\mathrm{s}}$ necessário $\left(\mathrm{cm}^{2}\right)$ & 2,40 & 5,10 & 6,30 & 4,40 & 3,70 \\
\hline$A_{s}$ Utilizado $\left(\mathrm{cm}^{2}\right)$ & 2,36 & 6,03 & 6,28 & 4,91 & 3,68 \\
\hline$\overline{\text { DTool }}$ & $3 \phi 16$ & $3 \phi 12,5$ & $4 \phi 16$ & $3 \phi 12,5$ & $3 \phi 16$ \\
\hline $\mathrm{M}_{\mathrm{k}}\left(\mathrm{kN}^{*} \mathrm{~m}\right)$ & 91,0 & 56,5 & 93,1 & 53,1 & 82,1 \\
\hline $\mathrm{A}_{\mathrm{s}}$ necessário $\left(\mathrm{cm}^{2}\right)$ & 5,30 & 3,50 & 6,20 & 3,30 & 5,40 \\
\hline$A_{s}$ Utilizado $\left(\mathrm{cm}^{2}\right)$ & 6,03 & 3,68 & 8,04 & 3,68 & 6,03 \\
\hline
\end{tabular}

Tabela 6.7 - Comparação entre o dimensionamento de TQS e DTool para a viga $\mathrm{V} 19$ na cobertura

\begin{tabular}{|c|c|c|c|c|c|}
\hline V19 & P17 & Vão 1 & P11 & Vão 2 & P3 \\
\hline Cobertura & Armadura & Armadura & Armadura & Armadura & Armadura \\
\hline $14 / 60$ & $\begin{array}{c}\text { Negativa } \\
\text { Apoio }\end{array}$ & Positiva & $\begin{array}{c}\text { Negativa } \\
\text { Apoio }\end{array}$ & Positiva & $\begin{array}{c}\text { Negativa } \\
\text { Apoio }\end{array}$ \\
\hline TQS & $2 \phi 10$ & $3 \phi 12,5$ & $2 \phi 16$ & $4 \phi 10$ & $3 \phi 10$ \\
\hline$M_{k}\left(k^{*} m\right)$ & 16,0 & 56,1 & 64,2 & 48,4 & 34,3 \\
\hline $\mathrm{A}_{\mathrm{s}}$ necessário $\left(\mathrm{cm}^{2}\right)$ & 1,20 & 3,50 & 4,00 & 3,00 & 2,10 \\
\hline $\mathrm{A}_{\mathrm{s}}$ Utilizado $\left(\mathrm{cm}^{2}\right)$ & 1,57 & 3,68 & 4,02 & 3,14 & 2,36 \\
\hline DTool & $2 \phi 12,5$ & $3 \phi 12,5$ & $4 \phi 12,5$ & $2 \phi 12,5$ & $2 \phi 12,5$ \\
\hline $\mathrm{M}_{\mathrm{k}}\left(\mathrm{kN}^{*} \mathrm{~m}\right)$ & 24,6 & 54,7 & 74,9 & 37,8 & 37,8 \\
\hline $\mathrm{A}_{\mathrm{s}}$ necessário $\left(\mathrm{cm}^{2}\right)$ & 1,40 & 3,40 & 4,90 & 2,30 & 2,30 \\
\hline $\mathrm{A}_{\mathrm{s}}$ Utilizado $\left(\mathrm{cm}^{2}\right)$ & 2,45 & 3,68 & 4,91 & 2,45 & 2,45 \\
\hline
\end{tabular}

\subsubsection{Viga V20}

$A$ viga $\mathrm{V} 20$ é paralela à $\mathrm{V} 19$, e perpendicular à $\mathrm{V} 6$, tendo em comum com esta última o pilar P12.

Nas figuras a seguir pode ser feita uma comparação entre os diagramas de momento fletores utilizados em TQS e DTool para dimensionamento da armadura longitudinal.

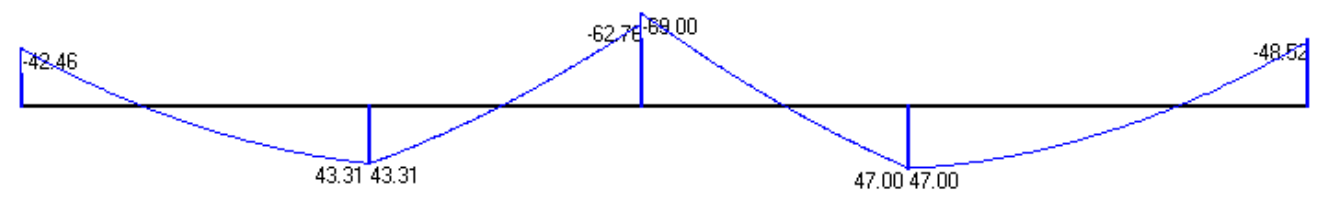

Figura 6.9 - Diagrama de momento fletor para a viga V20

em $\mathrm{kN}^{*} \mathrm{~m}$ dado por DTool no pavimento tipo. 


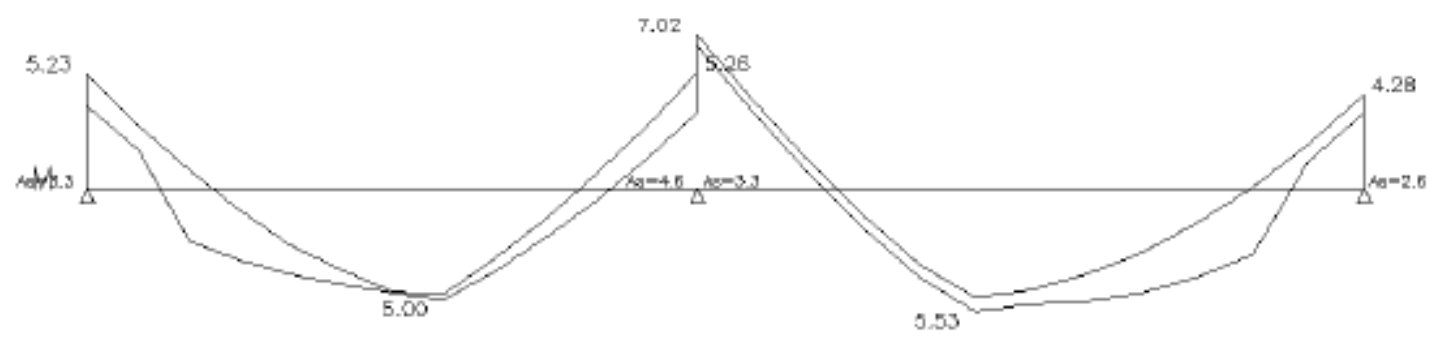

Figura 6.10 - Diagrama de momento fletor para a viga V20 em $\mathrm{ff}^{\star} \mathrm{m}$ dado por TQS no pavimento tipo.

As tabelas 6.8 a 6.10 fazem a comparação entre o dimensionamento realizado pelos dois programas.

Tabela 6.8 - Comparação entre o dimensionamento de TQS e DTool para a viga V20 no pavimento térreo

\begin{tabular}{lcccccc}
\multicolumn{1}{c}{ Térreo } & \multicolumn{2}{c}{$\begin{array}{c}\text { Armadura Armadura } \\
14 / 60\end{array}$} & $\begin{array}{c}\text { Armadura } \\
\text { Negativa } \\
\text { Apoio }\end{array}$ & Positiva & $\begin{array}{c}\text { Armadura } \\
\text { Negativa } \\
\text { Positiva }\end{array}$ & $\begin{array}{c}\text { Armadura } \\
\text { Apogativa }\end{array}$ \\
\hline TQS & $3 \phi 10$ & $4 \phi 10$ & $4 \phi 12,5$ & $3 \phi 12,5$ & $3 \phi 10$ \\
$\mathrm{M}_{\mathrm{k}}\left(\mathrm{kN}^{*} \mathrm{~m}\right)$ & 33,7 & 46,7 & 66,7 & 54,8 & 33,7 \\
$\mathrm{~A}_{\mathrm{s}}$ necessário $\left(\mathrm{cm}^{2}\right)$ & 2,00 & 2,90 & 4,30 & 3,40 & 2,00 \\
$\mathrm{~A}_{\mathrm{s}}$ Utilizado $\left(\mathrm{cm}^{2}\right)$ & 2,36 & 3,14 & 4,91 & 3,68 & 2,36 \\
\hline DTool & $2 \phi 12,5$ & $3 \phi 12,5$ & $4 \phi 12,5$ & $3 \phi 12,5$ & $3 \phi 12,5$ \\
$\mathrm{M}_{\mathrm{k}}\left(\mathrm{kN} \mathrm{N}^{*} \mathrm{~m}\right)$ & 37,5 & 43,3 & 72,5 & 47,0 & 43,3 \\
$\mathrm{~A}_{\mathrm{s}}$ necessário $\left(\mathrm{cm}^{2}\right)$ & 2,30 & 2,60 & 4,70 & 2,90 & 2,60 \\
$\mathrm{~A}_{\mathrm{s}}$ Utilizado $\left(\mathrm{cm}^{2}\right)$ & 2,45 & 3,68 & 4,91 & 3,68 & 3,68 \\
\hline
\end{tabular}

Tabela 6.9 - Comparação entre o dimensionamento de TQS e DTool para a viga V20 no pavimento tipo

\begin{tabular}{|c|c|c|c|c|c|}
\hline V20 & P18 & Vão 1 & P12 & Vão 2 & P4 \\
\hline Tipo & Armadura & Armadura & Armadura & Armadura & Armadura \\
\hline $14 / 60$ & Negativa & Positiva & Negativa & Positiva & Negativa \\
\hline & Apoio & & Apoio & & Apoio \\
\hline TQS & $3 \phi 12,5$ & $4 \phi 10$ & $4 \phi 12,5$ & $3 \phi 12,5$ & $4 \phi 10$ \\
\hline $\mathrm{M}_{\mathrm{k}}\left(\mathrm{kN}^{*} \mathrm{~m}\right)$ & 52,3 & 50,0 & 70,2 & 55,3 & 42,8 \\
\hline $\mathrm{A}_{\mathrm{s}}$ necessário $\left(\mathrm{cm}^{2}\right)$ & 3,30 & 3,10 & 4,60 & 3,40 & 2,80 \\
\hline $\mathrm{A}_{\mathrm{s}}$ Utilizado $\left(\mathrm{cm}^{2}\right)$ & 3,68 & 3,14 & 4,91 & 3,68 & 3,14 \\
\hline DTool & $3 \phi 12,5$ & $3 \phi 12,5$ & $4 \phi 12,5$ & $3 \phi 12,5$ & $3 \phi 12,5$ \\
\hline $\mathrm{M}_{\mathrm{k}}\left(\mathrm{kN}^{*} \mathrm{~m}\right)$ & 42,5 & 43,3 & 69,0 & 47,0 & 48,5 \\
\hline $\mathrm{A}_{\mathrm{s}}$ necessário $\left(\mathrm{cm}^{2}\right)$ & 2,60 & 2,60 & 4,50 & 2,90 & 3,00 \\
\hline$A_{s}$ Utilizado $\left(\mathrm{cm}^{2}\right)$ & 3,68 & 3,68 & 4,91 & 3,68 & 3,68 \\
\hline
\end{tabular}




\begin{tabular}{|c|c|c|c|c|c|}
\hline \multicolumn{6}{|c|}{ para a viga V20 na cobertura } \\
\hline V20 & P18 & Vão 1 & P12 & Vão 2 & P4 \\
\hline $\begin{array}{c}\text { Cobertura } \\
14 / 60\end{array}$ & $\begin{array}{c}\text { Armadura } \\
\text { Negativa } \\
\text { Apoio }\end{array}$ & $\begin{array}{c}\text { Armadura } \\
\text { Positiva }\end{array}$ & $\begin{array}{c}\text { Armadura } \\
\text { Negativa } \\
\text { Apoio }\end{array}$ & $\begin{array}{c}\text { Armadura } \\
\text { Positiva }\end{array}$ & $\begin{array}{c}\text { Armadura } \\
\text { Negativa } \\
\text { Apoio }\end{array}$ \\
\hline TQS & $2 \phi 10$ & $3 \phi 10$ & $4 \phi 10$ & $3 \phi 10$ & $2 \phi 10$ \\
\hline $\mathrm{M}_{\mathrm{k}}\left(\mathrm{kN}^{*} \mathrm{~m}\right)$ & 20,1 & 30,7 & 43,1 & 36,7 & 17,5 \\
\hline $\mathrm{A}_{\mathrm{s}}$ necessário $\left(\mathrm{cm}^{2}\right)$ & 1,20 & 1,80 & 2,70 & 2,20 & 1,20 \\
\hline$A_{s}$ Utilizado $\left(\mathrm{cm}^{2}\right)$ & 1,57 & 2,36 & 3,14 & 2,36 & 1,57 \\
\hline DTool & $2 \phi 10$ & $3 \phi 10$ & $4 \phi 10$ & $3 \phi 10$ & $3 \phi 10$ \\
\hline$M_{k}\left(k^{*} m\right)$ & 24,9 & 31,0 & 41,1 & 34,0 & 28,6 \\
\hline $\mathrm{A}_{\mathrm{s}}$ necessário $\left(\mathrm{cm}^{2}\right)$ & 1,50 & 1,80 & 2,50 & 2,00 & 1,70 \\
\hline$A_{s}$ Utilizado $\left(\mathrm{cm}^{2}\right)$ & 1,57 & 2,36 & 3,14 & 2,36 & 2,36 \\
\hline
\end{tabular}

\subsubsection{Discussão dos Resultados}

A variação nas áreas das armaduras dimensionadas por TQS e DTool se deve a dois fatores:

1) Diferença entre os diagramas de momento fletores, mostrados nas figuras $6.6,6.7,6.9$ e 6.10 .

2) Diferença na escolha do diâmetro das barras de aço a serem utilizadas.

As diferenças entre os diagramas de momento fletores existem como conseqüência das diferentes modelagens utilizadas. Em DTool, são considerados pórticos planos, em TQS os pórticos são tridimensionais.

Na modelagem tridimensional os esforços são distribuídos ao longo de toda a estrutura, sendo mais intensos nos elementos de maior rigidez, que podem resistir a maiores ações. No modelo de pórticos planos, tais esforços também são maiores nos elementos de maior rigidez, porém tal comparação entre rigidezes só pode ser feita no plano que contém os elementos da estrutura bidimensional.

A diferença entre os diâmetros das barras escolhidos para o projeto é conseqüência da utilização, em DTool, de somente um diâmetro para as barras de armadura positiva, e somente um para as negativas, podendo o primeiro diferir do segundo. Portanto, sendo escolhido um $\phi$ para a armadura positiva ou negativa, todo o detalhamento será feito em relação àquele diâmetro, variando -se somente o número de barras necessário para o dimensionamento. 
Em geral, a utilização do pórtico plano em relação ao pórtico tridimensional levou a momentos fletores negativos maiores e, conseqüentemente, a momentos fletores positivos menores. Os pilares absorveram mais os esforços de momento fletor no modelo de DTool do que no de TQS. Porém, quando estes esforços foram semelhantes, como no apoio do pilar P10, na viga V6, e em grande parte dos pontos nas vigas localizadas na cobertura, houve uma grande proximidade entre os valores dimensionados pelos dois programas, levando a crer que para esforços iguais o dimensionamento seria semelhante.

Para comprovar tal hipótese, foi modelada a viga V20 de modo a obterem-se exatamente os mesmos esforços encontrados em TQS no pavimento tipo, mostrados na figura 6.10, os resultados estão na tabela 6.11 .

\begin{tabular}{|c|c|c|c|c|c|}
\hline V20 & P18 & Vão 1 & P12 & Vão 2 & P4 \\
\hline $\begin{array}{c}\text { Tipo } \\
14 / 60\end{array}$ & $\begin{array}{c}\text { Armadura } \\
\text { Negativa } \\
\text { Apoio }\end{array}$ & $\begin{array}{c}\text { Armadura } \\
\text { Positiva }\end{array}$ & $\begin{array}{c}\text { Armadura } \\
\text { Negativa } \\
\text { Apoio }\end{array}$ & $\begin{array}{c}\text { Armadura } \\
\text { Positiva }\end{array}$ & $\begin{array}{c}\text { Armadura } \\
\text { Negativa } \\
\text { Apoio }\end{array}$ \\
\hline$\overline{T Q S}$ & $3 \phi 12,5$ & $4 \phi 10$ & $4 \phi 12,5$ & $3 \phi 12,5$ & $4 \phi 10$ \\
\hline$M_{k}\left(k N^{*} m\right)$ & 52,3 & 50,0 & 70,2 & 55,3 & 42,8 \\
\hline $\mathrm{A}_{\mathrm{s}}$ necessário $\left(\mathrm{cm}^{2}\right)$ & 3,30 & 3,10 & 4,60 & 3,40 & 2,80 \\
\hline$A_{s}$ Utilizado $\left(\mathrm{cm}^{2}\right)$ & 3,68 & 3,14 & 4,91 & 3,68 & 3,14 \\
\hline DTool & $3 \phi 12,5$ & $5 \phi 10$ & $4 \phi 12,5$ & $5 \phi 10$ & $3 \phi 12,5$ \\
\hline $\mathrm{M}_{\mathrm{k}}\left(\mathrm{kN}^{*} \mathrm{~m}\right)$ & 52,3 & 50,0 & 70,2 & 55,4 & 42,8 \\
\hline $\mathrm{A}_{\mathrm{s}}$ necessário $\left(\mathrm{cm}^{2}\right)$ & 3,30 & 3,20 & 4,60 & 3,60 & 2,60 \\
\hline$A_{s}$ Utilizado $\left(\mathrm{cm}^{2}\right)$ & 3,68 & 3,93 & 4,91 & 3,93 & 3,68 \\
\hline
\end{tabular}

$\mathrm{Na}$ tabela acima, as diferenças que houve são decorrentes da consideração, tanto em DTool quanto em TQS, da altura útil da viga como sendo sempre a distância entre a fibra mais comprimida e o centro de gravidade da armadura tracionada da peça. Sendo este valor, d, calculado sempre de acordo com o número de barras em cada camada utilizada na armadura tracionada, o diferente ponto do centro de gravidade levou a uma diferente área de aço necessária para a seção.

Nos casos em que o número de barras utilizadas para satisfazer a área de aço necessária diferiu em DTool em relação ao utilizado em TQS (valores em negrito na tabela 6.11), a diferente altura útil da seção levou a uma área de aço necessária diferente para as seções mostradas. 
Utilizando para armadura positiva um diâmetro de aço que possa ser colocado em uma só camada de aço, ou em número de camadas semelhante no detalhamento da seção, o dimensionamento se aproxima mais do realizado em TQS, conforme a tabela a seguir.

Tabela 6.12 - Comparação entre o dimensionamento de TQS e DTool para a viga V20 no pavimento tipo com esforços e altura útil semelhantes

\begin{tabular}{|c|c|c|c|c|c|}
\hline V20 & P18 & Vão 1 & P12 & Vão 2 & P4 \\
\hline Tipo & Armadura & Armadura & Armadura & Armadura & Armadura \\
\hline $14 / 60$ & $\begin{array}{l}\text { Negativa } \\
\text { Apoio }\end{array}$ & Positiva & $\begin{array}{c}\text { Negativa } \\
\text { Apoio }\end{array}$ & Positiva & $\begin{array}{c}\text { Negativa } \\
\text { Apoio }\end{array}$ \\
\hline TQS & $3 \phi 12,5$ & $4 \phi 10$ & $4 \phi 12,5$ & $3 \phi 12,5$ & $4 \phi 10$ \\
\hline $\mathrm{M}_{\mathrm{k}}\left(\mathrm{kN}^{*} \mathrm{~m}\right)$ & 52,3 & 50,0 & 70,2 & 55,3 & 42,8 \\
\hline $\mathrm{A}_{\mathrm{s}}$ necessário $\left(\mathrm{cm}^{2}\right)$ & 3,30 & 3,10 & 4,60 & 3,40 & 2,80 \\
\hline$A_{s}$ Utilizado $\left(\mathrm{cm}^{2}\right)$ & 3,68 & 3,14 & 4,91 & 3,68 & 3,14 \\
\hline DTool & $3 \phi 12,5$ & $3 \phi 12,5$ & $4 \phi 12,5$ & $3 \phi 12,5$ & $3 \phi 12,5$ \\
\hline $\mathrm{M}_{\mathrm{k}}\left(\mathrm{kN}^{*} \mathrm{~m}\right)$ & 52,3 & 50,0 & 70,2 & 55,4 & 42,8 \\
\hline $\mathrm{A}_{\mathrm{s}}$ necessário $\left(\mathrm{cm}^{2}\right)$ & 3,30 & 3,10 & 4,60 & 3,50 & 2,60 \\
\hline $\mathrm{A}_{\mathrm{s}}$ Utilizado $\left(\mathrm{cm}^{2}\right)$ & 3,68 & 3,68 & 4,91 & 3,68 & 3,68 \\
\hline
\end{tabular}

A tabela acima comprova que, quando os esforços considerados no programa DTool são semelhantes, o dimensionamento da estrutura também é igual, ou muito próximo, ao realizado pelo programa TQS. Sendo que a única diferença, no vão 2 , armadura positiva, foi de menos que $3 \%$ entre os dois valores.

\subsection{Força Cortante}

O dimensionamento em DTool segue as recomendações do texto conclusivo da NBR 6118:2001, conforme os itens 4.3.8.4 e 4.3.8.5, não podendo ser comparados os valores com o projeto ainda utilizando os critérios da NBR6118:1978. Porém, a tabela a seguir pode mostrar as diferentes áreas necessárias para projeto de armadura transversal.

Tabela 6.13 - Visualização das diferenças entre o dimensionamento de TQS e DTool para a armadura transversal da viga $\mathrm{V} 6$ no pavimento térreo

\begin{tabular}{|c|c|c|c|c|c|}
\hline V6 & & DTool & Área de aço $\left(\mathrm{cm}^{2} / \mathrm{cm}\right)$ & TQS & Área de aço $\left(\mathrm{cm}^{2} / \mathrm{cm}\right)$ \\
\hline Térreo & Уãก 1 & $13+63 \mathrm{c} / 30$ & 104 & $15 \phi 4,2 c / 17,5$ & 0,79 \\
\hline $10 / 60$ & VaO I & $13 \phi 6,3 \mathrm{c} / 30$ & 1,04 & $9 \phi 4,2 \mathrm{c} / 15$ & 0,92 \\
\hline & & & & $9 \phi 6,3 \mathrm{c} / 30$ & 1,04 \\
\hline & Vão 2 & 15 ф 6,3 c/ 20 & 1,04 & $3 \phi 6,3 c / 22,5$ & 1,39 \\
\hline & & & & $6 \phi 6.3 \mathrm{c} / 15$ & 2,08 \\
\hline & Vão 3 & $10 \phi 6.3 \mathrm{c} / 20$ & 104 & $6 \phi 5 \mathrm{c} / 15$ & 1,31 \\
\hline & & & & $9 \phi 5 \mathrm{c} / 17.5$ & 1,12 \\
\hline & & & & $6 \phi 6,3 \mathrm{c} / 15$ & 2,08 \\
\hline & Vão 4 & 15 ф 6,3 c/ 20 & 1,04 & $3 \mathrm{f} 6,3 \mathrm{c} / 22,5$ & 1,39 \\
\hline & & & & $9 \phi 6,3 \mathrm{c} / 30$ & 1,04 \\
\hline & Vãก 5 & 13 क 30120 & 104 & $9 \phi 4,2 c / 15$ & 0,92 \\
\hline & & $13 \phi 0,3 \mathrm{C} / 20$ & & $15 \phi 4,2 c / 17,5$ & 0,79 \\
\hline
\end{tabular}


As diferenças encontradas se devem æ̀s versões da norma brasileira que adotam critérios diferentes para cálculo da área de aço para armadura transversal.

\subsection{Pilares}

Os pilares dimensionados são os que se ligam diretamente ì vig as selecionadas para exemplificar o dimensionamento mostrado no item anterior. Será feita uma comparação entre o processo de dimensionamento e detalhamento realizado.

Nas tabelas a seguir, serão comparados os dimensionamentos dos pilares que apóiam as vigas analisadas V6, V19 e V20, feitos por DTool e TQS.

Os pilares serão dimensionados em DTool baseados nos esforços obtidos no pórtico utilizado para o projeto das vigas, utilizando, em cada um, os momentos fletores que atuam na direção do pórtico em questão e levando em conta as excentricidades necessárias para o dimensionamento naquela direção.

\subsubsection{Pórtico V6}

O pórtico V6 está mostrado na figura 6.4 e 6.5, sendo o que considera a viga V6 em todos os pavimentos da edificação. Na tabelas a seguir, serão comparados os resultados de projeto para os pilares existentes no pórtico, podendo ser localizados na figura 6.4 .

\begin{tabular}{|c|c|c|c|c|}
\hline \multicolumn{5}{|c|}{ para o pilar P7 no pórtico V6 } \\
\hline \multirow{2}{*}{$\begin{array}{c}\text { P7 } \\
40 / 20\end{array}$} & \multicolumn{4}{|c|}{ Lance } \\
\hline & 1 & 2 & 3 & 4 \\
\hline TQS & $10 \phi 10$ & $8 \phi 10$ & $6 \phi 10$ & $6 \phi 10$ \\
\hline $\mathrm{N}_{\mathrm{d}}(\mathrm{kN})$ & 721,0 & 524,0 & 330,0 & 137,0 \\
\hline $\mathrm{M}_{\mathrm{x}}\left(\mathrm{kN}^{*} \mathrm{~m}\right)$ & 34,90 & 26,90 & 22,80 & 47,20 \\
\hline$A_{s}$ Necessário $\left(\mathrm{cm}^{2}\right)$ & 7,90 & 6,30 & 4,70 & 4,70 \\
\hline$A_{s}$ Utilizado $\left(\mathrm{cm}^{2}\right)$ & 7,85 & 6,28 & 4,71 & 4,71 \\
\hline DTool & $8 \phi 10$ & $6 \phi 10$ & $6 \phi 10$ & $6 \phi 10$ \\
\hline $\mathrm{N}_{\mathrm{d}}(\mathrm{kN})$ & 716,0 & 529,0 & 342,0 & 129,2 \\
\hline $\mathrm{M}_{\mathrm{x}}\left(\mathrm{kN} \mathrm{N}^{*} \mathrm{~m}\right)$ & 33,30 & 26,80 & 20,70 & 12,90 \\
\hline$A_{s}$ Necessário $\left(\mathrm{cm}^{2}\right)$ & 5,60 & 3,20 & 3,20 & 3,20 \\
\hline$A_{s}$ Utilizado $\left(\mathrm{cm}^{2}\right)$ & 6,28 & 4,71 & 4,71 & 4,71 \\
\hline
\end{tabular}


Tabela 6.15 - Comparação entre o dimensionamento de TQS e DTool para o pilar P8 no pórtico V6

\begin{tabular}{lcccc}
\multicolumn{1}{c}{ P8 } & \multicolumn{4}{c}{ Lance } \\
\multicolumn{1}{c}{$50 / 20$} & 1 & 2 & 3 & 4 \\
\hline TQS & $6 \phi 25$ & $6 \phi 20$ & $6 \phi 12,5$ & $6 \phi 12,5$ \\
$\mathrm{~N}_{\mathrm{d}}(\mathrm{kN})$ & 1502,0 & 1096,0 & 697,0 & 298,0 \\
$\mathrm{M}_{\mathrm{x}}\left(\mathrm{kN}{ }^{*} \mathrm{~m}\right)$ & 58,20 & 44,60 & 33,70 & 18,80 \\
$\mathrm{~A}_{\mathrm{s}}$ Necessário $\left(\mathrm{cm}^{2}\right)$ & 29,50 & 18,80 & 7,40 & 7,40 \\
$\mathrm{~A}_{\mathrm{s}}$ Utilizado $\left(\mathrm{cm}^{2}\right)$ & 29,45 & 18,85 & 7,36 & 7,36 \\
\hline DTool & $6 \phi 22,5$ & $6 \phi 16$ & $6 \phi 10$ & $6 \phi 10$ \\
Nd $(\mathrm{kN})$ & 1490,0 & 1084,5 & 686,0 & 291,0 \\
$\mathrm{M}_{\mathrm{x}}\left(\mathrm{kN} \mathrm{N}^{*}\right)$ & 57,00 & 43,80 & 32,60 & 17,40 \\
$\mathrm{~A}_{\mathrm{s}}$ Necessário $\left(\mathrm{cm}^{2}\right)$ & 23,50 & 11,10 & 4,00 & 4,00 \\
$\mathrm{~A}_{\mathrm{s}}$ Utilizado $\left(\mathrm{cm}^{2}\right)$ & 23,86 & 12,06 & 4,71 & 4,71 \\
\hline
\end{tabular}

Tabela 6.16 - Comparação entre o dimensionamento de TQS e DTool para o pilar P9 no pórtico V6

\begin{tabular}{|c|c|c|c|c|c|}
\hline \multirow{2}{*}{$\begin{array}{c}\text { P9 } \\
20 / 77,5\end{array}$} & \multicolumn{5}{|c|}{ Lance } \\
\hline & 1 & 2 & 3 & 4 & 5 \\
\hline$\overline{T Q S}$ & $12 \phi 12,5$ & $10 \phi 12,5$ & $8 \phi 12,5$ & $8 \phi 12,5$ & $4 \phi 16$ \\
\hline $\mathrm{N}_{\mathrm{d}}(\mathrm{kN})$ & 1401,0 & 1037,0 & 674,0 & 304,0 & 92,0 \\
\hline $\mathrm{M}_{\mathrm{x}}\left(\mathrm{kN}^{*} \mathrm{~m}\right)$ & 65,00 & 51,70 & 30,50 & 38,60 & 2,40 \\
\hline $\mathrm{A}_{\mathrm{s}}$ Necessário $\left(\mathrm{cm}^{2}\right)$ & 14,70 & 12,30 & 9,80 & 9,80 & 8,00 \\
\hline$A_{s}$ Utilizado $\left(\mathrm{cm}^{2}\right)$ & 14,73 & 12,27 & 9,82 & 9,82 & 8,04 \\
\hline$\overline{\text { DTool }}$ & $8 \phi 10$ & $8 \phi 10$ & $8 \phi 10$ & $8 \phi 10$ & $4 \phi 10$ \\
\hline $\mathrm{N}_{\mathrm{d}}(\mathrm{kN})$ & 1397,6 & 1057,0 & 708,6 & 365,0 & 80,0 \\
\hline$M_{x}\left(k N^{*} m\right)$ & 57,44 & 57,50 & 46,00 & 56,40 & 5,70 \\
\hline $\mathrm{A}_{\mathrm{s}}$ Necessário $\left(\mathrm{cm}^{2}\right)$ & 6,20 & 6,20 & 6,20 & 6,20 & 1,60 \\
\hline$A_{s}$ Utilizado $\left(\mathrm{cm}^{2}\right)$ & 6,28 & 6,28 & 6,28 & 6,28 & 3,14 \\
\hline
\end{tabular}

Tabela 6.17 - Comparação entre o dimensionamento de TQS e DTool para o pilar P10 no pórtico V6

\begin{tabular}{|c|c|c|c|c|c|}
\hline \multirow{2}{*}{$\begin{array}{c}\text { P10 } \\
20 / 77,5\end{array}$} & \multicolumn{5}{|c|}{ Lance } \\
\hline & 1 & 2 & 3 & 4 & 5 \\
\hline TQS & $12 \phi 12,5$ & $10 \phi 12,5$ & $8 \phi 12,5$ & $8 \phi 12,5$ & $4 \phi 16$ \\
\hline $\mathrm{N}_{\mathrm{d}}(\mathrm{kN})$ & 1365,0 & 1003,0 & 642,0 & 282,0 & 52,0 \\
\hline $\mathrm{M}_{\mathrm{x}}\left(\mathrm{kN}^{*} \mathrm{~m}\right)$ & 63,70 & 50,50 & 34,50 & 46,50 & 1,35 \\
\hline $\mathrm{A}_{\mathrm{s}}$ Necessário $\left(\mathrm{cm}^{2}\right)$ & 14,70 & 12,30 & 9,80 & 9,80 & 9,80 \\
\hline$A_{s}$ Utilizado $\left(\mathrm{cm}^{2}\right)$ & 14,73 & 12,27 & 9,82 & 9,82 & 8,04 \\
\hline$\overline{\text { DTool }}$ & $10 \phi 10$ & $8 \phi 10$ & $8 \phi 10$ & $8 \phi 10$ & $4 \phi 10$ \\
\hline $\mathrm{N}_{\mathrm{d}}(\mathrm{kN})$ & 1387,0 & 1047,0 & 697,0 & 345,0 & 62,0 \\
\hline $\mathrm{M}_{\mathrm{x}}\left(\mathrm{kN}^{*} \mathrm{~m}\right)$ & 53,80 & 56,90 & 45,20 & 53,70 & 5,16 \\
\hline $\mathrm{A}_{\mathrm{s}}$ Necessário $\left(\mathrm{cm}^{2}\right)$ & 6,20 & 6,20 & 6,20 & 6,20 & 6,20 \\
\hline $\mathrm{A}_{\mathrm{s}}$ Utilizado $\left(\mathrm{cm}^{2}\right)$ & 7,85 & 6,28 & 6,28 & 6,28 & 3,14 \\
\hline
\end{tabular}


Tabela 6.18 - Comparação entre o dimensionamento de TQS e DTool para o pilar P11 no pórtico V6

\begin{tabular}{|c|c|c|c|c|}
\hline \multirow{2}{*}{$\begin{array}{l}\mathbf{P 1 1} \\
50 / 20\end{array}$} & \multicolumn{4}{|c|}{ Lance } \\
\hline & 1 & 2 & 3 & 4 \\
\hline TQS & $6 \phi 25$ & $6 \phi 20$ & $6 \phi 12,5$ & $6 \phi 12,5$ \\
\hline $\mathrm{N}_{\mathrm{d}}(\mathrm{kN})$ & 1489,0 & 1082,0 & 682,0 & 284,0 \\
\hline $\mathrm{M}_{\mathrm{x}}\left(\mathrm{kN}^{*} \mathrm{~m}\right)$ & 57,70 & 44,14 & 32,10 & 14,30 \\
\hline $\mathrm{A}_{\mathrm{s}}$ Necessário $\left(\mathrm{cm}^{2}\right)$ & 29,50 & 18,80 & 7,40 & 7,40 \\
\hline $\mathrm{A}_{\mathrm{s}}$ Utilizado $\left(\mathrm{cm}^{2}\right)$ & 29,45 & 18,85 & 7,36 & 7,36 \\
\hline DTool & $6 \phi 22,5$ & $6 \phi 16$ & $6 \phi 10$ & $6 \phi 10$ \\
\hline $\mathrm{N}_{\mathrm{d}}(\mathrm{kN})$ & 1490,0 & 1073,2 & 674,3 & 278,1 \\
\hline $\mathrm{M}_{\mathrm{x}}\left(\mathrm{kN}^{*} \mathrm{~m}\right)$ & 56,90 & 43,40 & 31,60 & 16,60 \\
\hline $\mathrm{A}_{\mathrm{s}}$ Necessário $\left(\mathrm{cm}^{2}\right)$ & 23,50 & 10,70 & 4,00 & 4,00 \\
\hline$A_{s}$ Utilizado $\left(\mathrm{cm}^{2}\right)$ & 23,86 & 12,06 & 4,71 & 4,71 \\
\hline
\end{tabular}

Tabela 6.19 - Comparação entre o dimensionamento de TQS e DTool para o pilar P12 no pórtico V6

\begin{tabular}{lcccc}
\multicolumn{1}{c}{ P12 } & \multicolumn{4}{c}{ Lance } \\
\multicolumn{1}{c}{$40 / 20$} & 1 & 2 & 3 & 4 \\
\hline TQS & $8 \phi 12,5$ & $6 \phi 12,5$ & $6 \phi 10$ & $6 \phi 10$ \\
$\mathrm{~N}_{\mathrm{d}}(\mathrm{kN})$ & 795,0 & 576,0 & 360,0 & 144,0 \\
$\mathrm{M}_{\mathrm{x}}\left(\mathrm{kN} \mathrm{N}^{*} \mathrm{~m}\right)$ & 35,80 & 28,70 & 19,60 & 12,20 \\
$\mathrm{~A}_{\mathrm{s}}$ Necessário $\left(\mathrm{cm}^{2}\right)$ & 9,80 & 7,40 & 4,70 & 4,70 \\
$\mathrm{~A}_{\mathrm{s}}$ Utilizado $\left(\mathrm{cm}^{2}\right)$ & 12,06 & 7,36 & 4,71 & 4,71 \\
\hline DTool & $6 \phi 12,5$ & $6 \phi 10$ & $6 \phi 10$ & $6 \phi 10$ \\
$\mathrm{~N}_{\mathrm{d}}(\mathrm{kN})$ & 764,4 & 555,5 & 347,0 & 136,3 \\
$\mathrm{M}_{\mathrm{x}}\left(\mathrm{kN} \mathrm{N}^{*} \mathrm{~m}\right)$ & 34,70 & 27,60 & 20,70 & 12,30 \\
$\mathrm{~A}_{\mathrm{s}}$ Necessário $\left(\mathrm{cm}^{2}\right)$ & 7,00 & 3,20 & 3,20 & 3,20 \\
$\mathrm{~A}_{\mathrm{s}}$ Utilizado $\left(\mathrm{cm}^{2}\right)$ & 7,36 & 4,71 & 4,71 & 4,71 \\
\hline
\end{tabular}

\subsubsection{Pórtico V19}

O pórtico V19 é o que considera a viga V19 do edifício, tendo como apoios os pilares P17, P11 e P3, conforme pode ser visto nas figuras 6.1 e 6.2.

Tabela 6.20 - Comparação entre o dimensionamento de TQS e DTool para o pilar P17 no pórtico V19

\begin{tabular}{lcccc}
\multicolumn{1}{c}{ P17 } & \multicolumn{4}{c}{ Lance } \\
\multicolumn{1}{c}{$40 / 20$} & 1 & 2 & 3 & 4 \\
\hline TQS & $10 \phi 10$ & $8 \phi 10$ & $8 \phi 10$ & $8 \phi 10$ \\
$\mathrm{~N}_{\mathrm{d}}(\mathrm{kN})$ & 661,0 & 482,0 & 301,0 & 121,0 \\
$\mathrm{M}_{\mathrm{x}}\left(\mathrm{kN} \mathrm{N}^{*} \mathrm{~m}\right)$ & 37,20 & 38,10 & 33,90 & 29,30 \\
$\mathrm{~A}_{\mathrm{s}}$ Necessário $\left(\mathrm{cm}^{2}\right)$ & 7,90 & 6,30 & 6,30 & 6,30 \\
$\mathrm{~A}_{\mathrm{s}}$ Utilizado $\left(\mathrm{cm}^{2}\right)$ & 7,85 & 6,28 & 6,28 & 6,28 \\
\hline DTool & $6 \phi 12,5$ & $6 \phi 12,5$ & $6 \phi 12,5$ & $6 \phi 12,5$ \\
$\mathrm{~N}_{\mathrm{d}}(\mathrm{kN})$ & 675,0 & 503,2 & 324,4 & 144,6 \\
$\mathrm{M}_{\mathrm{x}}\left(\mathrm{kN} \mathrm{N}^{*} \mathrm{~m}\right)$ & 38,20 & 43,70 & 40,50 & 37,40 \\
$\mathrm{~A}_{\mathrm{s}}$ Necessário $\left(\mathrm{cm}^{2}\right)$ & 6,67 & 6,37 & 5,50 & 7,33 \\
$\mathrm{~A}_{\mathrm{s}}$ Utilizado $\left(\mathrm{cm}^{2}\right)$ & 7,36 & 7,36 & 7,36 & 7,36 \\
\hline
\end{tabular}


Tabela 6.21 - Comparação entre o dimensionamento de TQS e DTool para o pilar P11 no pórtico V19

\begin{tabular}{|c|c|c|c|c|}
\hline \multirow{2}{*}{$\begin{array}{l}\text { P11 } \\
20 / 50\end{array}$} & \multicolumn{4}{|c|}{ Lance } \\
\hline & 1 & 2 & 3 & 4 \\
\hline TQS & $6 \phi 25$ & $6 \phi 20$ & $6 \phi 12,5$ & $6 \phi 12,5$ \\
\hline $\mathrm{N}_{\mathrm{d}}(\mathrm{kN})$ & 1489,0 & 1082,0 & 682,0 & 284,0 \\
\hline $\mathrm{M}_{\mathrm{x}}\left(\mathrm{kN} \mathrm{N}^{*} \mathrm{~m}\right)$ & 57,70 & 44,14 & 32,10 & 14,30 \\
\hline $\mathrm{A}_{\mathrm{s}}$ Necessário $\left(\mathrm{cm}^{2}\right)$ & 29,50 & 18,80 & 7,40 & 7,40 \\
\hline$A_{s}$ Utilizado $\left(\mathrm{cm}^{2}\right)$ & 29,45 & 18,85 & 7,36 & 7,36 \\
\hline DTool & $10 \phi 12,5$ & $6 \phi 10$ & $6 \phi 10$ & $6 \phi 10$ \\
\hline $\mathrm{N}_{\mathrm{d}}(\mathrm{kN})$ & 1433,6 & 1047,4 & 669,0 & 291,0 \\
\hline $\mathrm{M}_{\mathrm{x}}\left(\mathrm{kN}^{*} \mathrm{~m}\right)$ & 45,30 & 32,00 & 24,50 & 21,10 \\
\hline $\mathrm{A}_{\mathrm{s}}$ Necessário $\left(\mathrm{cm}^{2}\right)$ & 11,00 & 4,00 & 4,00 & 4,00 \\
\hline$A_{s}$ Utilizado $\left(\mathrm{cm}^{2}\right)$ & 12,27 & 4,71 & 4,71 & 4,71 \\
\hline
\end{tabular}

Tabela 6.22 - Comparação entre o dimensionamento de TQS e DTool para o pilar P3 no pórtico V19

\begin{tabular}{lcccc}
\multicolumn{1}{c}{ P3 } & \multicolumn{4}{c}{ Lance } \\
\multicolumn{1}{c}{$20 / 64$} & 1 & 2 & 3 & 4 \\
\hline TQS & $8 \phi 12,5$ & $6 \phi 12,5$ & $6 \phi 12,5$ & $6 \phi 12,5$ \\
$\mathrm{~N}_{\mathrm{d}}(\mathrm{kN})$ & 851,0 & 619,0 & 388,0 & 156,0 \\
$\mathrm{M}_{\mathrm{x}}\left(\mathrm{kN} \mathrm{N}^{*} \mathrm{~m}\right)$ & 47,90 & 36,40 & 25,50 & 89,50 \\
$\mathrm{~A}_{\mathrm{s}}$ Necessário $\left(\mathrm{cm}^{2}\right)$ & 9,80 & 7,40 & 7,40 & 7,40 \\
$\mathrm{~A}_{\mathrm{s}}$ Utilizado $\left(\mathrm{cm}^{2}\right)$ & 12,06 & 7,36 & 7,36 & 7,36 \\
\hline DTool & $6 \phi 12,5$ & $6 \phi 12,5$ & $6 \phi 12,5$ & $6 \phi 12,5$ \\
$\mathrm{~N}_{\mathrm{d}}(\mathrm{kN})$ & 829,1 & 604,5 & 378,0 & 151,0 \\
$\mathrm{M}_{\mathrm{x}}\left(\mathrm{kN} \mathrm{N}^{*} \mathrm{~m}\right)$ & 64,80 & 60,20 & 55,90 & 55,70 \\
$\mathrm{~A}_{\mathrm{s}}$ Necessário $\left(\mathrm{cm}^{2}\right)$ & 5,12 & 5,12 & 5,12 & 5,12 \\
$\mathrm{~A}_{\mathrm{s}}$ Utilizado $\left(\mathrm{cm}^{2}\right)$ & 7,36 & 7,36 & 7,36 & 7,36 \\
\hline
\end{tabular}

\subsubsection{Pórtico V20}

Considerando a viga V20 em todos os pavimentos, este pórtico tem como elementos verticais os pilares $\mathrm{P} 18, \mathrm{P} 12$ e $\mathrm{P} 4$, conforme pode ser visto nas figuras 6.1 e 6.2 .

Tabela 6.23 - Comparação entre o dimensionamento de TQS e DTool para o pilar P18 no pórtico V20

\begin{tabular}{|c|c|c|c|c|}
\hline \multirow{2}{*}{$\begin{array}{l}\mathbf{P 1 8} \\
20 / 40 \\
\end{array}$} & \multicolumn{4}{|c|}{ Lance } \\
\hline & 1 & 2 & 3 & 4 \\
\hline TQS & $6 \phi 10$ & $6 \phi 10$ & $6 \phi 10$ & $6 \phi 10$ \\
\hline $\mathrm{N}_{\mathrm{d}}(\mathrm{kN})$ & 368,0 & 268,0 & 167,0 & 65,0 \\
\hline $\mathrm{M}_{\mathrm{x}}\left(\mathrm{kN}^{*} \mathrm{~m}\right)$ & 21,60 & 18,10 & 39,30 & 38,00 \\
\hline $\mathrm{A}_{\mathrm{s}}$ Necessário $\left(\mathrm{cm}^{2}\right)$ & 4,70 & 4,70 & 4,70 & 4,70 \\
\hline $\mathrm{A}_{\mathrm{s}}$ Utilizado $\left(\mathrm{cm}^{2}\right)$ & 4,71 & 4,71 & 4,71 & 4,71 \\
\hline DTool & $6 \phi 10$ & $6 \phi 10$ & $6 \phi 10$ & $6 \phi 10$ \\
\hline $\mathrm{N}_{\mathrm{d}}(\mathrm{kN})$ & 356,6 & 259,8 & 160,4 & 60,2 \\
\hline $\mathrm{M}_{\mathrm{x}}\left(\mathrm{kN}^{*} \mathrm{~m}\right)$ & 28,50 & 36,90 & 33,90 & 34,15 \\
\hline $\mathrm{A}_{\mathrm{s}}$ Necessário $\left(\mathrm{cm}^{2}\right)$ & 3,20 & 3,20 & 3,20 & 3,20 \\
\hline$A_{s}$ Utilizado $\left(\mathrm{cm}^{2}\right)$ & 4,71 & 4,71 & 4,71 & 4,71 \\
\hline
\end{tabular}


Tabela 6.24 - Comparação entre o dimensionamento de TQS e DTool para o pilar P12 no pórtico V20

\begin{tabular}{|c|c|c|c|c|}
\hline \multirow{2}{*}{$\begin{array}{l}\text { P12 } \\
20 / 40\end{array}$} & \multicolumn{4}{|c|}{ Lance } \\
\hline & 1 & 2 & 3 & 4 \\
\hline TQS & $8 \phi 12,5$ & $6 \phi 12,5$ & $6 \phi 10$ & $6 \phi 10$ \\
\hline $\mathrm{N}_{\mathrm{d}}(\mathrm{kN})$ & 795,0 & 576,0 & 360,0 & 144,0 \\
\hline $\mathrm{M}_{\mathrm{x}}\left(\mathrm{kN} \mathrm{N}^{*} \mathrm{~m}\right)$ & 35,80 & 28,70 & 19,60 & 12,20 \\
\hline $\mathrm{A}_{\mathrm{s}}$ Necessário $\left(\mathrm{cm}^{2}\right)$ & 9,80 & 7,40 & 4,70 & 4,70 \\
\hline$A_{s}$ Utilizado $\left(\mathrm{cm}^{2}\right)$ & 12,06 & 7,36 & 4,71 & 4,71 \\
\hline DTool & $6 \phi 10$ & $6 \phi 10$ & $6 \phi 10$ & $6 \phi 10$ \\
\hline $\mathrm{N}_{\mathrm{d}}(\mathrm{kN})$ & 773,6 & 558,9 & 348,0 & 138,4 \\
\hline $\mathrm{M}_{\mathrm{x}}\left(\mathrm{kN}^{*} \mathrm{~m}\right)$ & 25,80 & 19,90 & 14,40 & 7,80 \\
\hline $\mathrm{A}_{\mathrm{s}}$ Necessário $\left(\mathrm{cm}^{2}\right)$ & 3,20 & 3,20 & 3,20 & 3,20 \\
\hline$A_{s}$ Utilizado $\left(\mathrm{cm}^{2}\right)$ & 4,71 & 4,71 & 4,71 & 4,71 \\
\hline
\end{tabular}

Tabela 6.25 - Comparação entre o dimensionamento de TQS e DTool para o pilar P4 no pórtico V20

\begin{tabular}{|c|c|c|c|c|}
\hline \multirow{2}{*}{$\begin{array}{c}\mathbf{P 4} \\
20 / 40\end{array}$} & \multicolumn{4}{|c|}{ Lance } \\
\hline & 1 & 2 & 3 & 4 \\
\hline TQS & $6 \phi 10$ & $6 \phi 10$ & $6 \phi 10$ & $6 \phi 10$ \\
\hline $\mathrm{N}_{\mathrm{d}}(\mathrm{kN})$ & 357,0 & 259,0 & 161,0 & 62,0 \\
\hline $\mathrm{M}_{\mathrm{x}}\left(\mathrm{kN}^{*} \mathrm{~m}\right)$ & 21,30 & 0,00 & 0,00 & 0,00 \\
\hline$A_{s}$ Necessário $\left(\mathrm{cm}^{2}\right)$ & 4,70 & 4,70 & 4,70 & 4,70 \\
\hline$A_{s}$ Utilizado $\left(\mathrm{cm}^{2}\right)$ & 4,71 & 4,71 & 4,71 & 4,71 \\
\hline DTool & $6 \phi 10$ & $6 \phi 10$ & $6 \phi 10$ & $6 \phi 10$ \\
\hline $\mathrm{N}_{\mathrm{d}}(\mathrm{kN})$ & 383,8 & 285,3 & 174,7 & 63,5 \\
\hline $\mathrm{M}_{\mathrm{x}}\left(\mathrm{kN}^{*} \mathrm{~m}\right)$ & 32,80 & 43,20 & 39,00 & 39,30 \\
\hline $\mathrm{A}_{\mathrm{s}}$ Necessário $\left(\mathrm{cm}^{2}\right)$ & 3,20 & 3,20 & 3,20 & 3,20 \\
\hline$A_{s}$ Utilizado $\left(\mathrm{cm}^{2}\right)$ & 4,71 & 4,71 & 4,71 & 4,71 \\
\hline
\end{tabular}

\subsubsection{Discussão dos Resultados}

Para obtenção dos esforços solicitantes pelo programa TQS foram consideradas somente as situações de cálculo que levavam à flexão normal composta com momento na direção do pórtico em questão. Foram desconsideradas as situações em que as excentricidades levavam ao dimensionamento àflexão oblíqua composta, poi s o DTool não prevê esta situação de solicitação. Tal condição, em DTool, levou a projeto de pilares sempre com armadura necessária menor do que em TQS.

Os pilares P11 e P12 foram dimensionados propositadamente em dois pórticos, com o intuito de verificar as diferenças entre o projeto nas duas direções. 
Tabela 6.26 - Comparação entre o dimensionamento para

o pilar P11 no pórtico V6 e V19

\begin{tabular}{|c|c|c|c|c|}
\hline \multirow{2}{*}{$\begin{array}{l}\text { P11 } \\
20 / 50\end{array}$} & \multicolumn{4}{|c|}{ Lance } \\
\hline & 1 & 2 & 3 & 4 \\
\hline$\overline{T Q S}$ & $6 \phi 25$ & $6 \phi 20$ & $6 \phi 12,5$ & $6 \phi 12,5$ \\
\hline $\mathrm{N}_{\mathrm{d}}(\mathrm{kN})$ & 1489,0 & 1082,0 & 682,0 & 284,0 \\
\hline $\mathrm{M}_{\mathrm{x}}\left(\mathrm{kN}^{*} \mathrm{~m}\right)$ & 57,70 & 44,14 & 32,10 & 14,30 \\
\hline$A_{s}$ Necessário $\left(\mathrm{cm}^{2}\right)$ & 29,50 & 18,80 & 7,40 & 7,40 \\
\hline$A_{s}$ Utilizado $\left(\mathrm{cm}^{2}\right)$ & 29,45 & 18,85 & 7,36 & 7,36 \\
\hline DTool V6 & $6 \phi 22,5$ & $6 \phi 16$ & $6 \phi 10$ & $6 \phi 10$ \\
\hline $\mathrm{N}_{\mathrm{d}}(\mathrm{kN})$ & 1490,0 & 1073,2 & 674,3 & 278,1 \\
\hline $\mathrm{M}_{\mathrm{x}}\left(\mathrm{kN}^{*} \mathrm{~m}\right)$ & 56,90 & 43,40 & 31,60 & 16,60 \\
\hline $\mathrm{A}_{\mathrm{s}}$ Necessário $\left(\mathrm{cm}^{2}\right)$ & 23,50 & 10,70 & 4,00 & 4,00 \\
\hline$A_{s}$ Utilizado $\left(\mathrm{cm}^{2}\right)$ & 23,86 & 12,06 & 4,71 & 4,71 \\
\hline DTool V19 & $10 \phi 12,5$ & $6 \phi 10$ & $6 \phi 10$ & $6 \phi 10$ \\
\hline $\mathrm{N}_{\mathrm{d}}(\mathrm{kN})$ & 1433,6 & 1047,4 & 669,0 & 291,0 \\
\hline $\mathrm{M}_{\mathrm{x}}\left(\mathrm{kN}^{*} \mathrm{~m}\right)$ & 45,30 & 32,00 & 24,50 & 21,10 \\
\hline$A_{s}$ Necessário $\left(\mathrm{cm}^{2}\right)$ & 11,00 & 4,00 & 4,00 & 4,00 \\
\hline$A_{s}$ Utilizado $\left(\mathrm{cm}^{2}\right)$ & 12,27 & 4,71 & 4,71 & 4,71 \\
\hline
\end{tabular}

Tanto os esforços quanto o dimensionamento foram mais próximos do encontrado em TQS quando o pilar estava sendo considerado com sua menor dimensão no plano do pórtico em questão (viga V6). O pilar P12 apresenta a mesma característica, porém, sendo um pilar de extremidade, a área de aço necessária diferiu um pouco mais em decorrência da existência da flexão oblíqua composta de forma mais intensa.

Tabela 6.27 - Comparação entre o dimensionamento para o pilar P12 no pórtico V6 e V20

\begin{tabular}{|c|c|c|c|c|}
\hline \multirow{2}{*}{$\begin{array}{l}\text { P12 } \\
20 / 40\end{array}$} & \multicolumn{4}{|c|}{ Lance } \\
\hline & 1 & 2 & 3 & 4 \\
\hline$\overline{\mathrm{TQS}}$ & $8 \phi 12,5$ & $6 \phi 12,5$ & $6 \phi 10$ & $6 \phi 10$ \\
\hline $\mathrm{N}_{\mathrm{d}}(\mathrm{kN})$ & 795,0 & 576,0 & 360,0 & 144,0 \\
\hline $\mathrm{M}_{\mathrm{x}}\left(\mathrm{kN}^{*} \mathrm{~m}\right)$ & 35,80 & 28,70 & 19,60 & 12,20 \\
\hline$A_{s}$ Necessário $\left(\mathrm{cm}^{2}\right)$ & 9,80 & 7,40 & 4,70 & 4,70 \\
\hline$A_{s}$ Utilizado $\left(\mathrm{cm}^{2}\right)$ & 12,06 & 7,36 & 4,71 & 4,71 \\
\hline DTool V6 & $6 \phi 12,5$ & $6 \phi 10$ & $6 \phi 10$ & $6 \phi 10$ \\
\hline $\mathrm{N}_{\mathrm{d}}(\mathrm{kN})$ & 764,4 & 555,5 & 347,0 & 136,3 \\
\hline $\mathrm{M}_{\mathrm{x}}\left(\mathrm{kN}^{*} \mathrm{~m}\right)$ & 34,70 & 27,60 & 20,70 & 12,30 \\
\hline$A_{s}$ Necessário $\left(\mathrm{cm}^{2}\right)$ & 7,00 & 3,20 & 3,20 & 3,20 \\
\hline$A_{s}$ Utilizado $\left(\mathrm{cm}^{2}\right)$ & 7,36 & 4,71 & 4,71 & 4,71 \\
\hline DTool V20 & $6 \phi 10$ & $6 \phi 10$ & $6 \phi 10$ & $6 \phi 10$ \\
\hline $\mathrm{N}_{\mathrm{d}}(\mathrm{kN})$ & 773,6 & 558,9 & 348,0 & 138,4 \\
\hline $\mathrm{M}_{\mathrm{x}}\left(\mathrm{kN}^{*} \mathrm{~m}\right)$ & 25,80 & 19,90 & 14,40 & 7,80 \\
\hline $\mathrm{A}_{\mathrm{s}}$ Necessário $\left(\mathrm{cm}^{2}\right)$ & 3,20 & 3,20 & 3,20 & 3,20 \\
\hline$A_{s}$ Utilizado $\left(\mathrm{cm}^{2}\right)$ & 4,71 & 4,71 & 4,71 & 4,71 \\
\hline
\end{tabular}




\subsubsection{Verificação}

Para verificar o processo de dimensionamento utilizado no DTool, será mostrado o processo de cálculo utilizado pelo programa. Escolhendo o pilar P11 no pórtico V6, no primeiro tramo, pode ser feito o seguinte projeto:

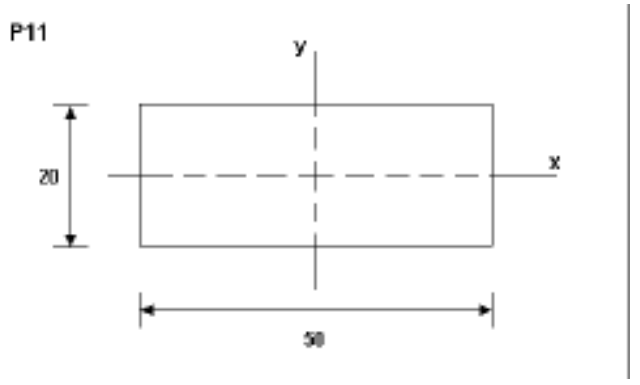

$$
\begin{aligned}
& \mathrm{N}_{\mathrm{k}}=1478,5 \mathrm{kN} \\
& \ell_{e}=310 \mathrm{~cm} \\
& \mathrm{~d}^{\prime}=2 \mathrm{~cm} \\
& \lambda_{x}=\frac{\ell_{e} \cdot \sqrt{12}}{a}=\frac{310 \cdot \sqrt{12}}{50}=21 \\
& \lambda_{y}=\frac{\ell_{e} \cdot \sqrt{12}}{a}=\frac{310 \cdot \sqrt{12}}{20}=54 \\
& e_{a x}=\frac{h}{30}=\frac{50}{30}=1,67 \mathrm{~cm}<2 \mathrm{~cm} \\
& e_{a y}=\frac{h}{30}=\frac{20}{30}=0,67 \mathrm{~cm}<2 \mathrm{~cm}
\end{aligned}
$$

As excentricidades em $x$ e y são iguais a $2 \mathrm{~cm}$.

Como $\lambda_{y}$ é maior que 40 , na direção y, é obrigatória a consideração do efeito de $2^{\mathrm{a}}$ ordem.

$$
\mathrm{v}_{d}=\frac{N_{d}}{A_{c} \cdot f_{c d}}=\frac{1478,5}{20 \cdot 50 \cdot \frac{2,0}{1,4}}=1,03
$$




$$
e_{2 y}=\frac{\ell_{e}^{2}}{10} \cdot \frac{0,0035+\frac{f_{y d}}{E_{s}}}{(v+0,5) \cdot h}=\frac{310^{2}}{10} \cdot \frac{0,0035+\frac{500}{1,15 \cdot 210000}}{(1,03+0,5) \cdot 20}=1,75 \mathrm{~cm}
$$

Seção de topo

$$
e_{i y}=\frac{231 \cdot 1,4}{1490}=0,22 \mathrm{~cm}
$$

Seção de base

$$
e_{i y}=\frac{-117 \cdot 1,4}{1490}=-0,11 \mathrm{~cm}
$$

Seção intermediária

$$
\begin{aligned}
& e_{i, \text { int }}=0,6 e_{i A}+0,4 e_{i B} \geq 0,4 e_{i A} \\
& e_{i, \text { int }}=0,6 \cdot 0,22+0,4 \cdot(-0,11) \geq 0,4 \cdot 0,22 \\
& e_{i, \text { int }}=0,09 \mathrm{~cm}
\end{aligned}
$$

Com a consideração do efeito de $2^{\mathrm{a}}$ ordem, a seção crítica é a intermediária.

Seção intermediária

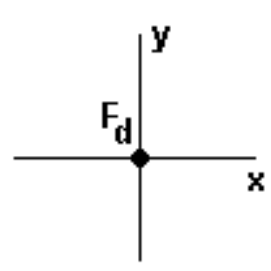

compressão centrada

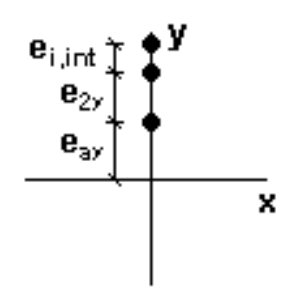

flexão normal composta

$$
\grave{i}_{y d}=i_{d} \cdot \frac{e_{y}}{h_{y}}=1,03 \cdot \frac{(2+1,75+0,09)}{20}=0,198
$$


Utilizando os ábacos de VENTURINI (1987) para flexão normal composta, o valor da taxa de armadura encontrado é:

$$
\varpi=0,70
$$

A área de aço necessária fica:

$$
A s=23 \mathrm{~cm}^{2}
$$

Utilizando 6 barras, a área de cada uma deve ser maior que $3,8 \mathrm{~cm}^{2}$. A barra que possui diâmetro comercial e, conseqüentemente, área maior que o valor citado é a de $22,5 \mathrm{~mm}$, com $3,98 \mathrm{~cm}^{2}$. Portanto, no primeiro tramo do pilar P11, para que a área de aço satisfaça a área calculada no dimensionamento são necessárias 6 barras de 22,5 mm de diâmetro, conforme dimensionamento realizado por DTool, mostrado na figura 6.14.

\subsection{Detalhamento}

O detalhamento feito por TQS e DTool pode ser visto exemplificado nas figuras a seguir.

O corte mostrado se encontra na região de apoio da viga V20 na região do apoio central.

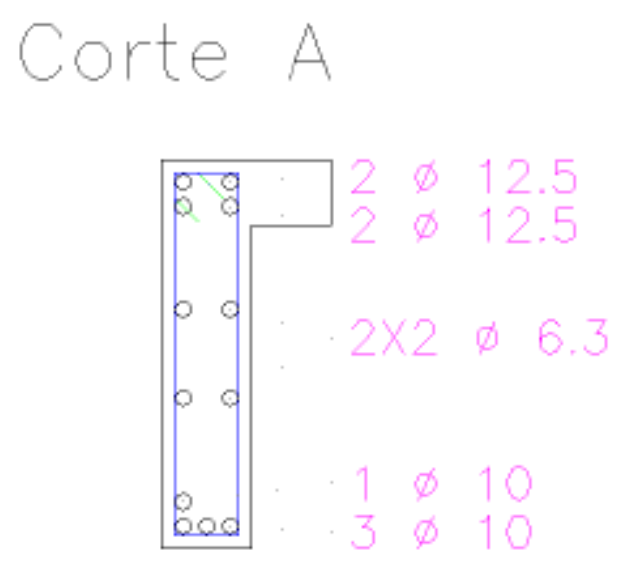

Figura 6.11 - Detalhamento da armadura para a viga V20

Em TQS no pavimento tipo junto ao pilar P12. 


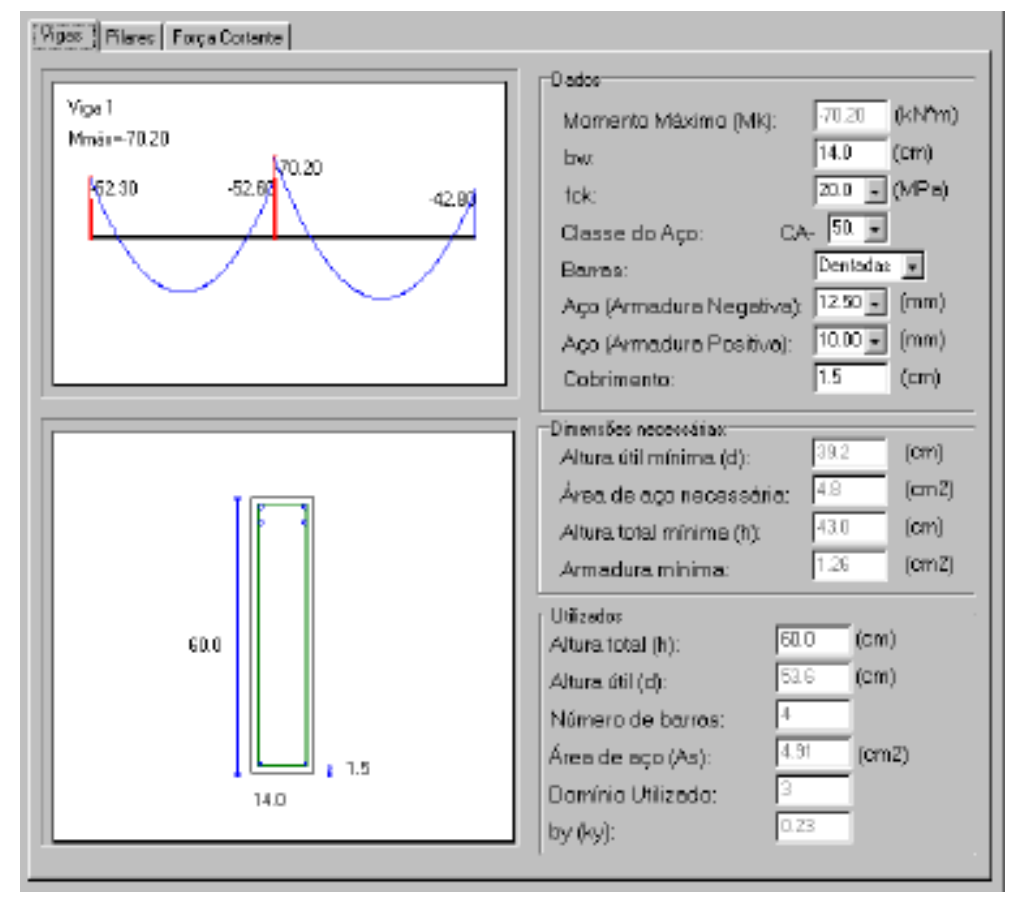

Figura 6.12 - Detalhamento da armadura para a viga V20 em DTool no pavimento tipo junto ao pilar P12.

Na figura 6.12 as barras estão desenhadas em escala, portanto tendo 1,25 cm de diâmetro algo que não acontece no programa TQS, sendo porém as barras mais visíveis na figura 6.11. As quatro barras junto a face inferior detalhadas na figura 6.11 estão em uma região de emenda por traspasse, sendo o número de barras igual a 2 .

O detalhamento de pilares pode ser comparado na figura a seguir

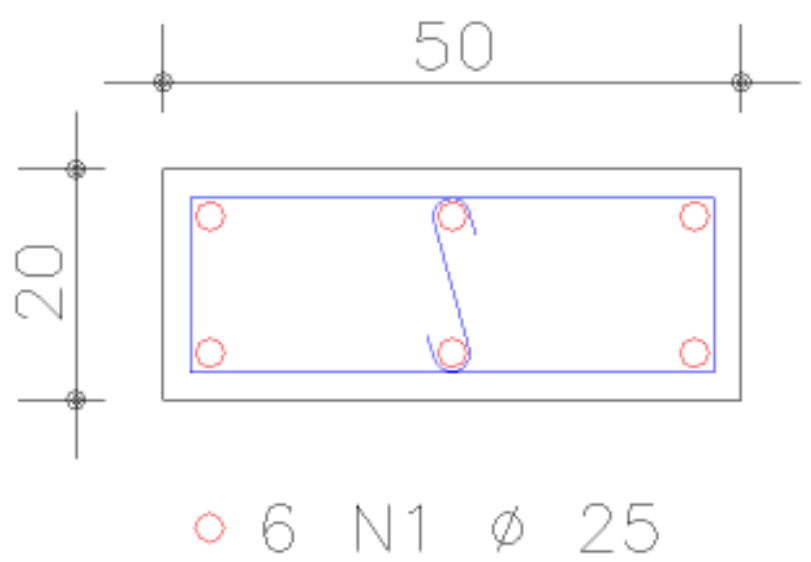

Figura 6.13 - Detalhamento da armadura para o pilar P8, primeiro tramo, em TQS 


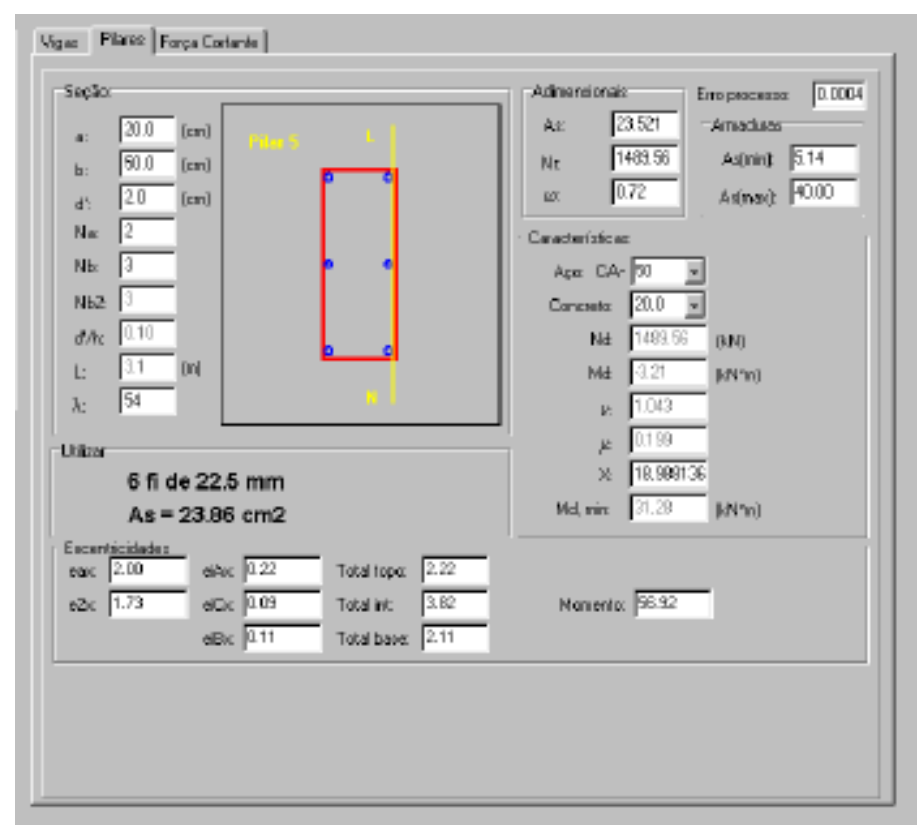

Figura 6.14 - Detalhamento da armadura para o pilar P8, primeiro tramo, em DTool

As diferenças no detalhamento são conseqüência das diferentes prioridades em cada programa. DTool tem como objetivo mostrar com clareza o processo de dimensionamento para auxiliar na compreensão dos passos envolvidos no projeto, enquanto TQS prioriza a clareza dos detalhes para facilidade de visualização nos desenhos enviados para a obra. 


\section{CAPÍTULO 7}

\section{CONSIDERAÇÕES FINAIS}

Neste trabalho, foi apresentada a utilização do programa DTool, desenvolvido com o intuito de auxiliar no ensino de disciplinas ligadas ao projeto de estruturas em concreto armado.

Os capítulos 2 a 5 foram elaborados de modo a embasar os conceitos utilizados em DTool no processo de dimensionamento de estruturas.

No capítulo 6 foi feita uma comparação entre os processos de dimensionamento de um edifício projetado com os programas TQS e com DTool.

Baseado nesta comparação, verificou-se que para vigas com cargas que levem a esforços iguais o dimensionamento é semelhante. E com esta verificação, pode-se concluir que o projeto para vigas está satisfatório, levando a resultados coerentes e aceitáveis. Porém, considerando somente as cargas verticais do pórtico tridimensional, utilizado em TQS, os esforços são diferentes em relação ao pórtico plano, levando a um dimensionamento diferente, por conseguinte.

Observou-se que o dimensionamento de pilares leva a diferenças constantes contra a segurança com a consideração somente das situações de cálculo que produzem flexão normal composta ao invés da flexão composta oblíqua, levando a crer que tal consideração é relevante para projetos destes elementos de forma satisfatória. Porém, com o exemplo de verificação de pilares, pode-se concluir que o projeto utilizando somente tais situações de cálculo está correto, encontrando-se uma área de aço de acordo com os ábacos para estes esforços. 
Constatou-se que a aplicação do processo iterativo para encontrar a taxa de armadura necessária para o dimensionamento, de acordo com os valores do momento fletor reduzido adimensional e a força normal adimensional, foi implementada satisfatoriamente, levando a taxas de armadura conforme os ábacos encontrados na literatura.

Também foi possível verificar algumas diferenças nos critérios adotados pela norma NBR 6118:2001 em relação a NBR 6118:1978.

O programa realizado é útil para o processo de aprendizagem, podendo mostrar o processo de dimensionamento para o usuário, de forma a facilitar a compreensão de cada passo envolvido no projeto. 


\section{REFERÊNCIAS BIBLIOGRÁFICAS}

ASSOCIAÇÃO BRASILEIRA DE NORMAS TÉCNICAS (1980). NBR 6118 - Projeto de estruturas de concreto armado. Rio de Janeiro.

ASSOCIAÇÃO BRASILEIRA DE NORMAS TÉCNICAS (2000). Projeto de revisão da NBR 6118 - Projeto de estruturas de concreto. Rio de Janeiro.

ASSOCIAÇÃO BRASILEIRA DE NORMAS TÉCNICAS (2001). Texto conclusivo do projeto de revisão da NBR 6118 - Projeto de estruturas de concreto armado. Rio de Janeiro.

AMARAL, N. A. (1969). Construções de concreto. São Paulo, Departamento de Livros e Publicações do Grêmio Politécnico.

AUFIERI, F.A. (1997). Diretrizes para o dimensionamento e detalhamento de pilares de edifícios de concreto armado. São Carlos. 146p. Dissertação (Mestrado) - Escola de Engenharia de São Carlos, Universidade de São Paulo.

BOWLES, R. E.; MERCHANT, W. (1956). Critical loads of tall building frames - part III. The Structural Engineer, v. 34, n. 8. 
BROHN, D. M.; COWAN, J. (1977). Teaching towards an improved understanding of structural behavior. The Structural Engineer, v.55, p. 9-17.

BROHN, D. M. (1983). Academic priorities in structural engineering - the importance of visual schema. The Structural Engineer, v. 61A, p.17-19.

CABRÉ, F.M. (1972). Cálculo de secciones de hormigón armado, sometidas a solicitacion normales, em el estado limite último. Madrid, Instituto Eduardo Torroja.

CILONI, A. D. (1993). Sobre o comportamento em serviço de estruturas planas de concreto armado. Tese (Doutorado). Escola de Engenharia de São Carlos, Universidade de São Paulo. São Carlos.

COHN, M. Z.; GRIERSON, D. E. (1969). An automatic approach to the analysis of plastic frames under fixed and variable loading. Waterloo, Ontário, University of Waterloo. (SM Report n. 22).

COROVIC, R.; PINO, J. A.; SARRAZIN, M. (1988). SATS: a microcomputer-based support for teaching structural analysis. Journal of Microcomputer Applications.

CORSEUIL, E. T. L. et al. (1992). FTOOL: um programa gráfico-interativo para ensino de comportamento de estruturas. http://www.tecgraf.puc-rio.br/ftool/manual/

COSTA, J.B. da. (1990). Automação do dimensionamento do vigamento de pavimentos tipo de edifícios de concreto armado. São Carlos. Dissertação (Mestrado) - Escola de Engenharia de São Carlos, Universidade de São Paulo. 
FIORIN, E. (1998) Arranjos de armaduras em estruturas de concreto armado. São Carlos. Dissertação (Mestrado) - Escola de Engenharia de São Carlos, Universidade de São Paulo.

FUSCO, P. B. (1981). Estruturas de concreto - solicitações normais, estados limites últimos: teoria e aplicações. Rio de Janeiro, Guanabara Dois.

FUSCO, P. B. (1989). $O$ cálculo de concreto armado em regime de ruptura. In: SIMPÓSIO EPUSP SOBRE ESTRUTURAS DE CONCRETO, 1.., São Paulo. Anais. v.1 , p. 239310.

GABBAY, A. (1977). Conceito de Rankine-Merchant e o cálculo automatizado de cargas aproximadas de colapso de pórticos planos. Rio de Janeiro. Dissertação (Mestrado) Pontifícia Universidade Católica do Rio de Janeiro.

GRIBBLE, C. (2000). History of C++. http://www.hitmill.com/programming/cpp/ cppHistory.html.

GRIERSON, D. E.; GLADWELL, G. M. L. (1971). Collapse load analysis using linear programming. Journal of Structural Division, ASCE, p. 8127.

HOLLINGWORTH, J. et al. (2000). C++ builder 5 - Developer's guide. Indianapolis, USA, Sams.

ISHITANI, H. et al. (1998). Estruturas de concreto I: notas de aula. /Apostila da Disciplina PEF-311. Escola Politécnica da Universidade de São Paulo. São Paulo/.

KAEFER, L. F. (2000). Desenvolvimento de uma ferramenta gráfica para análise de pórticos de concreto armado. São Paulo. Dissertação (Mestrado) - Escola Politécnica da Universidade de São Paulo. 
LEIMBACK, K. R. (1981). CAL-GRAF - A computer-graphics supplement for CAL. Computer and Structures. v.14, n. 1-2, p.135-141.

LEONHARDT, F. (1977). Construções de concreto. Rio de Janeiro, Interciência. v.1.

LINDQUIST, M. (1997). dimensionamento automático de peças de concreto armado submetidas à flexão em ambiente Windows. São Carlos. /Relatório Parcial, $\mathrm{PIBIC/CNPq/.}$

LINDQUIST, M. (1999). Dimensionamento automático de vigas de concreto armado submetidas à flexão Simples. São Carlos. /Relatório final, FAPESP/.

LIVESLEY, R. K. (1967). The selection of redundant forces in structures, with an application to the collapse analysis of frameworks. Proceedings of the Royal Society, London, v. 301, p. 493.

LORENZ, T. (2000). ComDim5: Betonbemessung für Windows 9x, NT, 2000. http://www.cis.tugraz.at/ifb/soft/soft_fr.htm

MAGGI, Y. I.; PEDROSO, P. H. (1998). Sistema multimídia para apoio ao ensino de estruturas de concreto. http://www.cesec.ufpr.br/ scheer/etools.html

MARTHA, L. F. (1999). FTOOL: a structural analysis educational interactive tool.. In: WORKSHOP IN MULTIMEDIA COMPUTER TECHNIQUES IN ENGINEERING EDUCATION. Proceedings. Technical University of Graz, Institute for Structural Analysis, p. 51-65.

MCMINN, S. J. (1961). The determination of the critical loads of plane frames. The Structural Engineer. v. 39, n.7. July. 
MONTOYA, P.J.; MESEGUER, A.G.; CABRÉ, F.M. (1973). Hormigón armado. 9. ed. Barcelona, Gustavo Gili. 2v.

MOSS, W. D.; KNOWLES, P. R.; AHMAD, K. (1979). CAL packages for civil engineering hydraulics and structural design. Computers \& Education. v.3, p. 91-399.

NEAL, B. G. (1963). The plastic methods of structural analysis. 2.ed. London, Chapman and Hall.

PFEILER, T. et al. (1994). Some remarks on the development of RuckZuck. http://www.cis.tugraz.at/ifb/soft/soft_htm

PINHEIRO, L. M. (1997). Concreto armado: tabelas e ábacos. São Carlos, EESC-USP.

PINHEIRO, L. M.; BRANDÃO, A. M. S. (1998). Concreto armado: bases para cálculo. São Carlos, EESC-USP.

PINHEIRO, L. M.; GIONGO, J. S. (1996). Concreto armado: propriedades dos materiais. São Carlos, EESC-USP.

RITCHIE, D. M. (1993). The development of the $C$ language. In: HISTORY OF PROGRAMMING LANGUAGES CONFERENCE, 2.,Cambridge, USA, April.

RODRIGUES, R.O.; VENTURINI, W.S.; ANDRADE, J.R.L. (1985). Ábacos para o dimensionamento de seções retangulares de concreto armado no estado limite último. In: CONGRESSO DE INICIAÇÃO CIENTÍFICA E TECNOLÓGICA EM ENGENHARIA, 4., São Carlos. Anais. São Carlos, EESC - USP. p.65. 
RÜSCH, H. (1960). Researches toward a general flexural theory for structural concrete. Journal of the American Concrete Institute. July.

SANTOS, L. M. (1983). Cálculo de concreto armado. 2.ed. São Paulo, LMS. 2v.

SANTOS, L. M. (1994). Sub-rotinas básicas do dimensionamento de concreto armado. São Paulo, Thot.

SAVASSI, W. (1996). Introdução ao método dos elementos finitos. São Carlos, EESC USP.

SCHMID, A. L. (1988). SIDICANU 1 e 2 - SIstema DIdático de Apoio ao ensino de CÁlculo NUmérico. http://www.cesec.ufpr.br/ scheer/etools.html

SILVA, R. M. (1996). Análise não linear de pórticos planos de concreto armado: modelagem numérica e avaliação dos métodos aproximados. São Carlos. Dissertação (Mestrado) - Escola de Engenharia de São Carlos, Universidade de São Paulo.

SLATER, J. H.; PETROSSIAN, R. B. P.; SHYAM-SUNDER, S. (1984). An expert tutor for rigid body mechanics: ATHENA CATS-MACAVITY. EXPERT SYSTEMS IN GOVERNMENT SYMPOSIUM. Proceedings. IEEE/CS, McLean, USA, 11p.

SMITH, J. W. (1984). Using computers to teach structural analysis. Computers \& Education. v. 8, p.101-105.

STROUSTRUP, B. (1999). An overview of the C++ programming language. In: ZAMIR, S., ed. Handbook of object technology. Boca Raton, USACRC Press.

SÜSSEKIND, J. C. (1984). Curso de concreto. Rio de Janeiro, v.2, Globo. 
SÜSSEKIND, J. C. (1991). Curso de análise estrutural. Rio de Janeiro, Globo.

TQS INFORMÁTICA. (2000). Sistemas computacionais - engenharia estrutural. http://www.tqs.com.br Eventos Marcantes

VENTURINI, W.S. (1987). Dimensionamento de peças retangulares de concreto armado solicitadas à flexão reta. São Carlos, EESC - USP. 286p.

WILSON, E.L. (1979). CAL - A computer analysis language for teaching structural analysis. Computers and Structures, v.10, p.127-132. 


\section{ANEXO A}

\section{TUTORIAL - DTOOL}

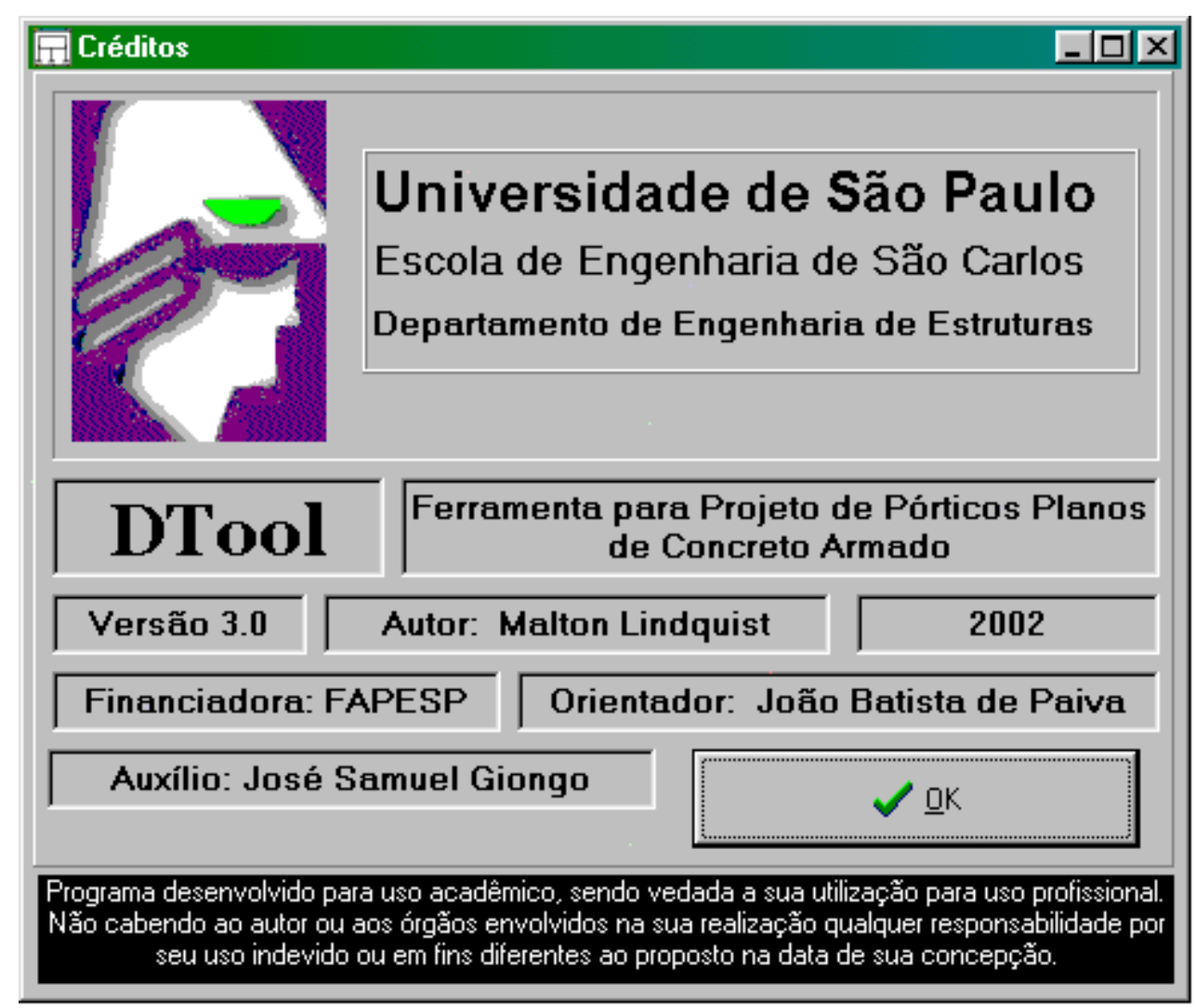

Figura A.1 - Janela de Entrada

\section{A.1. Introdução}

Com o intuito de facilitar a compreensão do funcionamento do programa chamado DTool, neste anexo será apresentada uma explicação de suas funções e métodos. Mostrar-se-á a utilidade de cada parte do programa, bem como a forma de visualização da estrutura utilizada. 


\section{A.2. Linguagem de Programação}

$\mathrm{Na}$ implementação do programa foi utilizado o compilador Borland $\mathrm{C}++$ Builder 5.0.

A linguagem de programação $\mathrm{C}++$ teve início paralelamente à história do desenvolvimento dos primeiros computadores. Na década de 60 , vários centros de pesquisa como MIT, General Electric e laboratórios Bell se uniram no propósito de desenvolver um projeto chamado Multics, que envolvia criar um novo computador com um novo sistema operacional. Mesmo depois que a máquina GE-645 Multics começou a tomar forma, um grupo informal, liderado inicialmente por Ken Thompson começou a investigar outras alternativas.

Thompson queria criar um ambiente computacional confortável de acordo com seus próprios ideais, usando quaisquer meios que tivesse. Uma linguagem alternativa da época, era chamada BCPL, possuía a vantagem de escrever os programas em uma linguagem fácil de escrever e entender.

Criada por Thompson, uma nova linguagem foi chamada de $B$, que pode ser considerada como a linguagem $\mathrm{C}$ sem símbolos; mais especificamente, era a linguagem BCPL ajustada para $8 \mathrm{~K}$ bytes de memória e adaptada pela mente de Thompson. Dennis Ritchie, realizou algumas modificações importantes na linguagem, como a utilização de um pré-processador, a inclusão dos comandos \#include e \#define como macros, o esquema de composição tendo como modelo a linguagem Algol68, entre outras. À linguagem resultante, Ritchie deu o nome de New B, NB, e depois de C por ser a letra posterior no alfabeto. (RITCHIE, 1993)

A linguagem C começou a ser desenvolvida entre os anos de 1969 e 1973, ao mesmo tempo em que os primeiros passos eram dados para o desenvolvimento do sistema operacional Unix; o período mais criativo ocorreu em 1972. Outras mudanças importantes aconteceram entre 1977 e 1979. No meio da década de 80, a linguagem foi oficialmente registrada pelo comitê ANSI, que fez algumas mudanças adicionais. Até o começo da década de 80, apesar de compiladores existirem para uma grande variedade de máquinas e sistemas operacionais, a linguagem era quase exclusivamente utilizada em sistema Unix. Mais 
recentemente, seu uso tem se espalhado amplamente, e hoje está entre as linguagens de programação mais utilizadas na indústria tecnológica. (RICTHIE, 1993)

A linguagem $C$ é portátil, não está atrelada a nenhum hardware particular ou sistema operacional. C combina os elementos de uma linguagem de alto nível com funcionalidade e torna fácil adaptar softwares de um computador para outro.

A linguagem $\mathrm{C}++$ também foi produzida nos laboratórios Bell (Atualmente AT\&T), tendo como seu autor Bjarne Stroustrup. Seu objetivo principal ao projetar a nova linguagem foi fazer com que o trabalho em escrever bons programas fosse mais fácil e agradável para o programador individual. A linguagem foi chamada de C com classes no início da década de 80. Com a adição de novos recursos e a eliminação de muitas das dificuldades que programadores iniciantes tinham ao utilizar C, a linguagem resultante foi chamada de $C_{++}$em 1983. Sua popularidade cresceu vertiginosamente na década de 90, quando vários recursos foram introduzidos, como classes, modelos, exceções, os conceitos de herança múltipla, etc. (GRIBBLE, 2000)

Muitas ferramentas e mesmo outras linguagens são baseadas em $\mathrm{C}_{++}$ como Microsoft Visual $\mathrm{C}++$, Java, entre outras.

A linguagem $\mathrm{C}++$ tem um modelo de memória e cálculo que é muito parecido com o da maioria dos computadores. Além disso, ela possui um poderoso e flexível mecanismo de abstração; que é uma linguagem que permite ao programador introduzir e usar novos tipos de objetos que se adaptam aos conceitos de uma aplicação. Além disso, $\mathrm{C}_{++}$contém estilos de programação que contam com tipos definidos pelo usuário que dão um modelo de dados e cálculo que é próximo àvisão humana da tarefa sendo realizada pelo computador. Este alto nível de estilo de programação é geralmente chamado de abstração de dados, programação orientada a objeto e programação genérica. (STROUSTRUP, 1999)

Atualmente a linguagem é utilizada por centenas de milhares de programadores. Esta utilização é embasada em dezenas de libraries* ${ }^{*}$ centenas de livros, vários periódicos técnicos, muitas conferências e inumeráveis consultores.

A linguagem $\mathrm{C}++$ é grandemente utilizada para ensino e pesquisa. Isto surpreende alguns que, corretamente, perceberam que esta não é a menor ou a mais clara linguagem existente. No entanto, segundo STROUSTRUP (1999) ela é:

Limpa o suficiente para um ensino bem sucedido de conceitos básicos, 
- Prática, eficiente e flexível o suficiente para atender aos projetos necessários,

- Suficientemente acessível para organizações e colaborações nos seus diversos ambientes de execução e desenvolvimento,

- Suficientemente compreensível para ser um veículo para ensinar conceitos avançados e técnicas, e

- $\quad$ Comercial o suficiente para ser utilizada fora do ambiente acadêmico.

* Libraries: Coleção de programas e comandos existente no compilador $\mathrm{C}++$ que facilitam o trabalho de programação.

\section{A.3. Programas Anteriores}

O programa DTool iniciou-se em um projeto de iniciação científica implementado com o intuito de dimensionar vigas de concreto armado. Tais vigas seriam dimensionadas àflexão. Ao programa, iniciado em agosto de 1996 , foi dado o sugestivo nome First. O objetivo era que os nomes fossem mudando com 0 aumento do número ordinal em inglês. (LINDQUIST, 1997)

A quarta versão nesta seqüência, Fourth, foi a primeira a desenhar em corte a viga que estava sendo dimensionada. Às versões foram dados nomes do número ordinal em inglês até a nona versão, terminada em julho de 1997, que foi chamada de MDI.

Neste primeiro ano de desenvolvimento, a maior dificuldade foi a familiarização com o compilador, na época Borland $C_{++} 4.0$, ainda sem os recursos Builder, que em muito facilitam o trabalho de programação. Por equilíbrio, dimensionava-se a armadura de flexão para uma seção transversal de viga, desenhando-se tal viga na janela principal do programa.

No segundo ano de bolsa foram colocados mais recursos no programa, que agora possuía uma barra de ferramentas e desenhava o estribo no corte transversal. Era possível verificar as distâncias vertical e horizontal entre as barras longitudinais, bem como calcular e desenhar a altura útil necessária para que a viga em questão resistisse ao momento fletor ao qual estava submetida. Ao programa terminado neste período, em julho de 1998, foi dado o nome de MDI_98. 
No último ano de trabalho em dimensionamento de vigas de concreto armado, entre março e dezembro de 1999, muitos recursos foram criados, desenvolvendo-se grandemente o programa devido à maior facilidade e familiaridade com a linguagem de programação. Neste período o programa recebeu o nome de DVCA, dimensionamento de vigas de concreto armado. O grande avanço alcançado em DVCA foi não só a consideração de um corte transversal na viga, mas a consideração da viga como um todo, com o cobrimento do diagrama de momento fletor e detalhamento da armadura longitudinal ao longo de todo o vão. O programa possuía recursos como a opção de salvar e abrir arquivos, diagrama de momento fletor e força cortante, assim como o detalhamento do corte transversal existente no programa anterior.

Um exemplo de uma viga sendo analisada em DVCA está mostrado na figura A.2.

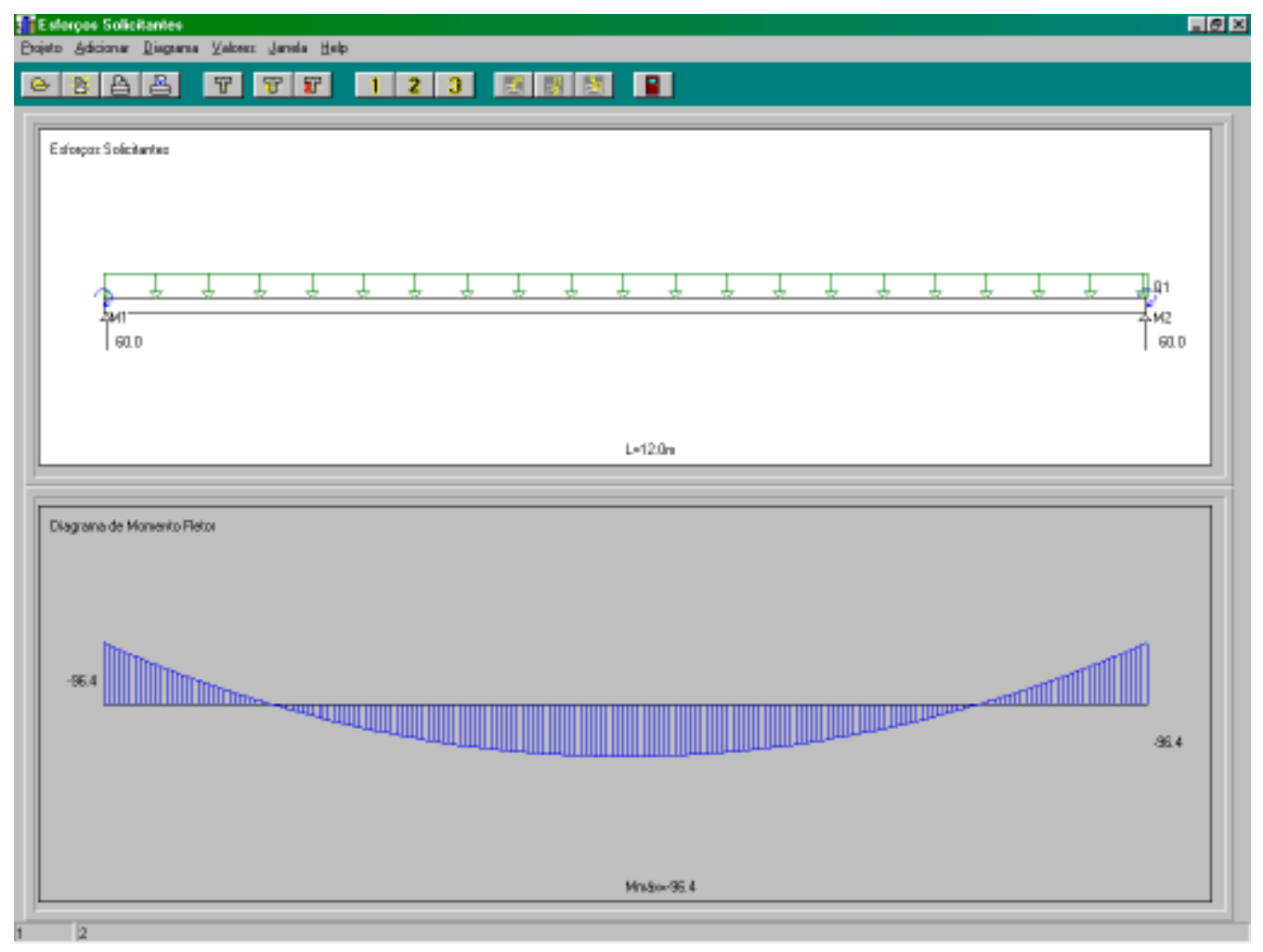

Figura A.2 - Programa DVCA 


\section{A.4. DTool}

Ao programa atual, foi dado o nome de DTool como referência à sua função de servir como ferramenta no projeto de estruturas de concreto armado e tem como mensagem inicial a caixa de diálogo mostrada na figura A.1.

\section{A.4.1 Janela Inicial}

Após a caixa de diálogo inicial ser fechada, o programa mostra a janela inicial, conforme a figura a seguir.

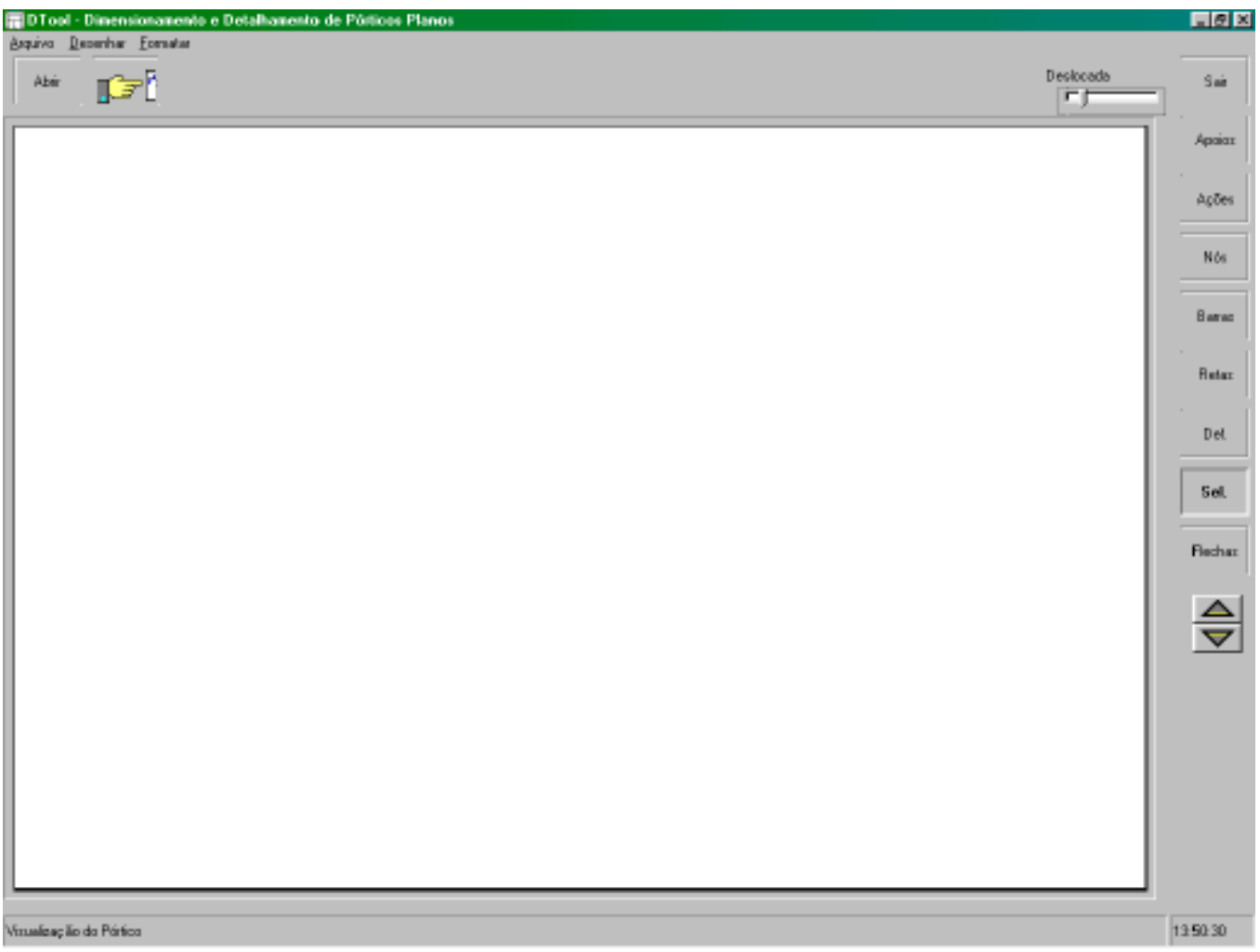

Figura A.3 - Programa DTool

Como DTool tem como função trabalhar com o pós-processamento no projeto de pórticos planos, ele não possui a opção de fazer um arquivo novo a partir do programa. Mas sua opção é só a de abrir um arquivo existente, a partir do qual serão feitos o dimensionamento e o detalhamento da estrutura. 
No estágio mostrado na figura A.3, os únicos botões ativos para clicar são a opção de abrir arquivos e a opção para sair.

A seguir serão mostradas as funções dos botões mostrados na figura A.3.

\section{A.4.1.1 Botão Abrir}

Abrii

Localizado no canto superior esquerdo da tela, ele aciona a caixa de diálogo para abrir arquivos, conforme mostrado na figura A.4. Também pode ser acionada esta opção pelo menu Arquivo->Abrir.

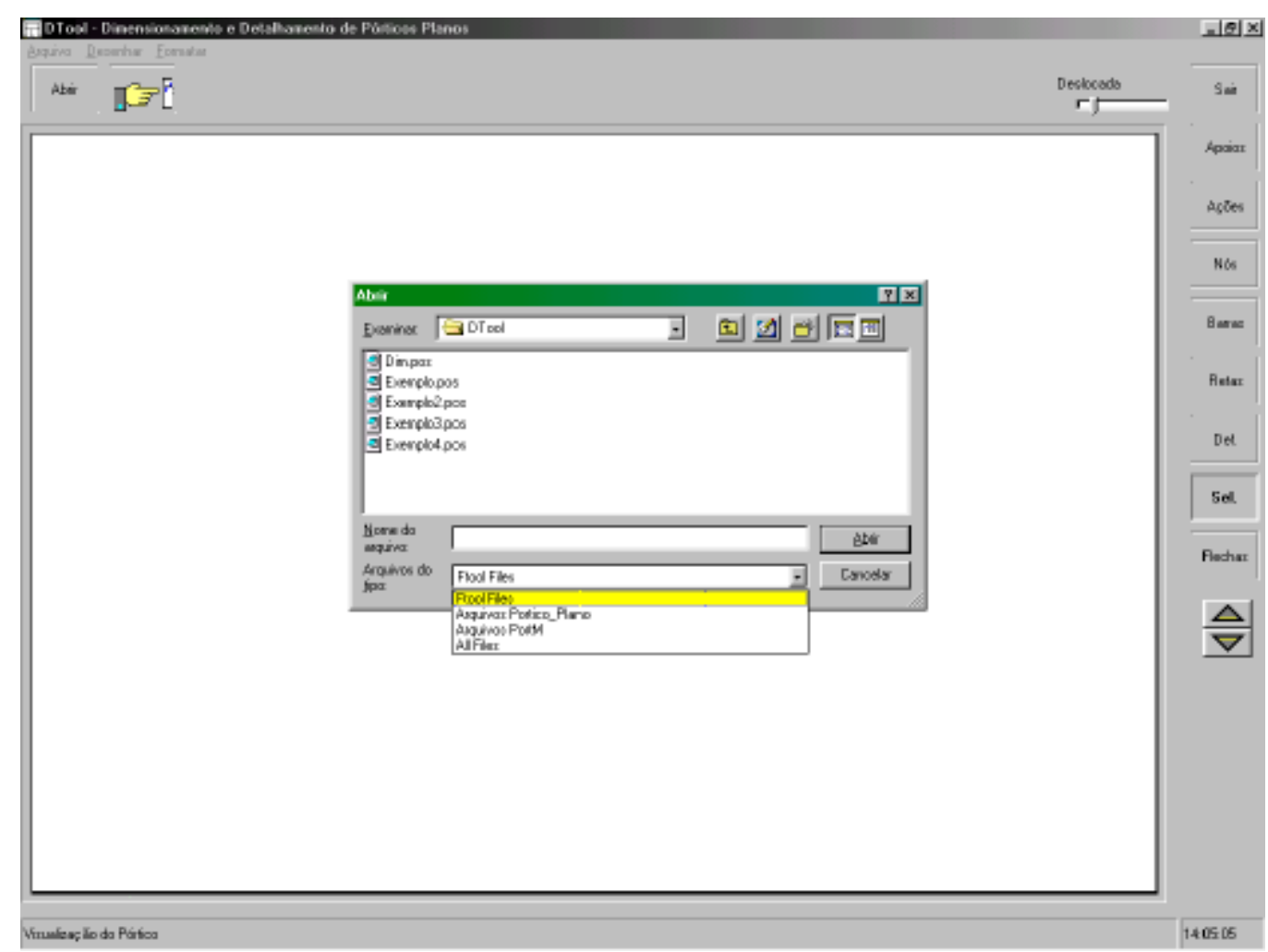

Figura A.4 - Caixa de Diálogo para Abrir Arquivos

Estão sendo mostradas as opções de arquivos que podem ser abertos. $O$ principal tipo de arquivo possui extensão pos, sendo o arquivo de processamento do programa FTool. KAEFER (2000) descreve tal programa como "um sistema 
gráfico interativo cujo objetivo principal é fornecer ao estudante de engenharia estrutural uma ferramenta para aprender o comportamento estrutural de pórticos planos".

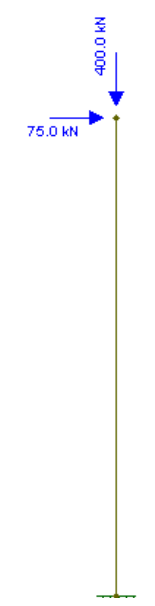

Um arquivo com extensão pos (.pos) para descrever um pilar conforme mostrado na figura A.5, tem a seguinte forma.

Figura A.5 - Pilar Exemplo

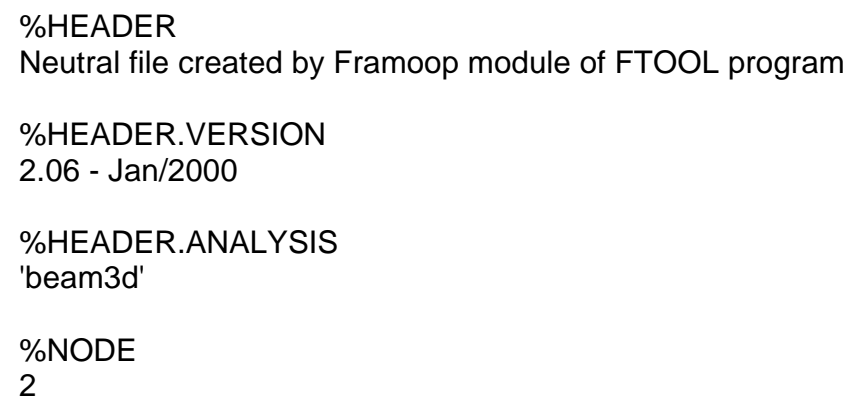




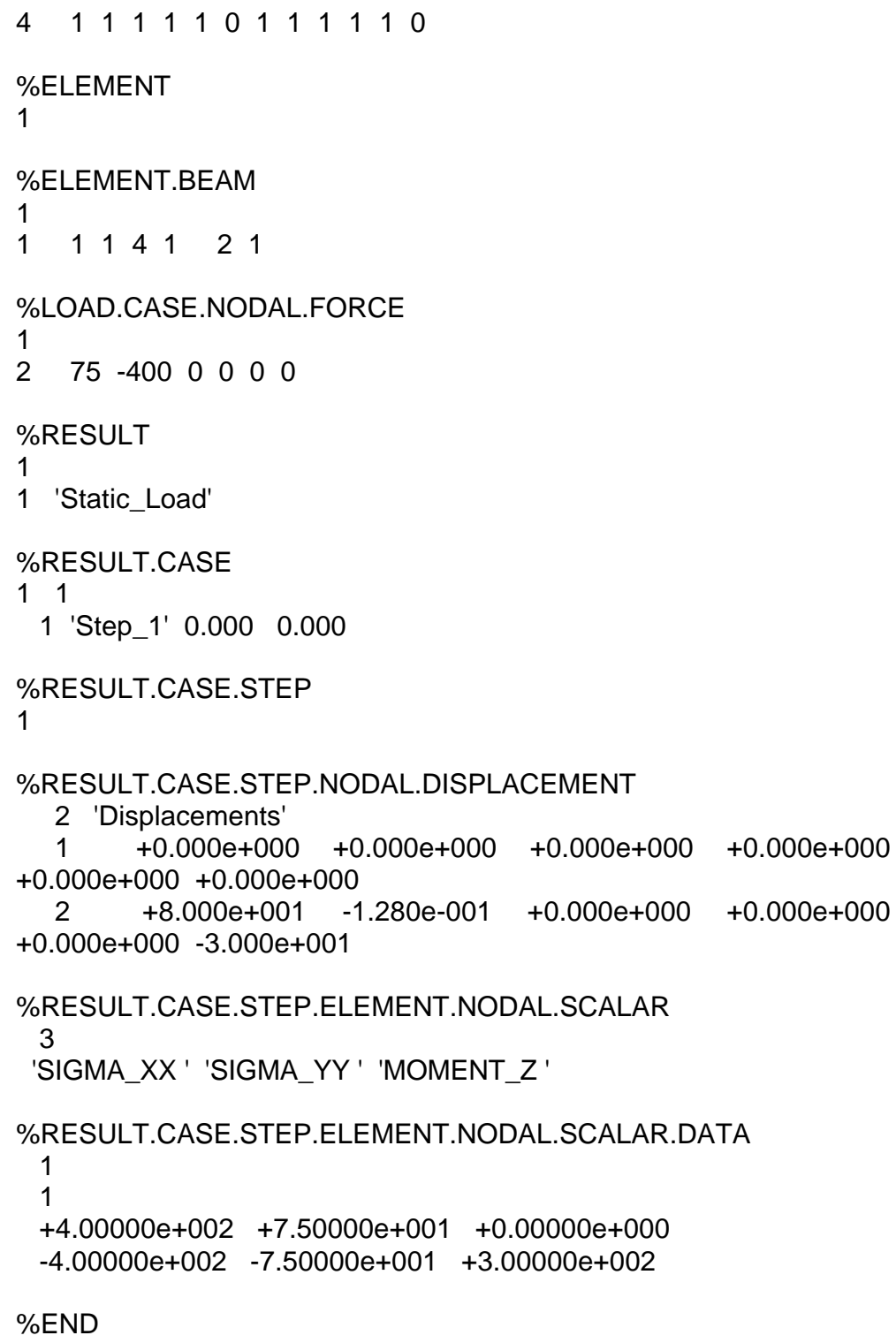

O programa DTool lerá os seguintes valores:

- Número de nós, dado depois de \%NODE;

- Coordenadas X e Y de cada nó, depois de $\%$ NODE.COORD;

- Condições de apoio de cada nó, \%NODE.SUPPORT;

- Nós inicial e final do elemento, \%ELEMENT.BEAM

- Forças nodais, \%LOAD.CASE.NODAL.FORCE

- Deslocamento nos nós, \%RESULT.CASE.STEP.NODAL.DISPLACEMENT; e

- Esforços nos nós, 
A segunda e a terceira opções da caixa de diálogo mostrada na figura A.4 são para abrir arquivos de saída dos programas feitos em Fortran Pórtico_Plano e PortM, ambos executados em DOS.

Logo após a abertura do arquivo, o diretório, juntamente com o arquivo selecionado é mostrado no canto inferior esquerdo da tela, conforme pode ser observado na figura A.6.

\section{A.4.1.2 Botão Sair}

Sair

O primeiro de uma série de botões no canto direito da tela, conforme pode ser visto nas figuras A.3 e A.4. Tem como função fechar o programa. Este botão está presente em todas as janelas, na mesma localização, tendo a mesma função. Também pode ser acessada esta opção no menu Arquivo->Sair.

\section{A.4.1.3 Botão Apoios}

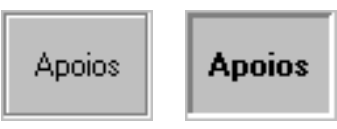

Quando esta opção está selecionada, o botão aparece conforme o desenho da direita indicando que a opção está ativada. Estando ativada, são desenhados os apoios da estrutura no desenho na parte central da tela, conforme a figura a seguir. Logo após abrir um arquivo, a opção de desenho dos apoios é automaticamente ativada. 


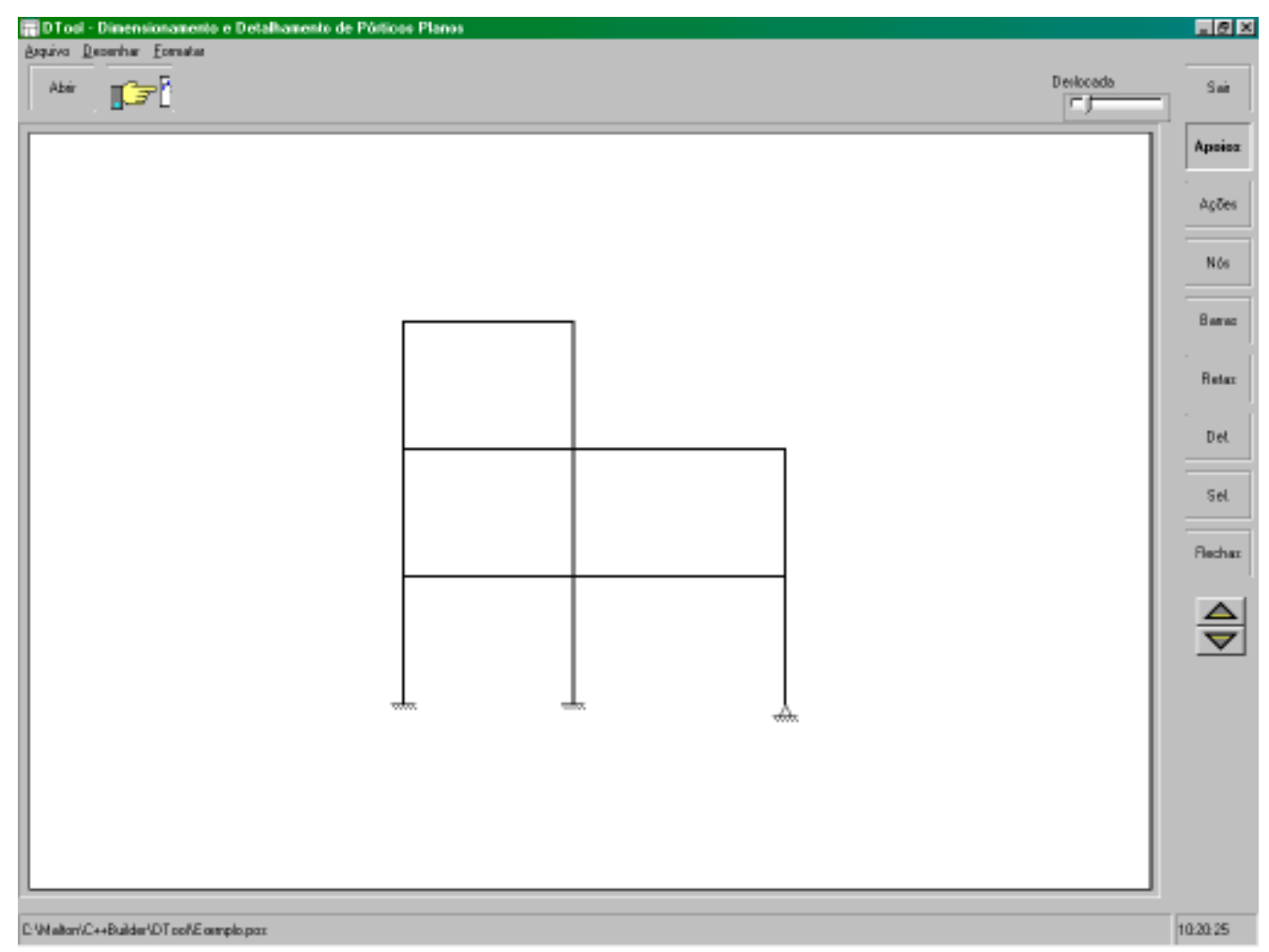

Figura A.6 - Opção de Desenho dos Apoios

\section{A.4.1.4 Botão Ações}

\section{Ações}

Açōes

O botão Ações tem como função acionar a opção de desenho das ações atuantes no pórtico visualizado. Novamente, se a opção estiver ativa, o aspecto do botão fica conforme figura mostrada à di reita. Selecionando-se tal função, o desenho para este pórtico exemplo será conforme a figura A.7. 


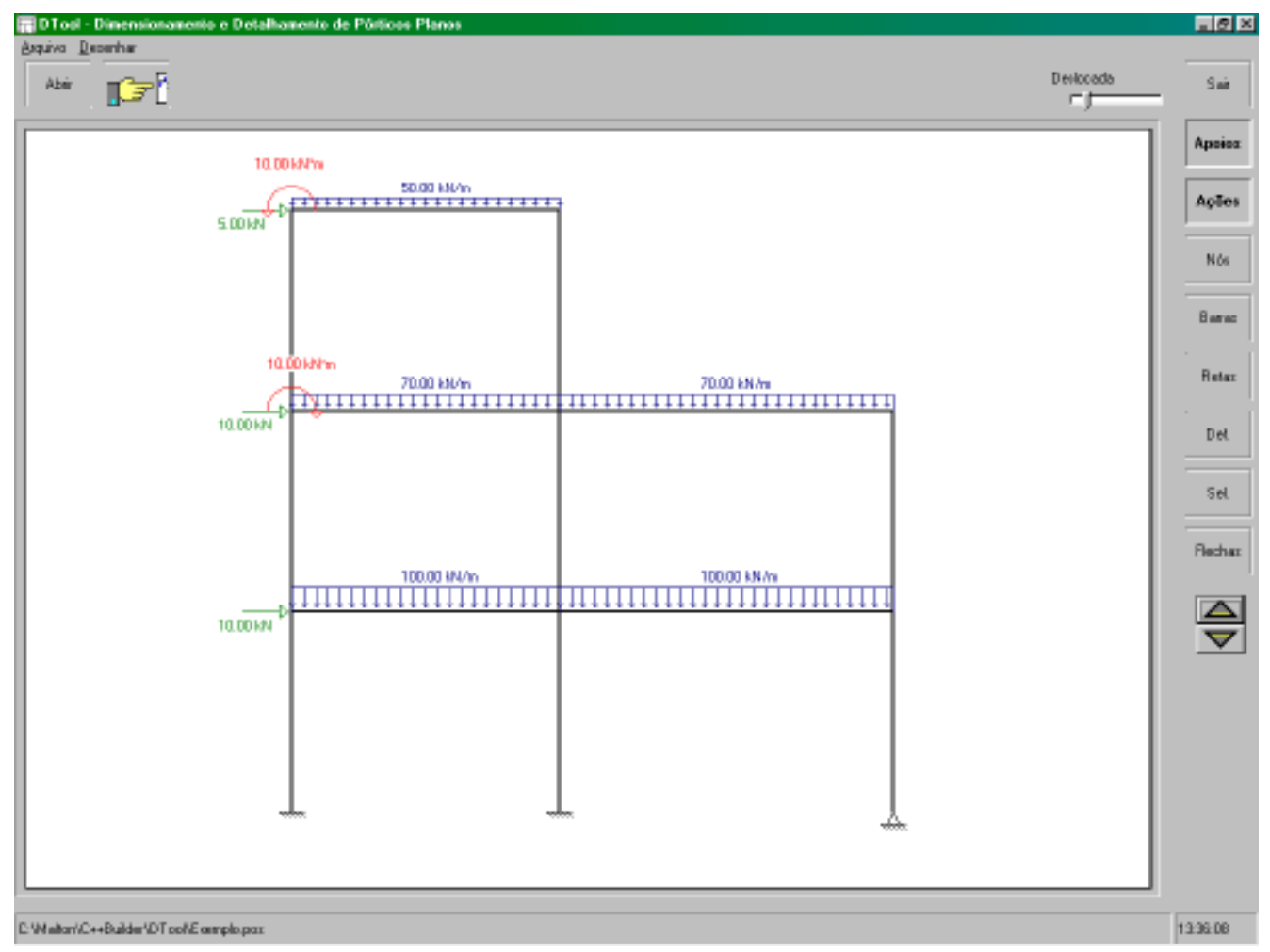

Figura A.7 - Desenho das Ações Atuantes na Estrutura

Pode-se observar que para o valor da carga distribuída, a sua altura é proporcional ao valor atuante. No exemplo desenhado, cada um dos momentos aplicados atua em um sentido, horário ou anti-horário. Para facilitar a visualização, ao invés de desenhar a seta para o mesmo lado e colocar o valor com sinal negativo, optou-se por deixar o valor positivo e simplesmente inverter a seta que indica o sentido de rotação do momento aplicado.

As cores, distintas para cada tipo de carregamento, tem como função um melhor reconhecimento do tipo de cada ação aplicada ao pórtico. As cores apresentadas são as seguintes:

- Azul Representa as cargas distribuídas;

- Verde Representa as cargas pontuais;

- Vermelho Representa os momentos fletores. 


\section{A.4.1.5 Botão Nós}

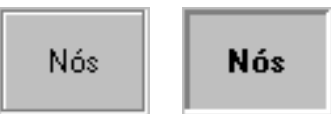

O botão abaixo do responsável para o desenho das ações atuantes na estrutura, é o mostrado nas figuras acima. Ao acionar esta opção, são mostrados os números dos nós na estrutura, bem como suas coordenadas. No exemplo considerado neste anexo, ao selecionar esta opção, o desenho fica conforme a figura a seguir.

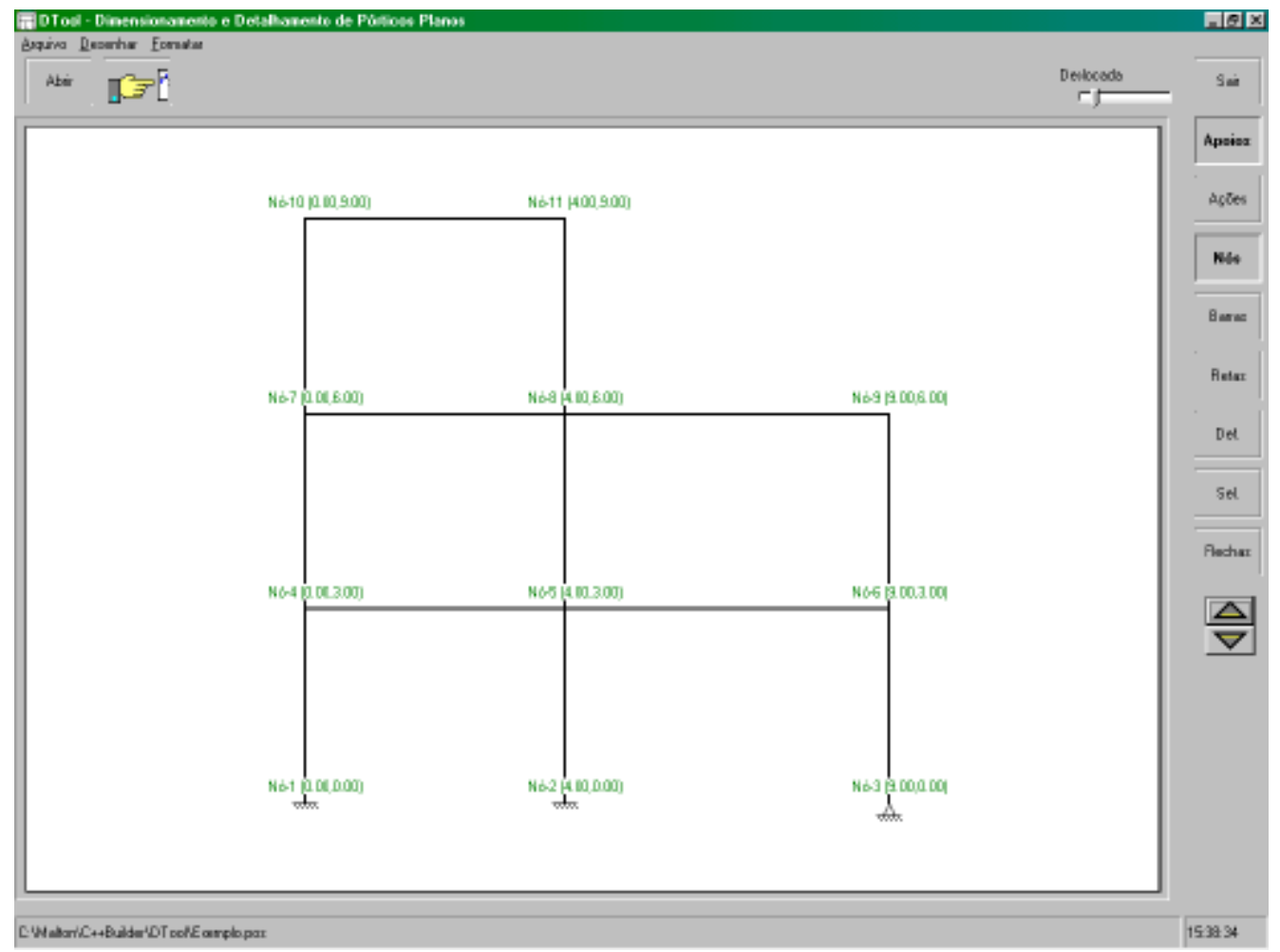

Figura A.8 - Desenho do Número e Coordenadas dos Nós

Pode-se observar na figura A.8 que a opção de desenho das ações foi desativada, com o intuito de facilitar a visualização das coordenadas dos nós, e desta forma deixar o desenho mais claro. 


\section{A.4.1.6 Botão Barras}

Barras

Barras

A opção de desenho acionada com o botão mostrado acima mostra o número de cada barra no pórtico em questão, conforme a figura A.9.

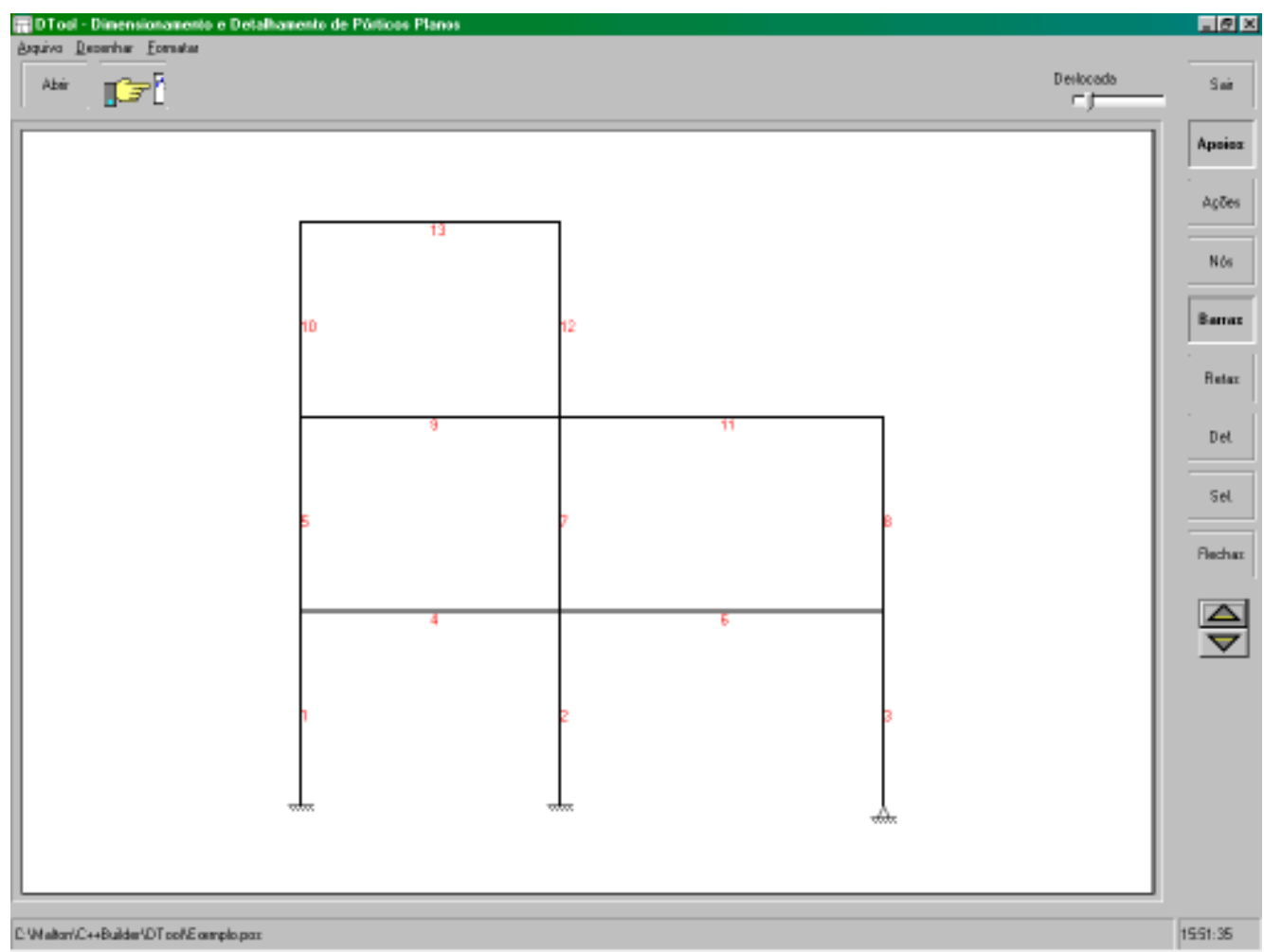

Figura A.9 - Desenho do Número das Barras

\section{A.4.1.7 Botão Retas}

Retas

Retas

O botão com nome Retas tem como função desenhar em retas a estrutura deslocada. Os valores de tais deslocamentos são dados de saída do processador, 
lidos no arquivo mostrado em A.4.1. A representação por retas mostra somente os deslocamentos nodais da estrutura, conforme a figura a seguir.

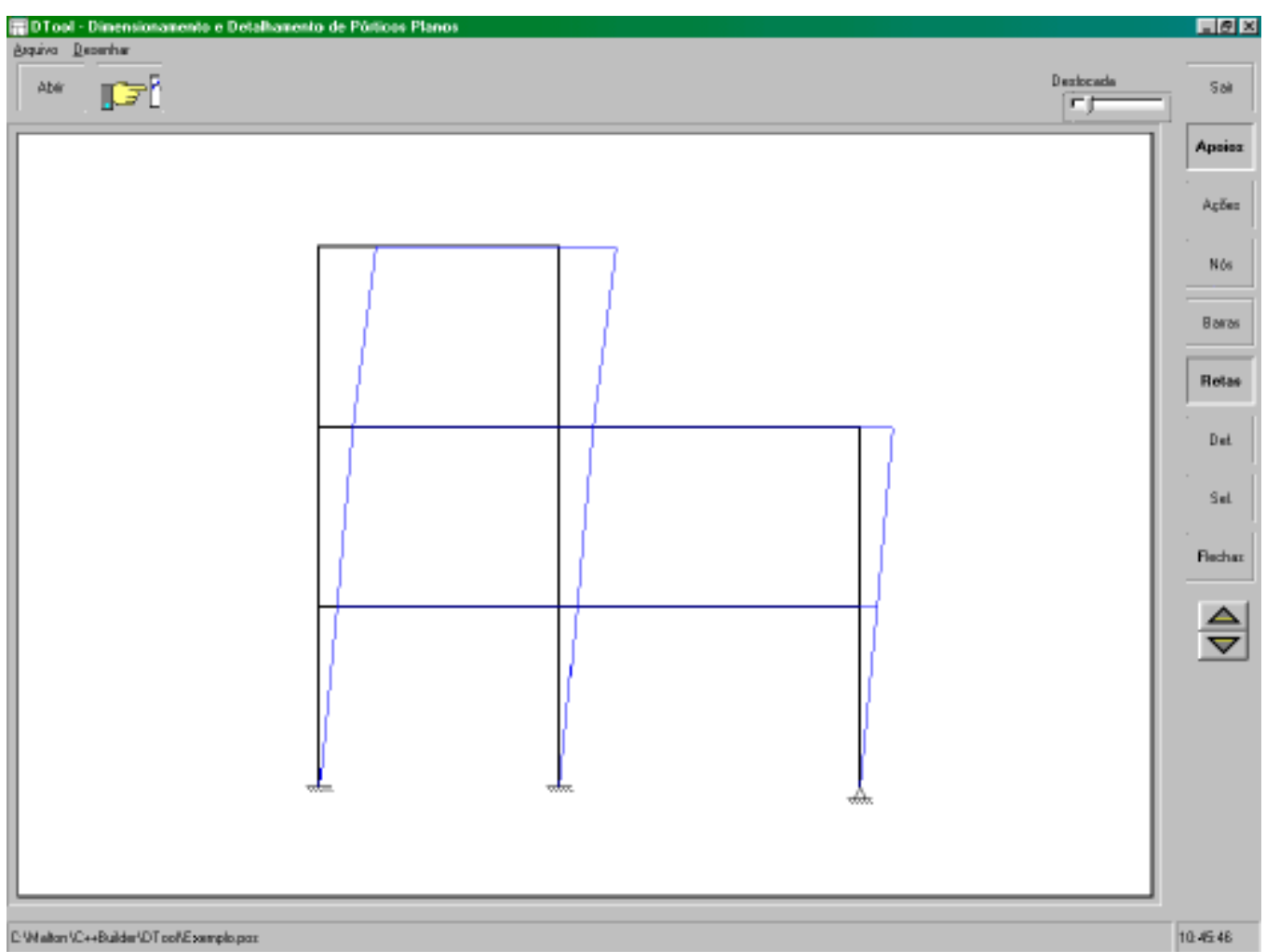

Figura A.10 - Desenho dos Deslocamentos Nodais

A escala para o desenho da estrutura deslocada é regida pela TrackBar no canto superior direito da tela, com o nome de Deslocada, conforme a figura A.11. Quanto mais para a direita for colocada a posição de seleção na barra, maior será a escala para representação da estrutura deslocada no desenho.

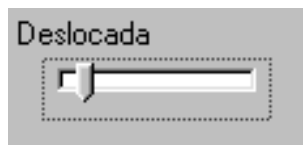

Figura A.11 - TrackBar para Desenho da Estrutura Deslocada

Aumentando-se a escala para o desenho, a figura representando a estrutura deslocada fica da seguinte forma: 


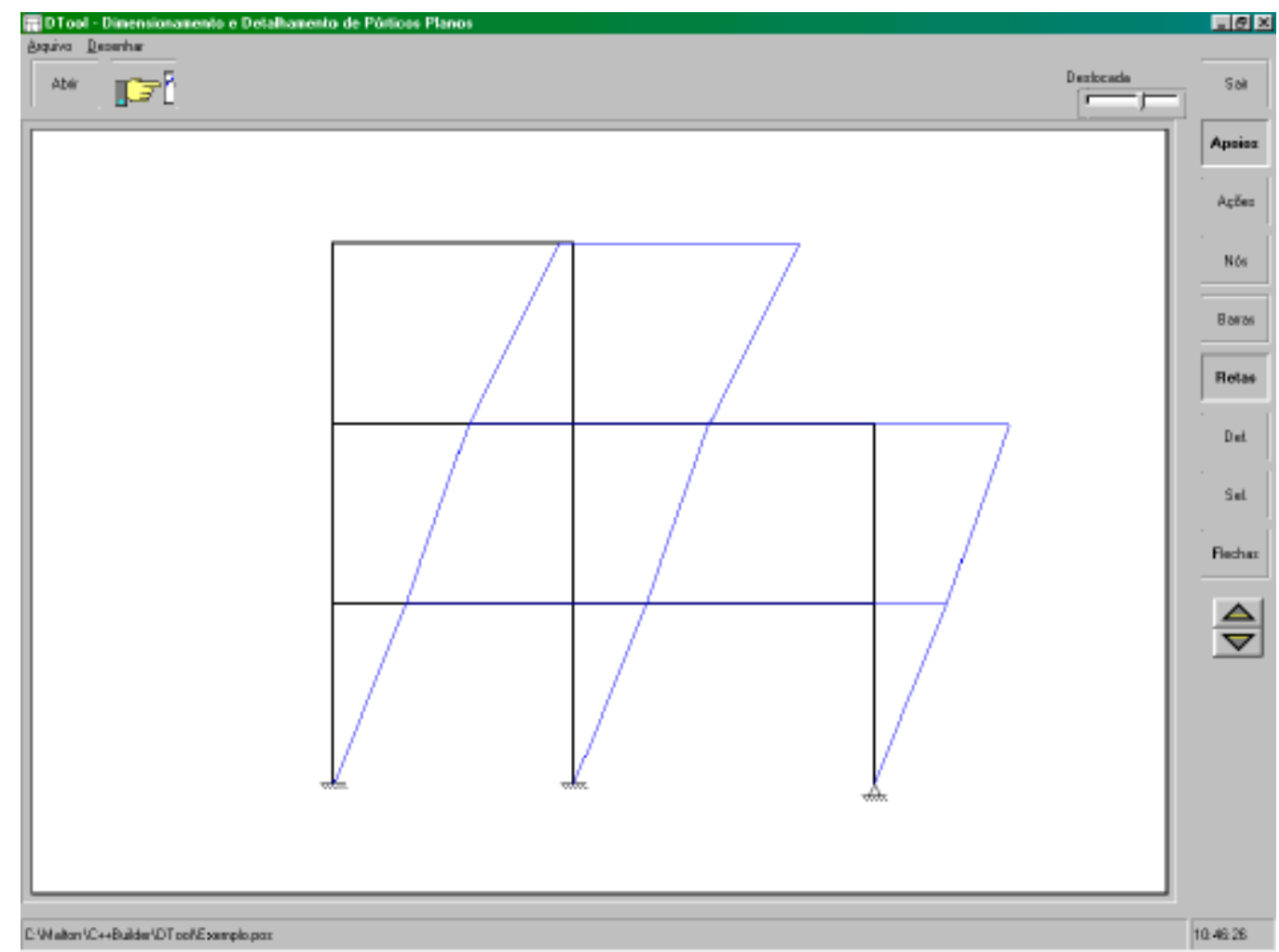

Figura A.12 - Desenho dos Deslocamentos Nodais em Escala Maior

\section{A.4.1.8 Botão Deformada}

Def.

\section{Def.}

Esta é a opção para desenho da estrutura deformada, mostrando a deformação de cada barra, não somente os deslocamentos nodais.

Os resultados do programa processador indicam somente os deslocamentos e rotações nos nós, conforme indicado em A.4.1. Porém, era necessário ter estes resultados ao longo da barra. Para tanto, foi utilizada a dedução encontrada em SAVASSI (1996), utilizando o método dos elementos finitos, com aproximação por polinômio algébrico cúbico completo.

$$
\mathrm{v}(\xi)=\alpha_{0}+\alpha_{1} \xi+\alpha_{2} \xi^{2}+\alpha_{3} \xi^{3}
$$


Utilizando os parâmetros nodais

$\mathrm{v}_{\mathrm{i}}=\mathrm{v}(0)=\alpha_{0}$

$\theta_{i}=\left.\frac{\mathrm{dv}}{\mathrm{dx}}\right|_{\mathrm{i}}=\left.\left[\frac{\mathrm{dv}}{\mathrm{d} \xi} \frac{\mathrm{d} \hat{\mathrm{\imath}}}{\mathrm{dx}}\right]\right|_{\mathrm{i}}=\frac{1}{\ell} \alpha_{1}$

$\mathrm{v}_{\mathrm{j}}=\mathrm{v}(1)=\alpha_{0}+\alpha_{1}+\alpha_{2}+\alpha_{3}$

$\theta_{j}=\left.\frac{\mathrm{dv}}{\mathrm{dx}}\right|_{j}=\frac{1}{\ell}\left(\alpha_{1}+2 \alpha_{2}+3 \alpha_{3}\right)$

Acham-se os valores:

$\alpha_{0}=\mathrm{v}_{\mathrm{i}}$

$\alpha_{1}=\ell \theta_{\mathrm{i}}$

$\alpha_{2}=-3 \mathrm{v}_{\mathrm{i}}+3 \mathrm{v}_{\mathrm{j}}-2 \ell \theta_{\mathrm{i}}-\ell \theta_{\mathrm{j}}$

$\alpha_{3}=2 \mathrm{v}_{\mathrm{i}}-2 \mathrm{v}_{\mathrm{j}}+\ell \theta_{\mathrm{i}}+\ell \theta_{\mathrm{j}}$

Então:

$\mathrm{v}(\hat{\imath})=\left(2 \hat{\imath}^{3}-3 \hat{\imath}^{2}+1\right) \mathrm{v}_{\mathrm{i}}+1\left(\hat{\imath}^{3}-2 \hat{\imath}^{2}+\hat{\imath}\right) \hat{\mathbf{e}}_{\mathrm{i}}+\left(-2 \hat{\imath}^{3}+3 \hat{\imath}^{2}\right) \mathrm{v}_{\mathrm{j}}+1\left(\hat{\imath}^{3}-\hat{\imath}^{2}\right) \grave{\hat{e}} \mathrm{j}$ 
Os valores $v_{i}, \theta_{i}, v_{j}$ e $\theta_{j}$, são os resultados lidos no arquivo de entrada, que constituem os deslocamentos na direção perpendicular ao eixo da barra no nó inicial e final, e as rotações nos mesmos nós. Sendo $\xi$ igual a $\frac{x}{\ell}$.

$\mathrm{Na}$ forma matricial, chamando o ponto i de ponto 1 e j de 2, poderia ser escrita a expressão da seguinte forma:

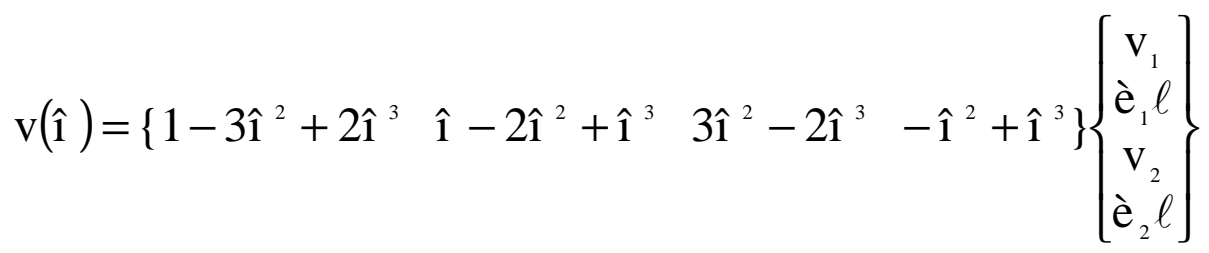

Baseado nesta equação, o programa pode calcular os pontos da barra deformada em questão considerando os dados nodais adquiridos no resultado do primeiro programa. Para determinar a barra deformada, são calculados 21 pontos para $\mathrm{v}(\xi)$, com $\xi$ variando de 0 a 1, estes pontos são ligados por 20 retas.

O desenho da estrutura deslocada ficará da seguinte forma:

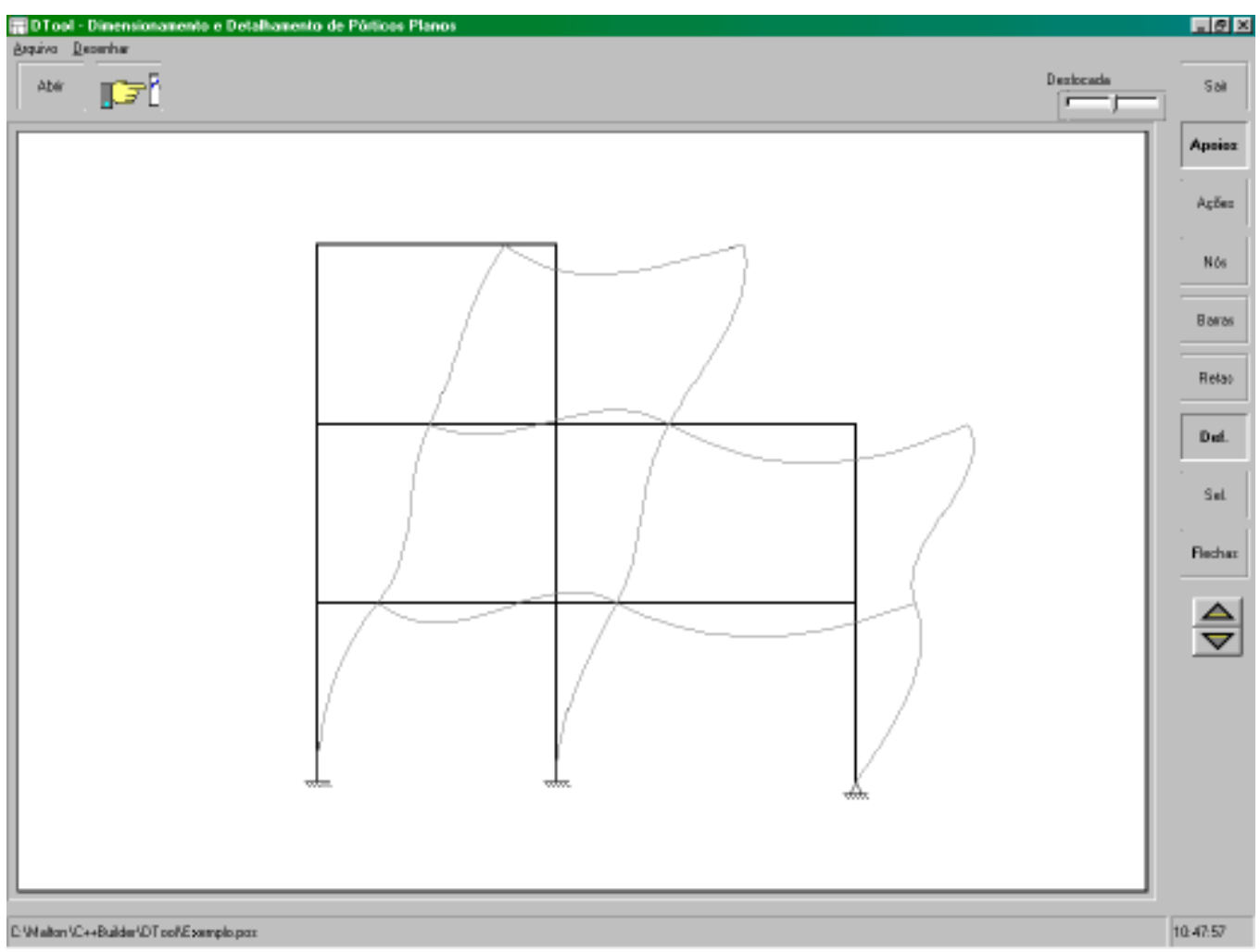

Figura A.13 - Desenho da Estrutura Deslocada 


\section{A.4.1.9 Botão Selecionar}

$$
\text { Sel. }
$$

Sel.

Clicando-se na área de desenho, é possível selecionar a barra mais próxima ao ponto em que foi clicado o mouse. Se entre os dois nós mais próximos do ponto clicado houver uma barra, tal barra será selecionada, e automaticamente o botão será ativado, ficando conforme a figura da direita acima.

Para mostrar o exemplo de uma barra selecionada, a figura a seguir mostra seu funcionamento.

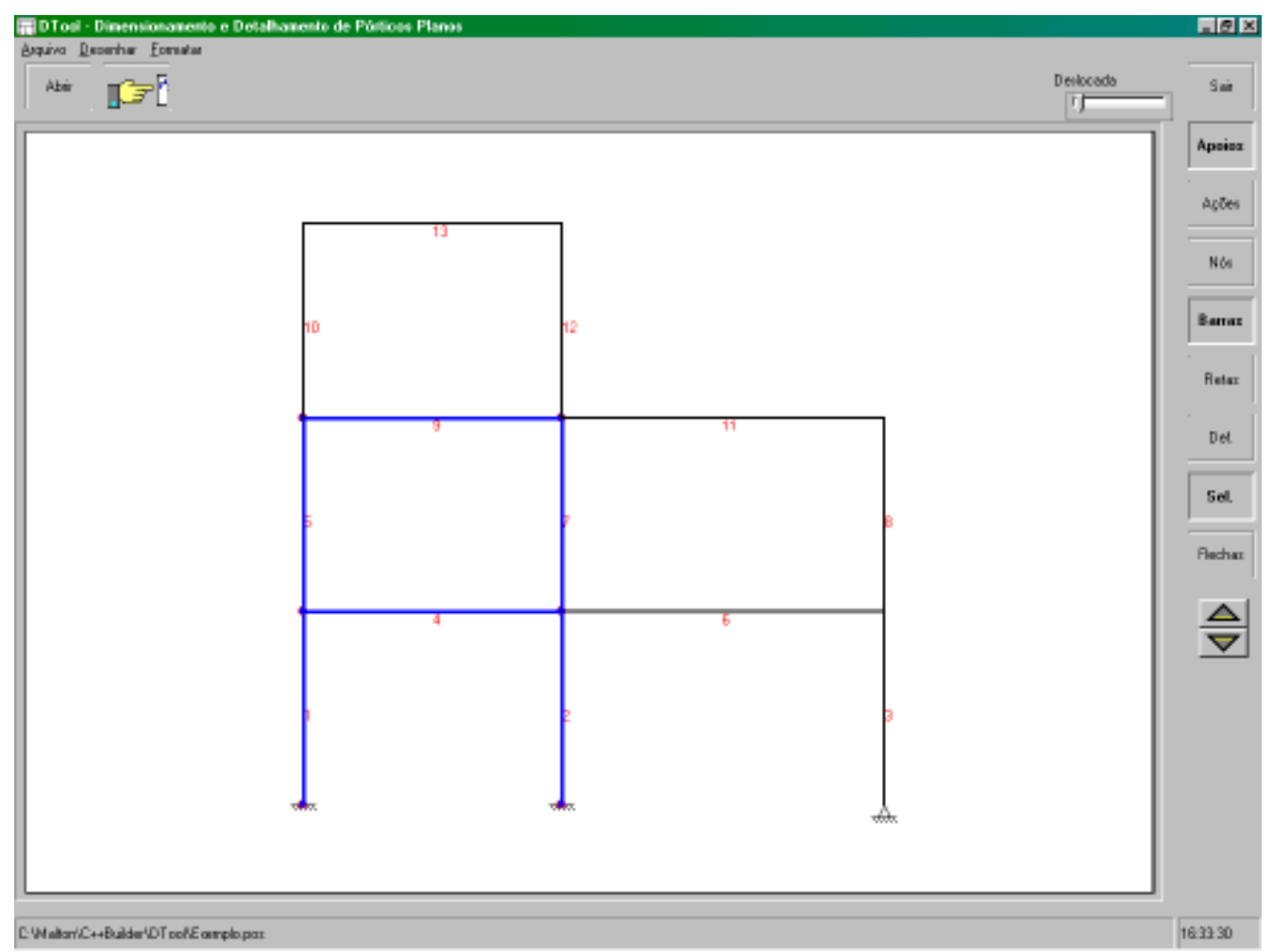

Figura A.14 - Barras Selecionadas

Na figura acima, estão selecionadas as barras 1, 2, 4, 5, 7 e 9; sendo o propósito de tal seleção explicado posteriormente. 


\section{A.4.1.10 Botão Flechas}

\section{Flechas}

\section{Flechas}

A opção acionada pelo botão flechas é para mostrar o deslocamento máximo em cada barra da estrutura deslocada, comparando-se com o vão da barra em que ocorre tal flecha.

Selecionando-se tal opção no exemplo deste anexo, o programa mostra o seguinte desenho.

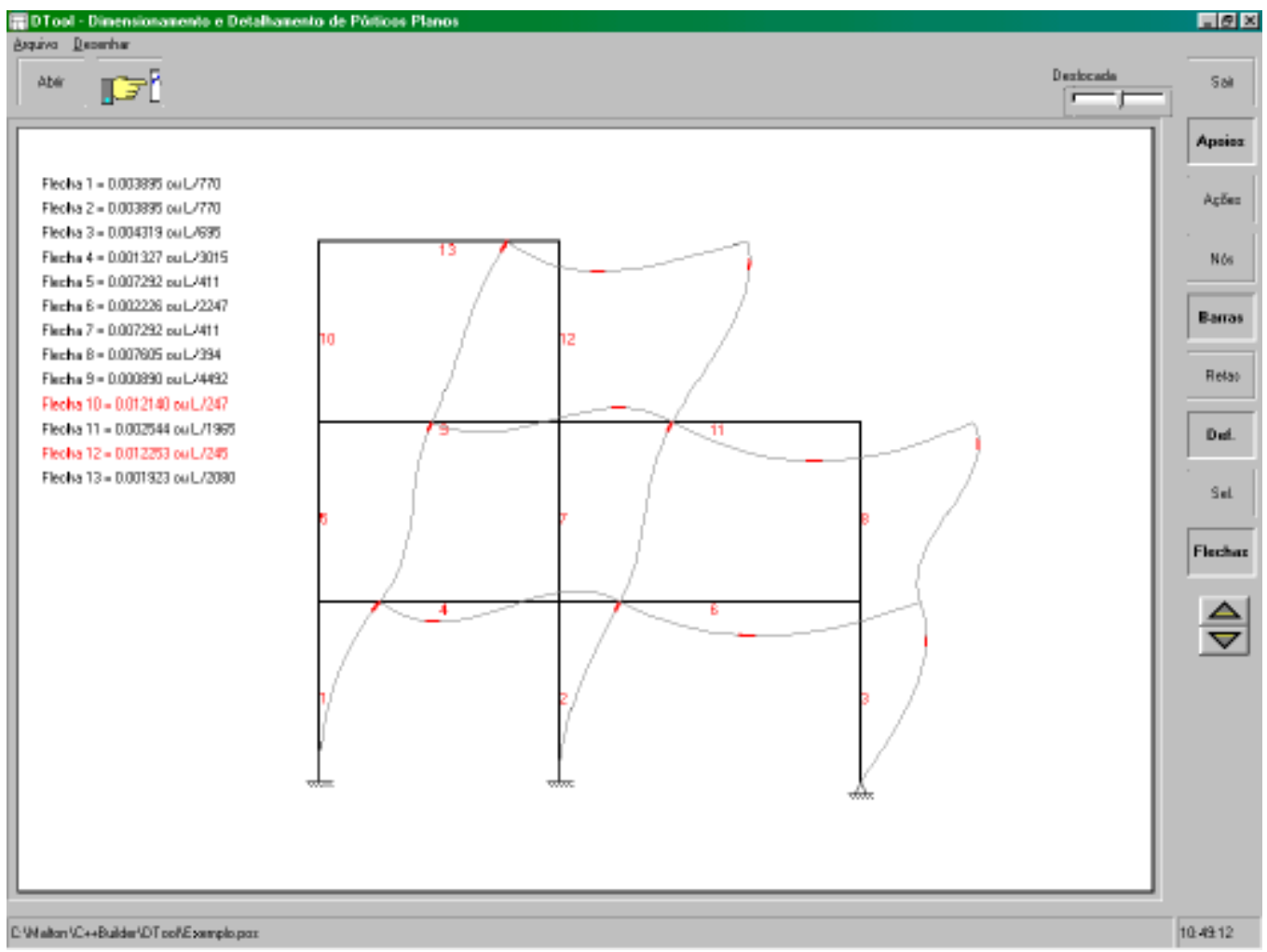

Figura A.15 - Desenho das Flechas na Estrutura Deslocada

Os pontos mostrados em vermelho em cada barra são os locais onde ocorrem os deslocamentos máximos em cada elemento. À esquerda estão os valores da flecha para cada barra mostrada no desenho ao centro, calculada também esta flecha em relação ao vão do elemento, mostrando tal flecha como uma fração do vão do elemento. 
As flechas mostradas em vermelho no texto à esquerda representam aquelas que estão acima dos limites de aceitabilidade sensorial definidos em NBR 6118:2001, de $\ell / 250$ para evitar o desconforto visual, e $\ell / 350$ para vibrações sentidas no piso devido a cargas acidentais.

\section{A.4.1.11 Botões de Controle do Tamanho do Desenho}

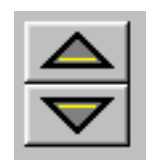

Os botões no canto inferior direito da tela têm como função o controle do tamanho do desenho, selecionando-se a seta para cima ou para baixo, o desenho aumenta ou diminui, respectivamente.

A diferença de tamanho nos desenhos das figuras A.6 e A.7 é resultado deste recurso.

\section{A.4.1.12 Botão Para Mudança de Janela}

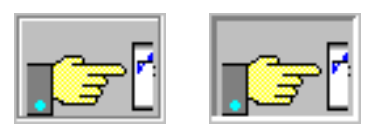

O botão para mudança de janela é o que está no canto superior esquerdo, tendo a aparência da figura acima. Quando é clicado com o mouse sobre ele, o botão aparece como se estivesse rebaixado, somente quando o usuário solta 0 mouse é que a função de troca de janela é efetuada.

\section{A.4.2 Janela de Diagramas}

Depois de acionado o botão indicado no item anterior, uma nova janela é acionada, na qual podem ser vistos os diagramas de momento fletor, força cortante e de força axial. 
Esta janela pode ser ativada somente com alguns dos elementos do pórtico, sendo que estes são selecionados na janela inicial.

Selecionando-se as barras mostradas em azul na figura A.14, o programa mostrará o seguinte desenho:

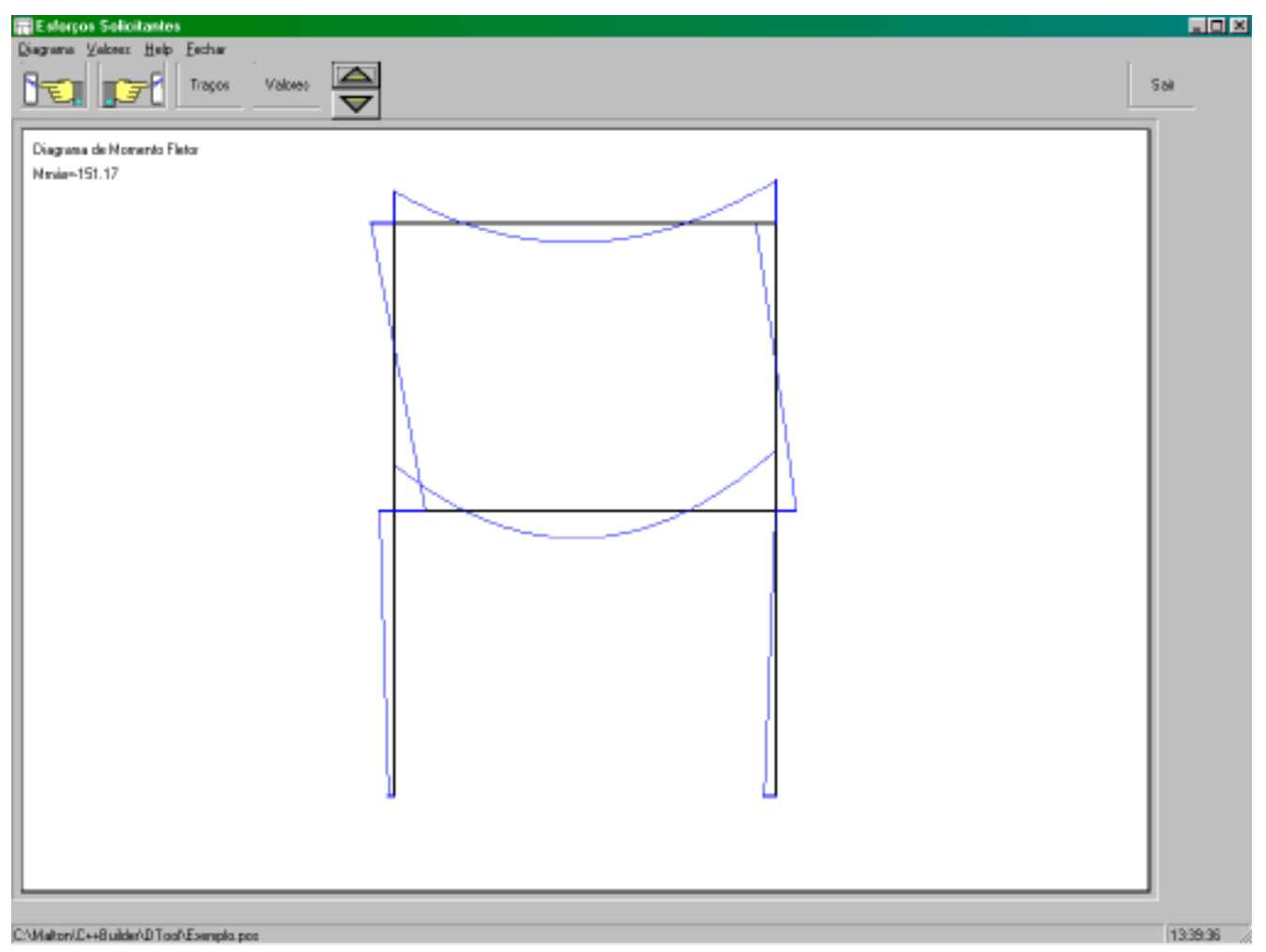

Figura A.16 - Diagrama de Momento Fletor para Barras Selecionadas

Para calcular o diagrama o programa calcula o momento fletor em duzentos pontos de cada elemento, a ligação entre esses pontos é feita por retas, que por serem pequenas, têm em conjunto a aparência de um diagrama de momento fletor conforme a figura acima.

Cada barra é calculada como uma viga biapoiada com momentos de extremidade oriundos do arquivo de entrada de dados. Para calcular os esforços em cada ponto do elemento, são consideradas as cargas atuantes ao longo da barra, como momentos fletores, cargas pontuais e cargas distribuídas.

O cálculo do diagrama de momentos e força cortante considerando os momentos aplicados no elemento é feito da seguinte forma: 


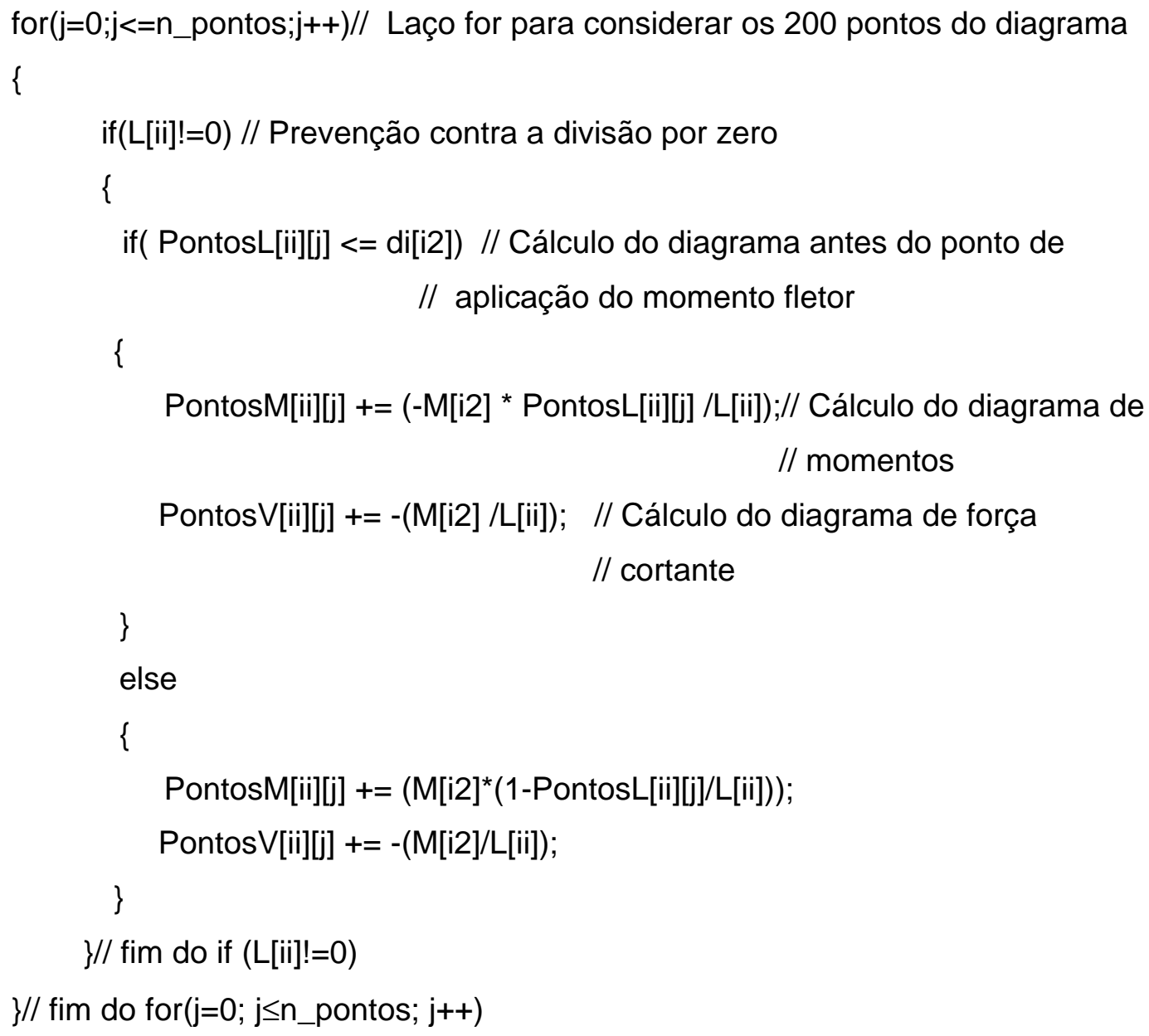

O valor de ii, no arquivo é o número do elemento que está sendo considerado e n_pontos é definido como 200. O valor de i2 é para considerar somente os momentos fletores atuantes no elemento ii. M[i2] é o momento aplicado no elemento, sendo a variável di[i2] a distância do ponto de aplicação do momento ao nó inicial do elemento.

Pode-se observar que os valores do momento são incrementais, de forma a sempre adicionar os efeitos de todas as cargas atuantes.

Utilizando-se todas as barras do pórtico em questão, o desenho do mesmo diagrama de momento fletor é o seguinte: 


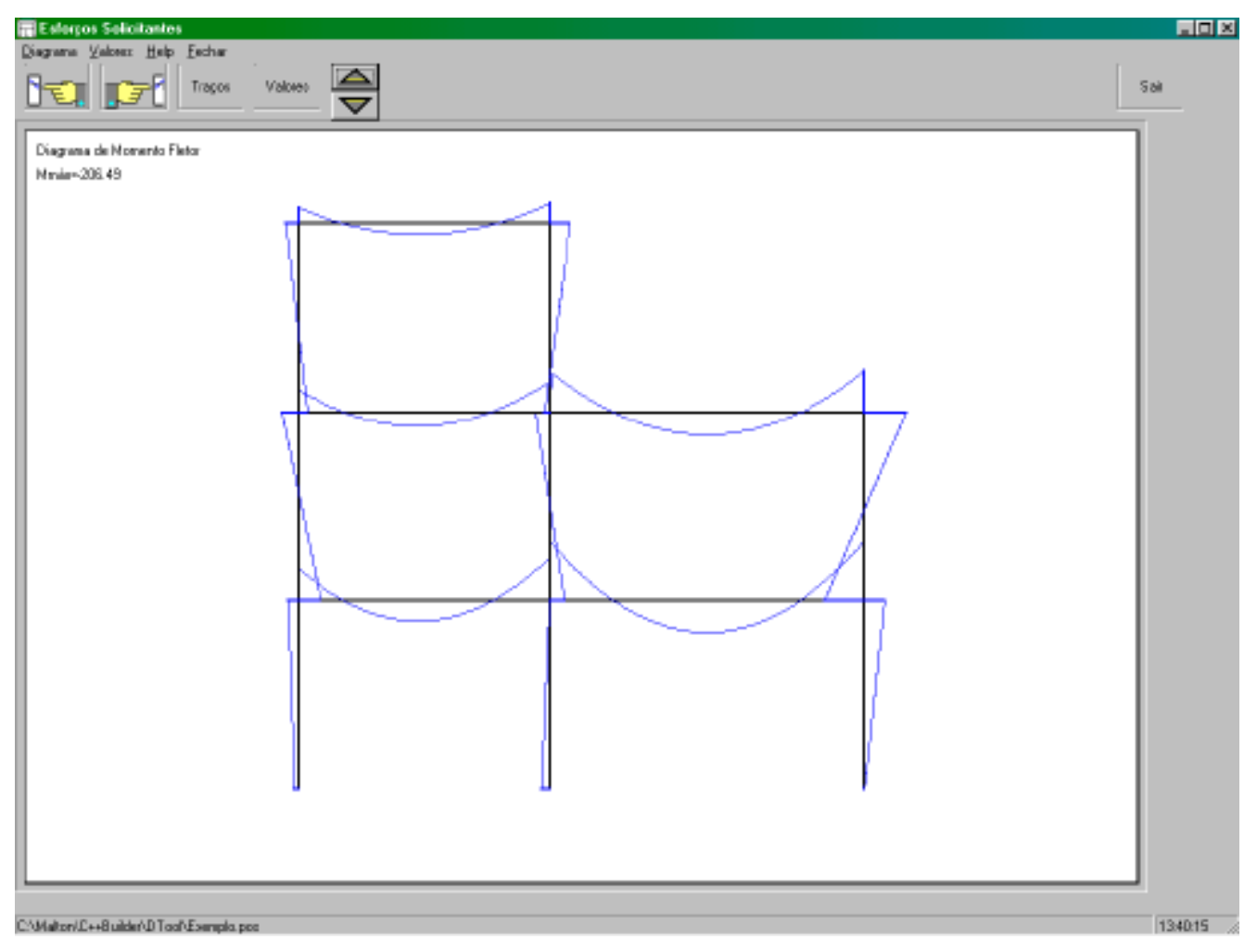

Figura A.17 - Diagrama de Momento Fletor

\section{A.4.2.1 Botão Traços}

$$
\text { Traços }
$$

\section{Traços}

Esta opção tem como função desenhar traços dentro do diagrama de momentos, dando-Ihe aparência cheia, porém, sendo mais difícil ver o diagrama nas regiões em que existem muitas barras chegando a um mesmo nó.

Os traços são a ligação entre cada um dos 200 pontos do diagrama com o elemento a que ele pertence.

Acionando-se esta opção de desenho com traços, a figura A.17 fica da seguinte forma: 


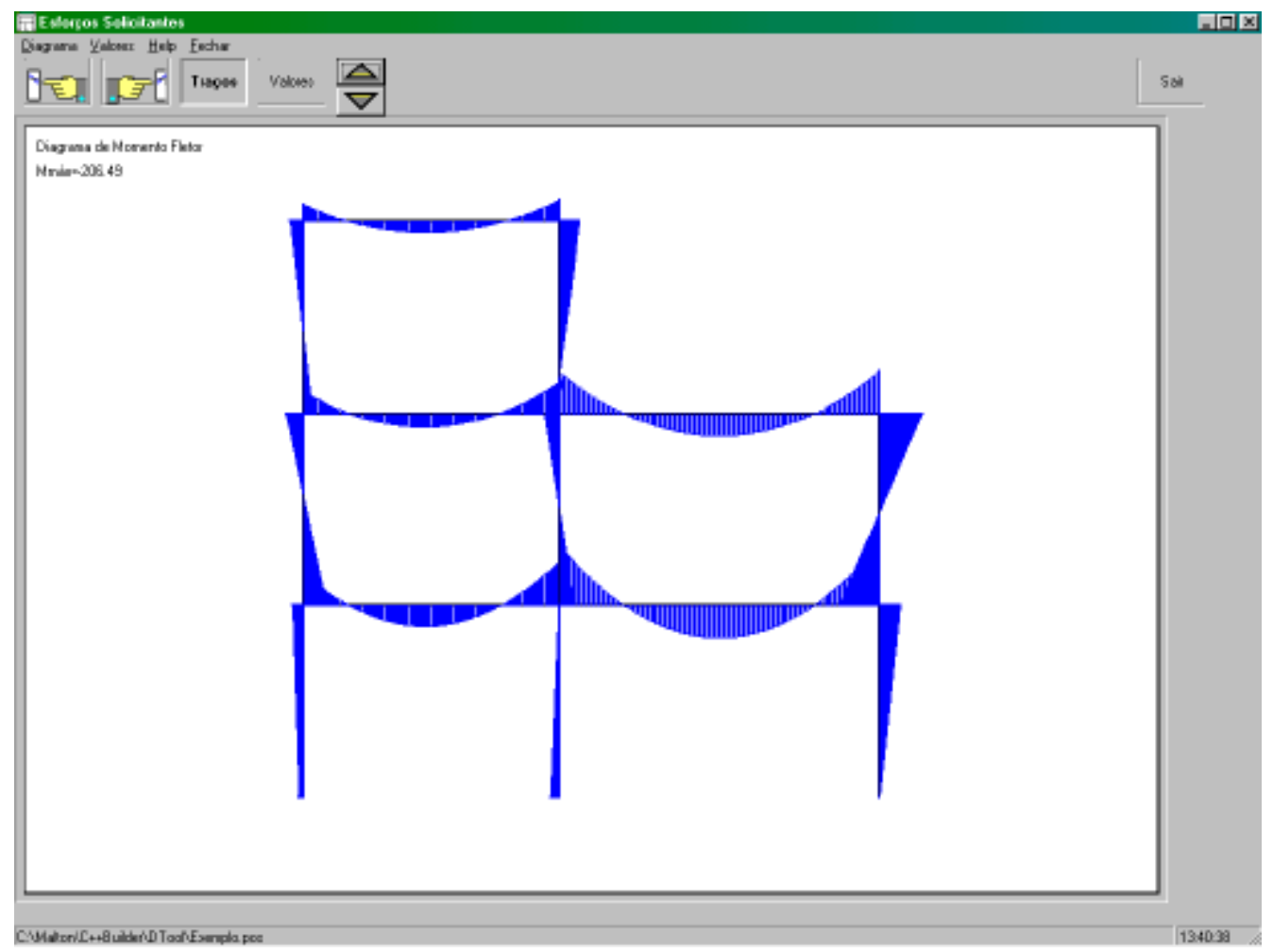

Figura A.18 - Diagrama de Momento Fletor com Traços Internos

\section{A.4.2.2 Botão Valores}

\section{Valores}

\section{Valores}

Utiliza-se este botão para acionar a opção que mostra os valores de momento fletor nos nós da estrutura. A figura A.19 mostra o desenho com essa opção ativa.

\section{A.4.2.3 Botões de Controle do Tamanho do Desenho}

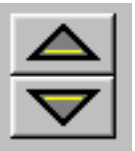


Tem seu funcionamento análogo ao mostrado no item A.4.1.11, agora porém, na janela de diagramas.

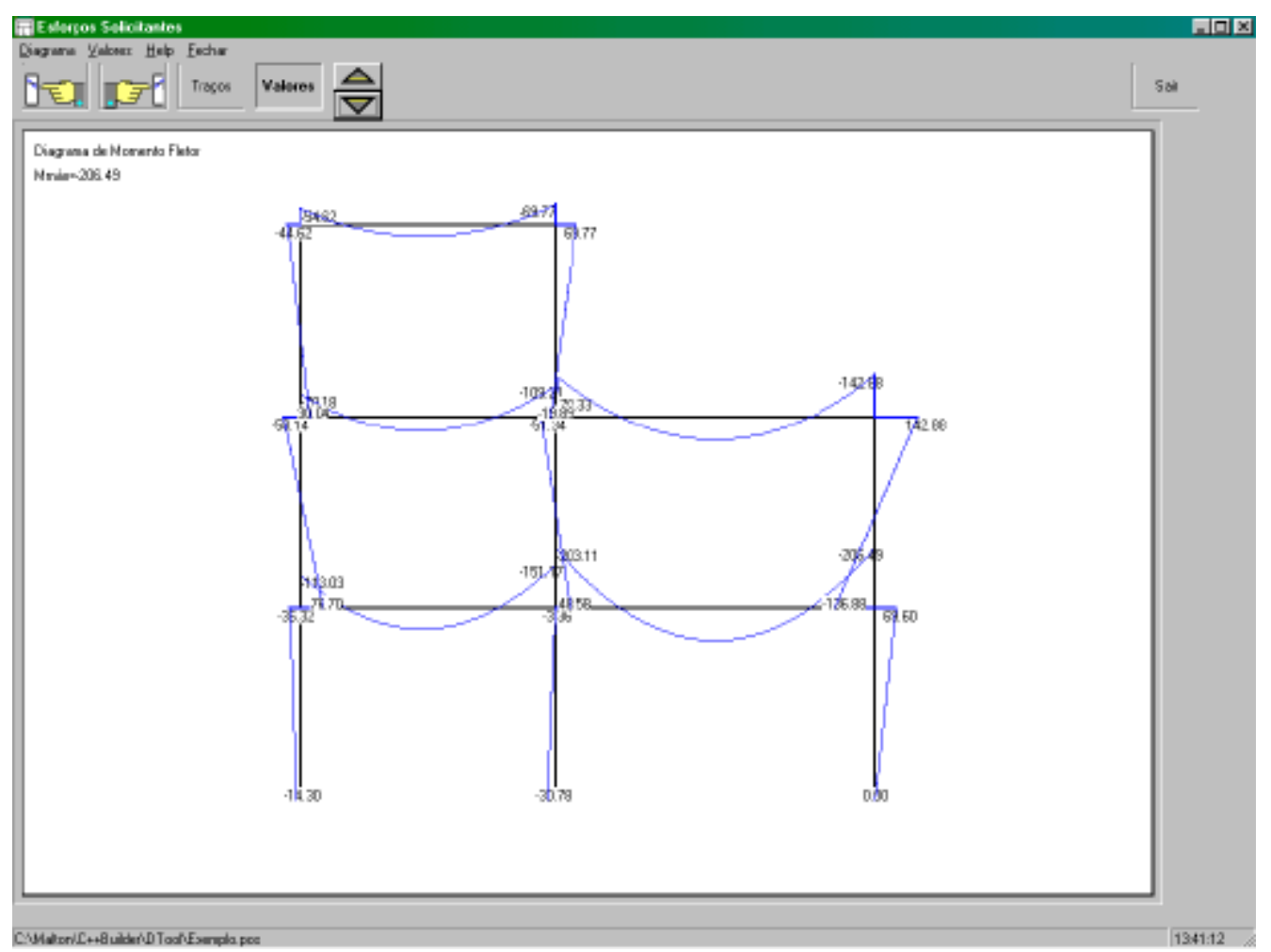

Figura A.19 - Diagrama de Momento Fletor com Valores

\section{A.4.2.4 Diagrama de Força Cortante}

Clicando-se na tela do programa, mostrada na figura A.19, modifica-se o diagrama a ser mostrado na tela. Do diagrama de momento fletor, passa-se para o de força cortante; e deste, para o de força normal.

Outra forma de modificar o diagrama mostrado na tela é utilizar o menu, conforme mostrado na figura A.20. 


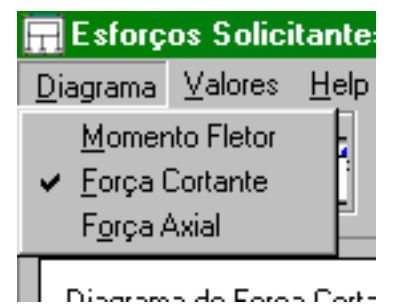

Figura A.20 - Menu para mudança de diagrama

O diagrama de força cortante para o pórtico exemplo está mostrado na figura A.21 e o de força axial na figura A.22.

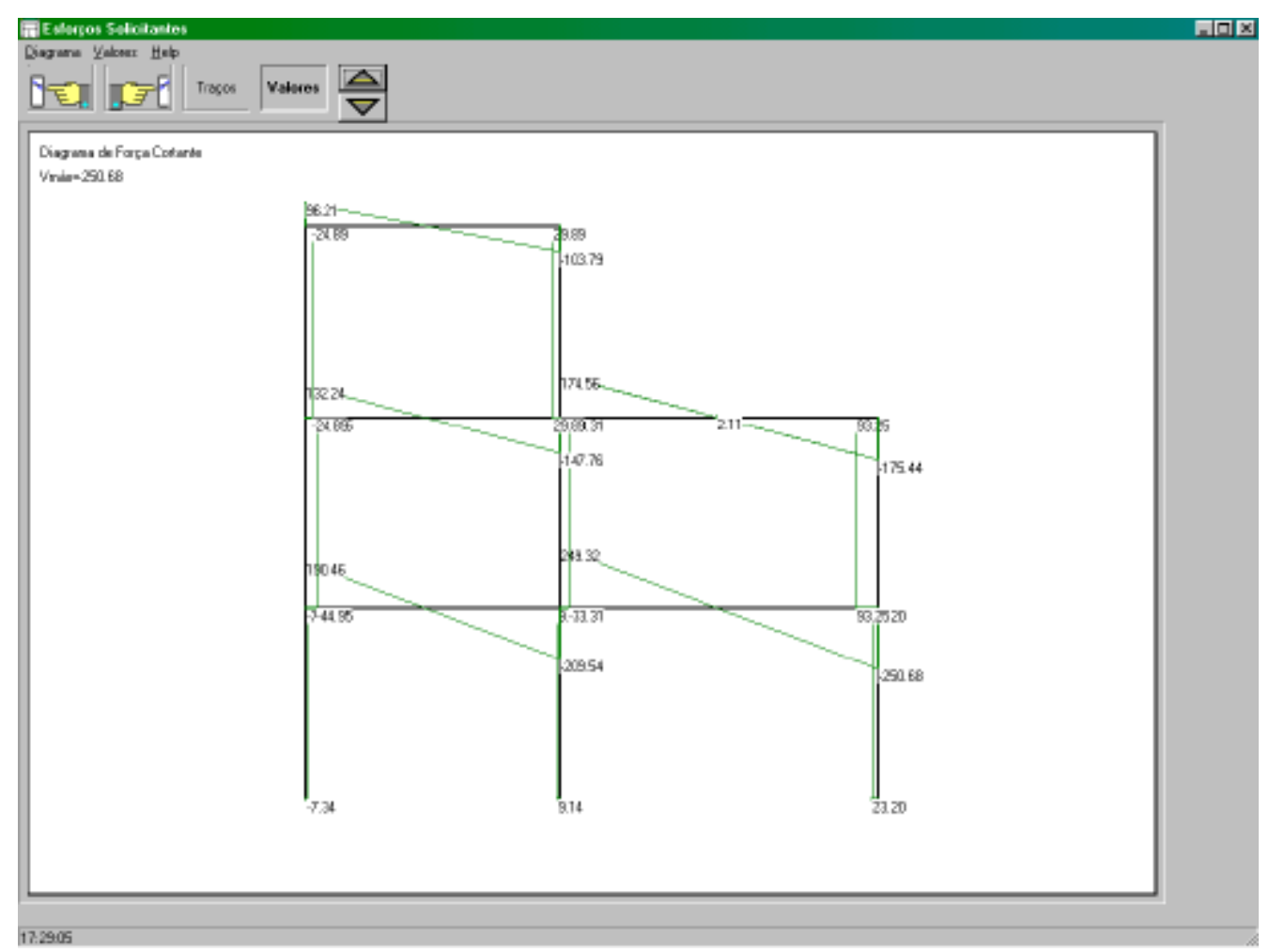

Figura A.21 - Diagrama de Força Cortante com Valores 


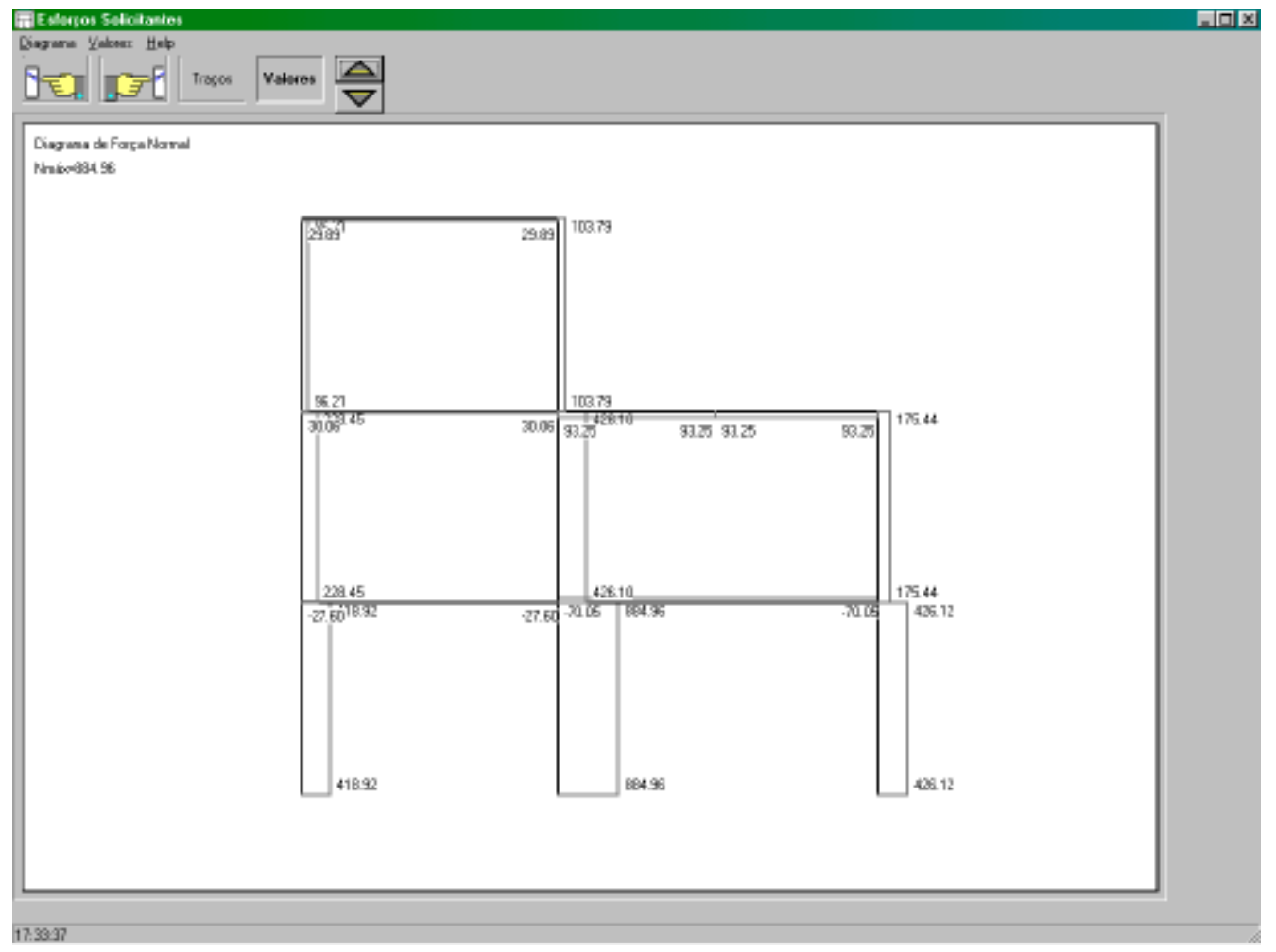

Figura A.22 - Diagrama de Esforço Axial com Valores

\section{A.4.2.5 Caixa de Diálogo de Valores}

Existe uma opção para saber o valor dos esforços em cada ponto de alguma das barras. Para tal função foi criada uma caixa de diálogo que mostra os valores do momento fletor e força cortante nos elementos do pórtico considerado. Ativa-se esta caixa de diálogo pelo menu Valores->Momento Fletor e Força Cortante. A caixa de diálogo está mostrada na figura A.20.

A barra indicada é a viga 4, mostrada nas figuras A.9 e A.14. Considerando que o programa divide todas as barras em 200 pontos e calcula os esforços para cada deles, o que está sendo mostrado na figura a seguir é o ponto 95, no qual está o máximo momento fletor positivo, sendo que a força cortante mais se aproxima de zero. 


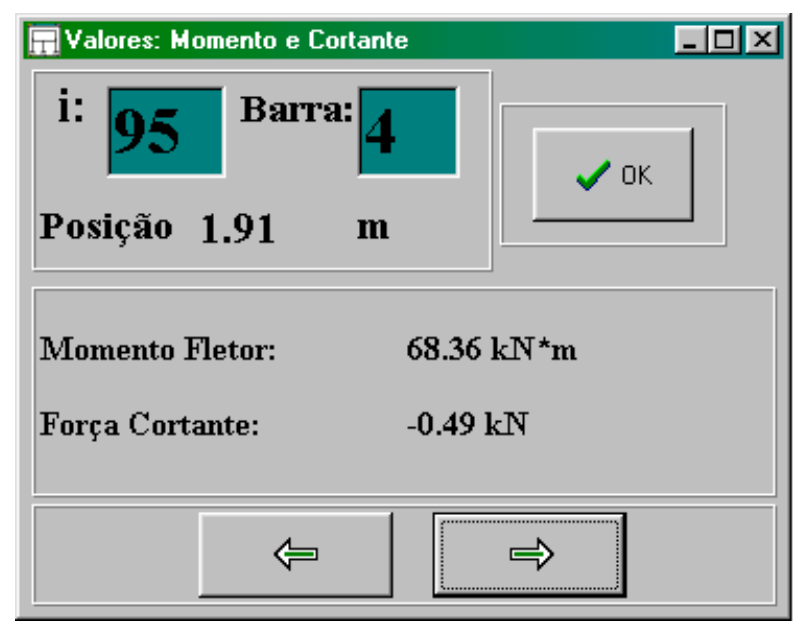

Figura A.23 - Caixa de Diálogo de Valores

\section{A.4.2.6 Botões Para Mudança de Janela}

a)

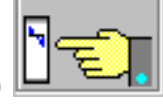

b)

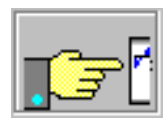

Nesta janela, há a possibilidade de dois tipos de mudanças:

a) Voltar para a janela inicial;

b) Avançar para a janela de dimensionamento.

Novamente, enquanto o usuário mantém o mouse clicado sobre o botão, tal espaço aparenta estar rebaixado em relação ao resto da tela, somente quando o mouse é solto é que se inicia o processo de mudança de janela.

Este processo é possível devido à divisão de funções ao clicar o mouse sobre o botão. Primeiramente é definida uma função para quando o botão do mouse for clicado, conforme a linha de comando a seguir:

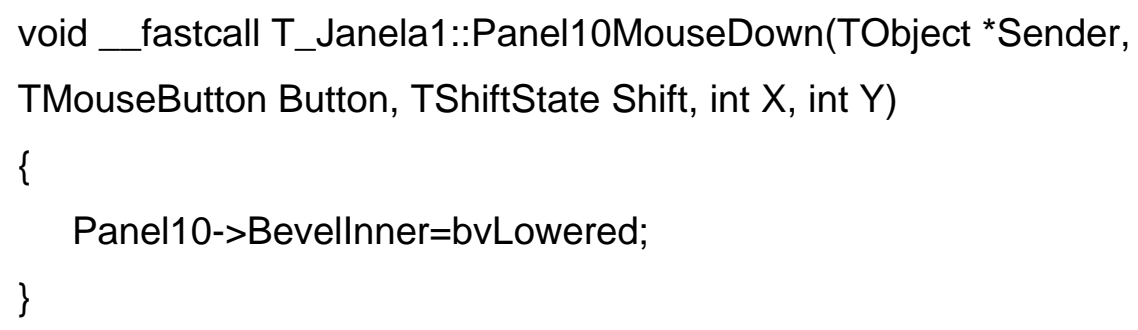


A função Panel10MouseDown, derivada de T_Janela1, que é o nome interno da janela mostrada a partir da figura A.16, é executada quando o botão do mouse está clicado sobre o Panel10 (botão em questão), e realiza uma única atividade: a de deixar a borda do Panel10 com o efeito de rebaixamento.

Uma nova função é colocada para ser ativada quando o botão do mouse é solto, conforme mostrado a seguir.

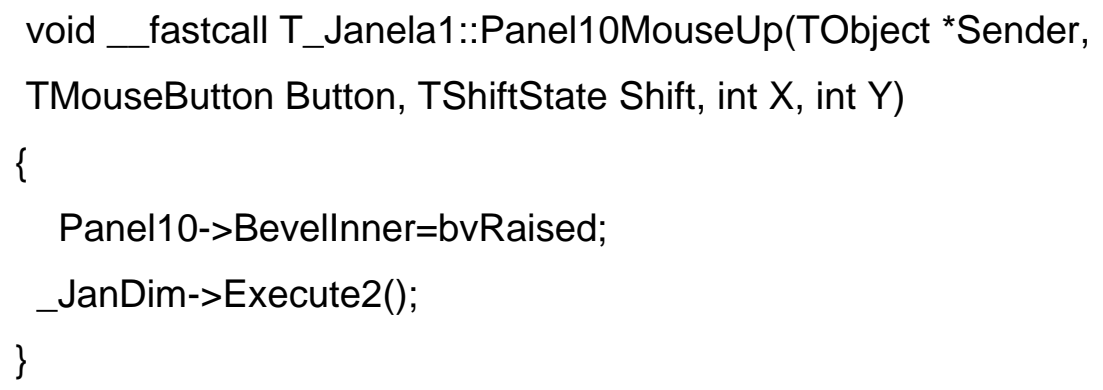

Pode-se observar nesta função que o primeiro evento a ser executado é o de mostrar o botão, Panel10, com a borda levantada, conforme a configuração inicial. E imediatamente após esta função, a janela de dimensionamento, chamada _JanDim dentro de DTool, é executada, apresentando a janela mostrada no item a seguir.

\section{A.4.3 Janela de Dimensionamento}

A terceira janela do programa DTool é a responsável pelo processo de dimensionamento das barras do pórtico plano que está sendo analisado. Nesta janela serão dimensionados os elementos do pórtico plano. Este dimensionamento está dividido em três partes.

- Dimensionamento de vigas ao momento fletor;

- Dimensionamento de pilares àflexão normal composta; e

- Dimensionamento da armadura transversal. 


\section{A.4.3.1 Dimensionamento de Vigas à Flexão Normal}

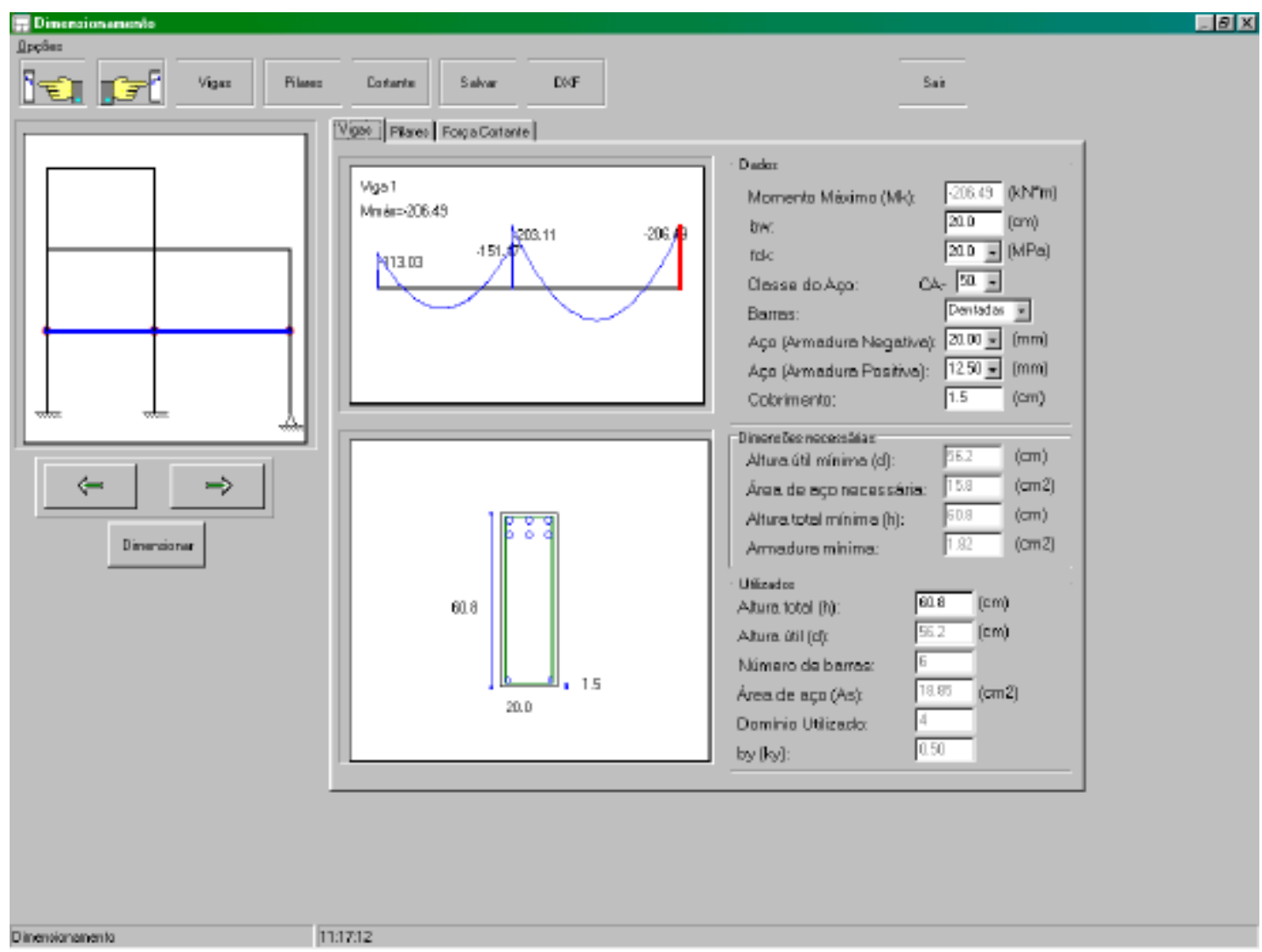

Figura A.24 - Janela de Dimensionamento - Vigas

A opção de dimensionamento de vigas, mostrada na figura A.24, está dimensionando a viga destacada em azul no desenho do pórtico à esquerda. A seção que está sendo dimensionada é a de momento máximo, que está em vermelho no diagrama de momentos na parte superior do centro da tela.

O desenho no centro da tela mostra a seção transversal dimensionada à flexão. Explicação de cada valor indicado nos GroupBoxes desta janela será dada a seguir. 


\section{A.4.3.1.1 GroupBox Dados}

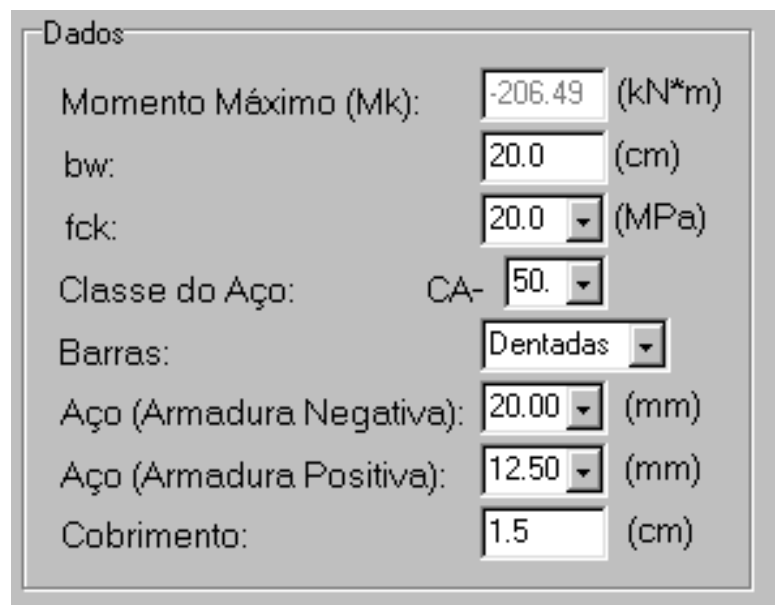

Neste GroupBox estão os seguintes valores:

- Momento Máximo (Mk): Momento Máximo na Viga em Questão em kNm; (Dado fornecido automaticamente pelo programa)

- bw: Largura da viga em cm;

$-f_{c k}$ : Resistência característica do concreto na viga considerada em MPa;

- Classe do Aço: $\quad$ Classe do aço utilizado no dimensionamento;

- Barras: Tipo de barras para cálculo do comprimento de ancoragem;

- Aço (Armadura Negativa): Diâmetros das barras utilizadas para armadura negativa, em mm;

- Aço (Armadura Positiva): Diâmetros das barras utilizadas para armadura positiva, em mm;

- Cobrimento: Cobrimento da armadura, em $\mathrm{cm}$.

Excetuando o valor do momento máximo, todos os outros valores podem ser dados pelo usuário para a determinação da altura útil da viga e da área de armadura necessária para resistir àação do m omento fletor. 


\section{A.4.3.1.2 GroupBox Dimensões Necessárias}

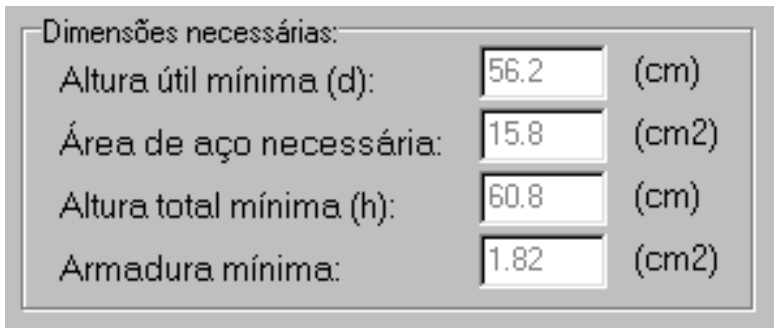

Neste grupo estão indicadas as dimensões mínimas para resistir aos esforços aos quais a viga está submetida, os valores existentes são:

- Altura Útil Mínima (d): $\quad$ Altura útil da viga, calculada conforme a equação 4.29;

- Área de Aço Necessária: Área de aço calculada de acordo com 4.31;

- Altura Total Mínima: Altura total necessária para que o centro de gravidade da armadura tracionada esteja a uma distância igual a d da face comprimida da peça;

- Armadura mínima: $\quad$ Calculada de acordo com o item 5.2.1.1.

\section{A.4.3.1.3 GroupBox Utilizados}

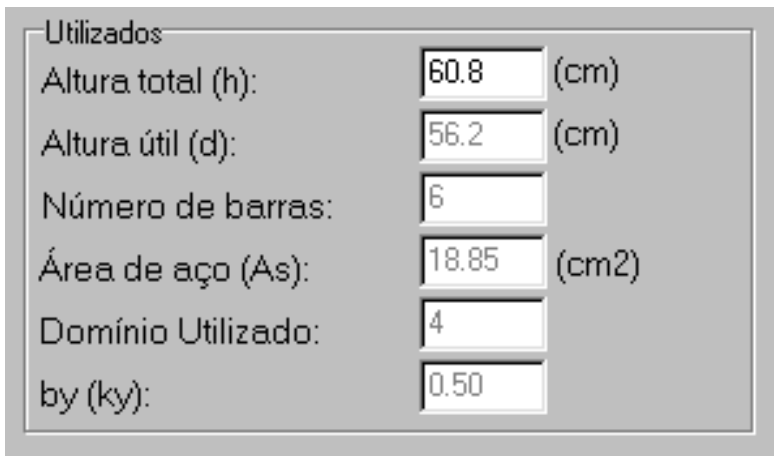

Neste grupo de valores pode-se modificar o valor da altura total da viga que será dimensionada. 
O grupo anterior define as quantidades mínimas. Para valores de $\mathrm{h}$ maiores que a altura total mínima definida no item A.4.3.1.2 o GroupBox mostrado é utilizado. Os valores são os seguintes:

- Altura Total (h):

- Altura Útil (d):

- Número de Barras:

- Área de Aço (As):

- Domínio Utilizado:

$-\beta_{y}$
Altura total da viga, definida pelo usuário em $\mathrm{cm}$;

Altura útil utilizada de acordo com a altura definida pelo usuário;

Número de barras necessário para satisfazer a armadura necessária;

Calculada de acordo com o item 4.4.6.5;

Achando o valor de $\beta_{y}$, mostrado no item abaixo, o domínio utilizado é encontrado pelos limites estabelecidos nos itens 4.4.4.2 e 4.4.4.3.

Valor utilizado para encontrar o domínio utilizado, encontrado de acordo com a equação 4.37.

\title{
A.4.3.1.4 Botão Dimensionar
}

\author{
Dimensionar
}

Com o acionamento deste botão, o programa passa a dimensionar, da esquerda para a direita, outras partes da viga em questão, mostrando em vermelho a localização do ponto que está sendo dimensionado no diagrama de momentos fletores desta janela.

O valor de $h$, mostrado no item anterior, é fixado, não podendo mais ser modificado, para não haver vigas com altura variável, e a partir deste ponto, só será feito o dimensionamento da armadura necessária em cada ponto, de acordo com o momento aplicado na seção.

No caso da figura A.24, ao clicar no botão dimensionar, o programa passará a considerar o ponto em que o diagrama de momentos tem o valor característico de $113,03 \mathrm{kN}^{*} \mathrm{~m}$. Clicando-se novamente, um novo ponto será considerado, mais à direita no mesmo elemento, com uma distância de um décimo do vão. Desta forma, 
são considerados 9 pontos internodais para dimensionamento de cada barra da viga contínua.

Na figura a seguir, será mostrado o dimensionamento para o meio do vão da barra àesquerda na viga contínua mostrada n a figura A.20.

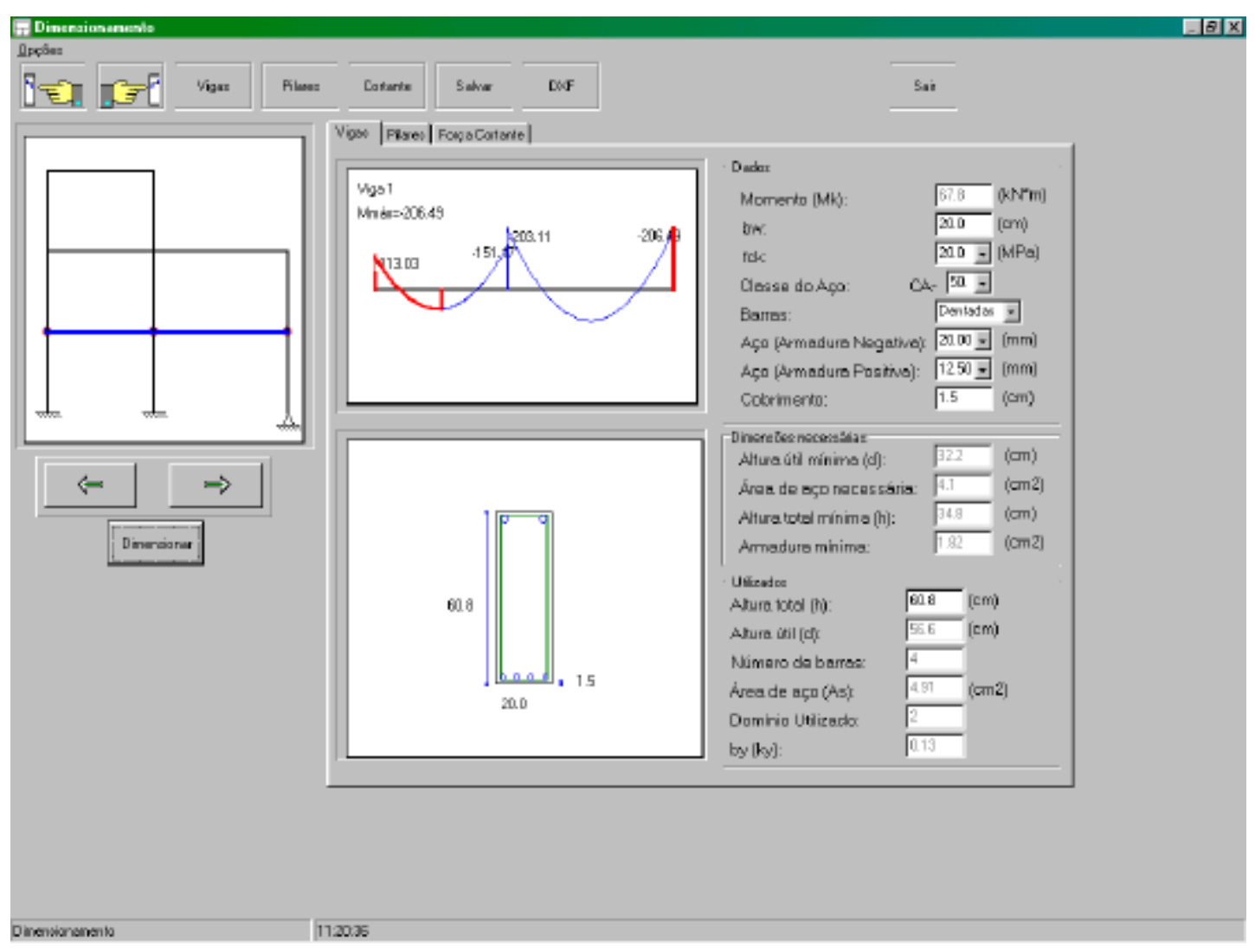

Figura A.25 - Dimensionamento do Ponto Central, Barra Esquerda

Pode-se observar que quatro barras de armadura positiva são necessárias para resistir ao momento fletor atuante na viga. No diagrama de momentos, os pontos já dimensionados aparecem em vermelho, enquanto o ponto que está sendo dimensionado tem uma reta vertical que o une àbarra a qual ele pertence.

A distribuição transversal das barras longitudinais respeita os limites impostos em 5.2.1.3, dividindo as barras em camadas conforme a necessidade imposta pelas limitações espaciais da largura da viga. Na figura A.24, duas camadas de 3 barras foram necessárias na armadura negativa para resistir ao momento fletor nesta seção. 


\section{A.4.3.1.5 Botões de Mudança de Vigas}

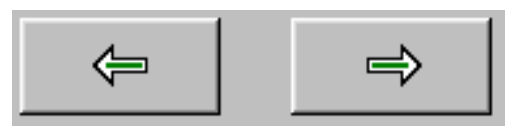

Os botões mostrados acima fazem com que uma outra viga seja considerada, sendo que o botão da direita e o da esquerda realizam um incremento e um decremento no número da viga selecionada, respectivamente.

Para considerar a segunda viga no pórtico exemplo, basta clicar na opção da direita, sendo selecionada a viga de número 2 , mostrada na figura a seguir.

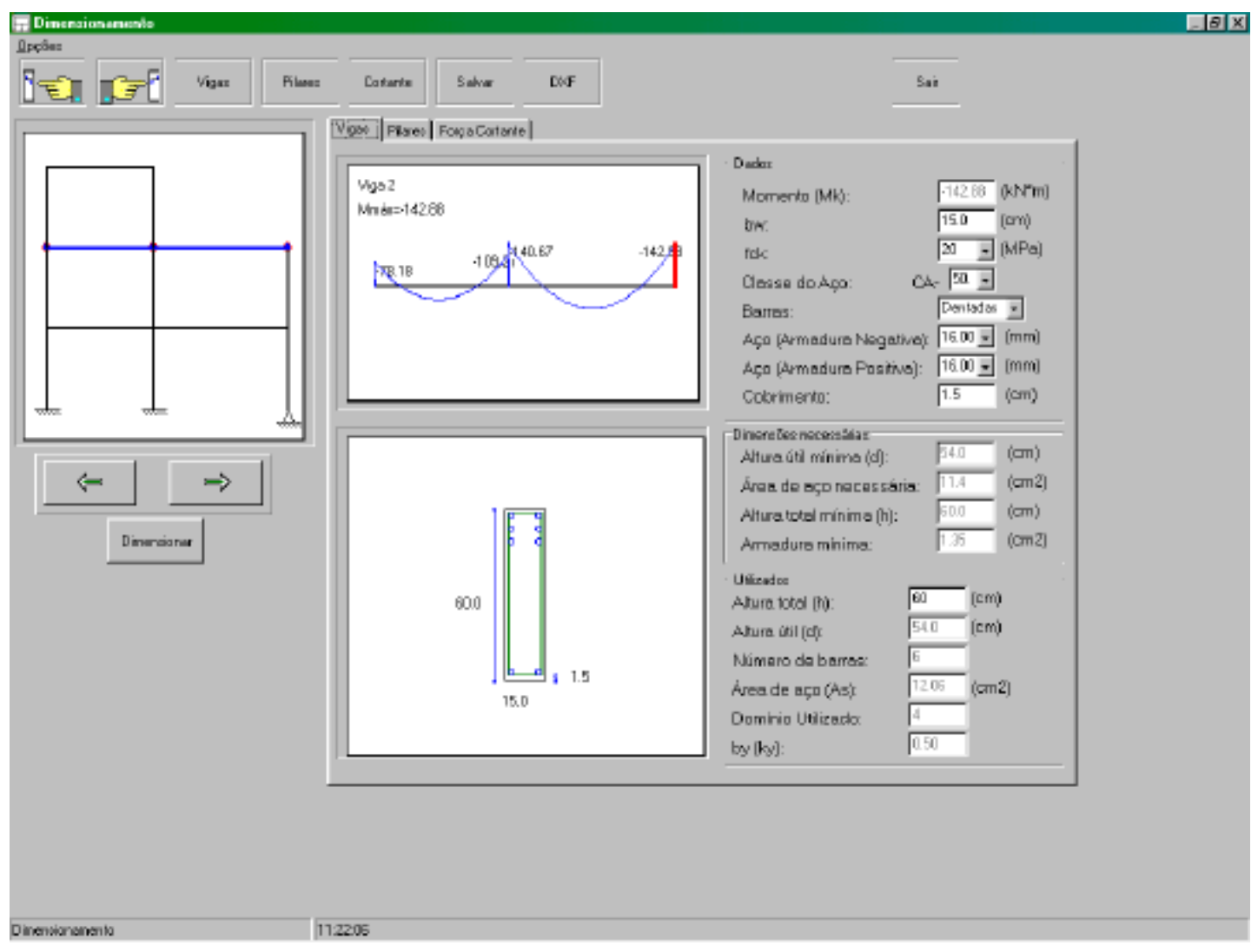

Figura A.26 - Dimensionamento da Viga 2

Pode-se observar a mudança no diagrama de momento fletor, mostrado para a viga em questão, bem como no dimensionamento, sendo necessárias 6 barras divididas em 3 camadas, e uma altura total de $60 \mathrm{~cm}$. 
Acionando-se o botão Dimensionar novamente a viga será dimensionada da esquerda para a direita, conforme mostrado no item anterior.

\section{A.4.3.1.6 Botão Pilares}

\section{Pilares $\quad$ Pilares}

Para mudar da opção de dimensionamento de vigas ao momento fletor para o dimensionamento de pilares, basta clicar no botão mostrado neste item. Quando ativada esta opção de dimensionamento, o botão fica conforme a figura da direita. Outra opção é clicar na "orelha" pilares na TabControl mostrada na figura abaixo.

\section{Vigas Pilares $\mid$ Força Cortante}

Figura A.27 - TabControl com a opção Pilares Ativa

\section{A.4.3.2 Dimensionamento de Pilares à Flexão Normal Composta}

Para o dimensionamento de pilares àflexão normal composta é utilizado o processo iterativo descrito em 4.3.7.2, equações 4.67 e 4.68. A janela para este dimensionamento, mostrando o primeiro pilar sendo dimensionado está mostrada a seguir. 


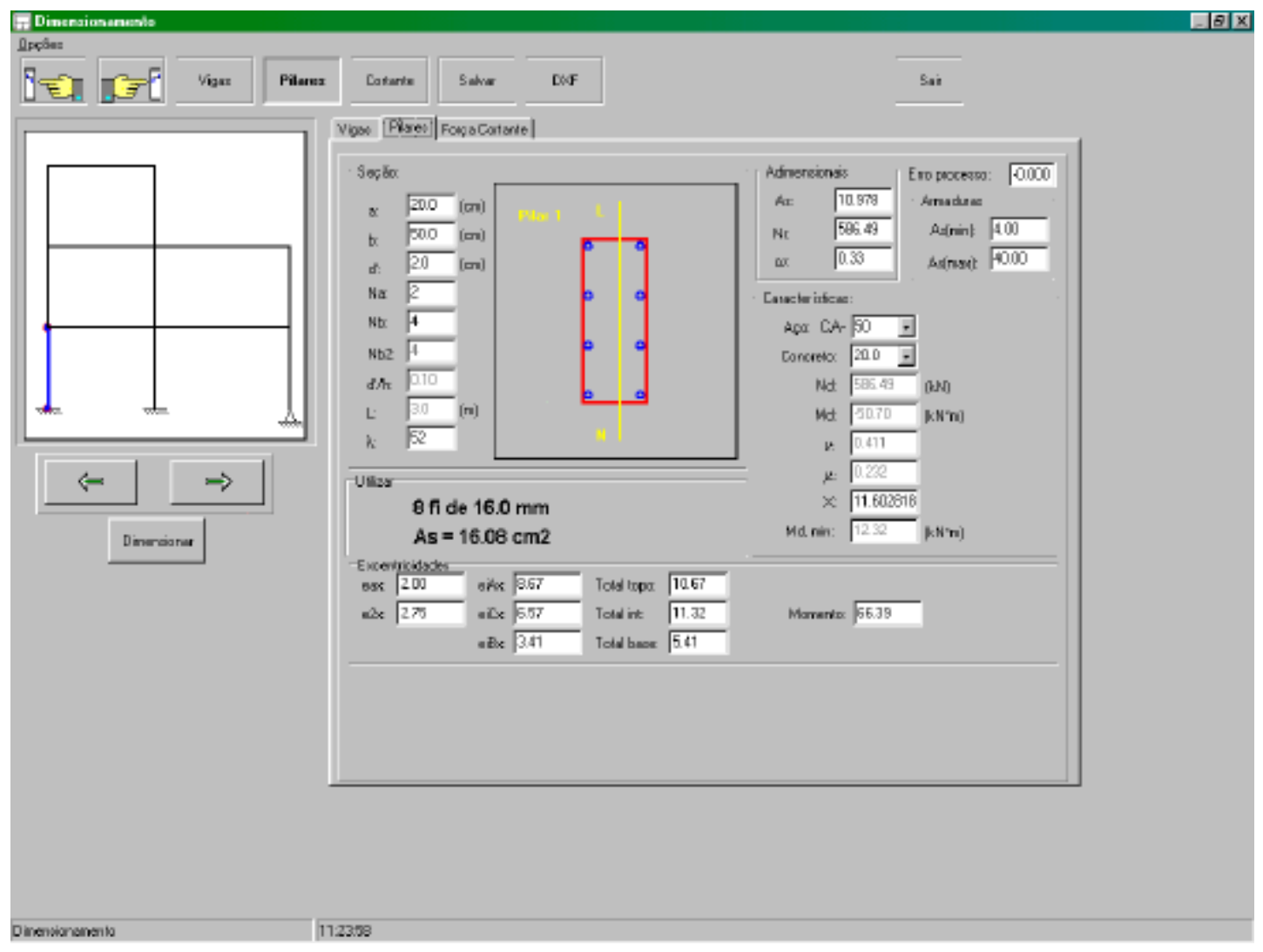

Figura A.28 - Janela de Dimensionamento - Pilares

Nesta opção de visualização estão os valores necessários para o dimensionamento de pilares. As explicações dos GroupBoxes a seguir darão o significado de cada um destes valores.

\section{A.4.3.2.1 GroupBox Seção}

Neste GroupBox estão as características da seção transversal do pilar, bem como o desenho com as características definidas. 


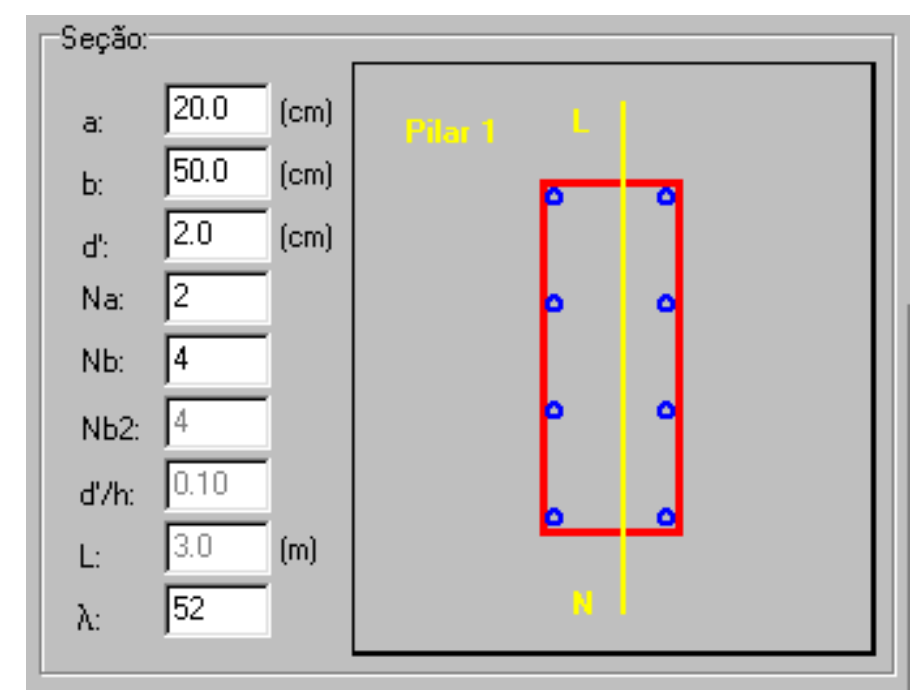

Figura A.29 - GroupBox de Características da Seção

Os valores contidos neste grupo de variáveis são os seguintes:

- a:

- b:

- d':

- Na:

$-\mathrm{Nb}$ :

- Nb2:

- d'/h:

- L:

$-\lambda$ :
Dimensão do pilar na direção em que está sendo considerada a ação do momento fletor, em cm;

Dimensão do pilar perpendicular à direção de a, no plano da seção transversal do elemento, em cm;

Valor do cobrimento da armadura em $\mathrm{cm}$;

Número de barras na face superior com dimensão a (esquerda no desenho);

Número de barras na face inferior com dimensão b (direita no desenho).

Número de barras na face esquerda do desenho. Opção desativada para que haja armadura simétrica; Valor para facilitar a aferição do resultado em tabelas correspondentes;

Altura de um lance do pilar; Índice de esbeltez considerando $\mathrm{H}$ como a dimensão a, na direção de atuação do momento fletor. 
No desenho estão demonstrados o número barras e sua posição na seção transversal do pilar. A linha em amarelo indica a posição da linha neutra que equilibra a peça de concreto em relação às ações a ela aplicadas.

\section{A.4.3.2.2 GroupBoxes de Informações}

À direita do desenho, no canto superior direito da parte destinada ao dimensionamento de pilares, estão algumas informações para facilitar a compreensão do processo de dimensionamento destes elementos.

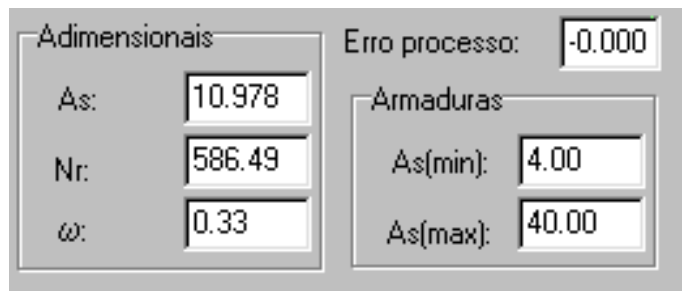

Primeiramente, no GroupBox Adimensionais, estão informações referentes à armadura necessária para resistir aos esforços atuantes na seção. Os valores são os seguintes:

- As:

Área de aço necessária para resistir à flexão normal composta;

$-\mathrm{Nr}$ :

Força normal resistente encontrada pelo processo iterativo;

$-\omega:$

Taxa de armadura na seção.

O valor referente ao erro no processo é a comparação entre a força normal resistente e a força normal atuante na seção, mostrada no GroupBox Caraterísticas. Quanto mais próximos forem estes dois valores, mais preciso terá sido o processo iterativo correspondente.

O GroupBox armaduras indica os valores mínimos e máximos para a quantidade de armadura em pilares estabelecidos pela NBR 6118:2001, de acordo com os itens 5.3.1.1 e 5.3.1.2. 


\section{A.4.3.2.3 GroupBox Características}

Neste GroupBox estão características da seção que serão necessárias para o dimensionamento, podendo ser modificadas quando a característica depender de uma definição do usuário.

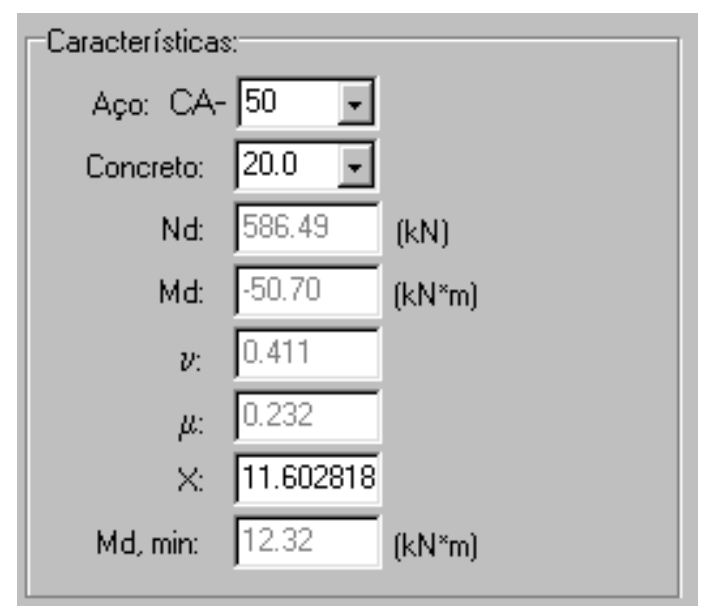

Os valores aqui encontrados são os seguintes:

- Aço:

Categoria do aço utilizado na seção, de acordo com o item 2.2.4;

- Concreto:

Classe do concreto utilizado, de acordo com o item 2.3.2;

- Nd:

Força normal de cálculo atuante na seção;

- Md:

Máximo momento fletor de cálculo atuante na seção;

$-v$ :

Força normal adimensional, conforme 4.40.

$-\mu:$

Momento fletor reduzido adimensional, $\mu=\frac{\mathrm{M}_{\mathrm{d}}}{\mathrm{A}_{\mathrm{c}} \cdot \mathrm{h} \cdot \mathrm{f}_{c d}} ;$

$-X:$

Valor da profundidade da linha neutra encontrada pelo processo iterativo para o elemento.

- Mdmin: Momento mínimo devido a imperfeições construtivas, conforme equação 3.15, item 3.6.4. 


\section{A.4.3.2.4 GroupBox Utilizar}

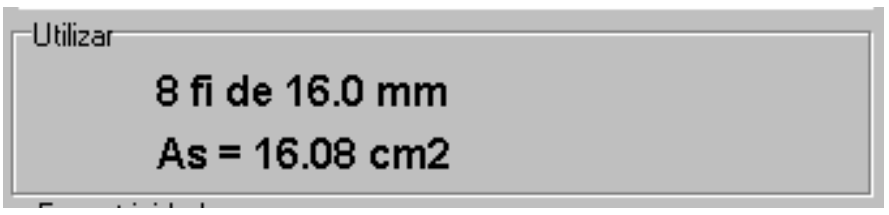

Neste GroupBox estão os valores efetivamente utilizados no elemento, necessários para resistir aos esforços existentes e para satisfazer os critérios de detalhamento e valores limites para armaduras longitudinais impostos pela norma.

Neste pilar serão necessárias 8 barras de $16 \mathrm{~mm}$ de diâmetro para que a área efetiva de armadura na seção, As $=16,08 \mathrm{~cm}^{2}$ satisfaça o valor de 10,978 cm mostrado na figura A.28 para resistir aos esforços na seção. Como o diâmetro mínimo a ser utilizado em pilares de concreto armado é $10 \mathrm{~mm}$, o dimensionamento sempre vai definir diâmetros maiores ou iguais a este valor. A determinação do diâmetro necessário vai se basear no número de barras definido pelo usuário, desde que satisfaça aos espaçamentos limites normatizados, definindo o menor diâmetro que faz com que a armadura utilizada seja maior do que a necessária, ou a mínima.

A figura a seguir mostra o efeito causado se fossem definidas 10 barras no pilar, cinco em cada face. Tal dimensionamento leva a barras com diâmetro menor, do que os $16 \mathrm{~mm}$ definidos na figura A.28. 


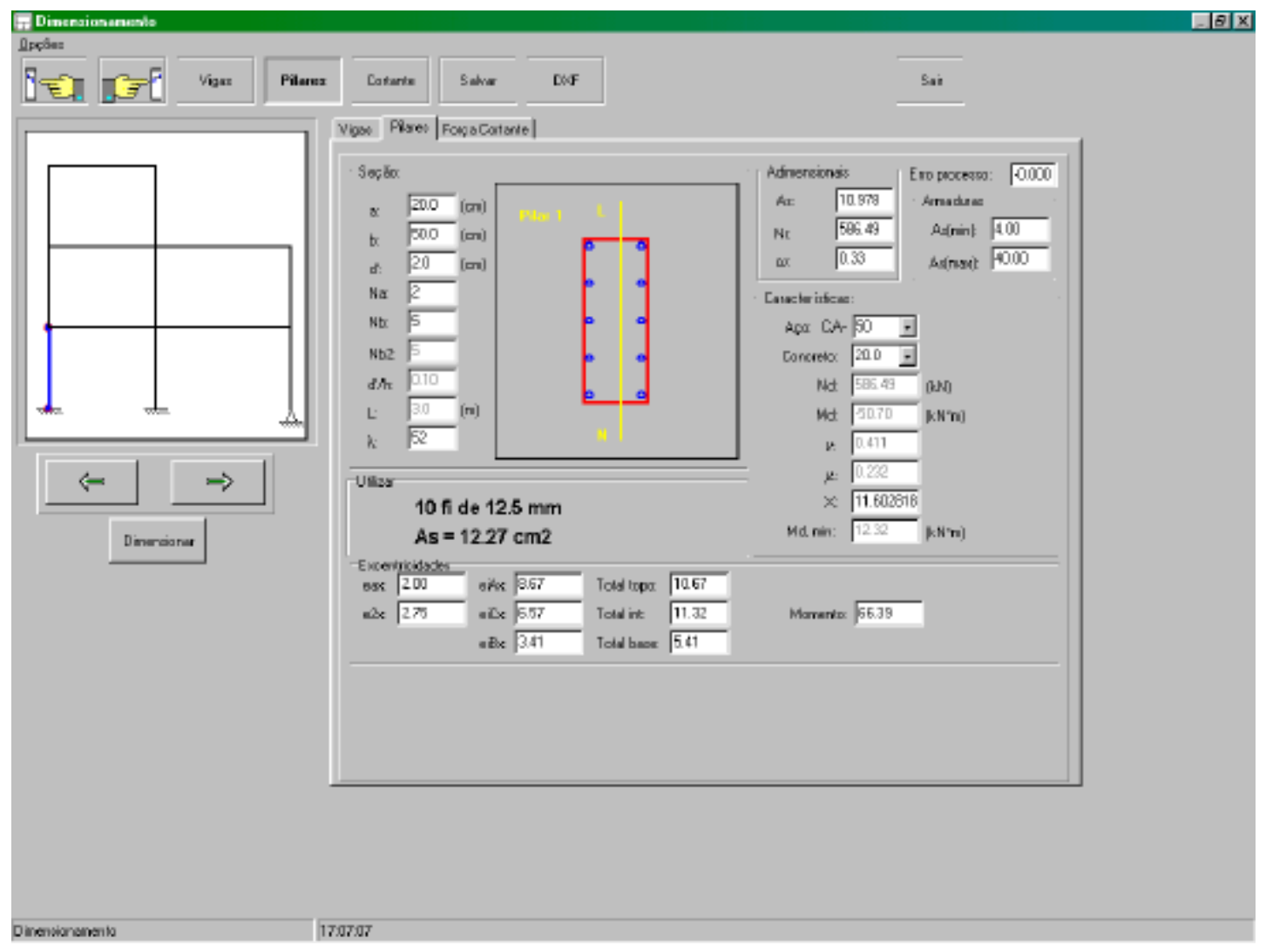

Figura A.30 - Dimensionamento utilizando 10 barras

As diferenças entre as figuras A.28 e A.30 indicam os valores que são modificados cada vez que uma nova seção é definida.

\section{A.4.3.2.5 Botões de Mudança de Pilares}

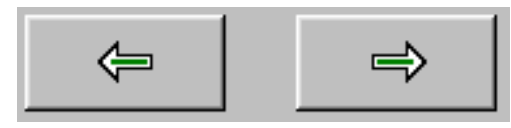

Assim como em A.4.3.1.5, esses botões podem ser utilizados para selecionar os outros pilares do pórtico.

A figura a seguir mostra o dimensionamento para o mesmo pilar, porém considerando a barra entre o primeiro e o segundo pavimento. Com o efeito maior do momento fletor atuante na seção, uma armadura maior foi necessária para resistir aos efeitos deste esforço. 


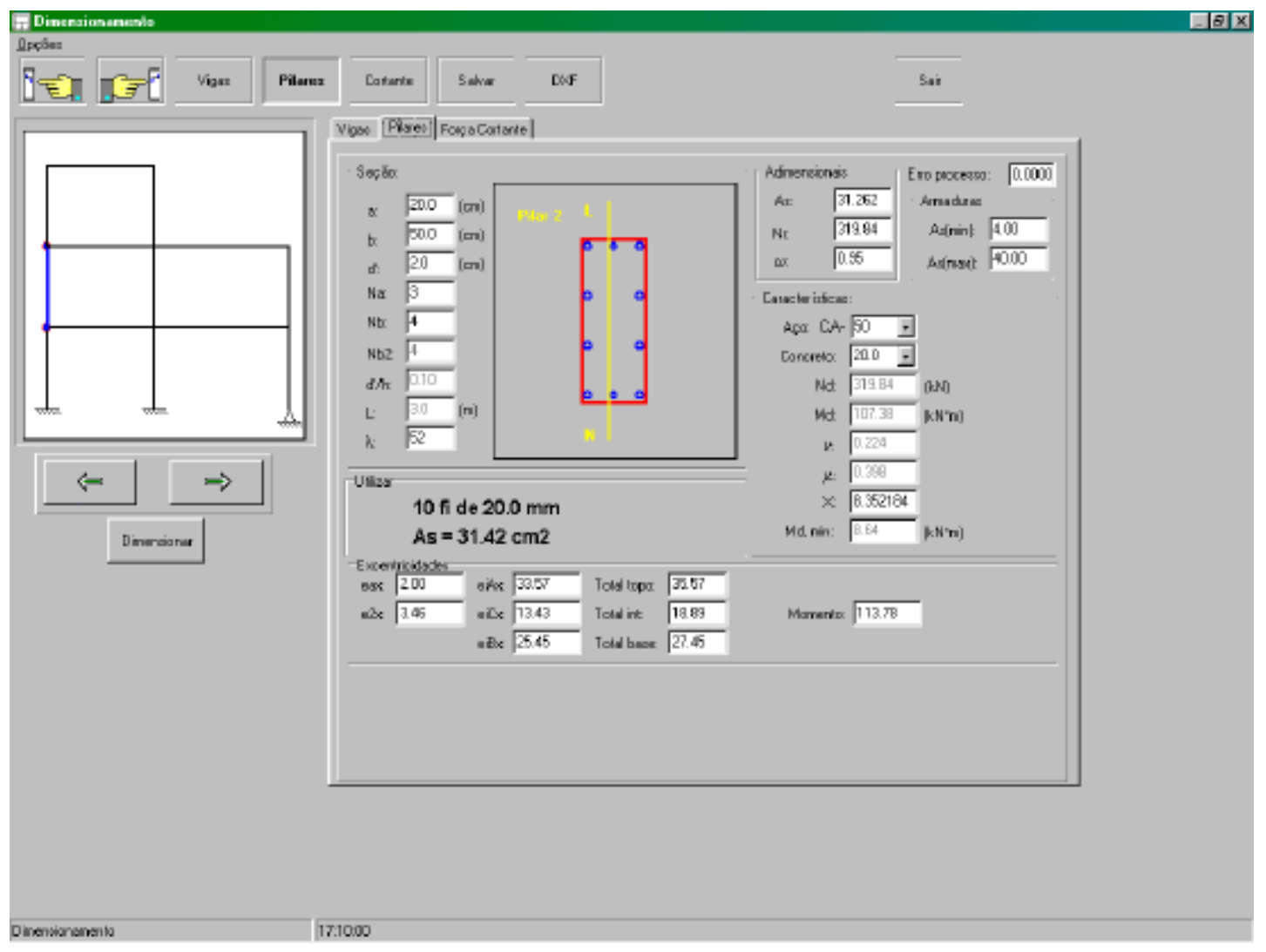

Figura A.31 - Dimensionamento do tramo superior

Pode-se observar que para este tramo, embora a força normal tenha sido menor, o momento fletor maior levou a uma área de armadura necessária também maior, utilizando 10 barras de $20 \mathrm{~mm}$ de diâmetro.

O botão dimensionar, nesta opção para pilares, não tem função.

\section{A.4.3.3 Dimensionamento à Força Cortante}

Utilizando a opção de dimensionamento à força cortante, a janela mostrará dois desenhos:

1- O diagrama de força cortante para a viga em questão;

2- O detalhamento dos estribos existentes na viga.

Neste último, em cinza estão desenhadas as barras longitudinais, e em azul os estribos necessários na seção. 
Nesta janela estão mostrados os fatores que influem no dimensionamento, bem como as medidas estabelecidas por norma para limitar o espaçamento e a armadura mínima para o elemento.

A janela de dimensionamento de vigas de concreto armado está mostrada na figura a seguir.

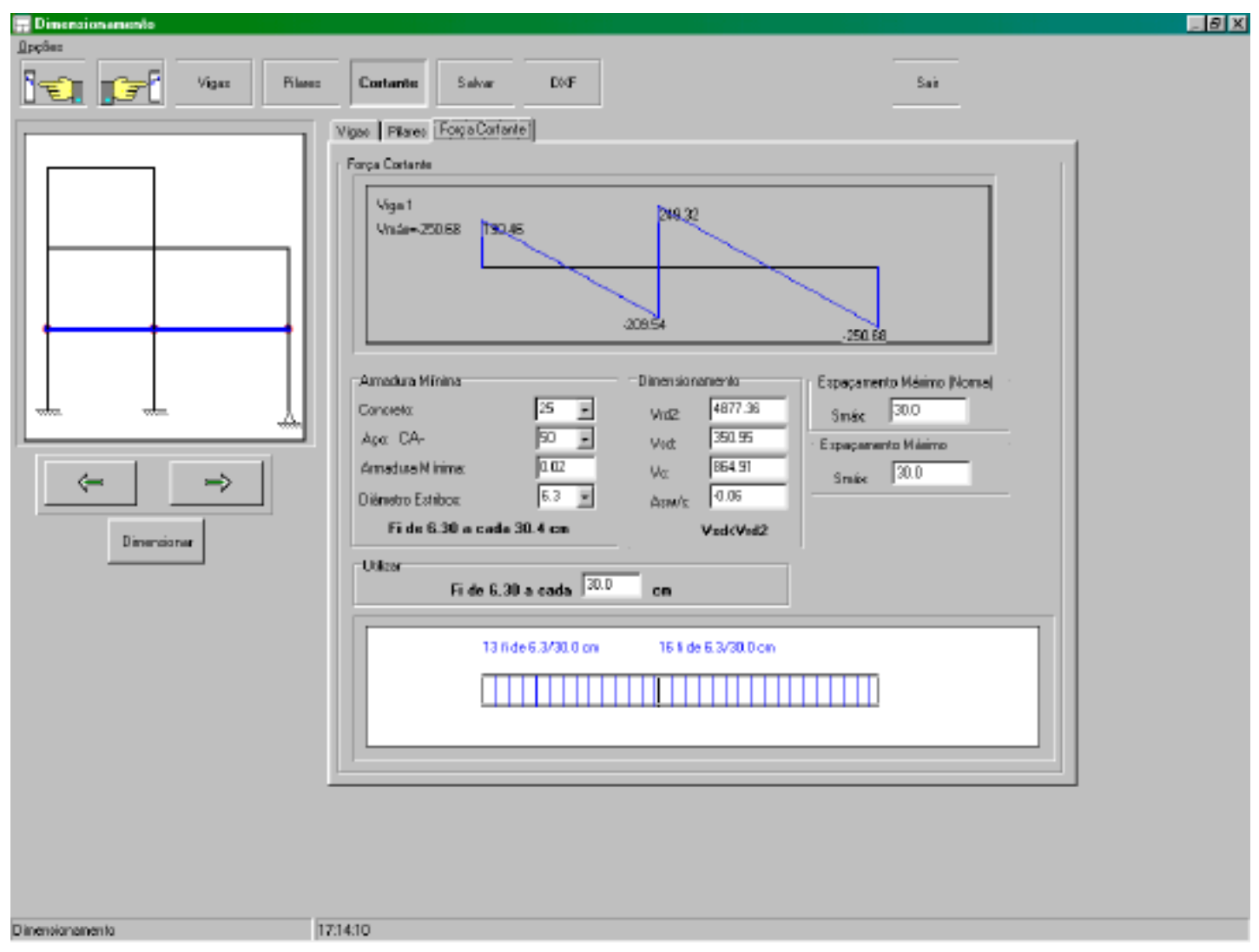

Figura A.32 - Dimensionamento a Força Cortante

A viga contínua em questão possui dois tramos, tendo o primeiro, quatro metros de vão e estribos de 6,3 milímetros de diâmetro a cada trinta centímetros, e o segundo com cinco metros e sendo necessários dezesseis estribos de 6,3 milímetros de diâmetro para resistir satisfatoriamente ao esforço cortante.

Os GroupBoxes existentes nesta janela estão explicados nos itens a seguir. 


\section{A.4.3.3.1 GroupBox Armadura Mínima}

Neste GroupBox estão características que podem ser modificadas pelo usuário, sendo a única definida pelo programa a armadura mínima.

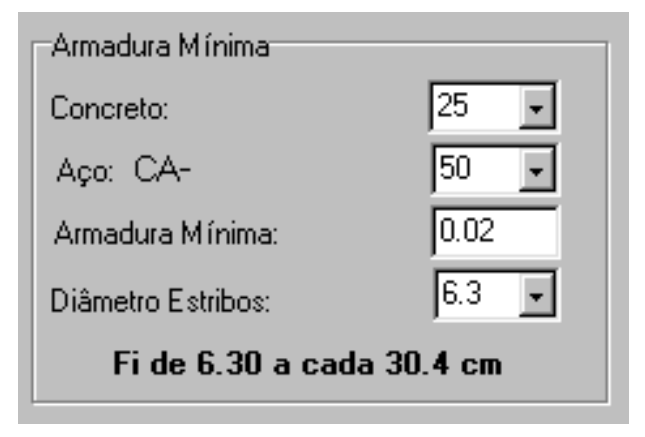

Os valores indicados neste GroupBox são os seguintes:

- Concreto:

- Aço:

- Armadura Mínima:

- Diâmetro Estribos:
Classe do concreto utilizado, de acordo com o item 2.3.2;

Categoria do aço utilizado na seção, de acordo com o item 2.2.4;

Armadura mínima necessária calculada de acordo com o item 5.2.2, equação 5.4 .

Diâmetro dos estribos para o dimensionamento.

O valor indicado em negrito abaixo da definição do diâmetro dos estribos mostra o espaçamento máximo para que a área de armadura mínima seja satisfeita para o diâmetro dos estribos selecionados, conforme a equação 5.5. Para estribos de $6,3 \mathrm{~mm}$ de diâmetro, o espaçamento necessário, considerando sempre dois ramos, é de $30,4 \mathrm{~cm}$.

\section{A.4.3.3.2 GroupBox Dimensionamento}

Este GroupBox mostra os valores para o dimensionamento da armadura para força cortante de acordo com os esforços atuantes na seção. Todos os valores indicados são definidos pelo programa. 


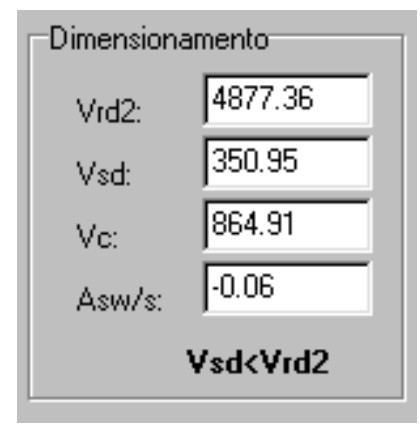

Os valores nele incluídos são:

$-V_{\text {Rd2 }}$ :

Força cortante resistente de cálculo, relativa à ruína das diagonais comprimidas de concreto, definida na equação 4.74;

$-V_{S d}:$

Força cortante solicitante de cálculo;

$-V_{c}$ :

Parcela de força cortante resistida por mecanismos complementares ao modelo em treliça;

$-A_{s w} / s:$

Área da seção transversal dos estribos de força cortante por unidade de comprimento do elemento necessária para resistir ao esforço cortante (caso o valor seja negativo, o projeto levará em consideração os limites mínimos de armadura e espaçamento).

\section{A.4.3.3.3 GroupBox Espaçamento Máximo (Norma)}

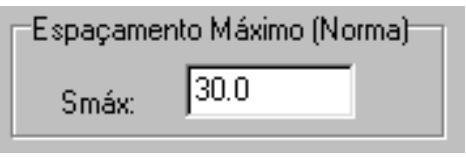

Neste GroupBox está o valor do espaçamento máximo para garantia da passagem do vibrador para o bom adensamento no concreto, indicado na equação 5.3. 


\section{A.4.3.3.4 GroupBox Espaçamento Máximo}

$$
\begin{aligned}
& \text { Espaçamento Máximo } \\
& \text { Smáx: } 30.0
\end{aligned}
$$

Nesta caixa de texto está o valor mais crítico entre A.4.3.3.1 e A.4.3.3.3, sendo o valor máximo possível para o espaçamento entre estribos no elemento em questão.

\section{A.4.3.3.5 GroupBox Utilizar}

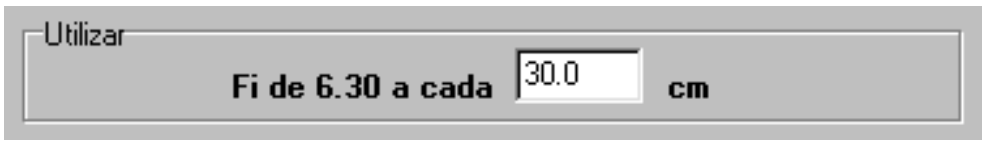

Este item pode ser modificado pelo usuário, desde que o valor selecionado seja menor que o indicado no item anterior. Modificando-se o espaçamento para 25 $\mathrm{cm}$, por exemplo, a janela fica da seguinte forma:

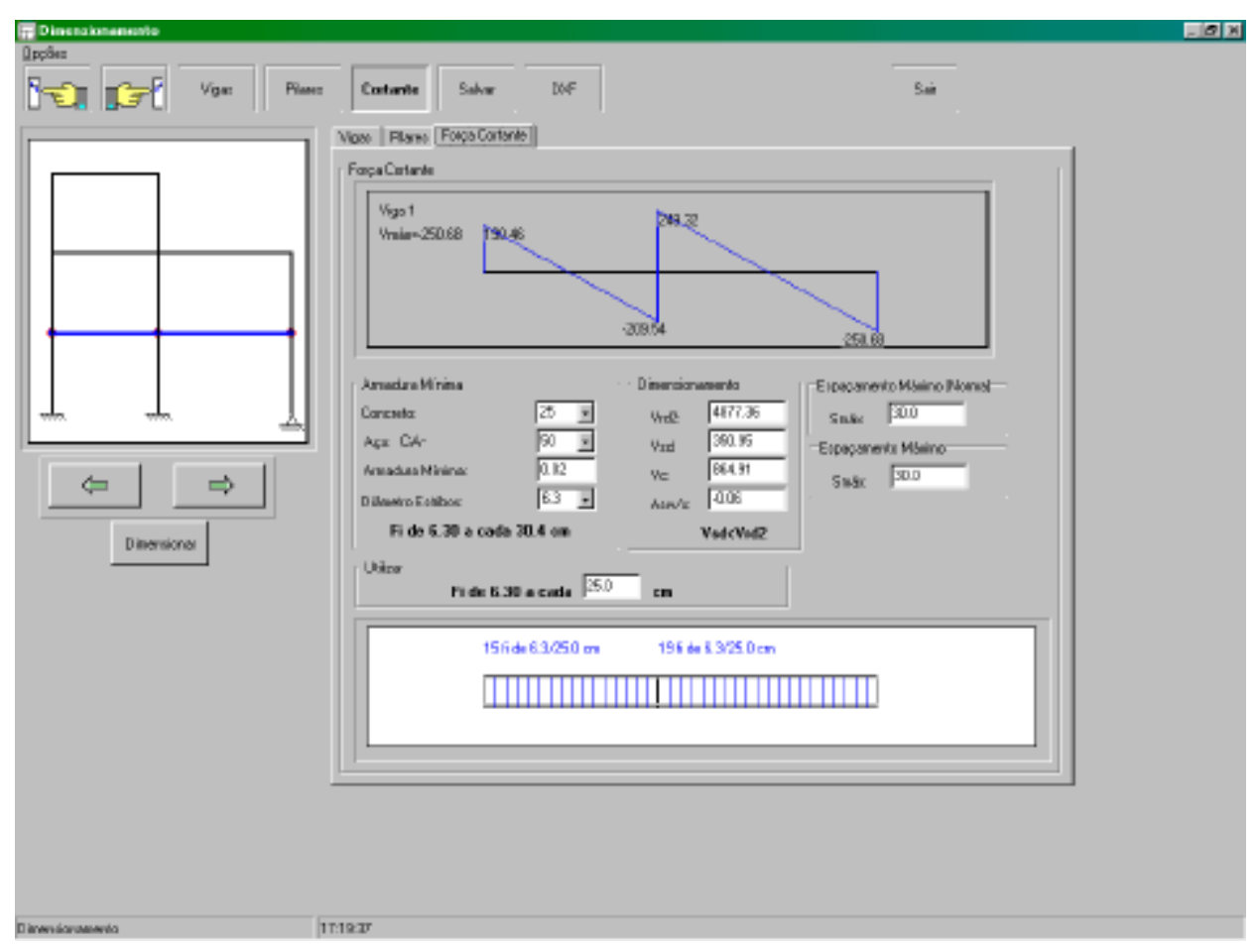

Figura A.33 - Dimensionamento àForça Cortante, Espaçamento $25 \mathrm{~cm}$ 


\section{A.4.3.4 Botão Salvar}

\section{Salvar}

As configurações selecionadas pelo usuário do programa no processo de dimensionamento podem ser salvas acionando-se o botão mostrado acima. Caso esta opção seja ativada, será criado um arquivo com o mesmo nome do arquivo de entrada e no mesmo diretório, porém com extensão dto, no caso Exemplo.dto.

As duas primeiras linhas são para definição do arquivo, conforme demonstrado abaixo, conforme o exemplo citado neste anexo. Os valores salvos para vigas estão mostrados abaixo para a viga 1 do exemplo. Pulando uma linha, em um arquivo completo seguir-se-iam os valores das vigas posteriores.

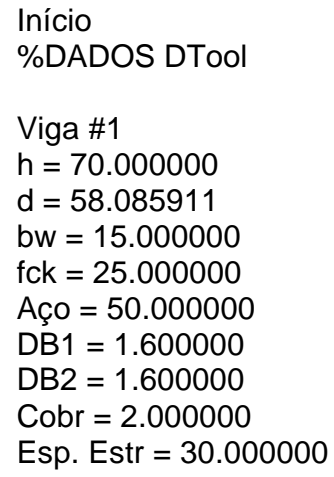

Para os pilares, os valores são salvos da seguinte forma:

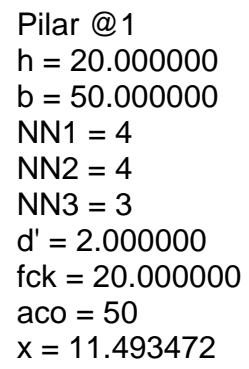

$\mathrm{O}$ arquivo salvo, se existente, é aberto juntamente com o arquivo de entrada de dados, ao fechar a caixa de diálogo mostrada na figura A.4.

A averiguação da existência deste arquivo com extensão dto é feita com a seguinte verificação:

StrCat(NomeB, "dto"); // Adicionar ao nome a extensão dto 


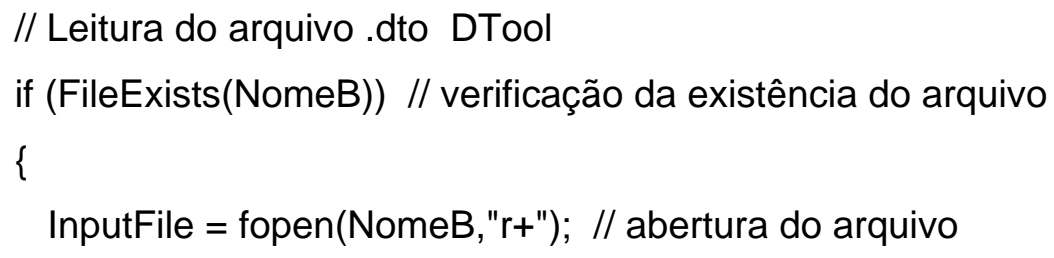

A variável char chamada de NomeB inclui o diretório onde está sendo aberto o arquivo principal, com as extensões mostradas na figura A.4.

\section{A.4.3.5 Botão DXF}

DXF

Salva o desenho mostrado na opção de dimensionamento ativada em formato DXF para leitura no programa AutoCad.

\section{A.4.4 Janela de Detalhamento}

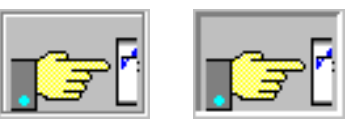

Acionando-se a opção de mudança de janela, conforme mostrado acima, é mostrada a janela de detalhamento das barras longitudinais das vigas, conforme a figura a seguir. 


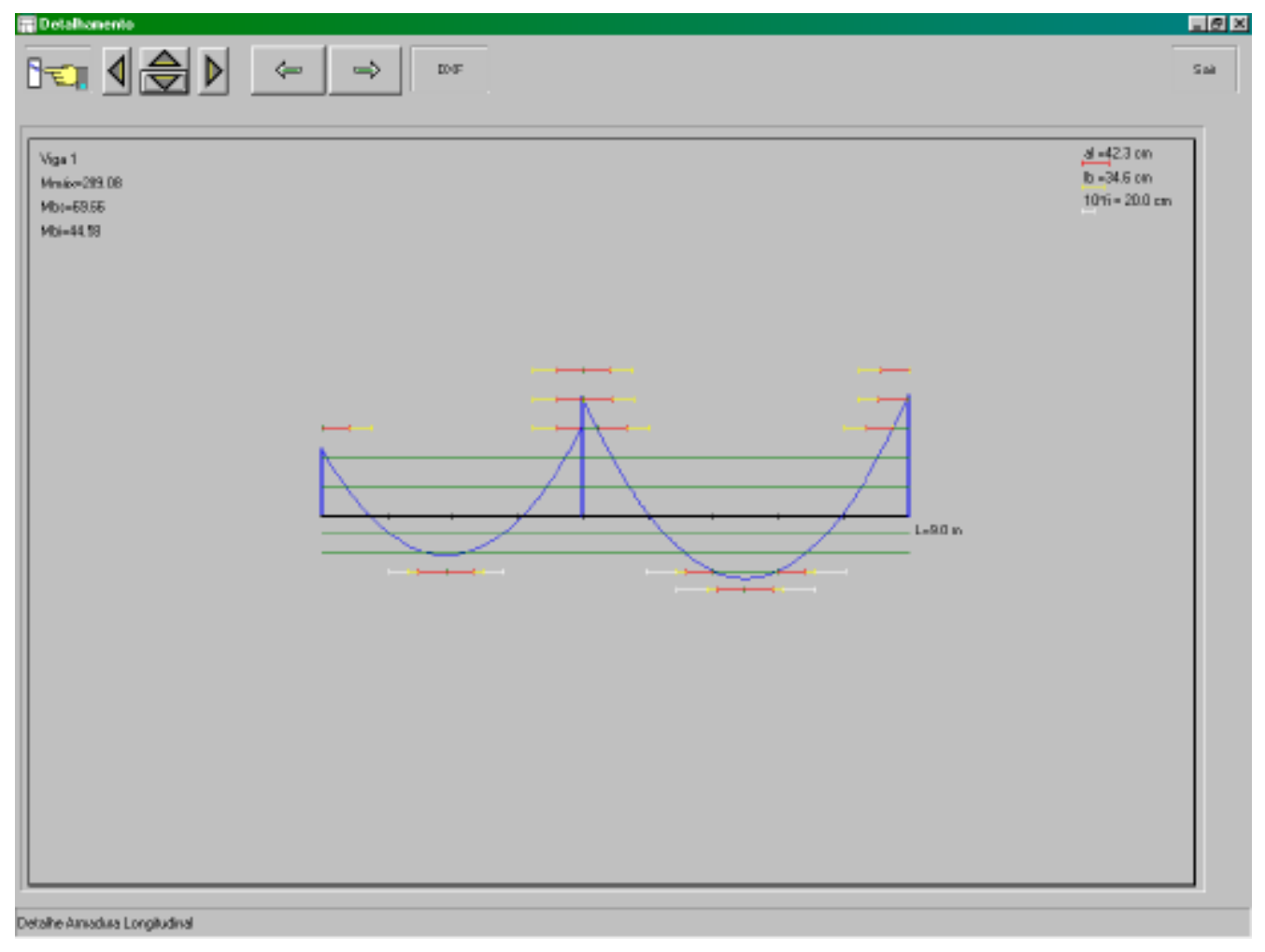

Figura A.34 - Janela de Detalhamento

Esta é a janela final do programa, só possuindo a opção de voltar à janela anterior. No desenho mostrado está o diagrama de momento fletor da viga 1, mostrando as barras necessárias para resistir a este esforço.

As primeiras duas barras em verde são porta-estribos, prolongando-se por todo o vão do elemento. As barras que não se prolongam até os apoios possuem trechos dentro do diagrama, também desenhados em verde; porém, suas extremidades possuem cores diferentes, indicadas pela legenda no canto superior direito da tela.

Os trechos em vermelho referem-se à decalagem no diagrama de momentos fletores, de acordo com o item 5.2.4. O trecho em amarelo representa o comprimento de ancoragem de cada barra, calculado de acordo com o item 5.2.3.

A parte em branco nas barras mostradas sobre o diagrama de momentos mostra o prolongamento da barra para que sua extremidade esteja a pelo menos 10 $\phi$ do ponto onde começa a ancoragem na barra imediatamente inferior (limite entre o trecho vermelho e o amarelo). 
É possível observar que em todas as barras necessárias para resistir ao momento fletor positivo na seção foi necessário realizar o prolongamento para a condição descrita no parágrafo anterior.

\section{A.4.4.1 Botões para Controle do Tamanho do Desenho na Tela}

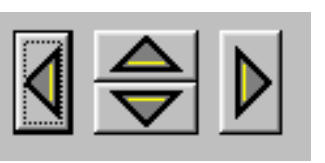

Neste grupo de botões, pode-se aumentar ou diminuir o desenho mostrado na figura A.34. Os botões da direita e da esquerda aumentam ou diminuem o comprimento do desenho na horizontal, respectivamente, referente ao comprimento da viga. Os botões para cima e para baixo aumentam ou diminuem o fator que multiplica os valores dos momentos fletores na viga em questão, fazendo com que o desenho destes fique maior ou menor, respectivamente.

Na figura a seguir está mostrado o mesmo desenho da figura A.34, porém maximizado com utilização dos botões mostrados neste item. 


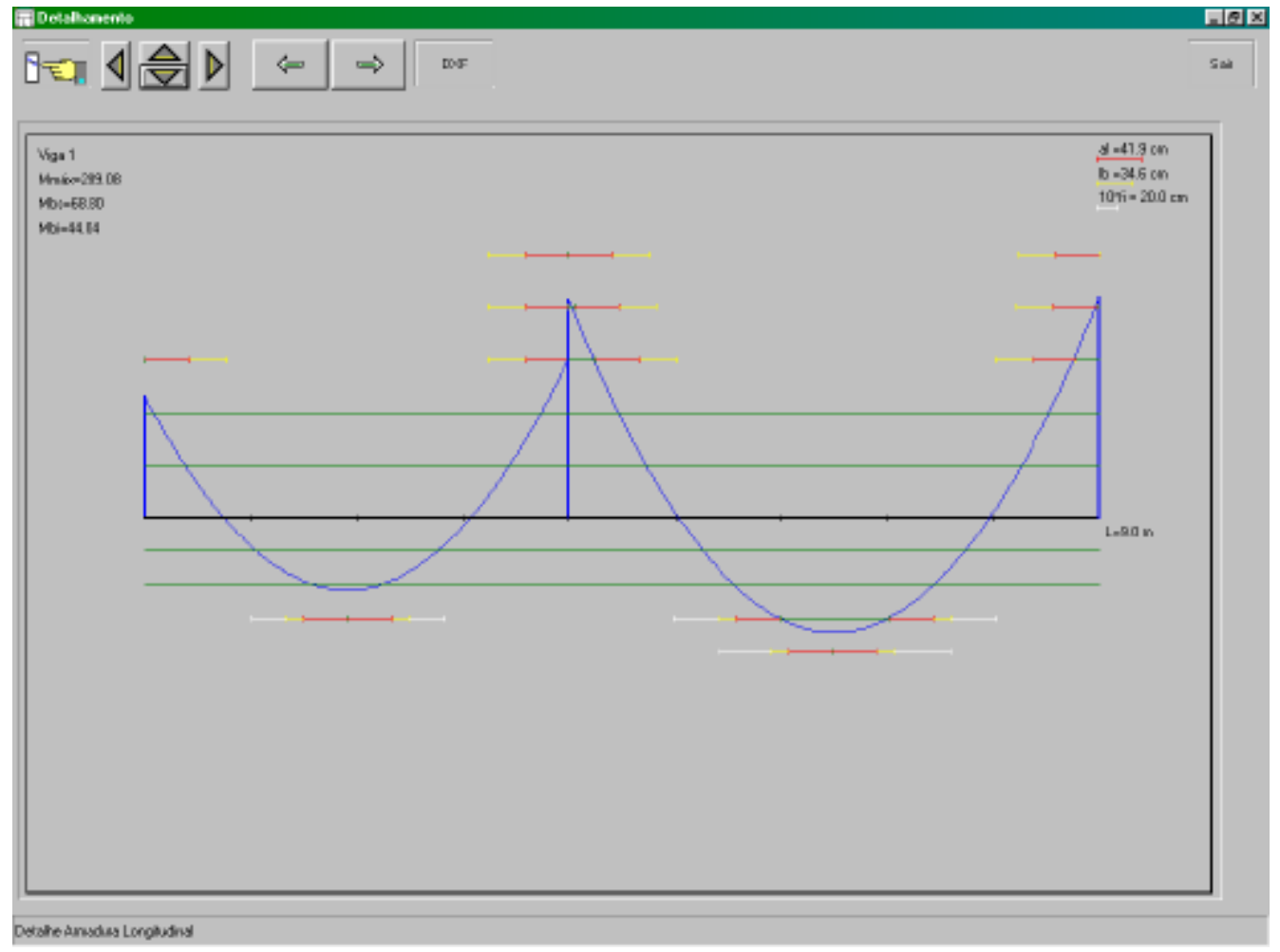

Figura A.35 - Janela de Detalhamento com Desenho Maximizado

\section{A.4.4.2 Botões para Mudança de Vigas}

$$
\Leftrightarrow \quad \Rightarrow
$$

Com a utilização dos botões mostrados acima, pode-se modificar a viga que está sendo mostrada na tela. Escolhendo-se mostrar a viga 3, o desenho fica da seguinte forma: 


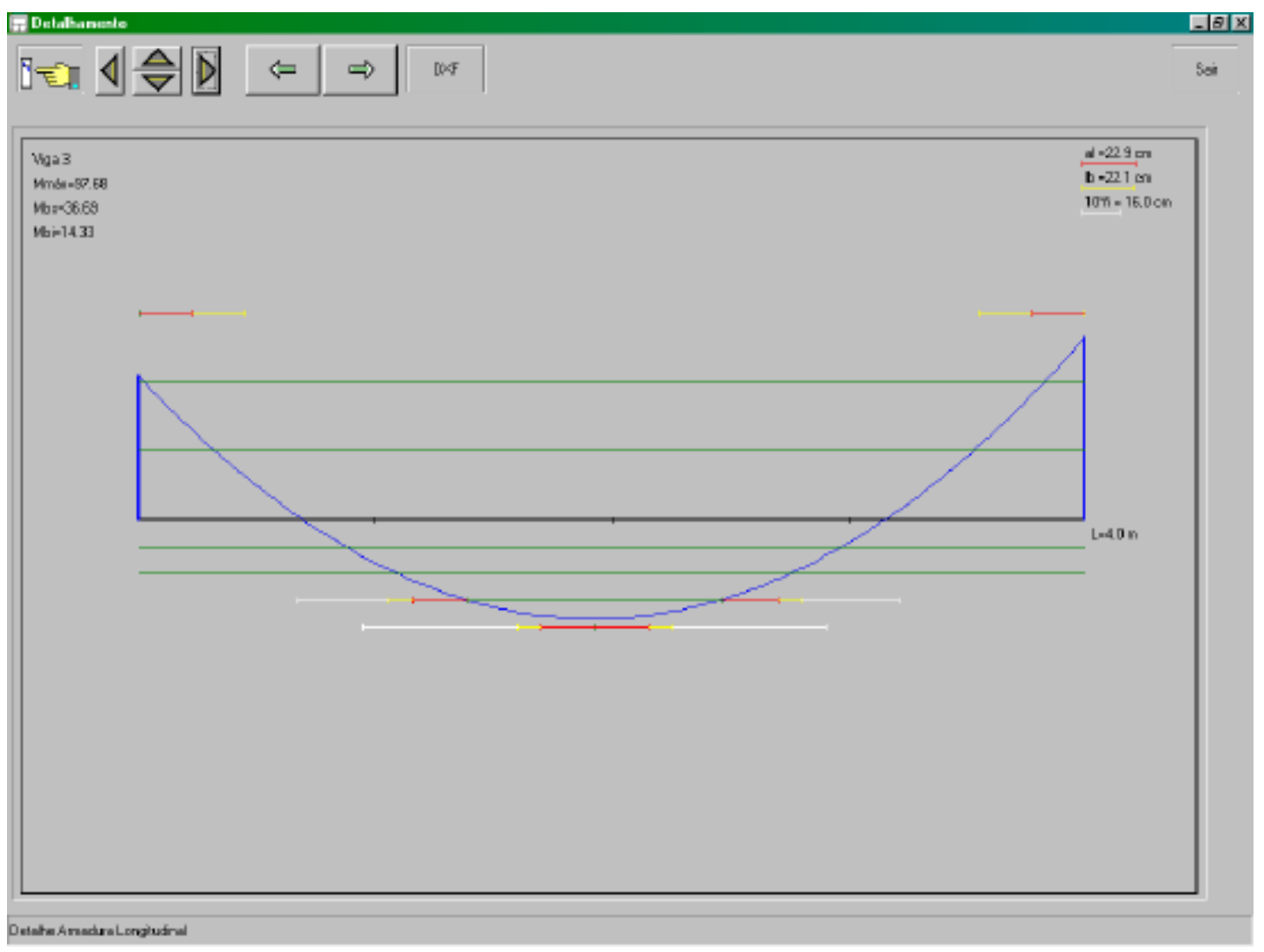

Figura A.36 - Janela de Detalhamento para a Viga 3

\section{A.5 Desenhos}

Na figura A.6, pela primeira vez aparece um exemplo de desenho de pórtico plano no espaço central do programa. Para delimitar tal área, foi criado um PaintBox, espaço destinado a desenho. Tais limites inicialmente não apareceriam, sendo desenhadas somente as linhas que delimitam o pórtico plano. Para definir fundo branco e para que sempre que o desenho for modificado o desenho anterior se apague, o primeiro comando da classe de desenho do PaintBox é o desenho de um retângulo branco exatamente do tamanho do PaintBox no qual ele está contido.

O comando para tal função pode ser expresso da seguinte forma:

Paint1->Canvas->Rectangle(0,0,Paint1->Width-5, Paint1->Height-5); 
São tirados 5 pixels da altura e largura do retângulo para que apareça na borda do desenho uma linha mais grossa nos lados direito e inferior, já que a linha que define o retângulo tem largura dupla.

Os desenhos mostrados no DTool são compostos basicamente pelos seguintes comandos:

- Paint1->Canvas->Rectangle $(x 1, y 1, x 2, y 2)$;

Desenha um retângulo com ponto inicial em x1, y1 e ponto final em x2, y2. $\mathrm{Na}$ tela, o ponto com abscissas e ordenadas nulas é o canto superior esquerdo, sendo positivos os outros pontos pertencentes ao PaintBox. $O$ desenho do retângulo sobrepõe-se a qualquer outro desenho realizado anteriormente, ficando o seu interior branco, por ser esta a cor definida para o PaintBox em questão. No caso das figuras A.32 a A.34, o PaintBox foi definido com a cor cinza, conforme demonstrado nas figuras mencionadas.

- Paint1->Canvas->Pen->Width = 2;

Define a espessura da linha de desenho utilizada. No caso da figura A.34, a linha da viga, em preto, tem largura igual a 2 , e as linhas que representam as barras de aço têm espessura igual a 1 .

- Paint1->Canvas->Pen->Color = clBlue;

Estabelece a cor da linha que vai ser desenhada. No caso, define a cor azul para a caneta.

- Paint1->Canvas->MoveTo(x1, y1);

Paint1->Canvas->LineTo(x2,y2);

Desenha uma linha, com as características definidas pela Pen, que liga 0 ponto com coordenadas $x 1, y 1$ até o ponto com coordenadas $x 2, y 2$. Se após esta linha de comando fosse colocada outra contendo o comando Paint1->Canvas$>$ LineTo $(x 3, y 3)$; seria desenhada outra linha ligando o ponto com coordenadas $x 2$, y2 ao ponto com $x 3, y 3$.

- Paint1->Canvas->TextOut(x1, y1, Palavra); 
Comando que escreve o texto armazenado no caractere Palavra a partir do ponto $x 1, y 1$.

- Paint1->Canvas->Ellipse(x1, y1, x2, y2);

Desenha uma elipse inscrita no retângulo definido pelos pontos $\mathrm{x} 1$, y1 e x2, y2. No caso em que as distâncias entre as abscissas e ordenadas entre os pontos 1 e 2 são iguais, é desenhado um círculo.

- Paint1->Canvas->Arc(x1, y1, x2, y2, x3, y3, x4, y4);

O arco é desenhado segundo o perímetro de uma elipse inscrita no retângulo delimitado pelos pontos x1, y1 e x2, y2. O arco é desenhado seguindo o perímetro da elipse no sentido horário, do ponto inicial para o ponto final. O ponto inicial é definido pela interseção entre a elipse e uma linha definida pelo centro da elipse e $x 3, y 3$. O ponto final é definido pela interseção entre a elipse e a linha definida pelo centro da elipse e o ponto $x 4$, y4.

No Windows 95, as somas, $x 1+x 2$ e y1 + y2, não podem exceder o valor 32768 , assim como a soma de todos estes valores, $x 1+x 2+y 1+y 2$, não pode exceder 32768.

Seguindo as informações mostradas nos comandos anteriormente citados, o desenho da viga mostrada na figura A.34 poderia ser realizado da seguinte forma:

$$
\begin{aligned}
& \text { ptoxi2=meiox- }(\text { Xmax-Xmin })^{\star} \mathrm{fc} / 2 ; \\
& \text { ptoyi2=meioy }+(Y \max -Y \min )^{\star} \mathrm{fc} / 2 ; \\
& \text { ptoxf2=meiox }+(X \max -\mathrm{Xmin})^{\star} \mathrm{fc} / 2 ; \\
& \text { ptoyf2=meioy-(Ymax-Ymin })^{\star} \mathrm{fc} / 2 ; \\
& \text { Paint1->Canvas->Pen->Width = 2; } \\
& \text { Paint1->Canvas->Pen->Color }=\text { clBlack; } \\
& \text { Paint1->Canvas->MoveTo(ptoxi2, ptoyi2); } \\
& \text { Paint1->Canvas->LineTo(ptoxf2, ptoyf2); }
\end{aligned}
$$

O ponto meiox é exatamente o ponto central para as abscissas no PaintBox, meioy é análogo para o eixo das ordenadas. O valor fc é o fator de correção para que o desenho sempre possa tanto estar visível na tela, ter tamanho suficiente, 
como não ultrapasse os limites da mesma. Este fator pode variar com a utilização dos botões para controle de tamanho horizontal mostrados no item A.4.4.1.

Desta forma são realizados os desenhos existentes no programa. 